\title{
Feminist perspectives on curating
}

Book or Report Section

Published Version

Richter, D. (2016) Feminist perspectives on curating. In:

Richter, D., Krasny, E. and Perry, L. (eds.) Curating in Feminist Thought. On-Curating, Zurich, pp. 64-76. ISBN

9781532873386 Available at

https://centaur.reading.ac.uk/74722/

It is advisable to refer to the publisher's version if you intend to cite from the work. See Guidance on citing.

Published version at: http://www.on-curating.org/issue-29.html\#.Wm8P9a5I-Uk

Publisher: On-Curating

All outputs in CentAUR are protected by Intellectual Property Rights law, including copyright law. Copyright and IPR is retained by the creators or other copyright holders. Terms and conditions for use of this material are defined in the End User Agreement.

www.reading.ac.uk/centaur

\section{CentAUR}

Central Archive at the University of Reading

Reading's research outputs online 


\section{OUCURATING.org}

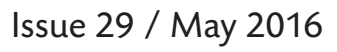

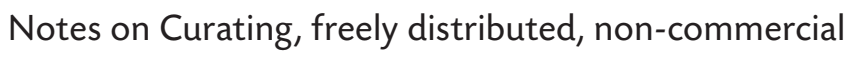
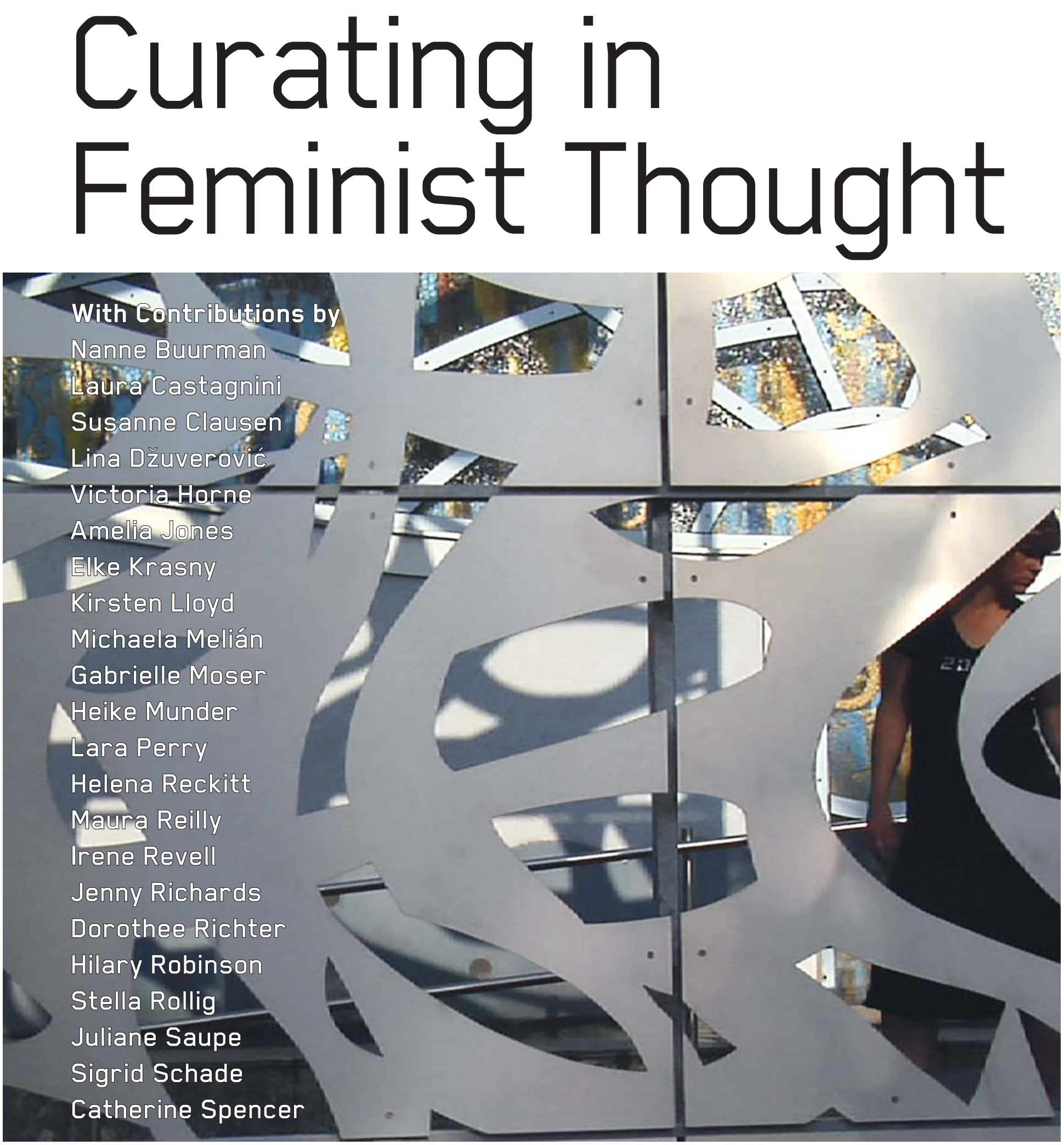



\section{Contents}

02

Editorial

Elke Krasny, Lara Perry, Dorothee Richter

05

Feminist Subjects versus Feminist Effects:

The Curating of Feminist Art

(or is it the Feminist Curating of Art?)

Amelia Jones

22

The Six Enemies of Greatness

Video programme compiled

by Susanne Clausen and Dorothee Richter

27

Slapping Scenes

Susanne Clausen

29

Feminism Meets the Big Exhibition:

Museum Survey Shows since 2005

Hilary Robinson

42

Feminist Tactics of Citation, Annotation, and Translation: Curatorial Reflections

on the Now You Can Go programme

Gabrielle Moser and Helena Reckitt

49

Living the Revolution

A Dialogue Between Maura Reilly e Lara Perry

54

The Biographical Exhibition as a Problem of Feminist Critique and the Case of the Exhibition Marlene Dumas - Female, 2005

Sigrid Schade

64

Feminist Perspectives on Curating

Dorothee Richter

77

In Search of the Feminist (in the) Institution

Stella Rollig in conversation with Juliane Saupe
82

It's Time for Action!

Heike Munder

91

Public Service Announcement:

On the Viewer's Rolein Curatorial Production

Lara Perry

96

Curatorial Materialism. A Feminist Perspective on Independent and Co-Dependent Curating

Elke Krasny

108

Performing Feminism 'Badly':

Hotham Street Ladies and Brown Council

Laura Castagnini

116

Taking Care: Feminist Curatorial Pasts,

Presents and Futures

Victoria Horne, Kirsten Lloyd,

Jenny Richards and Catherine Spencer

130

"We falter with feminist conviction".

Notes on Assumptions, Expectations,

Confidence, and Doubt

in the Feminist Art Organisation

Lina Džuverović and Irene Revell

146

Angels in the White Cube?

Rhetorics of Curatorial Innocence

at DOCUMENTA (13)

Nanne Buurman

$21,41,53,76,90,107,129,145$

Artist Inserts

Michaela Melián

162

Imprint 


\section{CURATING in Feminist Thought \\ Elke Krasny, Lara Perry, Dorothee Richter}

Curators and their partners are working in a contested field, in which the meanings of institutions, their power structures and modes of participation can be debated and reshaped. The number and diversity of high-profile major museum exhibitions in the twenty-first century that have been devoted to the themes of feminist and women's art has attracted an unprecedented critical attention to the practice of feminist curation. The diversity of the ways in which feminism has been represented in curatorial projects-from Womanhouse (1972) to Gender Battle (2007)-is explored here most fully in the essays by Amelia Jones and Hilary Robinson, which identify the range of these projects and the various ways in which exhibitions have articulated feminist perspectives.

At the same time that the nature of the feminist exhibition has been subjected to growing historical and critical scrutiny, the rise of the identification of the exhibition with the curator as its author (instead of the museum or indeed the artist or artwork) invites us to expand our considerations of the nature of curatorial work, histories, and scholarship. The focus on the curator often generates an account that individualizes or personalizes the agency of curatorial work (see Buurman's essay in this volume on the equivocal conceptualisation of curatorial agency), a tendency which we have aimed to resist. Instead, we have proposed the curator as an agency within which the art world locates its work of recognizing, celebrating, validating, and rejecting, and one that is susceptible to a feminist analysis. It is important to see the curatorial function as part of a developing discursive formation, with its specific inclusions, exclusions in respect of race, class, and gender: "To think of institutions in terms of production (of work and discourse and political practice and solidarity) instead of representation would be, to my mind, a first feminist step". With this provocation the curator Ruth Noack invited us to rethink the nature of feminist critique of the museum, the gallery, the exhibition space.

We must thank our contributors for their illuminating contributions that have allowed us to develop a cogent and timely interrogation of curating in feminism. In recent years the production modus and the ideological load of curating has increasingly become identified with "the new economic conditions that require new contexts of collaboration and interaction" (Olga Fernandez), conditions which are identified with celebrity and authority as well as precarity and casualisation. These essays unpack the gendered nature of the power relations, effects, inconsistencies, and contradictions of curating in the present, and help us to rethink the role of the curator. We present this volume with the wish that the practice of curating itself becomes one that is generative of a more inclusive and just art world. Therefore, it could be speculated that the notion of "the curatorial" implies a prob- 
lematic ennoblement of curating as a meaning-producing activity in a politically and ideologically contested field, as Dorothee Richter suggests.

The essays and interviews that are gathered here unravel many aspects of curatorial labour that work to produce, or counter, gender inequalities. As Amelia Jones observes here, curatorial labour is "driven by concepts of what is important, how and what to see, and what ends up being encountered in the space of the museum". The work might then be considered (and critiqued) as the work of selection and exclusion; but one of the themes that emerges prominently in these essays is the importance of affirmation, attachment, and affiliation as modes by which feminist curators imagine their work. This theme is especially powerful in the essays by Lina Džuverović and Irene Revell, the essay on parafeminist parody by Laura Castagnani, Heike Munder's account of the 'girl' energy traceable in certain popular forms of feminist art practice, and the interview between Gabrielle Moser and Helena Reckitt. These essays also specify theoretical models for the replacement of critical with affirmative feminist engagements, including Italian feminism of the 1970s; Catherine Grant's article on 'fans' of feminism; and theorizations of 'friendship' or affectionate parody as the generative modes by which feminist curatorial work is performed.

That selection by affiliation is simultaneously a process of exclusion is raised by Helena Reckitt in her contribution, and also by Amelia Jones in the brief history of Womanhouse with which her article opens. Jones notes that women of colour were largely excluded from Womanhouse, which she explains was a consequence of the class/ race orientations of the university within which the project was formed. The absence, or problematic forms of inclusion, of women of colour within many curatorial and critical art ventures is an issue that has given many of us pause, and that as editors/organizers of this programme we have worked hard to avoid. Is it the case that the forms of feminism that operate in art history/theory continue to be incompatible with the feminist perspectives of women of colour? Is the art historical/curatorial concern with occupational achievement alienating to women of colour, who may neither value nor have meaningful access to the work? The issue of how to achieve equal and diverse representation that is implied in such questions is often sidestepped in these essays.

The reshaping of issues of representation within feminism is suggested by the presentation of exclusion-as a voluntary withdrawal-as a valid feminist strategy, as discussed for example by Moser and Reckitt in their account of the events programme of "Now You can Go", held across sites in London in 2015, and its inspirations. Rather than aiming for equality of representation, many of the feminist curators and critics represented here are more concerned with resisting the 'dominant drives' of curating, which are connected with structures of domination (including colonialisation). That these nameable dominant structures shape the work of feminists within conventional art institutions is a problem raised in several essays, including Sigrid Schade's essay on biographical exhibitions, or Stella Rollig's comment that "the game rules and compulsions imposed on the institution from outside" limit feminist agency in areas such as programming. On the other hand, the demand for an equality of representation is still held up by Dorothee Richter and Maura Reilly in their contributions, which present the inventory of equality as a temporary strategy, a support structure on the way to diversity and multiplicity beyond fixed categories as a horizon.

Examples of practices of resistance to the drives/structures of domination cited in these essays include eschewing the imperatives of curatorial discovery 
(Džuverović and Revell); refusing the hierarchical pay structures that govern institutional work (Lloyd et al.); and avoiding the material structures of the museum (Krasny). Elke Krasny's essay highlights the dependence of conventional curatorial practices on the material and particularly the real estate or property resources that are commanded by the museum. The complex interrelationship between the significance of 'real' property in the art world (the 'buildings' of the museums and exhibition halls, the dealer-critic system that produces art objects as commodities,) and the unwaged and uncapitalised resource of 'immaterial' or 'social' labour is a recurrent theme in these texts. A newly revived gender analysis of the structural importance of a typically unwaged form of labour-the labour of social reproduction-to the curatorial role is central to many of the essays (Buurman, Reckitt, Perry, Lloyd et al., Krasny).

The relationship between the material and social status of artworks under the purview of curating is key to the question of how artworks and exhibitions themselves might resist dominant and dominating modes of curatorial work. The nature of the works exhibited and the mode of their display is gestured to in Buurman's discussion of the 'white cube' presentation at dOCUMENTA, and in Jones's call for a feminist curatorial project that addresses the ephemeral, the fragmentary, and the intimate forms of art production that have sustained feminist practice. That such accounts must be produced in relation to resistant forms of art historical and critical writing is argued by Jones, and by Džuverović and Revell in their advocacy of a feminist art history rendered as "a crumpled heap" rather than a series of examples. That feminist forms of curatorial, artistic, and historical/critical practice form a powerfully interconnected body of material from which to draw inspiration for feminist agency is certainly in evidence here. 


\section{Feminist Subjects versus Feminist Effects: The Curating of Feminist Art (or is it the Feminist Curating of Art?) Amelia Jones}

This paper sketches a schematic history of feminist curating and the curating of feminist or women's art in the North American and European contexts. My aim is to think about the dual projects of feminist curating-either curating from a feminist point of view or curating works of feminist or women's art (or both)-in order to cast light on what it means to evoke feminism in relation to the curatorial enterprise. Curating involves both working with archives and constructing histories; it involves looking at works of art and making choices about which to include; it is driven by concepts of what is important, how and what to see, and what ends up being encountered in the space of the museum.

Curating makes arguments about feminist art histories and strategies concrete; curating constructs certain kinds of historical narratives, or in some cases intervenes in existing narratives. As such, while scholarly histories and theories of feminist art and culture are crucial to the feminist projects of expanding histories as well as interrogating the structures through which art is made and historicized, curatorial practice is one of the most important sites for the constitution of both historical narratives about feminist art (the histories of feminist art) and feminist theories of curating and writing histories (the feminist histories and theories of art).

The joining of feminism and curating has a long history, at least since the beginning of the feminist art movement in the late 1960s in the US and UK (the dominant sites for the early articulation of the movement). In 2010, Bojana Pejić, assisted by a group of feminist art specialists from twenty-four countries, curated the 2009-10 exhibition Gender Check: Femininity and Masculinity in the Art of Eastern Europe at the Museum of Modern Art in Vienna; in the program for the symposium relating to this show (also in 2010, in November), feminist curating is articulated as a "junction [...] between practice and theoretical thought, between powers of inscription and perception, between political agendas, discourses of the institutions and acts of critical 'resistant' reading." As well, the organizers raise the question of how "social, political and ideological contexts translate in the story (and space) of an art exhibition", and whether exhibitions "'inform, 'mediate,' and 'represent' or, alongside artworks, [become][...] battlegrounds [for][...] agendas of sexual and gender difference." ${ }^{\prime 1}$ 
I propose to explore these interrelated questions through a two-part inquiry, first sketching in brief form the interrelated histories of feminist curating and of the curating of feminist or women's art, and, second, exploring a small selection of practices that might, precisely by maintaining an openness to ever-shifting "agendas of sexual and gender difference", as the Gender Check curators put it, be impossible to "tame" fully through curatorial practice. These untameable practices tend to be community-based, often performative, and activist; they tend to perform or evoke the female sex in ways that are provocative, ephemeral, haptic, and/or have otherwise not been embraced by exhibitionary strategies. While this kind of feminist practice is not always excluded from feminist scholarship on the visual arts, the works it generates cannot be incorporated into exhibitions in any simple way. When they are on rare occasion included, they still arguably challenge attempts to tame them: to "curate" them into proper museum spaces and to "organize" them into seamless narratives of art historical progress.

Feminist Exhibitions, A Brief and Singular History, focusing on Los Angeles

One of the key issues for the nascent feminist art movement in the late 1960s, particularly in the US and UK, was the exclusion of women's artistic work from exhibitions of modern and contemporary art. To that end, it is not surprising that one of the key motivations was to redress this situation, either (more commonly) by founding feminist art venues independent of the dominant cultural and funding situations or by developing exhibitions of women's art in mainstream institutions. Two major examples will suffice to sketch this early period here: the establishment of a series of alternative spaces in Los Angeles that were aimed at developing both a separate feminist pedagogy and a separate site for the presentation of feminist art and performance; and the first major exhibition organized for a mainstream art museum, Linda Nochlin and Linda Sutherland Harris's 1976 exhibition, commissioned by the Los Angeles County Museum of Art (LACMA), Women Artists: 1550 to 1950.

A small number of excellent histories have been published on the Los Angeles-area feminist art movement, from Judy Chicago's 1975 autobiography, Through the Flower, to Terry Wolverton's 2002 Insurgent Muse: Life and Art at the Woman's Building to recent exhibition catalogues by Laura Meyer. ${ }^{2}$ This is a complex and vast history, but the key notes to strike here are the founding of the Feminist Art Program at California State College Fresno (now California State University Fresno) in 1970 by Judy Chicago (with the help of graduate students Faith Wilding and Suzanne Lacy), its move to California Institute of the Arts (CalArts) in 1971, where Miriam Schapiro joined forces with Chicago for the final year of the programme, culminating in the 1972 project Womanhouse, reported on widely across the United States, including in high-circulation mass media magazines such as Time.

The deeply radical nature of the feminist art programme and of Womanhouse was in its combination of pedagogy and practice: Chicago in particular aimed to empower women both by encouraging them to mould their "personal" stories into "political" feminist art and performance, and by teaching them how to make things, build things, and generally assert themselves in the public realm of the art school and the city as a whole. ${ }^{3}$ With Womanhouse-a tour de force of feminist curating-as-pedagogy-Chicago and Schapiro thus worked with the Feminist Art Program students to gain the range of carpentry and other hands-on skills necessary to renovate a derelict house near downtown LA, and then to fill the rooms of the house with feminist performance and art installations open to the public. Each installation provided feminist commentary on various aspects of domestic spacesuch as Susan Frazier, Vicki Hodgett, and Robin Weltsch's "nurturant kitchen" with 
its egg-breasts covering the walls and ceiling, Sandy Orgel's "linen closet", with its spatial literalization of a young woman being trapped in social expectations, Wilding's "womb room", and Chicago's "menstruation bathroom".

The activation of female experience through the body was a key element of the broader strategy developed within the Feminist Art Program-thus key feminist performances took place at Womanhouse, such as Faith Wilding's Waiting, in which she rocked back and forth in front of an audience, reciting the litany of events women have to "wait" for in their position as passive members of family and society, Chris Rush's piece Scrubbing and Sandra Orgel's Ironing, commenting on women's work, and Karen LeCocq and Leah Youdelman's performance and installation Léa's Room, an exploration of oppressive ideals of female beauty. The concept of performance as activating women's experiences in the public arena-experiences that had long been seen as "private", "domestic", and thus as "unimportant" to the larger political scene-was a key aspect of early feminist art and exhibition practices. These concepts were carried through with the founding of the Woman's Building, which was a key cultural centre from 1973 to 1991, in downtown Los Angeles.

The Woman's Building was imagined to include the flagship program of the Feminist Studio Workshop, co-founded (after the Feminist Art Program at CalArts ended) by Judy Chicago, designer Sheila de Bretteville, and art historian Arlene Raven, as well as potentially exhibition spaces, theatre companies, a feminist bookstore, and other feminist organizations. ${ }^{4}$ The Woman's Building was by no means the only alternative feminist art space in Los Angeles. Womanspace Gallery, for example, was another alternative feminist gallery founded in 1972; and other alternative exhibition venues founded in LA in the early to late 1970s, from Los Angeles Institute of Contemporary Art to Los Angeles Contemporary Exhibitions, also hosted feminist events.

This network of spaces provided both "separatist" and mixed sites for the display and performance of feminist art. As feminist art historian Ruth Iskin, who was active in LA at the time, noted, Womanspace (like the Woman's Building) aimed to provide an alternative to the "dealer-critic system" dominated by male artists, patrons, curators, and critics through the establishment of alternative feminist galleries and systems of critical and historical analysis. ${ }^{5}$ The separatist feminist sites were founded with radical political motivations and yet were in some ways limited in their demographic-being dominated by white middle-class (although not always heterosexual) women and so inevitably by their interests. This is so in spite of the fact that members of Womanhouse such as Iskin (an Israeli-born lesbian feminist) noted the crucial importance of not only supporting "women" artists per se but for this feminist goal to encompass an anti-racist and queer agenda: "For feminist art and feminist revolution to take priority [...], the exhibitions should give maximum exposure to female artists [...], and to provide special opportunities for visibility to minority groups within the female community (such as the Black Women's Show and the Gay Week)."

Many Latino and Black women artists in LA in particular have felt that this gesture of inclusion was not fully successful. Black feminist artist Senga Nengudi, active in LA in the 1970s and 1980s, thus noted recently to me that, unlike the Latino community's efforts to include Black artists such as herself, and the Black Art Movement's embrace of her artistic work, "The [white dominated Los Angeles] feminist movement was a WHOLE other story. Don't get me started! We were included in as a necessity. I hardly felt like an equal partner. Although I did sit on a couple of Women's Building committees, it never felt quite like home in the [1970s]".7 
I bring up Senga Nengudi (not to mention Judy Baca, Betye Saar, and numerous other women of colour practicing in LA at the time, who might on occasion have had work included in Woman's Building activities, but never felt fully embraced), because it is important to note the exclusions within feminist exhibition practices even in the most successful radical moments of establishing a feminist alternative to mainstream institutions. Also, the Los Angeles case makes very clear, I hope, the crucial interrelationships among pedagogy, art-making and performance, critical writing about art (by scholars and art critics such as Iskin and her partner Arlene Raven), and exhibition practices. To some degree, the exclusions even within these radical feminist venues in LA was due in part to their roots in pedagogy, since art schools such as California Institute of the Arts were hardly encouraging Black and Latina and/or working class women to apply.

The second example of historical feminist curatorial practice, briefly, is the organisation by art historians Linda Nochlin and Ann Sutherland Harris in a mainstream venue-the Los Angeles County Museum of Art-of the major exhibition, Women Artists: 1550 to 1950. Described generally as the "first" exhibition of women artists in history (obviously within the Western context), the Women Artists show expanded on Nochlin's now famous arguments in her 1971 essay, "Why Have There Been No Great Women Artists?", where she rejects both the feminist strategy of simply trying to redress the exclusion of art history by recuperating lost women artists for a new canon, and the strategy (exemplified in Chicago's pedagogy and artwork) of promoting a particular "female experience" as defining women's art in different terms from men's. ${ }^{8}$ Nochlin argues, controversially, "that there have been no supremely great women artists, as far as we know, although there have been many interesting and very good ones who remain insufficiently investigated or appreciated." ${ }^{\prime 9}$ Nochlin and Sutherland-Harris continue along this line in the catalogue, asserting that an approach to feminist curating that involves simply inserting the work of historical women artists into un-touched canonical frameworks is "ultimately self-defeating, for it fixes women within preexisting structures without questioning the validity of these structures"; through such misbegotten methods, they argue, feminism "has come dangerously close to creating its own canon." ${ }^{\prime \prime}$

As already suggested, by the mid to late 1970 s across Los Angeles, young feminist artists and teachers were developing entirely new institutions to articulate new modes of thinking, making, displaying, and teaching art and performance. At the same time, even large and relatively entrenched institutions such as Los Angeles County Museum of Art were not just accepting but commissioning a major exhibition on women's art in history: notably, Sutherland Harris was recruited in 1971 by LACMA director Kenneth Donahue to organize Women Artists. Donahue had been approached by a group of activist women artists in LA who demanded "gallery space and exhibition time for women equal to that being given to male artists." 11 Here, the impact of the growing pedagogical and curatorial efforts on the part of Chicago and her students can clearly be seen as having a direct impact on the programming of a major art institution (guided by a brave and enlightened older white man-Donahue was in his late 50s! ${ }^{12}$ ). Los Angeles, of course, was not typical in the US at the time, and other major cities were not hosting major feminist art shows nor were broad-based initiatives in feminist art pedagogy developing elsewhere in the US or Europe to such a degree.

I hope this brief history brings to life at least in a partial way a very small part of a huge history of feminist curating in the early stages of the feminist art movement, with Los Angeles being both exemplary but to some degree unique in the 
intensity and wide-ranging success of its sudden immersion in feminist art initiatives. ${ }^{13}$ This brief history points to the motivations behind such curatorial efforts, and the deep connections between feminist curating and pedagogy and art history. It points to the exclusions within mainstream institutions and discourses that feminists were fighting against, as well as to the inevitable exclusions within the very venues feminists established-limitations often due to frictions among the diverse communities of women working in the arts in cities with complex demographics such as Los Angeles.

\section{0-1990: A "Lack" of Feminist Shows}

After the 1970s, aside from a very few exceptions, such as the important 1984 exhibition Difference: On Representation and Sexuality at the New Museum in New York, organized by Kate Linker and Jane Weinstock, there were no large-scale feminist art exhibitions in the 1980s in the US or, to my knowledge, in Europe. Difference, however, was a major show with a profound influence; the exhibition, which gave a particular kind of avant-gardist feminist art and theory (informed by poststructuralist, Marxist, and psychoanalytical methods) credibility, helped open the commercial US art market (based in New York at the time) to feminist artists such as Cindy Sherman, Barbara Kruger, Jenny Holzer, and Sherrie Levine for the first time (the signing of Kruger by the highly successful Mary Boone Gallery in the mid 1980s was a dramatic sign of the perceived commercial viability of feminist art by that time, due in part to exhibitions such as Difference).

In the 1990s there was still a paucity of feminist curatorial work in major institutions. There were only a handful of exhibitions of feminist art (or feminist exhibitions, curated from a feminist point of view) across the Anglophone art world, the US and the UK still being the dominant sites for the feminist art movement and for feminist exhibition practices. ${ }^{14}$ However, in the early 1990 s a spate of exhibitions in New York, Los Angeles, Glasgow, and London (the former two of these curatorially linked) entitled Bad Girls signalled a return to feminism, but through a lens coloured heavily by trends in popular culture-in particular the rise of pop stars such as Madonna and Cyndi Lauper-and by the larger backlash against feminism in mainstream media across the US, as identified by Susan Faludi in her 1991 book Backlash: The Undeclared War Against American Women. ${ }^{15}$

The Bad Girls shows foregrounded the work of artists such as Nicole Eisenman, Sue Williams, Dorothy Cross, and Sarah Lucas-work that explicitly refused the niceties of a feminism that recuperated "positive images" of women such as the goddess imagery of the early 1970s, promoted "central core" imagery (such as Wilding's Womb), as well as the avant-gardist strategies of feminist artists promoted in the 1980s such as Kruger - in favour of provoking the viewer through nasty, aggressive pictures and installations promoting female sexual empowerment. Lucas's provocative 1997 Bunny Gets Snookered thus presents a bawdy and slightly creepy image of a female form in a chair with her legs spread, but the "woman" seems to be fabricated from stuffed tights and clothing, her crotch disturbingly gaping yet closed off (literally sealed) and unavailable.

While the curators (particularly of the British versions) included work by artists identified with a "working-class aesthetic" in the UK (including Tracey Emin and Sarah Lucas), the Bad Girls shows on the whole were still almost entirely whiterepresenting a continuing tendency to conceive of feminist issues in the visual arts as exclusively the concern of white women. ${ }^{16}$ Also, they were not historical shows but exhibited work from the late 1980s and early 1990s-a period notably marked by a dearth of large-scale exhibitions exploring the histories of feminist art (although 
Division of Labor: "Women's Work" in Contemporary Art, at the Bronx Museum in 1995, included some historical feminist work from the 1970s). ${ }^{17}$ It was only in 1996 that two major feminist shows emerged internationally that addressed and presented feminist art, one explicitly historical and one only obliquely (or ineffectively, depending on one's point of view).

I organized in 1996 at the UCLA/Hammer Museum of Art, Sexual Politics: Judy Chicago's Dinner Party in Feminist Art History. Given the mandate to show Judy Chicago's large-scale feminist installation piece, the 1979 Dinner Party, I organized Sexual Politics around a progression of feminist art debates which had crystallized around Chicago's practice. While many feminists from London and New York had decried Chicago's "essentialism", her projects drew vast popular audiences-one of the many contradictions I hoped to point to in my essays in the catalogue and through exhibiting a broad choice of other types of feminist art in the show addressing a range of topics of debate from "cunt art" to "bodily functions", "politicizing the domestic sphere", "diversity" within feminism, and "intimacy and autobiography".18

Here, rather than analyzing my own exhibition anew, it is worth quoting at length from an interview Angela Dimitrakaki completed with me and published in 2013 in her volume Politics in a Glass Case: Feminism, Exhibition Cultures and Curatorial Transgressions, co-edited with Lara Perry. While I have mixed feelings about the effectiveness of Sexual Politics (which, as many critics argued at the time, ended up being perceived too much as a "Judy Chicago" show), Dimitrakaki has an extremely and intelligent view of the show and we debated its merits as follows.

Dimitrakaki introduces our interview by noting the following:

One of the reasons that Sexual Politics remains a distinctive intervention is that it negotiated a particular structure for showcasing both feminist work and the complex processes through which art is associated with political discourse-here feminism. As a curatorial experiment, the exhibition assumed the structure of a critical essay: it did not just focus on artists or art but on providing a context. The context provided focused on the terms in which an iconic yet controversial artwork, namely Judy Chicago's The Dinner Party (1973-9), could be seen to be part of feminist politics as a terrain of a complex and evolving ideological struggle [...]. / The exhibition and its accompanying publication proved to be a critical exercise on how to narrate an artwork's political history through research and display [...].

She also noted, in an earlier manuscript version of this text, in comments that did not fully make the final publication:

Arguably, [in this way] Sexual Politics proposed a model of curatorial work whereby the curatorial gesture is concerned with histories to come rather than just exploring those already in place (which the show and book also did, functioning to an extent as a document) ... The Dinner Party did not just belong to a feminist past; in the 1990s it could also be deployed in the context of strategic thinking about the present and future of feminism in the arts. ${ }^{19}$

I followed up on her generous (and to my mind exactly right) comments by stressing my desire to use the piece as a "pivot" through which to explore conflicts and debated terms in feminism and beyond. To my knowledge, my strategy of using curating to make a political and historical proposition about feminist legacies remains unique. What failed about this strategy was clearly the very thing I had 
hoped would innovate how we organize feminist histories-the use of one artist's work as a pivot. The show was criticized roundly by conservatives and feminists alike for wrongly featuring Chicago, already a divisive figure in the feminist art movement due to her grand ambitions and tendency to make use of the labour of many other artists and artisans (albeit, all scrupulously credited in the text panels displayed with The Dinner Party).

Another large and important feminist show that same year was often cited by feminist critics and historians such as Griselda Pollock as the pinnacle of feminist curatorial practice: Inside the Visible: An Elliptical Traverse of Twentieth Century Art in, of and from the Feminine, which was organized by Catherine de Zegher initially for the Beguinage of Saint-Elizabeth in Kortrijk, Belgium, in 1994-5 and expanded for the Institute of Contemporary Art in Boston in 1996; it also travelled to the National Museum of Women in the Arts in Washington, D.C., and the Whitechapel Art Gallery in London. Inside the Visible included work from the 1930s up to the 1990s, brought together under "elliptical" arguments focusing on the works' shared experiential "femininity", but did not offer a historical framework in which to understand the very different premises and motivations and contexts of artists as diverse as, for example, Claude Cahun, Charlotte Solomon, and Mona Hatoum.

In spite of its largely positive reception and continued reputation in feminist art history and curatorial studies as the epitome of a certain kind of theoretically rigorous feminist curatorial practice, then, the show and catalogue were and are problematic in their failure to clarify the project's oblique relationship to a more explicitly stated or activist feminism, and to specific histories of feminist art (or to history tout court). Furthermore, while distancing itself from "essentializing" approaches to feminist art, eschewing even the terms "feminism", "women", "gender", or "sexuality" in the title, the show was ultimately based on similar bases to those of any feminist exhibition-for what brings together such disparate artists across time and space other than an assumption that they are joined by what 1970s feminists might have called their "women's experience"? It is not enough to avoid such a term by substituting for it, as de Zegher does, "the feminine" or the trendy notion, drawn from feminist artist and theorist Bracha Lichtenberg Ettinger, of the "matrixial". ${ }^{20}$

\section{Exhibitions of Historical Feminist or Genderqueer Art, c. 2005-2009}

If Dimitrakaki's assessment, and my comparison of Sexual Politics and Inside the Visible, provide a compelling basis for future evaluations of effective historical exhibitions of feminist art, perhaps Sexual Politics can be viewed as an important precedent for the spate of exhibitions addressing the histories of feminist art that emerged from 2005 through 2009 in venues across Europe and North America. ${ }^{21}$ These shows were paralleled by a burgeoning interest in feminist art in Europe and North America, testified by the publication of numerous articles in the popular and art press and special issues of art magazines on feminism published during this period. ${ }^{22}$ Academic feminist art history and theory were, for this brief moment, actively revived as crucial discourses, signalled as well by a range of major conferences that have addressed feminist art histories and theories in South Africa, Los Angeles, New York, and Stockholm. ${ }^{23}$

Here, just a few very brief comments on six of these shows will be revealing in terms of the tension between exhibitions of art deemed to be feminist and exhibitions curated from a feminist point of view. 
Gender Battle: The Impact of Feminism in the Art of the 1970s, curated by Juan Vicente Aliaga for the Contemporary Art Centre of Galicia, Santiago de Compostela, Spain, in 2007

Gender Battle incisively addressed the issue of gender critique, clearly beginning from a politically feminist point of view, rather than proposing a strictly "feminist" approach or a strictly "feminist" range of artworks, but it also directly credited feminist discourse for a broad range of works addressing gender and sexuality and critiquing what he calls in the Press Release the "macho patriarchal society" of the 1970s. Aliaga continues in the release: "This project attempts to examine feminism's contributions, during the seventies, brought to light and served as a platform to launch a series of approaches, without which it would be impossible to understand the present." ${ }^{24}$ This approach enabled Aliaga to include but also expand beyond classic feminist works such as Carolee Schneemann's body-oriented pieces, to show works by lesser-known (at least to a US audience) artists such as German performative photographer Jürgen Klauke. In the end, this show was both political (pointing to key issues in feminism and the impact of the feminist critique on women and men artists) and historical (raising our consciousness of lesser known works that preceded, say, the work of Cindy Sherman).

elles@centrepompidou: Women Artists in the Collection of the Musée National d'Art Moderne, Centre de Création Industrielle, curated by Camille Morineau. Originated in Paris at the Musée National d'Art Moderne, Centre Pompidou, 2009-11; travelled to Seattle Art Museum in reduced form in 2012-13.

Camille Morineau, then staff curator at the Centre Pompidou, spent years proposing a thematic feminist exhibition at the Pompidou and was in the end only able to organize elles@centrepompidou, a show that is surreptitiously feminist (all of the work in the show made after 1960 is deeply informed by feminism, if not explicitly in all cases feminist). ${ }^{25}$ The anxiety over feminism is indicated in the Preface to the catalogue by Alfred Pacquement, then director of the Musée National d'Art Moderne, who notes that the plethora of important works by women in their permanent collections signals "a possible development of a history of art in the feminine", only to backtrack: "it is [now] possible to unfold a full and entire history of art with 'elles.' A history about which there is nothing feminine at all [my emphasis]". ${ }^{26}$

Regardless of the director's apparent anxiety about "the feminine" and his reduction of radical feminist work to feminine qualities, the show presented one of the best collections of art that was either explicitly feminist or deeply informed by feminism, mostly from the US and Western Europe. However, the exhibition also (due to the constraints noted) begged some questions about whether one can make a political point about feminist issues in such a context, including both explicitly feminist work and work by artists bent on actively disavowing the importance of feminism such as Marina Abramović. Still, given the limitations of what Morineau could do, the show was a fantastic argument in favour of continuing to mount shows of "women's art". The smash success of the exhibition, which was extended far beyond its initially scheduled run into 2011 because of its popularity, proved that, while large art institutions are still highly conservative and entrenched (viz., Pacquement's hedging remarks), the general public was ready for feminist art; art presenting explicitly feminist forms, such as the radical erotic photographs of Alina Szapoznikow, was clearly of huge interest to the general public in France, as well as in Seattle where the show travelled in 2012-13. 


\section{Love and Democracy, organized by Pawel Leszkowicz in Poznan and Gdansk, 2005-6}

In this context, the important work being done by Pawel Leszkowicz organizing exhibitions of queer art in Poland must be noted: Leszkowicz honours feminism and queer politics by assertively organizing shows that directly challenge the growing reactionism of the Polish state. His two-part 2005-6 exhibition Love and Democracy in Poznan and Gdansk, with its accompanying catalogue (co-authored by his partner, the cultural studies scholar Tomasz Kitlinski), Love and Democracy: Reflections on the Homosexual Question in Poland, were, on the one hand, necessarily essentializing, as is arguably required in order to make a space for feminist, gay, and lesbian culture in an increasingly conservative Poland: there is little room for nuance when you are fighting for the right to debate and exhibit feminist and queer art and theory. The exhibition and catalogue, on the other hand, together provide a radically open-minded concept of the interrelatedness of queer and feminist art and theory-de-essentialized in their refusal to assume, for example, queer feminist art can only be made by women; in this way, they also expand in a crucial context the loosely feminist and queer approach to curating that I am addressing here. ${ }^{27}$

Wack! Art and the Feminist Revolution, curated by Connie Butler for the Museum of Contemporary Art, Los Angeles, 2007; travelled to the National Museum of Women in the Arts (2007), PS1/Museum of Modern Art, New York (2008), and the Vancouver Art Gallery, Vancouver, British Columbia (2008-9)

Global Feminisms, curated by Maura Reilly and Linda Nochlin for the Brooklyn Museum of Art, Elizabeth Sackler Center for Feminist Art, 2007; travelled to Davis Museum and Cultural Center, Wellesley College, Wellesley, Massachusetts, USA (2008)

Two major US shows have dominated debates about feminist curating in the US for the past decade: the 2007 exhibitions Wack! Art and the Feminist Revolution, curated by Connie Butler originally for a Los Angeles debut at the Museum of Contemporary Art (and traveling to PS1 in New York in 2008), and Global Feminisms, organized by Moira Reilly and Linda Nochlin for the Elizabeth Sackler Center for Feminist Art at the Brooklyn Museum in New York. These exhibitions have received a lot of press. Suffice it to say here, Wack! was the first major institutional show presenting historical feminist art since my show Sexual Politics in 1996, and even included an work by less well-known feminist artists such as Senga Nengudi-but the exhibition itself lacked any historical contextualization, going so far as to show work such as Nengudi's and Suzanne Lacy and Leslie Labowicz's important activist performances (via documentary photographs) with no information about where these pieces were made, took place, or how they were originally contextualized. Wack! thus simultaneously presented a historical and geographical range of feminist work (all by women) and erased the political and cultural specificity of each practice. $^{28}$

Alternatively, Global Feminisms presented very recent art by women (whether all explicitly feminist is up to debate-see Wangechi Mutu for example) from a broad, global context (although, perhaps inevitably, given that feminism is a "Western" discourse for the most part, many of the artists from other parts of the world are currently living in Europe or North America and thus potentially engaging more directly with art-world feminism). The catalogue included important essays correcting the erasure of non-European and non-American art from histories of feminist art-the exhibition included works from India, Japan, Korea, Central America, and other places usually invisible in Western-oriented feminist art exhibitions and histories. The question of whether including a broader range of art by women implicitly essentializes (for example, avoiding the question of whether an artist such as Mutu 
produces feminist work or considers herself feminist) is begged in interesting and productive ways by Global Feminisms.

Gender Check: Femininity and Masculinity in the Art of Eastern Europe, 200910; curated by Bojana Pejić with consultants from twenty-four countries across Eastern Europe. Initiated at the MUMOK (Museum of Modern Art) Vienna in 2010; travelled to Zachęta, Warsaw. ${ }^{29}$

Gender Check, a show I did not see, focussed on "gender in the art and social history of Eastern and Southeastern Europe" and thus, it seems to me, followed on the illustrious heels of Gender Battle in rightly opening up what we might think of as "gender-critical" art practice within a very specific context-in this case pre- and post-Soviet bloc countries. As Pejić put it in a 2010 interview with Hedvig Turai, she was motivated by the exclusion of issues of gender and sexuality in studies of art from this part of the world and aimed to deploy a Foucauldian framework to explore gender as a relation of power within socialist state politics. ${ }^{30}$ In this sense I would argue that her curatorial strategy is exemplary of the kind of feminist curatorial strategy that is essential in locating and maintaining the relevance (even urgency) of feminism today. Like Aliaga, then, Pejić applies "gender check" as an art historical "method" or "operation" in order to broaden the understanding of gender critique to point to its interrelationship with issues of sexuality, masculinity, and class. Hence the inclusion of works such as Vlad Mamyshev-Monroe's performance of himself as Marilyn Monroe in a section dedicated to the "Heroic Male Subject"exemplifying vulnerability in the face of the general tendency of masculinity to subordinate to power, a notion with particular relevance in the context of socialist Eastern European cultures; the show thus presented obviously feminist work by women but also works by men that, as Pejić describes to Turai, foregrounded male vulnerability. ${ }^{31}$

This huge and rich range of shows curated from a feminist point of view all highlight power relations as these relate to gendered and sexed bodies and subjects. What they do not do is question the limits of large object-based shows. For the remainder of this paper, I want to address one final show in relation to the question of renegade artworks or practices that refuse the kind of narratives about sexual and gender identification that tend to be sketched whether directly (as in historical shows such as Sexual Politics) or indirectly (with most of the other shows noted above) in curating relating to feminist or women's art.

\section{Coda: Contentious Body Works / Contentious Histories}

A big media splash accompanied the opening of the Spring 2016 inaugural exhibition at the new Hauser Wirth $\mathrm{r}$ Schimmel in Los Angeles-Revolution in the Making: Abstract Sculpture by Women, 1947-2016. Co-curated by Paul Schimmel and Jenni Sorkin, the show is presented as a "thematic historical survey that is international in scope and fundamentally revisionist, making women artists central to the history of sculpture by tracing the legacy of studio-based organic abstraction." ${ }^{\prime 32}$ The title of the exhibition, which includes almost 100 works by 34 women artists, does not include the word feminism-rather, the focus is on "sculpture by women", along with the frisson created by this unlikely combination (given the long history of masculinist values attached to sculpture in particular among the arts). When a major commercial gallery sees fit to promote its interests by hosting a show that is marketed as "revisionist" and is thus implicitly feminist show as its inaugural event, we know feminist curating (and feminist modes of writing history, as indicated in the text noted above) have become not only acceptable but trendy-as long as they don't announce themselves as feminist. 
After decades of studied neglect on the part of galleries, museums, and the art market in general, all of this renewed interest in feminist art - both historical and contemporary-makes me nervous. Among other things, I'm very worried about what kinds of feminist art (or arguably, as in the case of Global Feminisms or Revolution in the Making, art by women) are being marketed and what kinds are being left out-surely it's no accident, for example, that the messy activism-driven or overtly sexualized, queer, and/or raced feminist practices tend to be excluded from these exhibitions as these are not as "exhibition-friendly", not as easily marketable as certain varieties of photographic or object-based practices. Sculpture, after all, is imminently marketable and apparently about $30 \%$ of the works in Revolution in the Making are for sale. Excluded, still, from such blockbuster shows is more difficult work addressing serious political issues on the ground that are affecting women in violently negative ways. Or work taking more oblique, quiet, or non-marketable forms that might be accessible only through another kind of research practice.

Coming to an ending here, then, I want to explore a particular feminist art practice from 1960s Los Angeles that has not made it into the major histories or exhibitions of feminist art. If we could say that feminist artists have, since the mid1960s, consistently and explicitly worked to explore what it means to identify as "women" (Simone de Beauvoir's question of "becoming woman") or to examine how power accrues along lines relating to perceived gender identifications, then this practice exemplifies a strategy of interrogating the links between one's perceived bodily identification (via the visual field) and one's voice in the public sphere in ways that are deeply threatening even to feminist frameworks-that in fact I myself found too messy and confusing to include in Sexual Politics, where I was intent on sketching a history of feminist ideas and practices relating to the visual arts. Enacting the "becoming-ness" of femininity-the way in which, as Simone de Beauvoir argued, it is never "essentially" fixed or static-the argument might go, feminist artists can both denaturalize gender (marking it as performative) and assertively activate the feminine body-a body that had previously been, in the logic of Western thought (as Beauvoir theorizes), rendered inactive, consigned to "immanence" and thus to "otherness", maintaining the inequities of patriarchy. ${ }^{33}$

In the mid 1960s, Barbara Smith, then more or less a housewife and mother living in the Los Angeles area, rented an early (and very bulky) Xerox machine, photocopied her cunt, breasts, and body, and made a series of albums of these ghostly indexical impressions of her body. Like other amazingly prescient protofeminist works from the early and mid 1960s-such as Carolee Schneemann's 1963 performance Eye Body-Smith's Xeroxes were ahead of their time. Born in 1931, Smith studied painting and art history in the early 1950s and continued to paint while raising children; she became a professional artist only in her 30s. Not only did Smith break free from her middle-class role as a housewife to imagine renting a Xerox machine in one of its earliest manifestations, to explore the capacity of this type of indexical rendering of the body; she also mobilized this technology to explore the very unseen aspects of female embodiment (or at least unseen within the purview of the art world-in pornography of course the female sex is persistently rendered, though in ways that tend to depersonalize the bodies attached to it).

Smith's images are collected into scrapbooks that she squirreled away in her modest house in Venice, California; this is important performative work that I saw only because I was interviewing her in 2009 for a research project on LA performance. These intimate scrapbooked pictures are enigmatic and indexical marks of a 
young woman finding her way out of a suburban lifestyle of wife and mother into the role of radical body artist-scrimping together all of her savings to rent what at the time was a hugely expensive early photocopier in order to register her own embodiment in the ghostly traces of toner it produces so easily. Palimpsests of embodiment-they read forty-five years later (held in my hands sitting on her couch while interviewing her at her home) as gorgeous fleshy layered pages of promised interiors. ${ }^{34}$ As Smith pointed out to me, the Xerox is technologically unique as a medium-it works by impressing paper with beads of plastic that mimic, in the density through which the machine deposits them on the page, the lights and darks of whatever forms or images were placed on top of the horizontal screen; the Xeroxes of Smith's cunt, which looks tender and beckoning, like flowers pressed and dried in the pages of a dictionary, are technically then as indexical as an analogue photograph-the lights and darks materially mimic the lights and darks of the "original" form. I feel this, with a sense of haunting, as I hold these fragile fading books-each page of cunt, a hole in their logic of wholeness-in my hands.

Without art historical or curatorial interventions such as this, such work might "disappear" historically. Hence the political urgency of rethinking how we research and what we show in major feminist exhibitions. If it weren't for such intimacies-moments of fortuitous scholarly curiosity become friendship-such works would remain unknown forever. Smith is not a self-promoter. It was only a passing reference she made in our interview-and the lucky fact that she had the albums right there in a bureau, rather than in her studio or rented storage-that enabled me to re-discover these amazing works. Such are in some cases the vicissitudes of history (and feminist curating!).

The point I am making here with this example of work by Barbara Smith, in terms of feminist curating, is that this kind of work is rarely deeply researched-or even known; what tends to happen in organizing shows about feminist art, or shows taking a wider purview and exploring contemporary art and issues of gender and sexuality, is that feminist strategies get pinpointed and defined often via previous publications and exhibitions-leaving out work that might have feminist effects or that might have been articulated in messy and open-ended ways that don't fit such definitions. These are works that might be performative and not quite coherent "objects"; they are often explicitly activist and intertwined with larger urban and visual and performance art contexts, as well as (in both cases) with alternative arts venues that do not always lend themselves to easy historicization.

To some degree, curating necessitates definitions and the exhibition of "things" that can be put in place, grasped, and understood-requiring a certain element of what Gayatri Spivak would call "strategic essentialism" in identifying "feminist art", and "feminist artists". ${ }^{35}$ I would argue, however, that the most effective curatorial work keeps a balance between a political sharpness (underlaid by a deep commitment to theory and philosophies of gender and sexuality and, as such, a strategic essentialism) and a curiosity about what feminist practices might not be so well known, entailing that the curator both acknowledge the importance of defining terms and political locations (of feminism, for example) while remaining open to unexpected cultural productions that might promote feminist interests while not being so obviously part of feminist histories and institutions. It is in the spirit of this idea of keeping the tension between feminist subjects and feminist effects that I offer the arguments in this paper. 


\section{Notes}

1 From the program released by the organizers of the November 2010 conference at the MUMOK (Museum of Modern Art) in Vienna, in conjunction with the exhibition Gender Check. I participated in this event and this document was sent to me.

2 Judy Chicago, Through the Flower: My Struggle as a Woman Artist, Doubleday, New York, 1975; Terry Wolverton, Insurgent Muse: Life and Art at the Woman's Building, City Lights, San Francisco, 2002; and Laura Meyer, A Studio of their Own: The Legacy of the Fresno Feminist Experiment, California State University, Art Gallery, Fresno, 2009. See also Faith Wilding, By Our Own Hands: The Women Artist's Movement Southern California 1970-1976, Double X, Santa Monica, 1977; Moira Roth, Amazing Decade: Women and Performance Art in the 70s, Astro Artz, Los Angeles, 1984.

3 Chicago, chapter four "Fresno and the Women's Program," Through the Flower, 70-92.

4 See Wolverton, Insurgent Muse; and Laura Meyer, "The Los Angeles Woman's Building and the Feminist Art Community, 1973-1991," in The Sons and Daughters of Los: Culture and Community in LA, David E. James, ed., Temple U Press, Philadelphia, 2003, pp. 39-62.

5 Iskin, "A Space of Our Own, Its Meanings and Implications," WOMANSPACE Journal 1, n. 1 (February/March 1973), p. 9. Interestingly, Iskin also connects this initiative to feminist art theory and art history, noting: "In order to preserve the notion of a modernist mainstream it is necessary to categorize as peripheral and minor any art that does not address itself solely and primarily to the set of issues to which the modernist line is dedicated. It is for this reason that the art of the best women artists has been categorized as minor, when addressing itself to uniquely female subject matter. Therefore, it is the task of the feminist theoretician to explicate feminist art on its own terms, with a new set of independent criteria," Ibid., p. 9.

6 Ibid.

7 Senga Nengudi interview with Amelia Jones October 2009; transcript available in Los Angeles Contemporary Exhibitions archive.

8 See Nochlin, "Why Have There Been No Great Women Artists?," ARTnews (January 1971). Available online at: http://www.artnews.com/2015/05/30/ why-have-there-been-no-great-women-artists/. Accessed 18.03.2016.

9 Ibid.

10 Linda Nochlin and Ann Sutherland Harris, from the introduction to Women Artists: 1550-1950, Los Angeles County Museum of Art, Los Angeles; Random House, New York, 1976, p. 327; as quoted in Thalia Gouma-Peterson and Patricia Mathews, "The Feminist Critique of Art History," Art Bulletin 69, n. 3 (Sept. 1987), pp. 326-357.

11 Sutherland Harris describes meeting Donohue at a conference Caravaggio and His Followers held at the Cleveland Museum of Art in 1971; during the course of related meetings, as Sutherland Harris narrates, Donohue noted to her that he had been approached by a group of women artists at LACMA who demanded "gallery space and exhibition time for women equal to that being given to male artists." See Sutherland Harris, "Acknowledgments," Women Artists 1550-1950, p. 8.

12 Donohue, born in 1915, the second director of LACMA and a specialist in Italian art, does not seem the obvious candidate for promoting the first exhibition of women's art (see "Donahue, [John] Kenneth," biographical entry in Dictionary of Art Historians; available online at: http://www.dictionaryofarthistorians.org/ donahuek.htm. Accessed 18.03.2016).

13 See also the At Home exhibition at Long Beach Museum of Art, curated by Arlene Raven in homage to Woman's Building on the occasion of its tenth 
anniversary See the catalogue, At Home, Arlene Raven, Long Beach Museum of Art, 1983.

14 Difference travelled to the Renaissance Society, Chicago, and to ICA London in 1984-5; it was accompanied by an important catalogue, Difference: On Representation and Sexuality, including now classic essays by Kate Linker, Craig Owens, Lisa Tickner, Jacqueline Rose, Peter Wollen, Jane Weinstock, Marcia Tucker, New Museum of Contemporary Art, New York, 1984.

15 These shows included the 1993 Bad Girls exhibition co-sponsored by the Institute of Contemporary Art, London and the Contemporary Arts Centre, Glasgow and the Bad Girls exhibition at the New Museum of Contemporary Art in New York and its "sister" show with the same title at the Wight Art Gallery, UCLA, in 1994. Susan Faludi in her book Backlash: The Undeclared War Against American Women, Crown Publishing, New York, 1991.

16 On the "working class aesthetic" in British feminist art, see Laura Bedford Turner, "Tracey Emin, Sarah Lucas $\Theta r$ Rachael Whiteread: Did feminism feature as a part of Young British Art?," Chalk: University of Sussex Arts Society Journal (April 19, 2012). Accessed March 18, 2016. https://chalkjournal.wordpress.

com/2012/04/19/emin-lucas-whiteread/.

17 To some degree this show followed on the premise established by the 1983 At Home exhibition at Long Beach.

18 Amelia Jones, ed., Sexual Politics: Judy Chicago's Dinner Party in Feminist Art History, University of California Press, Berkeley, 2006.

19 Dimitrakaki's introduction to and first question in "The Lessons of Sexual Politics: From the 1970s to Empire: An Interview with Amelia Jones," Politics in a Glass Case: Feminism, Exhibition Cultures and Curatorial Transgressions, Angela Dimitrakaki and Lara Perry, eds., Liverpool University Press, Liverpool, 2013, pp. 93-94.

20 Two key shows in the 1990s related to feminist curating histories, but not explicitly feminist, include Zdenka Badinovinac's important Body and the East, at Museum of Modern Art, Ljubljana, Slovenia in 1998 (the catalogue is entitled Body and the East: From the 1960s to the Present, MIT Press, Cambridge, Massachusetts, 1998), and Bojana Pejić's After the Wall: Art and Culture in Post-Communist Europe, which initially opened at the Moderna Museet, Stockholm, in 1999 (catalogue by the same name, in two volumes, edited by Pejić and David Elliot, Moderna Museet, Stockholm 1999). Pejić's show presented art from the former Soviet bloc (and related) countries in Eastern Europe and included one section on gender.

21 In addition to the shows highlighted here, the exhibitions include: the 2005 Venice Biennale, curated by Rosa Martinez and Maria De Corral, with its feminist theme; the large-scale exhibition of feminist art at the Migros Museum in Zurich in 2006, It's Time for Action (There's No Option): About Feminism, curated by Heike Munder; the ambitious Kiss Kiss Bang Bang: 45 Years of Art and Feminism at the Museum of Fine Arts, Bilbao (2007), curated by Xabier Arakistain. In addition, numerous spin-off or critically interventionist exhibitions organized at commercial and community galleries presumably to counter the narratives posed by these major venues (including the rather disturbing Womanizer exhibition at Deitch Projects, New York, in January 2007, the advertisement of which depicts a woman's naked body being mutilated in a meat grinder); the exhibition Role Play: Feminist Art Revisited, 1960-1980, at Galerie Lelong in spring of 2007; and two exhibitions in Los Angeles intervening in the narrative of feminist art history posed by the Museum of Contemporary Art Wack! exhibition,, the sharp-edged Aqui No Hay Virgenes: Queer Latina Visibility, organized by Jennifer Doyle and Raquel Gutiérrez for the Los Angeles Gay and Lesbian Center Gallery, and the Shared Women show highlighting queer feminist relations at Los Angeles Contemporary Exhibitions, both in the spring of 2007; and, at New York University, Off-Center Femininities: Regards from Serbia and Montenegro, organized by Jovana Stokic. 
22 Special journal issues include the March 2007 issue of Frieze, and the February 2007 issue of Art News, entitled "Feminist Art: The Next Wave." See also, Viv Groskop, "All Hail the Feminaissance," with the subtitle "For years feminist artists have been sidelined, or even derided. But now, almost overnight, the art world can't get enough of them," The Guardian section G-2 (11 May, 2007), pp. 14-15.

23 For example, in 2007 the Museum of Modern Art in New York hosted the symposium "The Feminist Future: Theory and Practice in the Visual Arts"; the Museum of Contemporary Art and University of Southern California sponsored a symposium entitled "Is Feminism Still Relevant?: Race and Globalisation in the Twenty-First Century"; the University of Pretoria in Johannesburg hosted the conference "Taking a Hard Look: Feminism and Visual Culture"; and the conference "Gender Values and the Impact of Feminism in the 1970s" was held at the Contemporary Art Centre of Galicia, Santiago de Compostela, Spain. In 2008, the Moderna Museet in Stockholm hosted the conference "Feminisms, Historiography and Curatorial Practices," where I presented the first version of this material. I participated in all of these events with the exception of the Museum of Modern Art conference and there are surely more I am not aware of that took place in this period.

24 Juan Vicente Aliaga, Press Release for Gender Battle. Accessed 18.032016. http://www.undo.net/cgi-bin/undo/pressrelease/pressrelease.pl?id=1189601592 eday $=1189634400$.

25 I am grateful to Camille Morineau for discussing the genesis of the show with me in Paris, 1 October 2009.

26 Aldred Paquement, Preface to elles@centrepompidou: Women Artists in the Collection of the Musée National d'Art Moderne, Centre de Création Industrielle, Centre Pompidou, Paris, 2009, p. 13.

27 The first part of the exhibition took place in May 2005 as a part of Poznan Art Fair in the Kulczyk Foundation Galleries, the second, larger, part of the exhibition in the Center of Contemporary Art "Laznia" in Gdansk in June 2006. See Leszkowicz, "The Queer Story of Polish Art and Subjectivity," ArtMargins: Contemporary Central and East European Visual Culture (April 10, 2006), available at: http://www.artmargins.com/index.php/featured-articles/163-the-queer-story-ofpolish-art-and-subjectivity-. Accessed 18.03.2016. See also Leszkowicz's essay "The Male Nude as a Queer Feminist Iconography in Contemporary Polish Art," Otherwise: Imagining Queer Feminist Art Histories, Amelia Jones and Erin Silver, eds., University of Manchester Press, Manchester, 2016, pp. 185-203.

28 In conversation with Connie Butler in 2009, she noted to me that the Museum of Contemporary Art had constrained her by not allowing her to include extended wall texts on individual works.

29 See the catalogue by the same name, Agnieszka Morawinska and Boris Marte, eds., Walther König, Cologne, 2010; and the reader edited by Pejić, Gender Check: A Reader, Walther König, Cologne, 2011.

30 As Pejić noted, "it is indeed surprising that gender is discussed in countless books and anthologies analyzing communist and post-communist condition from a sociological point of view, but there is no publication focusing on gender in socialist art," from "Bojana Pejić on Gender and Feminism in Eastern European Art," Interview with Hedvig Turai (Budapest), ArtMargins: Contemporary Culture and East European Visual Culture (December 18, 2009). Accessed 07.11.2010. http://www. artmargins.com/index.php/interviews/540-bojana-pejic-gender-feminism-eastern-european-art-interview.

$31 \mathrm{lbid}$.

32 See the Hauser $\mathrm{r}$ Wirth website statement about the show, available at: http://www.hauserwirth.com/exhibitions/2712/revolution-in-the-making-br- 
abstract-sculpture-by-women-1947-y-2016/view/. Accessed 20.03.2016. Presumably this statement was written by Sorkin, who is a feminist, rather than by Schimmel, who is (to say the least) not noted as one.

$33 \mathrm{I}$ am referring at the end here to the arguments Simone de Beauvoir makes in The Second Sex (1949), first translated into English in 1953 and retranslated by Constance Borde, Vintage, London, 2011. The text in this paragraph is revised from my essay in the elles@centrepompidou catalogue: "'Genital Panic,' the Threat of Feminist Bodies, and Parafeminism," elles@centrepompidou, pp. 290-295.

34 This scholar was myself; the interview took place 6 November 2009 and was for a project entitled "Los Angeles Goes Live," sponsored by Los Angeles Contemporary Exhibitions.

35 On strategic essentialism, see Gayatri Spivak, "Subaltern Studies: Deconstructing Historiography" (1985), In Other Worlds: Essays in Cultural Politics, Routledge, New York e London, 1987, pp. 197-221.

Amelia Jones is the Robert A. Day Professor in Art and Design and Vice-Dean of Critical Studies at the Roski School of Art and Design at University of Southern California; she has also taught at University of California, Riverside, University of Manchester (UK), and McGill University (Canada). A curator as well as a theorist and historian of art and performance, her recent publications include Perform Repeat Record: Live Art in History (2012), co-edited with Adrian Heathfield, a single authored book Seeing Differently: A History and Theory of Identification and the Visual Arts (2012), the edited volume Sexuality (2014), and, co-edited with Erin Silver, Otherwise: Imagining Queer Feminist Art Histories (2015). Her exhibition Material Traces: Time and the Gesture in Contemporary Art took place in 2013 in Montreal, as did the event Trans-Montréal (Performance Studies International, 2015) and Live Artists Live took place at USC (2016); both of the latter included performances and lectures. 


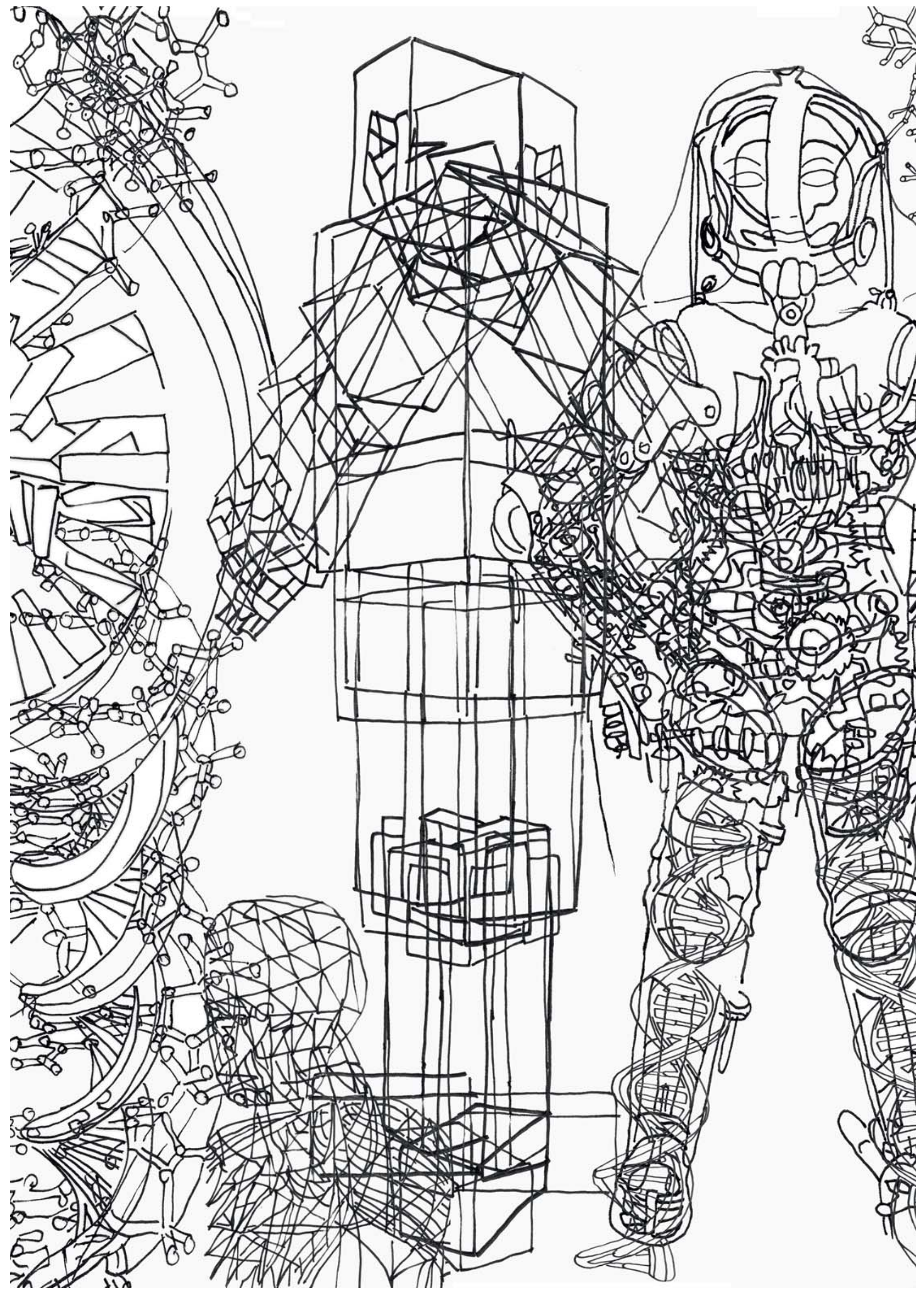




\section{The Six Enemies of Greatness} Video programme compiled by Susanne Clausen and Dorothee Richter

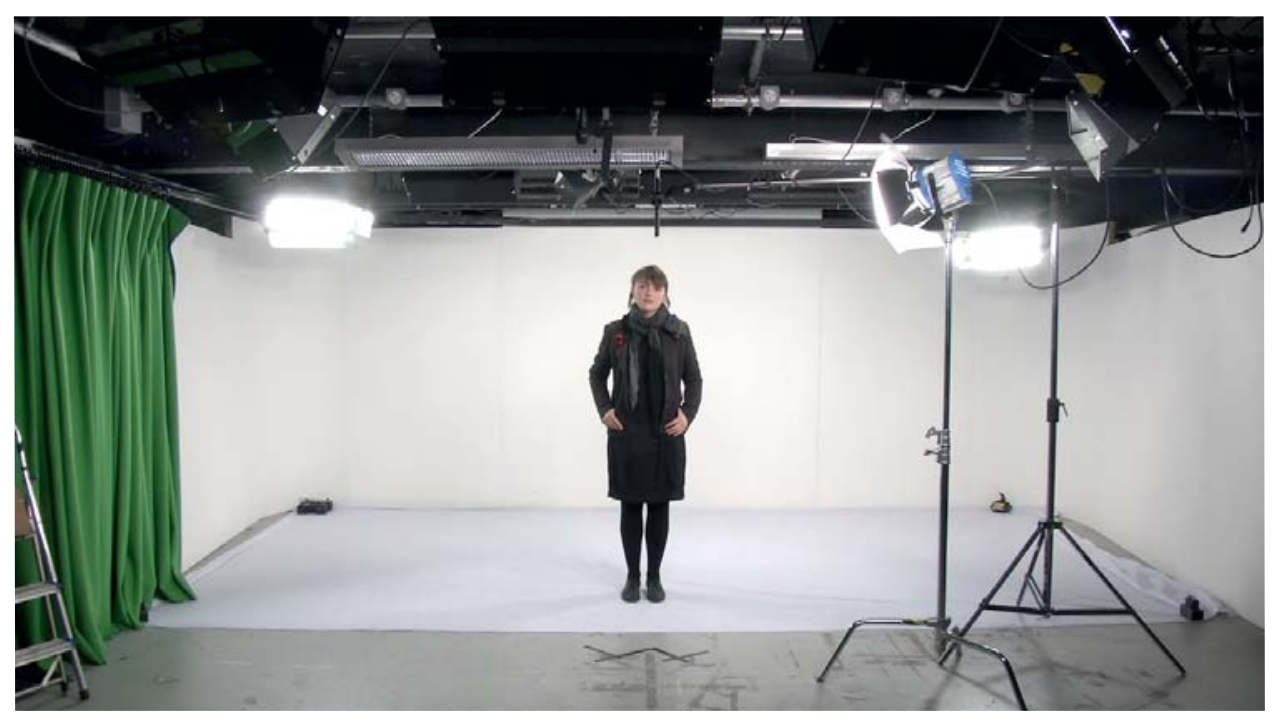

Martina Mullaney

Enemies of Good Art, Single-channel video, 10 min., 2012

http://www.enemiesofgoodart.org

https://vimeo.com/161482260

Enemies of Good Art was performed in a TV studio in London in 2012. It was a response to the activities and concerns of the wider project under the same name. The project evolved around a series of discursive events held between 2009 and 2014. Reproduction, social reproduction, labour, domestic labour, and the nature of creativity for the artist with children were the main subjects discussed during open public meetings and live radio broadcasts.

Martina Mullaney is an Irish artist and PhD Candidate at University of Reading, looking at the missing mother from public, social, and academic contexts. She won the Red Mansion Art Prize in 2003 and graduated with an MA in Photography from the Royal College of Art in 2004. She has exhibited with Yossi Milo Gallery in New York, Fraenkel Gallery, San Francisco, Gallery of Photography, Dublin, and Ffotogallery, Cardiff. After the birth of her daughter, she initiated the project Enemies of Good Art in 2009-a multi-disciplinary project interrogating the position of the artist in relation to the family. The project was executed through a series of public meetings, performances, lectures, and live radio discussions. Events took place at: Tate Modern, the ICA, Southbank Centre, and Chisenhale Gallery, as well as at Tranzit Display Gallery in Prague, Czech Republic, and Galerija Nova, Zagreb, in 2015. Enemies of Good Art was also broadcast on Resonance 104.4FM.
Video still Enemies of Good Art, Martina Mullaney 


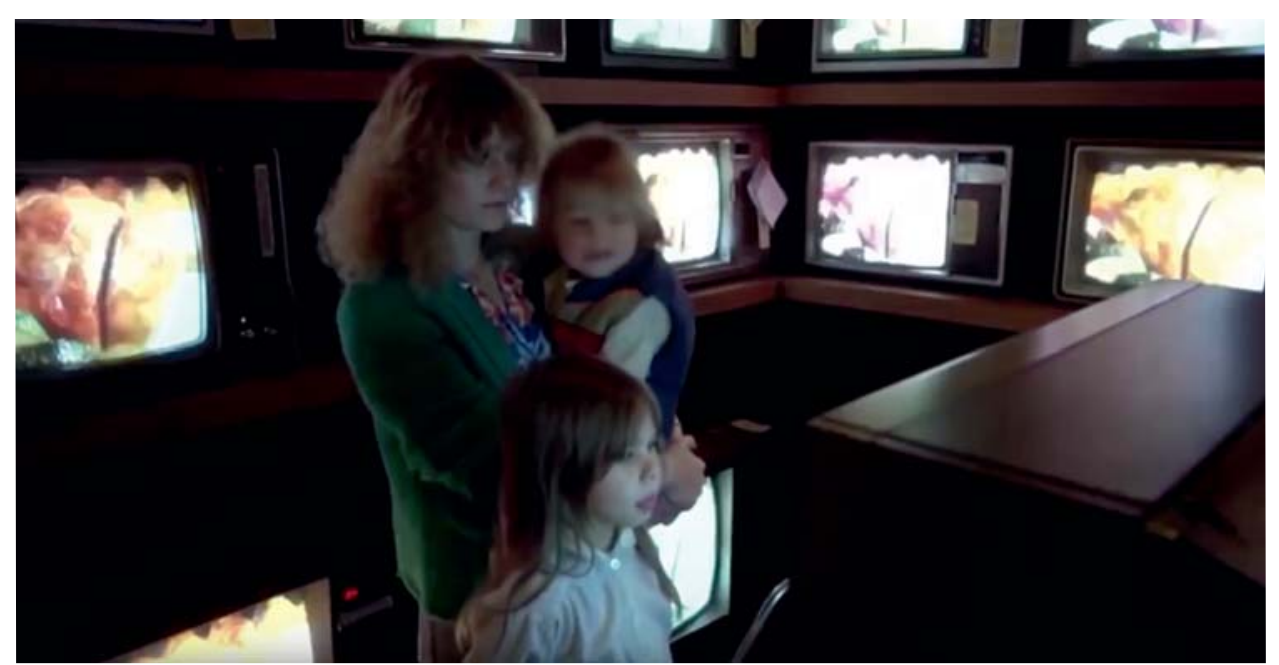

Video still, What the $f^{* *} k$ is social reproduction? An introduction by Plan C, Plan C

Plan C

What the $f^{* *} k$ is social reproduction? An introduction by Plan $C$

Single-channel video, 3:41 min., 2015

http://www.weareplanc.org

https://www.youtube.com/watch?v=apO3B_o6dz8

A short introduction to the idea of social reproduction and what it means for those organising in, against, and beyond capitalism. Made for Plan C, a UK-based communist organisation.

Plan C is an organisation of people who are politically active in their workplaces and communities. We work together to support each other, amplify our struggles, and think strategically. We want to go beyond network-based organisation, without falling back on the model of a party. We are committed to ongoing experimentation to find the forms of collective activity needed to build a world beyond capitalism. Plan $C$ is also concerned with making plans-plans to survive and resist capitalism's attack on our lives, and plans for collective self-organisation.

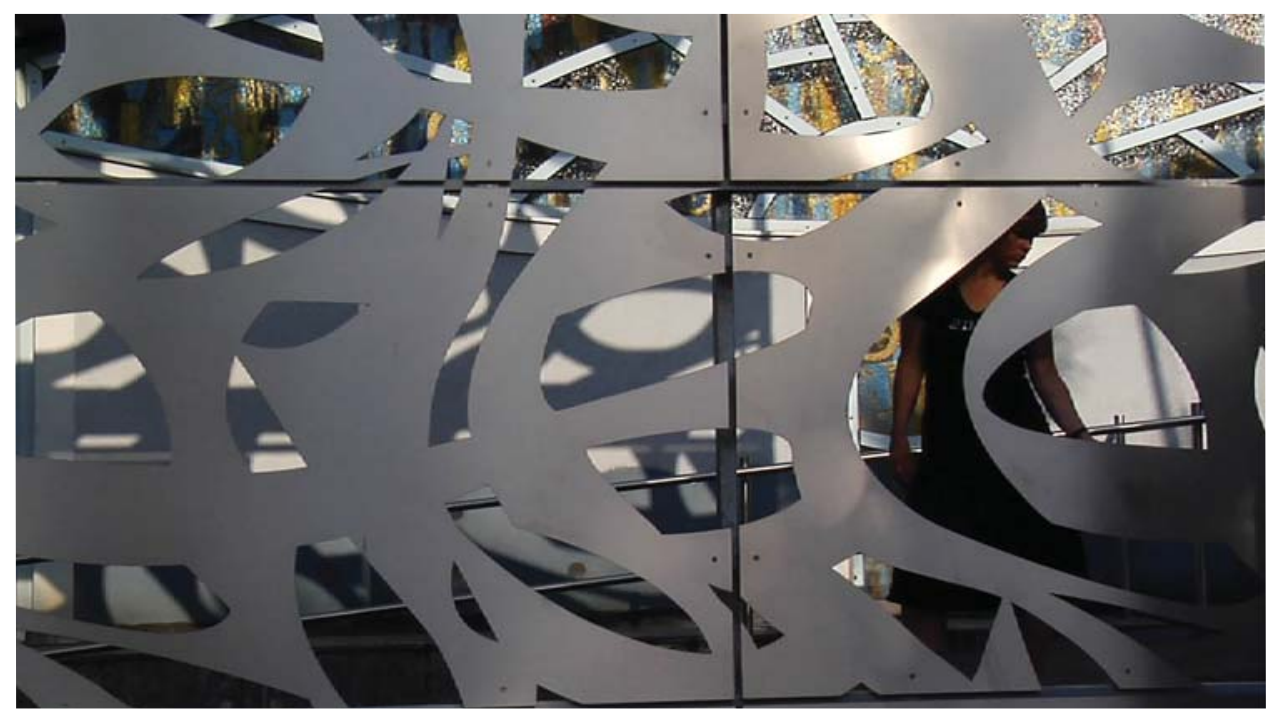

\section{Szuper Gallery}

I will survive, Single-channel video, 7:55 min.

https://vimeo.com/163036953/5d6f396298 
Can love be genuine and at the same time for sale? If it is purchased, it obeys a calculation, and hence it is dependent on something other than itself, is instrumentalised, and hence devalued. If it lies beyond calculation, however, it contradicts the supreme premises of our economic order, by which standards it is dangerous nonsense. A video performed by

Susanne Clausen and Pawlo Kerestey, masquerading as their own younger and older selves.

Szuper Gallery: Susanne Clausen and Pavlo Kerestey initially formed Szuper Gallery as a tool to explore the concept of gallery as institutional critique. Operating as an artists' collective, they have since moved on to larger sites for art production and continue to renegotiate their East-West experiences through a number of projects looking at precarious working conditions, disaster narratives and social choreography. They recently exhibited at GRAD London, Western Front Vancouver (2014), National Museum of Art Ukraine (2013), Perm Museum of Contemporary Art (2012), Kunstmuseum Thun (2012), MacKenzie Art Gallery (2011), Kunsthalle Helsinki (2005) and Para/Site Art Space, Hong Kong (2005). Susanne Clausen is a Professor in Art the University of Reading

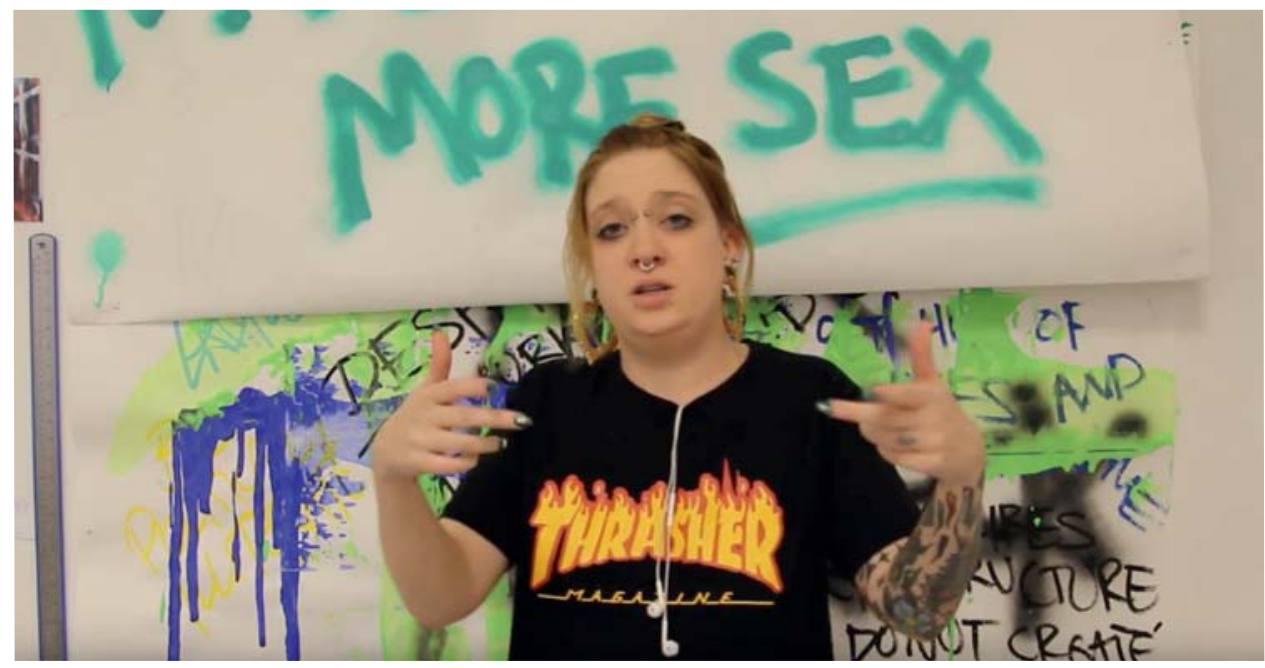

\section{Liv Wynter}

Liv Wynter performing F\#@kin Artists, 2015, 1:59 min.

https://www.youtube.com/watch?v=bCroqNWwUzk

Pedro vs Liv Wynter / Don't Flop Rap Battle, 2015

https://www.youtube.com/watch?v=v6LH71UGko0elist=RDv6LH71UGko0\#t=13

Fuckin' Artists written and performed by Liv Wynter: Liv Wynter spits about how some men just wish all your work was about them.

Liv Wynter is a queer female artist working and living in London. Through her anarchic and punk exploration of language, rap, and poetry, Wynter uses performance to bring attention to issues such as trauma, recovery, abuse, sexual violence, and identity. Wynter's work takes the form of performances of polemic text, most often live. Her work challenges the idea of intimacy and negotiates ways to exist and show work outside of the institution and without compromise. 


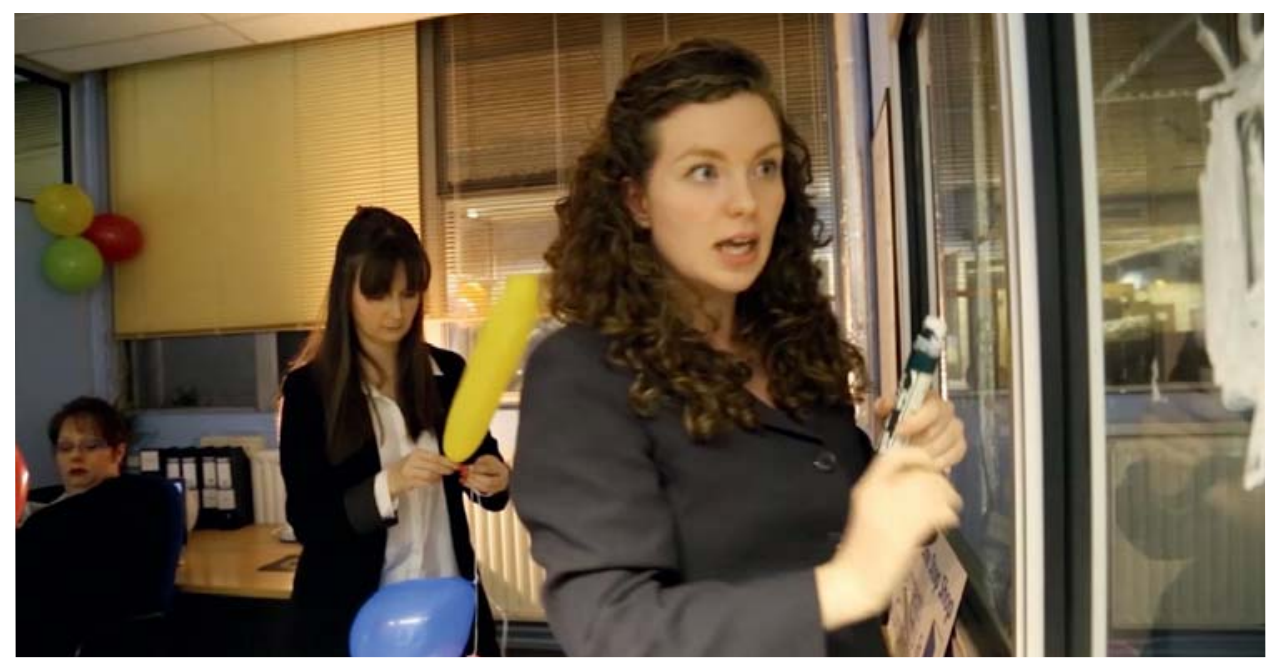

Louise Fitzgerald

We're on it, 2015, 2:56 min.

https://vimeo.com/131790384

We're on it explores the potential to expose political stereotypes and rhetoric. Through staging short vignettes that focus on a futile group activity, contemporary working relations and 'issues' are performed and satirised. Through fast-paced and absurd narratives, the films portray the struggle between individual self-expression and communal belonging against a backdrop of confused dogmas and information overload.

Louise Fitzgerald is a recent graduate from The Royal College of Art, London (2015). She previously studied at the University of Reading (2013) and Mason Gross School of the Arts, New Jersey. Recent shows include: Laugh Launch, Cheviot House, London (2015); The Octopus was Naked but the Crab was Dressed, Plymouth Art Centre, Plymouth (2015); Script, Bresse Little, London (2015); The State of Things, Dyson Gallery, London (2014); Dizziness of Freedom, Bermondsey Project, London (2014) and Platform, Modern Art Oxford, Oxford (2013).

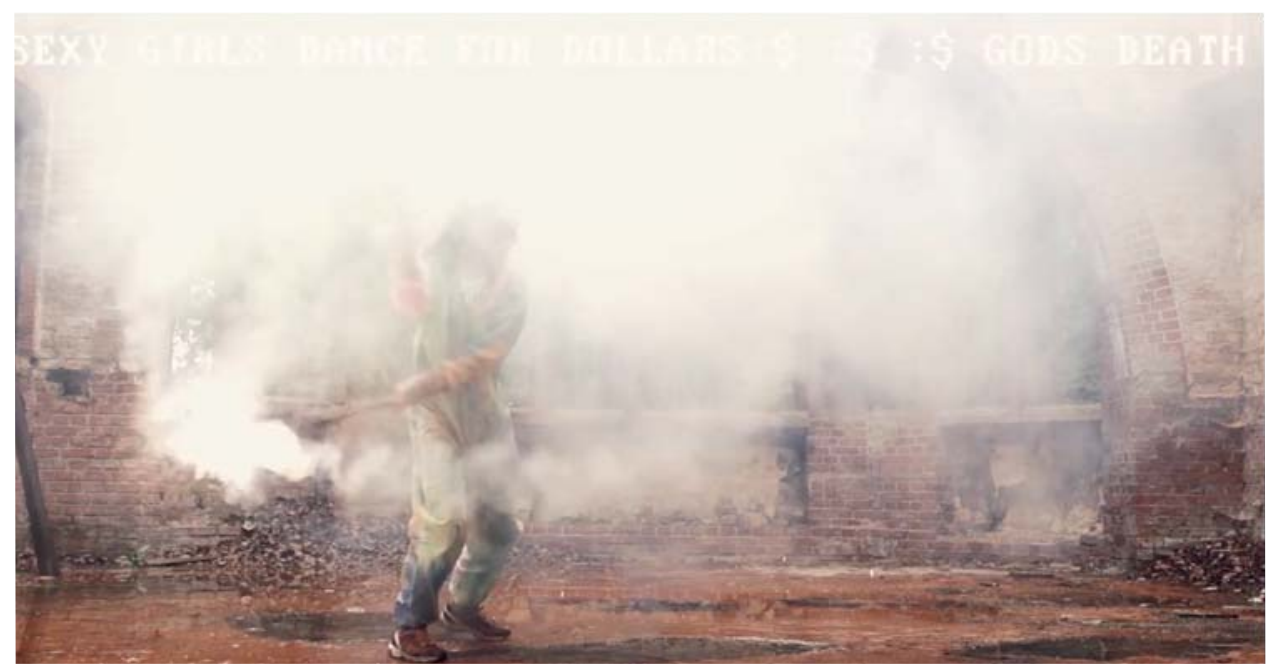

PUNK IS DADA

MEAT SPACE \# MY GIRLFRIEND IS THE REVOLUTION, 9:13 min. 2014

https://vimeo.com/101294620 
MEAT SPACE \# MY GIRLFRIEND IS THE REVOLUTION represents a new genre of ephemeral action-it commodifies the cultural shift from Cyberpunk '90s dream utopias to the legitimacy of reality in cyberspace. MEAT SPACE also showcases PUNK IS DADA's new online collection of clothing, face wear, and hair for anti-face detection via CCTV or OPENCV, one of the most widely used face detectors on the Internet-style tips have been taken from Adam Harvey's extensive research on camouflage from face detection with CV Dazzle. Cyberspace knows everything as devoid of consequences, even her own utopia.

PUNK IS DADA is "futuristically political", [i.e. unrealistic], proposing the contents and makings as a form of post-political entertainment. The content examines other virtual egos and experiences, allowing the works to become a dematerialised hybrid of modern day culture. Yet she declares herself an untrend; PUNK IS DADA assumes the visage of poverty in her anti-nostalgic dystopia-she is industrial by nature and de-gendered by style. 


\section{Slapping Scenes Susanne Clausen}

One of those nightly Google and YouTube sessions. Search terms "Interview with" and "performance."

A sonorous commentator's voice announces an interview sequence with a famous young woman. White title on a green background. The first thing you see are slender hands noting something with a thin pencil and then rolling together a small piece of paper. The piano playing in the background slowly grows louder. A child is sitting at the piano. She has short blonde hair and is wearing a pretty dress. The child is playing, then turns around and smiles proudly into the camera. Cut to the hand nervously rolling the small piece of paper open and closed. Next to the ashtray is a half-full pack of Roth-Händle cigarettes. The piano can still be heard in the background. The woman is speaking into a microphone, and her head is slightly lowered. The camera keeps the woman in one corner of the visual field, revealing a table with a floral tablecloth in the background.

I would like to shoot cold from the hip and Love is colder than capital, or perhaps rather a scenario full of warm concepts: sofa, love, life, loss.

The hands snip off the cigarette into an ashtray. She has a determined voice: Private matters are imminently political; raising children is terribly political; seen from the perspective of the children, the place of the family, the stable, human place of the family is absolutely necessary ... and essential. Cut. She lights a match. Difficult, terribly difficult .... it is difficult, terribly difficult.... the voice breaks off, the match flickers.

So this woman has problems. She lowers her head, but nevertheless directs a brief rebellious gaze upward. She says: Naturally it's a lot simpler if you have a wife who does all that, who takes care of the kids and everything works out.... and children really do need stable relationships, and everything, and someone who has a lot of time for them. And if you are a woman, and don't have anyone who can take that over for you, you have to do everything yourself. And that is terribly difficult ...

So a bad mother. The woman's face is now lowered:

So that's the problem of all politically active women, my own too, that on the one hand they are doing socially necessary work ... but on the other hand sit there just as helplessly with their children as all other women do ...

The handheld camera floats over the woman. Her face is framed by dark bangs. The camera tracks nervously up to and away from the woman, and her answers become dialectical.

The central oppression of women, if her life is made to contradict her private life ... if you can call it a contradiction when political work has nothing to do with your private life, then something is wrong, then it's a perspective that cannot be endured. You can't pursue antiauthoritarian politics and then beat your children at home. But in the long run, you can't not beat your children at home without pursuing politics, without fighting for the elimination of competition outside the family ... which is where everyone ends up who starts to ... leave her family.... 
Now the message of the film clip is insistent: the woman really is a bad mother. Keywords: psychology, critique of kitsch, comedy of despair.

Voice: The conflict between private life and political ambition remained, even grew worse as a result of her new role as the mother of two children. She felt overwhelmed, tortured, to the point of despair. ... A few months later she left her own children.

New search: "Competence for one's own problems."

Why do I want to maintain my ambition to realize myself in my profession despite the precarious circumstances of the work? And does it still work?

Should I hit her? Should I? Do you want me to hit her in the face?

Search: "Slapping scene." Open a new window.

An actress is standing on the front of the rehearsal stage and has to explain why she does not want to allow herself to be slapped by her colleague as the work requires. She reacts hysterically. The author of the play they are rehearsing is sitting in the parquet, annoyed. You find that funny? This famous scene is apparently being staged by students here. In this scene, the actress can no longer calm down at all. She rolls on the floor, wails hysterically; her male colleague: You don't get to me, you really don't get to me. René Pollesch reads the logic of creating art out of this slapping scene. So the actors rehearse on an evidently moving Broadway play. Keyword: Successful product and everyone falls out of character; keyword: Rebellion in miniature.

I have lost touch with reality; reality simply no longer seems real to me anymore.

Making a move becomes a problem here because it stands for everything you doubt: explainability, resolution, crisis, success. How do norms emerge in the defect and how does understanding process these defects? The scene is no longer a brief aperçu but appears rather as a model that causes the regulation and its outputs to be considered more selectively.

Susanne Clausen and Pavlo Kerestey initially formed Szuper Gallery as a tool to explore the concept of gallery as institutional critique. Operating as an artists' collective, they have since moved on to larger sites for art production and continue to renegotiate their East-West experiences through a number of projects looking at precarious working conditions, disaster narratives and social choreography. They recently exhibited at GRAD London, Western Front Vancouver (2014), National Museum of Art Ukraine (2013), Perm Museum of Contemporary Art (2012), Kunstmuseum Thun (2012), MacKenzie Art Gallery (2011), Kunsthalle Helsinki (2005) and Para/Site Art Space, Hong Kong (2005). Susanne Clausen is a Professor in Art the University of Reading 


\section{Feminism Meets the Big Exhibition: Museum Survey Shows since 2005 Hilary Robinson}

In the years 2005-2011 something remarkable happened. Feminist art and/ or art by women was made the focus of many exhibitions in major museums. If we include the venues that hosted touring versions of the exhibitions, some twenty or more institutions in different parts of the world put significant time and financial resources into surveys of feminist art and/or art by women. This phenomenon occurred mostly in European countries, but also in the USA, Iceland, Russia, Japan and elsewhere. In addition to these survey exhibitions, feminism intersected with other major spaces and places in the global field of contemporary art. The Venice Biennale, with its national pavilions, is the longest-standing international art exhibition; its 51st edition (Venice, Italy, 2005) was spoken of as "the so-called 'feminist Biennale'" (O'Donnell; see also Nochlin, Jones). In the 12th manifestation of the massive quinquennial survey of contemporary art, documenta (Kassel, Germany, 2007), women formed $46 \%$ of the artists-an unusually high percentage-and "feminism and feminist art were on the agenda" (Esner 239). In various countries other mainstream museums put on thematic exhibitions of feminist work with smaller numbers of artists, such as It's Time For Action (There's No Option): About Feminism (Migros Museum für Gegenwartskunst, Zürich, Switzerland, 2006); The International Incheon Women Artists' Biennale was established in Incheon, Korea (2007, 2009, 2011); and in 2010 the Modern Woman project at the Museum of Modern Art, New York, was made manifest through a series of exhibitions, a publication, film screenings, gallery talks, and a symposium.

These exhibitions have occurred 35-40 years after the women's liberation movement, the art world, and art history first intersected in a way that was highly productive, and they have occurred in venues that are in sharp contrast to the often alternative, non-traditional, venues that hosted the first exhibitions informed by the women's liberation movement. That so many major museums felt that it was timely to reassess this movement and its intersection with the art world provokes the questions: What feminist politics informed these exhibitions, and what feminist politics did they produce? As a result of the choices made by the curators, how would viewers of these exhibitions understand the intersection of feminism with the art world? What was the curators' reading of the history of this work? What histories of feminism have these exhibitions produced? This essay will examine four of the survey exhibitions in an attempt to answer some of these questions.

\section{Context}

Some of the survey exhibitions were national. For example, the MOT Annual 2005: Life Actually, The Works of Contemporary Japanese Women in Japan, The Will as a Weapon: Review, in Iceland, and Dream and Reality: Modern and Contemporary Women Artists from Turkey explored the movement within national contexts and cultural specificities. Some were regional or cultural. Gender Check: Femininity and Masculinity 
in the Art of Eastern Europe, which was shown in both Austria and Poland, explored art made in twenty-four countries over a period of fifty years both before and after the fall of the Berlin Wall; La Costilla Maldita, in Gran Canaria focused on Spanish-speaking artists from Europe and from Latin America, with the aim of showing similarities and differences. Other exhibitions were more fully international in intent. WACK! Art and the Feminist Revolution (USA), Kiss Kiss Bang Bang: 45 Years of Art and Feminism (Spain), and REBELLE. Art and Feminism 1969-2009, all aimed at an international representation of the movement, although with different results. Some were limited to particular decades or timeframes (WACK! Art and the Feminist Revolution focused on the late '60s and the '70s, while Global Feminisms (USA) took the period 1990-2007); Gender Check: Femininity and Masculinity in the Art of Eastern Europe encompassed the construction and representation of sexual identity by both male and female artists, as did A Batalla dos Xéneros/Gender Battles (Spain).

But despite these significant differences, what the exhibitions share is crucial in four respects. First, they all purport to be surveys, as distinct from the many themed feminist exhibitions or exhibitions of women's art that also occurred during these years, like It's Time For Action (There's No Option): About Feminism. Second, they all intersect with feminist thought, in either the stated curatorial impulse for the exhibition, and/or in much of the art selected, and/or in the ancillary products of the exhibition such as the catalogues. Third, they have occurred at the time when the lived experience of the women's movement is turning into the subject of History, and its impulses are being disciplined, defined, written, and, in the art world, canonized. Fourth, they all occupied major national or regional museums and galleries.

Thus, what we see happening during this time is that institutions that are structurally central to the art world (national or regional museums, the kind of institutions that are arguably most able to determine the definition and reach of categories in Art History, and the artists and art works of most significance to them) were presenting their own definitions of what they consider a feminist art movement to be, or what they consider contemporary art by women to be capable of saying. In this manner, these institutions are determining an Art Historical category of 'Feminist Art' or 'Art by Women'. As they do this, they offer the exhibition visitor an apparently seamless proposition: the visitor sees what is there, and doesn't see what is not there, and it can be hard to argue with the proposition as a result. If the exhibition is elegantly structured in relation to the exhibiting space, and the works are beautifully positioned in relation to the gallery and each other, the visitor can be lulled into an unquestioning acceptance. There can be great pleasure in seeing works that had previously only been known through reproductions in books, and also in encountering previously unknown works in that context. Unless s/he has a deep knowledge of an exhibition's subject of enquiry, the visitor will be unlikely to see the gaps and the choices; s/he will certainly not see the stories behind certain works not being there because of, say, the artist's or the owner's unwillingness to loan them, and even less will $s /$ he see the active choices of exclusion made by the curator. $S /$ he will have the experience of walking around the exhibition, from room to room, and will glean important understandings of the intent of the curator from the way the works are grouped together and placed in relation to each other; s/he will be able to read any labels and wall-mounted texts, pick up leaflets and other material. Eventually, the major trace of the exhibition will be in the catalogue, if there is one, available either for purchase or for loan through library systems. Increasingly, catalogues contain commissioned essays by people who have had no part in making the exhibition, but who write in broad support, complementarity, or augmentation, rather than close critique, of the curator's 
argument. But catalogues also usually contain an essay by the curator or curators, outlining the intent of the exhibition-the story that they are trying to tell, its background, and what has informed the way they have structured this narrative. The catalogue is often a lavish publication (the $\$ 60$ or $£ 45$ catalogue is not a rarity), intended to have integrity as a publication independently from the exhibition, and to be coherent and of interest to people who were unable to see the exhibition. At the same time, it is also often the main source of information about the thinking that went into structuring and presenting the exhibition. It can thus provide a point of contrast for the visitor to the exhibition between the curatorial intent and its realization in the museum; and to the non-visitor, it exists as an opaque stand-in for the first-hand experience of exhibition.

What is clear from the catalogues for the exhibitions listed above, and from personal visits that I was able to make to some of them, is that each of the exhibitions had a further distinction, over and above the overt distinctions giving bounds to the exhibition-distinctions of location or chronology-that I indicated. Possibly the most significant distinction between the exhibitions-and, by extension, their curators-is their definition of, and relationship to, feminism. While the words "feminism" or "feminist" were in many of the exhibition titles, there is by no means curatorial agreement on what this might mean, how significant it is, whether it is located in the realm of politics, or culture, or social exchange. Still less is there agreement on what might constitute feminist practices in art. I will explore some of these exhibitions, particularly through their catalogues, in order to draw out this point.

\section{WACK! Art and the Feminist Revolution}

The title of WACK! Art and the Feminist Revolution (Museum of Contemporary Art, Los Angeles, 2007) indicated that the art exhibited would not necessarily be feminist art; rather, the exhibition explored the relationships between art and what is termed (in the first sentence in the catalogue) the "social movement" of feminism (Strick 7). This was reinforced at its originating venue, the Los Angeles Museum of Contemporary Art (LA MoCA), when visitors entered the exhibition to see a 13-foot-diameter hanging fabric piece, a magnificent work by Magdalena Abakanowicz: Abakan Red (1969). Abakanowicz is an artist not known for identification with the women's movement or feminist thought. This piece, however, has some formal resonances with what in the early 1970s Judy Chicago was to call "central core" or "cunt" imagery, and Barbara Rose was to call "vaginal iconology", and it was presumably selected to open the exhibition for this reason.

WACK! was a large, rambling exhibition. The viewer walked from one (unlabelled) section to another, around the screens and partitions in the hangar-like museum, without necessarily recognising the categories that were laid out in the catalogue; rather, there was a flow, with works in different areas relating to each other through their media and their content. It was an extraordinary opportunity for the visitor to see work in actuality that had often only circulated in black-andwhite photographs in significant publications from the 1970s. This was one of the great pleasures for the viewer in visiting WACK!: seeing works that might be recognised from having seen them in reproduction-works that could be named, but had rarely been exhibited before. In total there were 119 artists and artist groups arranged in eighteen different curatorial sections. It is worth naming these sections: Goddess; Gender Performance; Pattern and Assemblage; Body Trauma; Taped and Measured; Autophotography; Making Art History; Speaking in Public; Silence and Noise; Female Sensibility; Abstraction; Gendered Space; Collective Impulse; Social Sculpture; Knowledge as Power; Body as Medium; Labor; Family Stories. These are 
categories of style, media, imagery, content, and intent. As a group they are surprisingly apolitical for a field that included so many activist individuals, groups, interventions, and artworks.

In the first few lines of her catalogue essay, curator Cornelia Butler states her definition of feminism. It is one that she quotes from Peggy Phelan who, Butler says, "has offered what seems to be the most serviceable definition of feminism: 'the conviction that gender has been, and continues to be, a fundamental category for the organization of culture. Moreover, the pattern of that organization usually favours men over women'" (Butler, 15). Stated like this, the definition emphasises the apolitical, non-activist curatorial categories used in placing the works in the exhibition space. It also removes it from a chronology that Phelan laid out in her original text, written in 2001 (two decades after the time period for WACK! came to an end) and in the context of a survey essay in a volume on feminism and art that covers nearly four decades, up to the time of her writing. In that book, Phelan offers her "bold, if broad, definition" in recognition that "the ideological stakes in the question 'what is feminism?' have often led to increasingly sophisticated but, it must be admitted also, increasingly evasive responses" (18). Butler goes on to situate her own first "interest in 1970s feminist art" in her witness of two catalysts for the formation of the Women's Action Coalition in New York in 1991 and 1992 (17). First was the way in which attention to Matthew Barney's breakthrough exhibition "virtually eclipsed several other simultaneous exhibitions featuring women artists" and dominated the discussion in a panel with the title "What Role Will the Language of Feminism Play in the Art World of the '90s?" Second was the intention of the Guggenheim Museum to open its new branch in New York's Soho with an exhibition of only white men (Butler 18-20).

So here Butler is indicating her interest in feminist art as the product of internal art world events, rather than as a commitment to feminist thought and action as a broader political position that is then brought to bear upon the art world amongst other things. In the article from which Butler quotes, Peggy Phelan called our attention to this distinction when working from and within a highly localised art world framework: "Writing about art has traditionally been concerned with that which is interior to the frame, whereas feminism has focused primarily on what lies outside the frame of patriarchal logic, representation, history and justicewhich is to say the lives of most women" (17). Identifying this difference is not to deny that the awareness of the need for feminist thought and action can come from any catalyst; but there is a move towards vigilance and activism in Phelan's observation, which is not embraced by Butler. Instead, what we find in Butler's essay is the conceptualisation and articulation of two things: first, of a feminism that is interior to the frame of US (or New York) Art History; and, second, of an exhibition that embodies the struggle to move beyond that frame. It is fundamentally an incorporative approach-one that attempts to assimilate feminism as a practice of art into the particularity of that art history.

This is made evident in the catalogue essay written by Connie Butler as the curator of WACK! Exclusions from exhibitions are always interesting, as they form the framework that determines the argument presented by the curator: not part of the picture, they constitute its borders, and therefore, its definition, its 'edge'. The exclusions that are brought to the attention of the exhibition-viewer and the catalogue-reader become precisely those porous and slippery moments where intention is made explicit. Apart from discussing her reasons for excluding men artists as a category from the exhibition, Butler tells us why she excluded one artist whom she names: 
Another test of feminism's relevance and resiliency occurs with artists who did not participate in, and whose work did not circulate through, the mainstream (read: white) art world. Emily Kame Kngwarreye, for example, was an Australian aboriginal artist who, during the 1970s, made textiles as part of the Utopia Women's Batik Group [...] Though Kngwarreye later gained recognition for her abstract paintings, which were shown in galleries during the 1980 s, she is not represented in WACK! because the economy in which the Utopia Group's early production circulated did not favor institutional collections and archives. (17)

From a feminist perspective, this is a surprising statement for two reasons. First is the identification of "the mainstream (read: white) art world" without equal recognition of the mainstream being additionally male and Eurocentric: feminist thinking in the art world has not only happened within the traditional studio, but to a very large extent as an institutional critique of the structures of the art world it was trying to occupy and change. The position of what the mainstream art world of the 1970s might define as ethnically specific craft-work made by a woman (in this case, the textiles made by Kngwarreye as a member of the Utopia Women's Batik Group) would be one that was compromised on numerous fronts, and Western feminists at the time and in subsequent decades were struggling (often with each other) over the re-contextualisation of works such as those by Kngwarreye. This included direct challenges to, and circumvention of, the curatorial categories that produced such exclusions. The second surprising aspect to Butler's statement is that as feminist artists and writers of the 1970s were analysing the exclusion by the mainstream of artists who were women, who were black, and who were non-Western European, they were also identifying a number of different strategies that artists and curators could take. One was what might be called "an equal-rights feminism"-an attempt to enter institutional structures on a par with men. A second strategy was to re-structure the art world to make it less exclusionary-"that rotten pie", as Lucy Lippard called it in 1974 (26). A third strategy was to set up alternative, feminist, or woman-centred structures, as happened through Europe, the USA, and elsewhere in the 1970s, in the process reconfiguring the relationship between artists and curators. The realities with which Emily Kane Kngwarreye was dealing as an Aboriginal woman in Australia in the 1970s were very different from those of the vast majority of women living in the USA or Europe at that time; but the fact remains that many of the works in WACK! were made deliberately for circulation in environments that bypassed the mainstream of the art world. This was not peculiar to feminist artists: for example, in the 1960s and 1970s performance artist Allan Kaprow recognised that much art produced as "anti-art" was eventually incorporated into art world institutions and market without disturbance, and he consequently focused on producing "non-art" (Kaprow passim). But the analysis-and eschewing-of patriarchal mainstream structures was a notable part of feminist practices in the 1970s. Indeed, a number of artists in WACK! produced works in this way, even if they did later gain entrance to the authorizing place of the museum exhibition. So we can see through Butler's positioning of Kngwareye that WACK! is a fundamentally revisionist version of the history that is less impelled by feminist thinking than it is by contemporary curatorial and art historical practices, realised on an archival scale.

\section{Kiss Kiss Bang Bang: 45 Years of Art and Feminism}

There is a great contrast between Connie Butler's curatorial catalogue essay, and the one provided by Xabier Arakistain in Kiss Kiss Bang Bang: 45 Years of Art and Feminism (Bilbao, 2007). This exhibition, five years in the making, opened three months after WACK!, and comprised " 69 works and 36 artists and three feminist 
groups from various countries which initiated and/or have continued to give substance to what has come to be known as 'feminist art'", according to the museum website. In comparison with the 129 artists of the USA exhibition, this is much smaller, but there is also this clear indication that all the work is feminist. In his curator's essay, like Butler in hers, Arakistain outlines the thinking that informed the curating of the exhibition; he gives the curatorial categories developed for the exhibition, and he comments on a small amount of his autobiographical experience with feminist thinking in the art world prior to the exhibition.

Despite covering forty-five years of work, in distinction from the focus on approximately twelve years of work included in WACK!, Kiss Kiss Bang Bang had five curatorial categories rather than WACK!'s eighteen. Arakistain describes them thus:

1. The fight for the civil and political rights of women and the political and artistic implications of the maxim "the personal is political", revealing the political nature of the private sphere, without excluding categories of class and race. 2. The cultural construction of sex, gender and sexuality and denunciation of sexist stereotypes.

3. Struggles relation to the liberalisation of women's bodies.

4. Condemnation of violence against women.

5. Feminist practice to make women visible and include them in the history of humankind, to write a true history that does not leave more than fifty per cent of the population out of the story. (242)

In contrast to WACK!'s more museological and art-world categories, all of the categories in Kiss Kiss Bang Bang are directly related to political and activist themes central to feminist thought and the women's movement. The approach to the selection and installation of work is, therefore, thoroughly informed by knowledge of feminist activism, its foci, and the theory it produced. More than that, it is informed by Arakistain's earlier work as the co-ordinator of the Arts and Feminisms ARCO Forum 2002-2005, which led to the ARCO 2005 Manifesto (Arakistain 244). The Manifesto gives a brief but forceful account of the exclusion of women in the Spanish state-run museums and other state-sponsored exhibitions, such as participation in international biennials. It then calls for the establishment of an expert group to analyse the situation; for in-house policies of equity in museums; and for the application of feminist policies, including the establishment of quotas. The manifesto then informed the drawing up of Article 26 of a 2007 Act of Parliament concerning the equality of the sexes. This article requires that all Spanish government structures responsible for the production and management of Spanish culture must ensure gender equity among exhibiting artists, advisory groups, and decision-makers, and that they must be pro-active in supporting women artists fulfil their potential. This is possibly the most radical legislation in support of women artists anywhere (Ley Orgánica).

Throughout his essay, Arakistain is careful to avoid essentialising the category of 'Feminist Art', instead indicating how the category has been constructed. His argument is that the feminist movement as we know it now can be traced back to the 18th-century Enlightenment, and that the calls for political and civil rights for women that materialised in the 1960s began to manifest themselves in art for the first time at that moment. Thus, his focus is upon particular works of art that demonstrate this, specifically, works that are "placing the problematic of representation right in the foreground. This means asking oneself who represents whom, from what point of view and how, keeping constant tabs on the different systems of representation that continue to construct and transmit stereotypes of sex, gen- 
der, 'race' and sexuality" (Arakistain 241). He argues that the concepts of 'excellence' and 'the canon' within the art world are constructions of power, and notes with surprise and concern that many key works he selected for the exhibition still belonged to the artists themselves, and had not been purchased whether by private collectors or by public institutions. The market had not valued such work, despite their appearance in books and catalogues, and their 'aura' for those who have valued feminism. This discussion of his curatorial process and thinking is in contrast with Butler's positioning of Kngwarreye's work, demonstrating the political and activist definitions of feminism that informed his choices. It is precisely what Phelan calls a focus "on what lies outside the frame of patriarchal logic, representation, history and justice" (17).

REBELLE. Art and Feminism 1969-2009

In 2009, approximately two years after WACK! and Kiss Kiss Bang Bang had opened, elles@centrepompidou opened in Paris and (three days later and about an hour's flight away) REBELLE: Art and Feminism 1969-2009 opened in Arnhem.elles@centrepompidou came about in part after it proved too expensive to host WACK! for another stop on its tour: ironically, as a result, the Pompidou mounted one of the more politically complex and certainly the largest of the survey exhibitions. REBELLE, conversely, was a long time in the making; while it "concretely started taking shape in 2004", it was eventually timed for 2009, a significant feminist anniversary in the Netherlands as it was both thirty years after the important Dutch exhibition Feministische kunste internationaal (International Feminist Art) (1979) and forty years after the founding of the Dutch feminist group Dolle Mina in 1969 (Westen 13).

REBELLE, held in the Museum voor Moderne Kunst Arnhem (MMKA) in the Netherlands, was an interestingly diverse exhibition. Of the eighty-seven artists, twenty were either Dutch in origin, or trans-national and at the time living in the Netherlands. Many of the Dutch artists were represented by recent work focused in the latter galleries of the exhibition, giving local currency to the presentation. While there were just a handful of artists from the former Eastern bloc, Asia, or Americas beyond the USA, eighteen of the artists were from the Middle East and Africa; the work of all of these artists was integrated in the different thematic areas of the exhibition as appropriate. Seven of the artists were represented by work dating from the 1960 s, demonstrating that art was being made from a feminist position in a number of countries while the women's movement was growing, and before the designation "feminist art" had been coined. However, the message that one got from this exhibition was not of nostalgia for a time gone that cannot be recuperated, that can only be celebrated, mourned, and archived. Rather, although the exhibition was not arranged chronologically, it was a demonstration of a movement that is growing, vibrant, and with a lot of work still to do: thirty-three of the artists were represented solely through work made in or since 2000. The presence of artists from African and Arabic countries, alongside artists from Israel, Turkey, and Iran, and some from China, India and elsewhere in Asia, demonstrated a set of feminist issues and languages that, although they may be newly visible in Europe or the USA, should not be confused with or equated with the then-emerging Western European and North American feminist art of the '60s and '70s. Thus REBELLE was an exhibition that demonstrated feminisms not solely situated in a Western European/USA past, but in a broader state of becoming, and without a geographical centre-or centres-determining the feminist present and future. The exhibition as a whole, with one focus on Dutch work, and another focus on African and Middle Eastern work, set up a dialogue between a deep, local site, and a broader, developing context. 
By the time REBELLE opened, MKKA already had a reputation for being supportive of work by women and of feminist work, and had been nicknamed "the women's museum" in the 1980s. The director from 1982-2000, Liesbeth Brandt Corstius, "developed exhibition and collection policies through which the work of female artists became widely represented". She had organised exhibitions of the work of Magdalena Abakanovicz, Miriam Cahn, Dorothy lannone, Nancy Spero, and others, as well as Het Persoonlijke $=$ Politiek (The Personal $=$ Political) in 1984 (Westen 10, 12). She was also a contributor to the catalogue for Feministische kunste internationaal in 1979 (Corstius). The curator of Rebelle, Mirjam Westen, was also the MKKA's curator of contemporary art. She had been actively involved in the women's movement and with feminist arts groups in the 1980s, including Stichting Vrouwen in Beeldende Kunst (Women in the Visual Arts, known as SVBK) and had published in a number of feminist journals. She had also co-organized the historical exhibition Elck zijn waerom: Vrouwelijke kunstenaars in Noord-en Zuid Nederland 15501950 (Everyone Has Their Reasons: Female Artists in the North and South of the Netherlands 1550-1950), in 1990-2000 (Westen 12). Under their leadership, the museum had adopted a policy that $50 \%$ of the work purchased by the museum should be work by women (Butcher). Such depth of experience and commitment to feminism provided a rare environment-an institutional commitment to feminist thinking and processes-and this in turn is reflected in the structure of the catalogue. Taken as a whole, it follows a different track than either the catalogue for WACK! or that for Kiss Kiss Bang Bang. Rather than bringing together contemporary art historians and theorists from different countries to comment on different aspects of this historicizing moment, the five main essays in the catalogue are written by Dutch authors. Intended as "a retrospective look at the Dutch women's art movement", Westen's aim in editing the catalogue in this way was to "include less well-known voices, perspectives and stories, to particularize the history which has been written about in general terms elsewhere" (18). While the catalogue does indeed do that, it does more. It provides an account of an international movement from the point of view of a small European country no longer regarded as a major global force politically or economically, working in a minority language, which at the same time has been pioneering in the feminist thinking, feminist structures, and feminist art it produces. The catalogue does not constantly look over its shoulder to countries like the USA, the UK, and Germany, but rather it acknowledges and incorporates the importance of what happened in a more dominant art and feminist world, while retaining a fully motivated, locally driven and developed set of strategies and politics. Adding further to its particularity, the catalogue was published after the opening of the exhibition, and was therefore able to include documentation of related events and performances.

The curator's essay provided by Westen does echo those of Butler and Arakistain in providing an overview, a personal history and process, and an indication of the themes of the exhibition. The extensive overview is written from the point of view of Westen's process of researching and curating the exhibition. It follows the growing feminist interrogation of the art world and how feminist thinking was used to develop new structures, exhibitions, and practices such as teaching, and then moves on to an exploration of different themes that she identifies within the work of feminist artists. She is careful not to put this in generational terms, not to use the concept of 'waves' of feminism, "in order to avoid the pitfalls of oppositional and linear historical thinking" (13). Westen describes the thematic structure of the exhibition as five loose groups: 1 ) criticism of the representation of the feminine; 2 ) the social constructedness of masculinity and femininity; 3 ) lesbian and black identities: 4) the creation of new images; and 5) the crossing of boundaries, such as between the public and the private, the personal and the political, and between the 
local and the global (18). At least four of these themes can be described as politically informed categories (if not as overtly activist as the themes identified in Kiss Kiss Bang Bang) rather than categories determined by medium, quasi-art-historical categories, or categories of the museum archive. The invitation extended to this visitor walking around the exhibition was to contrast how different artists had approached these different representational issues. It was a curatorial approach that constructed feminist processes as a set of local strategies and histories with comprehension of a growing global network.

\section{elles@centrepompidou}

By far the largest of all the survey exhibitionswas elles@centrepompidou. This exhibition aimed to be a story of contemporary art told only by women artists, and all the works were ones that were in the collection of the Musée national d'art moderne (MNAM-the museum of the Centre Pompidou). The catalogue lists all of the women artists in the collection, naming in bold the impressive figure of 343 artistswho were in the exhibition.elles@centrepompidou was also the longest exhibition: originally intended to be something over a year, it was extended to be a year and nine months, due to the extraordinary public response. During this time, there were two partial re-hangs swapping about one-fourth of the works on each occasion. The fact that all of the works came from the MNAM's own collection should not be remarkable, but it is. As the catalogue for elles@centrepompidou lists the date of purchase of works, it is possible to see that while MNAM bought a good amount of work by women in the time immediately leading up to the exhibition, it has also systematically bought work by women over many years. So while we can see that in the 2000s the museum was buying earlier works (for example, Niki de Saint Phalle's Tir of 1961, purchased in 2004, and a Nancy Spero drawing of 1967, also purchased in 2004), it is also possible to see that the museum has more often bought works within a decade of their creation. Even so, the curator Camille Morineau notes defensively that women artists "only comprise $18 \%$ of our collections and $25 \%$ of the contemporary collections"-although she later notes with surprise that "two great neighbouring museums, the Louvre and the Musée d'Orsay, exhibit works exclusively-or almost exclusively-by men" (15-16).

The opening sentence of the catalogue (similarly to that of WACK!, as noted above) is written by the head of the institution (Alain Seban) and situates "the transformation of the condition of women [as] a major economic, social and cultural fact" (Morineau 9), rather than a result of political engagement and struggle. The curatorial themes, at seven, are more manageable than the eighteen of WACK!, but like that exhibition, they combine the art historical, the material, and the social, but ironically also add the activist: Pioneers; Free Fire; The Activist Body; Eccentric Abstraction; A Room of One's Own; Words at Work; Immatérielles (Morineau 18). Morineau's curatorial approach as outlined in her essay differs from those of Butler, Arakistian, and Westen in significant ways. Her aim is not to define feminism, or the exhibition's relationship to feminism, or her own relationship to feminism. Rather, at the core of the essay is an attempt to explain what she terms "the French paradox" (Morineau 16): how can a political and cultural system that is based upon the concept of "égalité"-equality-acknowledge difference? How can women "take the floor" from which they have been excluded when they cannot do so structurally in the name of women? How can women argue for universalism by addressing difference? Morineau paraphrases historian Joan Scott's work on the "French paradox" when she writes of the MNAM: "Whatever the specifics of its exhibitions (and these have varied depending upon the period, because it is a museum of the present day), a museum concerned about equality within its collections has to argue against exclusion and for universalism by addressing women's difference-the very 
difference which led to their exclusion in the first half of the century" (17). This in turn can prompt in the non-French reader the reflection that there is another layer of paradox for readers outside France: that to an extent not experienced in relation to other nationalities, "French feminism" has become a theoretical and cultural category (despite the often vitriolic differences between writers such as Hélène Cixous, Luce Irigaray, and Julia Kristeva), and that contemporary French philosophers in particular have developed the category of "difference" as an intellectual and political tool that has been of great use in developing feminist thinking.

While Morineau states that the selection of work from the collection "is as anthropological, sociological, and political as it is art historical", she is also at pains to deny that this is a feminist project: "The goal is neither to show that female art exists nor to produce a feminist event, but to present the public with a hanging that appears to offer a good history of twentieth-century art. The goal is to show that representation of women versus men is, ultimately, no longer important. Proving it is another matter" (16-17). And here is another paradox: much of the work in the exhibition focuses on being female-inhabiting a female body, a feminine cultural position, and/or a feminist political position. Even with works where a woman is in the image but the work is not overtly political (for example, in "Voices of Reason/ Voices of Madness" (1984) by the Canadian, Geneviève Cadieux; or "Electric Dress" (1956, reconstituted 1999) by the Japanese Atsuko Tanaka; or "Lying with the Wolf" (2001) by the American Kiki Smith), the marked cultural construction of women's bodies (versus the 'neutral' or 'universal' or 'human' cultural construction of the bodies of men) overladen with the gendered associations of particular representational tropes (in turn, hysteria; the traditional wedding dress; the sexually predatory attributes of the wolf in myths and tales) means that each of these works are available for deeply political readings. Further, certain curatorial decisions left the viewer with fruitfully frustrating and ambiguous readings of the various works. For example, in the section on design that focused on kitchens and dining, the curator had included a 1970s TV showing Martha Rosler's acerbically (and now iconically) feminist video "Semiotics of the Kitchen" (1975). One-activist-reading of this sly move would be that the anger represented by Rosler is enhanced by the work's enforced position in the kitchen; another-revisionist -reading might be that all Martha needed were these neglected women designers to make her domestic experiences happier. A third-anti-feminist-reading might be that the women designers were not neglected-they were in the collection of the MNAM, and some had had highly successful careers-and Rosler's piece was emotional and misplaced. In the case of all of these artworks, the specificity of the subject demonstrates that, contrary to her stated aim, Morineau had constructed an exhibition where representation of women versus men was, ultimately, central. Where the frustration lay for a feminist viewer of elles@centrepompidou was in the gap between, on the one hand, the assumption that simply 'being a woman' would be sufficient to make a coherent exhibition, and on the other hand the rejection of the category 'woman' in favour of the individualism inherent in the feminine plural "elles" (a grammatical construction that does not exist in-and is not readily translatable into-English). While the exhibition enjoyed an elegant and generous installation, the political thinking that could have filled that gap-the deconstruction of the category 'woman' and the production of new forms of representation-was missing. Instead, 'being a woman' was at times denied or (as in the placing of Rosler's video) was exposed as being an unresolved and unstable category, ready and waiting to undo the museological, archival, approach, but in the context de-historicised and de-politicised: feminism in limbo. 


\section{Some Concluding Thoughts}

So why is it important to think closely about how museums curate such exhibitions? There is an increasing tendency for museums to expand collections through donations from donors. Donors, of course, collect to their own loves, and to their own prejudices. The saga of the relationship between Eli Broad and the Los Angeles County Museum of Art (LACMA) is an example of this: he is both a trustee of, and has loaned works to, LACMA. Broad's collection is notoriously light on women, but nonetheless is going to form a major part of what the public who go to LACMA will begin to understand as contemporary art-a series of exclusions that is deeply regressive. At the same time as the increase in donor-driven exhibitions, the museums that have put on these survey feminist exhibitions (or exhibitions of women artists) will be able to rest on their laurels. They will have 'been there, done that' and unless there has been a deep, political change in approaches to the collection and curation of contemporary art in these institutions, it may well be business as usual after those exhibitions. As Griselda Pollock asks:

What is the effect of separating feminist aesthetic interventions from the larger political and cultural revolution that was feminism and feminist theory, and isolating works and artists within a relatively unaltered curatorial approach and exhibitionary model? We might gain this work for art, but miss its significance in transforming art. For feminism was never an art movement. Feminism is a resource for artistic practices, inflecting them and allying them with equally radical realignments within the art world at the conjunction with which a feminist effect became possible. As a repoliticization of gender and the cultural-semiotic enquiry into sexual difference, feminism made things possible within emerging forms and practices of expanded art practice post 1970 . The price of not taking seriously this double process of changes in art making and art thought and of changes in social movements and political thought is that we assimilate and domesticate the feminist rupture into a deadened, museal category of "feminist art" while unthinkingly continuing ineffectually to add women artists to existing models of the history of art. (127)

For my students, born as many were around about 1990, the pioneering feminist work of the late ' 60 s and the ' 70 s is like art of the late ' 30 s is for me: it is real art history. If today's young artists are to practice feminist resistance, they can learn from the successes and from the failures of earlier moments and movements of resistance. They need not the fixity of museal and archival categories, but unfixity.

Works Cited

Xabier Arakistain, "Kiss Kiss Bang Bang: 86 Steps in 45 Years of Art and Feminism," Kiss Kiss Bang Bang: 45 Años De Arte Y Feminismo, Margarita Aizpuru, ed., Museo de Bellas Artes De Bilbao, Bilbao, 2007, pp. 241-244.

Liesbeth Brandt, Corstius. "Van Binnen Naar Buiten, Rolpatronen Van Vrouwen En Mannen in Beeld." In Feministische Kunst Internationaal, 36-39. Den Haag: Haags Gemeentemuseum, 1979.

Connie Butler, "Art and Feminism: An Ideology of Shifting Criteria," WACK! Art and the Feminist Revolution, Lisa Gabrielle Mark, ed., The Museum of Contemporary Art, Los Angeles; MIT Press, Cambridge, MA, 2007, pp. 14-23.

Bettina Messians Carbonell, "Introduction. Museum Studies and the 'Eccentric Space' of an Anthology," Museum Studies: An Anthology of Contexts, Bettina Messians Carbonell., ed.,. Oxford, Malden; Blackwell Publishing Ltd., Victoria, 2004, pp. 1-13. 
Rachel Esner, "The Ties That Bind: Women Artists at Documenta 12," Journal of Visual Culture 7, 2008, pp. 239-43.

Amelia Jones, "1970/2007: The Return of Feminist Art." X-TRA: Contemporary Art Quarterly, no. 4 (2008), http://x-traonline.org/past_articles.php?articlelD $=184$.

Allan Kaprow, Essays on the Blurring of Art and Life, Jeff Kelley, ed., University of California Press, Berkeley; Los Angeles; London, 1993.

Lucy Lippard, "Freelancing the Dragon," From the Center: Feminist Essays on Women's Art, E.P. Dutton, New York, 1976.

Camille Morineau and Annalisa Rimmaudo, eds., elles@centrepompidou: Women Artists in the Collection of the Musée National d'Art Moderne, Centre de Création Industrielle, Éditions du Centre Pompidou, Paris, 2009. Exhibition catalogue.

Linda Nochlin, "Venice Biennale: What Befits a Woman?" Art in America (2005): $120-25$.

Natalie Hope O'Donnell, "Postcard from the $53^{\text {rd }}$ Venice Biennale." Artvehicle, no. 43 (n/d).

Peggy Phelan, "Survey," Art and Feminism, Helena Reckitt, ed., Phaidon Press Ltd., London, New York, 2001, pp. 14-49.

Griselda Pollock, "Encounters in the Virtual Feminist Museum: Time, Space, and the Archive," Feminisms is Still Our Name: Seven Essays on Historiography and Curatorial Practices, Malin Hedlin Hayde and Jessica Sjöholm Skrube, eds., Cambridge Scholars Publishing, Newcastle upon Tyne, 2010, pp. 105-139.

Mirjam Westen, "Rebelle: Introduction," Rebelle: Art er Feminism 1969-2009, Mirjam Westen, ed., Museum voor Moderne kunst Arnhem, Arnhem, 2010, pp. 5-20.

Hilary Robinson is Dean of the School of Art and Design and Professor of Visual Culture at Middlesex University, London. Her teaching and research focuses on feminist art theory, and publications include Visibly Female: Women and Art Today (1987); Reading Art, Reading Irigaray: The Politics of Art by Women (2006); Feminism-Art-Theory 1968-2014 (2015). She is currently working on a history of the feminist movement in art internationally. Hilary's academic career has been in Belfast, Northern Ireland; Pittsburgh PA, USA; and London, England. At the University of Ulster (1992-2005), she taught art theory to studio students. She became Research Co-ordinator and subsequently Head of School for Art er Design. She also gained her first Chair, as Professor of the Politics of Art. In 2005, Hilary was appointed Dean, College of Fine Arts and Professor of Art Theory and Criticism, Carnegie Mellon University, Pittsburgh. In Pittsburgh she was a board member of The Andy Warhol Museum; Quantum Theatre; Silver Eye Centre for Photography; Greater Pittsburgh Arts Council and The Mattress Factory. She headed the Creative Entrepreneurs research project, to retain artists in post-industrial Pittsburgh. She moved back to the UK to take up the deanship at Middlesex University. She is presently on the advisory and management boards for the AHRC-funded research project Black Arts and Modernism, led by Sonia Boyce. 


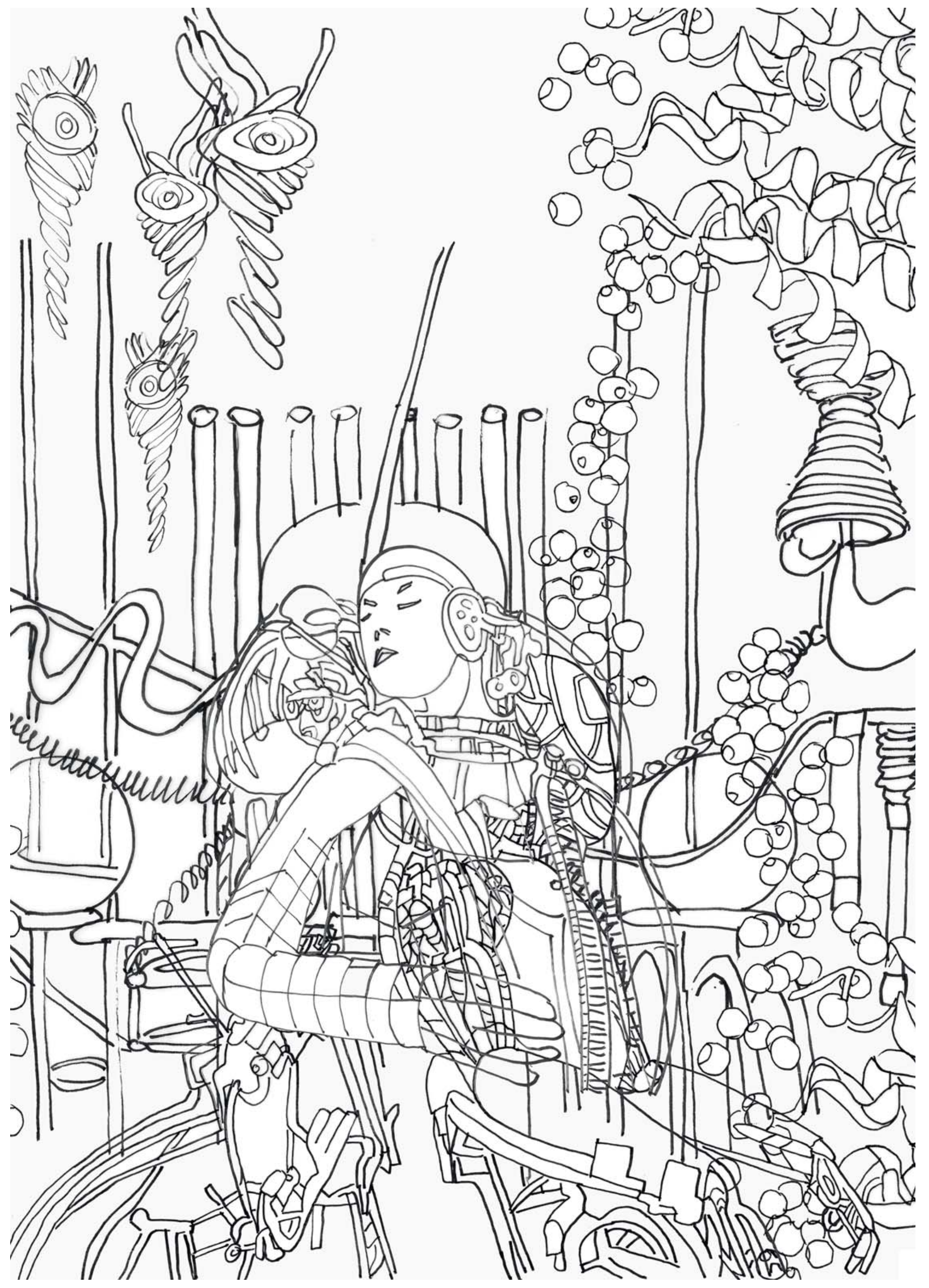




\section{Feminist Tactics of Citation, Annotation, and Translation: Curatorial Reflections on the Now You Can Go programme Gabrielle Moser and Helena Reckitt}

Helena Reckitt: In December 2015 I worked with six other feminist curators, artists, and researchers to develop an events programme in London called Now You Can Go (see http://nowyoucango.tumblr. com). Through panel discussions, talks, performances, film screenings, workshops, and a reading group, and taking place across four venues-The Showroom, the ICA, Raven Row, and Space Studios-the series explored the resonance of Italian feminisms from the 1970 s and 1980s in relation to questions of intergenerational feminism, consciousness raising, and affective withdrawal.

When I thought about reflecting on the programme for this issue of OnCurating, you were the first person I wanted to think it over with. For one thing, you have an outside perspective, as you came to London for the series, and attended almost all of its events. Yet you are hardly a disinterested spectator. You have been researching withdrawal, strike, and exit for a show you are curating in Canada. We have also been in dialogue about affective labour and contagion for several years, after you sent me texts from the If I Can't Dance... reading group on affect that you were exploring with the Toronto branch, and which I read with curating masters students in London. I'm interested in how the Now You Can Go programme did, and didn't, meet your expectations.

Gabby Moser: Perhaps because I've been thinking so much about strategies of striking and the withdrawal of labour in my curatorial research, I expected there to be more focus on this theme in the programme. There were a few events that directly addressed work and exit strategies, such as the panel on social reproduction at the ICA-which included Marissa Begonia from Justice for Domestic Workers and Nic Beurat from the activist group Plan C-Giovanna Zapperi's talk about Carla Lonzi's tactics of withdrawal, and two panel discussions titled, "In or Out?: On Leaving the Art World and Other Systems".

HR: One of which you chaired, though I think we were both surprised that the artists, thinkers, and activists that we invited did not address the question of exit strategies more directly.

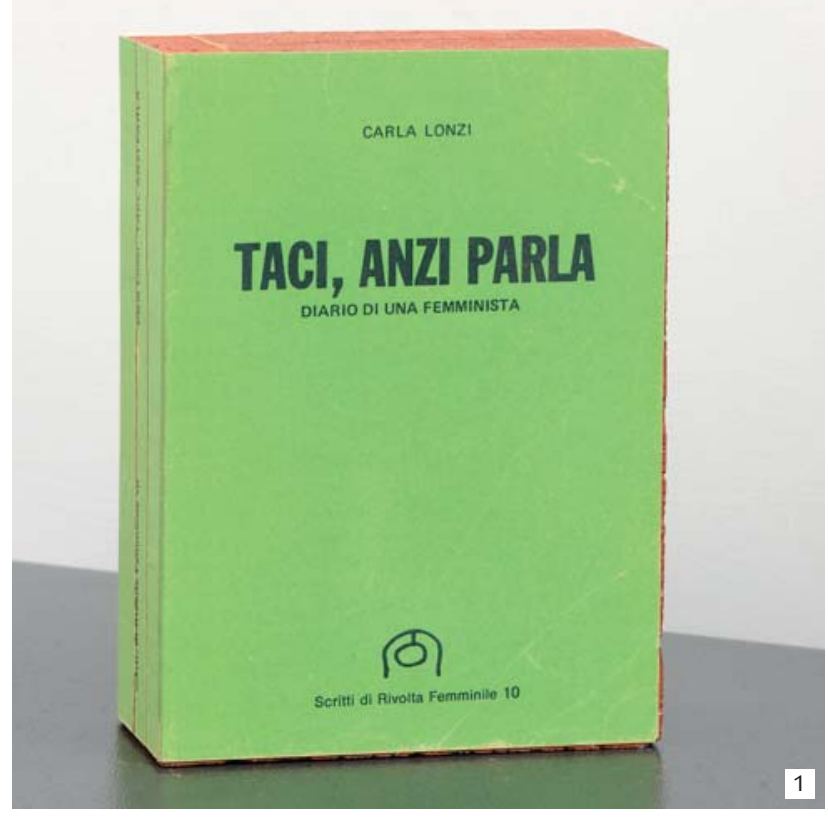

GM: Yes, exactly. Though I do wonder whether there is something unrepresentable, or perhaps difficult to represent, about the gesture of striking or withdrawing? This is an issue I'm tackling in trying 
to pull together works on this theme for the exhibition I'm curating. But what surprised me with Now You Can Go was the centrality of Italian feminism to the whole programme, both the ideas of Carla Lonzi and Rivolta Femminile and the work of Adriana Cavarero and the Milan Women's Bookstore collective. That was a body of feminism that was unfamiliar to me, and which I found incredibly generative and exciting. I suppose what has become the central theme for me as I reflect on the programme are practices of citation, annotation, and translation, and how these strategies can activate feminist practices and feminist knowledges from the past in the present moment.

HR: Citation has become the key model for how I think about intergenerational feminisms. I am interested in the importance of citation in both a traditional, bibliographic way-who we reference, who we acknowledge-as well as part of a broader understanding of where we put our energy.

GM: Can you give me some examples?

HR: Sara Ahmed, for instance, in her work of queer feminist phenomenology, foregrounds the affective implications of how we orient ourselves towards others, through literary reference as much as through physical movement. Another current example is the work of the artist Céline Condorelli, which explores friendship as a lived condition, wherein one befriends ideas and issues as well as people, and which has its own responsibilities and demands. In her recent exhibition The Company She Keeps, she named each artwork after a friend who had influenced and sustained her. She takes a similar approach in her PhD thesis, which is called In Support. The dissertation enacts her debt to the various artistic, cultural, and critical projects that provide the frame of reference and legibility for her work. Instead of the traditional one or two pages of acknowledgements, she includes sixteen pages of "Dedications" which hail an earlier creative or critical project without which her project "could have never happened"1.

GM: It was precisely this idea of indebtedness that I found so appealing about the workshops on translation and annotation in Now You Can Go. Both the "Intimate Acts" workshop that Kajsa Dahlberg and Laura Guy organised, which asked participants to quote from, and then collectively annotate or translate, sources that were meaningful to them, and Alex Martinis Roe's "Our Future Network" workshop were transformative for my practice as a writer and curator. The ideas of the Milan Women's Bookstore collective, which are central to Roe's work and this workshop, have directly influenced my work in Toronto. Since returning from London, I've started a reading and working group with artists Annie MacDonell and Cecilia Berkovic and curators Leila Timmins and cheyanne turions that will explore relationships of affidamento, or "entrustment", between women, and use writing and autobiography to think about questions of voice, authority, and citation. We're calling the group EMILIA-AMALIA.

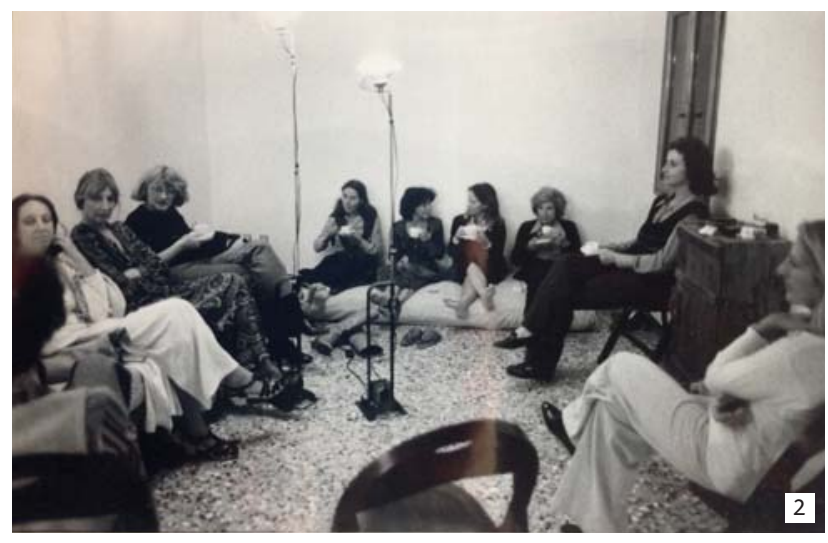
reference!

HR: That's a direct Milan Women's Bookstore

GM: Yes, the name comes from a story of an entrustment relationship that the Milan group describes in their collectively written book Non credere di avere dei diritti (Don't Think You Have Any Rights, 1987, published in English under the title Sexual Difference: A Theory of Social-Symbolic Practice, 1990) and which Cavarero cites in her essay "On the Outskirts of Milan", where two women meet and become friends through one of the 150-hour schools in Italy. In it, Emilia has the tendency to constantly tell her life story to Amalia, but always in a disorganized and fragmented way. Amalia, who has the capacity to write beautifully, eventually becomes so frustrated with Emilia's repetitive need to tell her story that she writes it out for her as a coherent narrative and gives it to her. Emilia carries the story with her in her purse, reads it daily and weeps over the authority and recognition her friend has given to her life.

HR: You might consider kicking off your reading group with one of the activities that Alex developed, in response to the practices of the Milan collective. You remember that exercise in affidamento that we carried out in Alex's workshop, where one woman listened to another recount a key relationship of 
affidamento from her life, which the listener then wrote up in what Alex described as a form of a gift?

GM: Absolutely! That was one the exercises I related to the Toronto group.

HR: We did that last month in the Feminist Duration Reading Group in London, which is the group out of which the Now You Can Go programme emerged, as part of our desire to take these tactics further on an everyday, practised level. It was very powerful, not least for the few men in the group who Alex assigned a different exercise. Instead of writing about their relationship with another woman, they were asked to talk about two women's relationships with one another. It was initially quite hard for at least one male member, although afterwards he commented that it had a valuable effect of decentring his own male position.

GM: The relationship of entrustment that the Milan collective describes is the main interest for our group. The idea of a relationship between two women that not only acknowledges difference or disparity between them, but makes it into a productive and meaningful part of their relationship, seems so radical to me, still. It's especially generative because many of us are engaged in teaching and other forms of mentorship. We're interested in ways of relating to younger, as well as older, women that get outside the horizontal model of "sisterhood" that pervaded 1970s Anglo-American feminism-or at least the story of 1970 s feminism many of us have inherited.

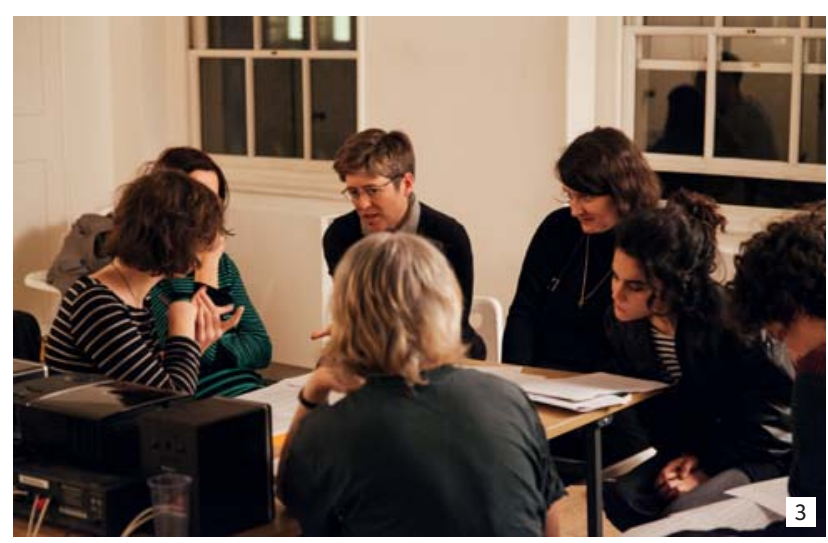

HR: What are the dangers of horizontality?

GM: The familiar narratives we hear about this era of feminism, whether they are historically accurate or not (and this is one sub-theme we are interested in as a group) are based on structures of sister- hood that assume an essentializing biological sameness between women. This model does not recognize differences between women, nor does it allow a consideration of intersectionality or the ways multiple forms of difference and oppression affect women differently. In the book they wrote about their practice, the Milan group is quite clear that they came to entrustment because of the lessons they learned from the failures of horizontality in 1970s American feminism. Older, more experienced women's authority could not be recognized through the model of sisterhood. This created resentment within the group and prevented the transmission of important forms of intergenerational knowledge. What I find so appealing about the practice of entrustment is that it asserts that two women have unique capacities and experiences they can share with one another, and that both play a vital role in giving authority to the other to pursue their desires and goals. There is an onus in this model on seeking out the support of another who has experiences outside your own, and an implicit erotics.

HR: As someone who has actively sought out relationships with older, more "experienced" feminists, I appreciate the erotics of this dynamic very well. The question of intersectionality is also one that we are exploring in the Feminist Duration Reading Group. While the group is quite diverse in terms of age and nationality, it's not so in terms of ethnicity or class. It's clear that the core participants and I are in danger of reproducing ourselves in relation to many of our subject positions; hardly surprising, perhaps, given that the project emerged in an academic art context, with a focus on Italian feminisms. But how to broaden the scope and relevance of the project, without lapsing into tokenism, is something we are thinking through. How are you addressing this in your group?

GM: In our planning meetings for EMILIAAMALIA we are acutely aware of how similar we are to one another, as individual members: for the most part, we are white, cis-gender women. Many of us identify as queer, and we come from a variety of class backgrounds. But it's important to us that we invite people who have experiences and capacities that differ from our own who might be able to activate other overlooked feminist histories that we can cite as a group. The question is how, as organizers, to invite other people to the reading group without tokenizing them. 
HR: The invitation to participate has to be based on finding common ground for dialogue and exploration. Otherwise it risks being an empty or superficial gesture.

GM: Yes, I guess it comes back to a central problem for feminism: how intimately the personal and the political are intertwined. Are you asking someone to participate in the dialogue because of their research area, because of their personal background, or both?

HR: One of the most rigorous conversations we had as part of Now You Can Go was unfortunately the event you missed, which was a reading group led by Laura Guy on translation as a feminist practice. We read Gayatri Spivak's "The Politics of Translation" (1993), where she asserts that the translator needs to immerse herself in the language or culture of the original text, what she calls its "rhetoricity". The work of translation, according to Spivak, is about so much more than the literal language: it could be done fast, or it could take a long time. In the text, she's also critical of Western feminists for demanding that she "hurry up" and translate these writings quickly, to satisfy their voracious appetite for the new.

GM: EMILIA-AMALIA is making writing a central practice for the group, and is working towards a final publication, which we imagine will take the form of a compilation of reprints of historical texts that have inspired our work, alongside new writing by members who might work to annotate or translate them in the present. Spivak's work could be an important starting point for us.

HR: Why do you think we are experiencing this resurgence of interest in feminist thinking and activism and their genealogies?

GM: Queer theory and feminism have always been lenses through which I approach my work as a critic, art historian, and curator. But it's only recently that I've begun to turn to feminism as the object of my research. I have long been interested in how people learn to be feminist, or learn to be queer, since these are identities that usually have to be transmitted outside of biological families, across generations. I'm curious about how we can imagine these practices of transmission outside the language of kinship and lineage, which both seem too close to ideas of the family tree or other patriarchal models. The Milan group calls these historical models our "symbolic mothers", which is one way to imagine patterns of influence across generations and geographies. The idea of feminist "waves" is another with which we are familiar. I wonder if there are other genealogies we might trace?
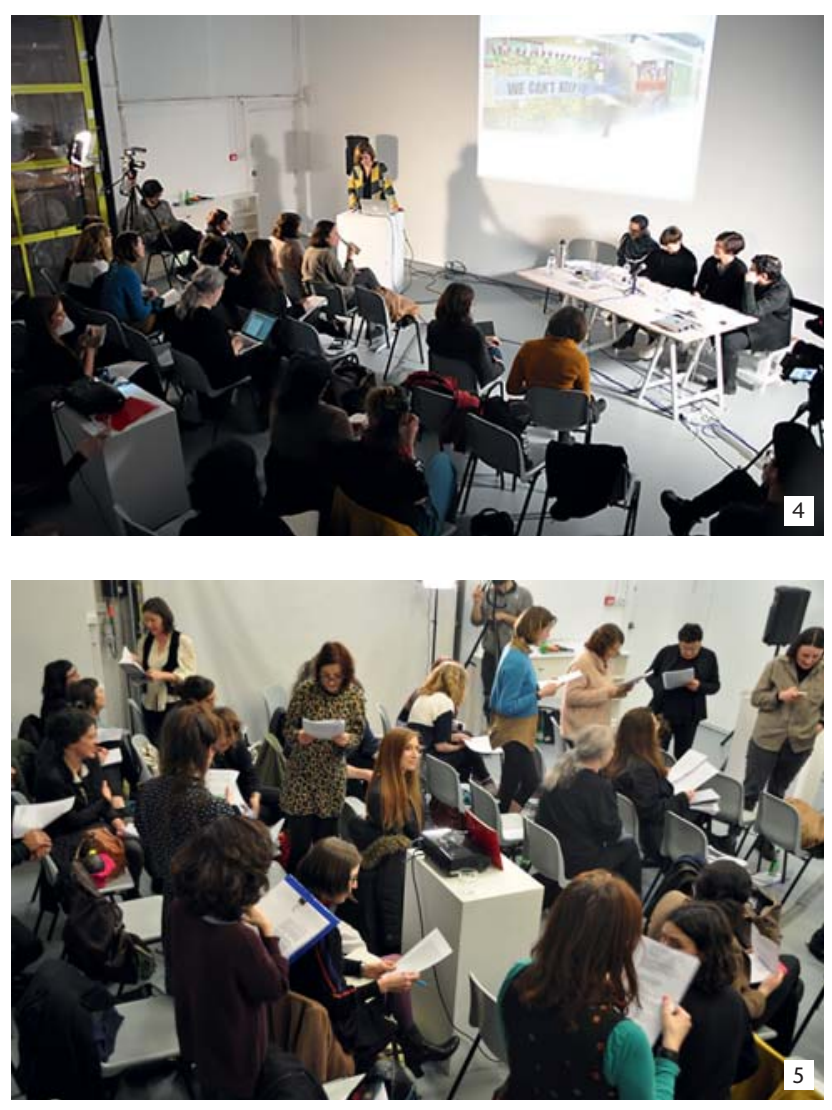

HR: We ourselves are one example of transgenerational feminism, having met when I was a curator at The Power Plant in Toronto, and you were an intern, though we now work together as colleagues.

GM: This is exactly the kind of extra-familial relationship I'm invested in. I have learned so much from you, not only about being a curator, but also about being a queer feminist. It's funny that you raise our history as curatorial co-workers-one of the questions I've been thinking about since Now You Can Go is how the feminist strategies that the programme explored might pose challenges to traditional curatorial practice. One of the most obvious ways it might do this is to put the stress on relational and durational events, like the ones that comprised the programme. Though I sometimes worry about the trend in curatorial practice towards curators who don't curate exhibitions any more, but organize events in the gallery instead. 
HR: I think I am becoming one of those curators who doesn't curate exhibitions any more!

GM: Me too! Why do you think that is?

HR: Part of it is practical: the days of freelance curators sending off exhibition proposals into the blue, and waiting for institutions to accept them, are probably over. In most institutions, curators and directors either want to develop the exhibition programme themselves, or they invite a curator or artist with a specific background to guest curate. However, institutions generally seem to be more responsive to one-off events and programmes, partly because they require less investment of time, finances, and real estate than exhibitions do.

That said, the informality that less visible activities like workshops and reading groups afford can be powerful. Moving away from art as spectacle or performance, they offer the chance for collective exploration and sharing in a more provisional and vulnerable spirit. It's interesting that it was the smaller meetings and workshops-rather than the public panels and talks-that proved to be the most affectively resonant elements of Now You Can Go for us both.

GM: I have often found this to be the case in my own work. Activities like this have become increasingly important to my curatorial practice over the past three years: events like artist talks, "looking groups", and performances, which were once considered "public programming", or supplementary to the main event of the exhibition, are important ways of doing research in public.

HR: I still have a concern that mainstream institutions are fine with supporting practices informed by feminism, queer theory, postcolonialism, trans politics, etc., as one-off programmes, but that they aren't prepared to give them sustained financial and infrastructural support. There is the danger that as such they can tick the boxes that show their commitment to "alternative" perspectives, while not investing significantly in them. Moreover, by presenting these practices on a programming level, but without incorporating their critiques into how they carry out their business behind-the-scenes, institutions talk the talk without walking the walk.

GM: Absolutely. I sometimes worry about the politics of this so-called discursive or pedagogical turn in curating. As much as I find these temporary events rich and meaningful spaces for conversation, they don't always produce the same historical records that traditional exhibitions do. Exhibitions leave behind more substantial traces, such as catalogues, that can be vital for transmitting feminist practices and modes of thinking across generations and audiences. As problematic as the "blockbuster" survey exhibitions of feminism often are, such as elles@ pompidou in Paris or the touring WACK! Art and the Feminist Revolution, these shows produce lasting documents. If we want to build a lineage of feminist research and citation, these public exhibitions would seem to play an important role in making that possible.

HR: But it's not a simple matter of replacing a dominant canon with a feminist one, is it? It's not as if we have a choice whether to accept canons or not. They are imposed on us, and are premised on a problematic market logic of competition that pits artists, regions, media, and generations as well as genders against one another ${ }^{2}$. All canons entail processes of discrimination and classification, inclusion and exclusion. For a previously overlooked or excluded artist or practice to be "added" to an existing tradition can have violent connotations of incorporation, too.

GM: Perhaps, though, as a university lecturer, I see the power of providing an alternative or new canon to students. It will never be perfect, but it at least offers something to bat against, and gives researchers, curators, and writers somewhere to begin in the process of citation.

HR: I'd like to see a Guerrilla Girls-style survey of where institutions actually put their resources, in terms of solo exhibitions with scholarly catalogues, works added to the permanent collection, and major commissions for women, feminist, non-cis gender, black, and other under-represented artists. Such a study would also need to take on board the infrastructural activities such as fair payment for artists, writers, as well as curators that Working Artists and the Greater Economy (WAGE) are agitating for around artists' fees and best non-profit practices.

GM: This brings me back to the question of creating an historical record of feminist activities, and which stories appear and disappear in our collective archives. I was so pleased to see such thorough documentation of Now You Can Go events through Video in Common (2015), and I wish we had a similar organization in Canada. But in talking with colleagues in Toronto, several expressed frustration that some components of the programme-such 
as Nina Wakeford's "Feeling Backwards" workshop, or Alex's "Our Future Network" - were not documented. While, to me, it's obvious why these events weren't documented, mostly because they entailed very intimate, personal modes of storytelling and (auto)biography, I can also understand the desire to want access to the knowledge that comes from these experiences.

HR: I'm working on how to document these events, through disseminating a series of participants' reports that I have yet to consolidate. Actually the decision to ask Video in Common to film and archive events at The Showroom was taken quite late in the day. The possibility only emerged after a fund I had applied to for speaker travel expenses agreed to support the programme but didn't cover travel costs. So I asked them to pay for video archiving instead. It was a great decision. Another late decision was to allocate budget for a crèche at The Showroom. It was Emily Pethick, The Showroom's Director, who raised the issue of childcare. I hadn't thought it through, which is terrible given the programme's emphasis on maternal and domestic labour. Emily's insistence that we think more cohesively about where we put our resources is something that more curatorial projects should take on board.

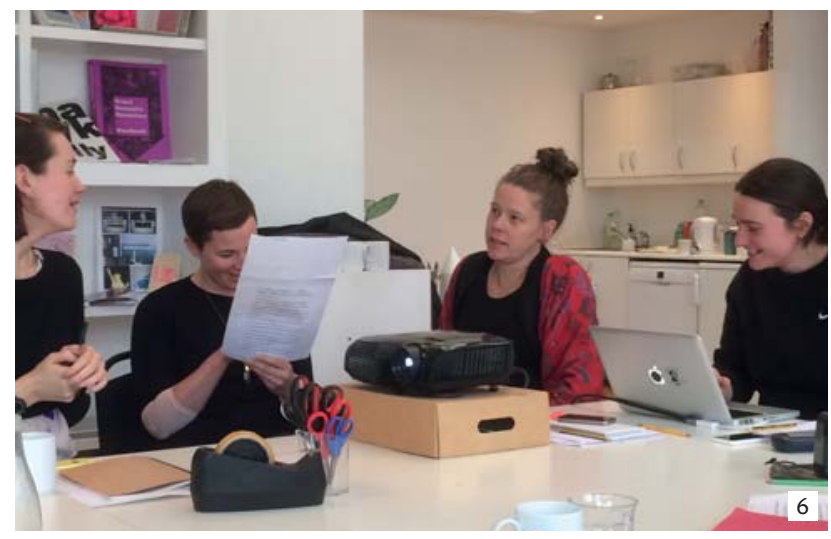

GM: This element of collaboration seemed vital to Now You Can Go's planning, and yet it was an incredibly cohesive programme in its execution. I was remembering recently that, many years ago, you spoke on a panel on curatorial practice and authorship that I chaired where you mentioned finding co-curating difficult. Yet, for this programme, you collaborated curatorially with six other people. How was the experience for you?

HR: It's funny you remember this! It's true, I've had some challenging experiences co-curating and in general find it difficult, as it assumes an understand- ing and shared sensibility that doesn't come easily. For Now You Can Go, the collaboration emerged quite organically and dynamically from an informal interpretive community that had gathered around a shared exploration of Italian feminisms. The six women who developed the programme with me, who included MA and PhD researchers as well as seasoned feminist curators, each brought something that related to their own research or practice-be it ideas for a film screening, speakers, workshop leaders, performers, institutional collaborators, or funding. While I acted as the filter, it was more a case of steering the results of other people's enthusiasm and desire than the traditional curatorial role of inviting and selecting.

GM: I think this is what set the programme apart from most academic conferences I attend. The sense that this material mattered to people, and informed their practice in a very direct way, was palpable. It's probably why I found the workshops the most compelling and productive elements. These were the places where the practice of consciousnessraising, or autocoscienza, were central, asking participants to engage with readings, with ideas from the past, or with artists' practices, but through their own lived experience: a strategy the Milan Women's Bookstore collective described as "beginning from oneself".

HR: There's been a viral quality to how these activities have unfolded. The process started for me almost two years ago when Fulvia Carnevale from Claire Fontaine gave a talk about Italian feminisms as part of an exhibition I curated in Toronto. I found her ideas spellbinding, and their radicalism urgently needed in the light of the co-option and dilution of feminism under "lean-in" rhetorics. I couldn't believe I knew so little about this vital movement, and I wanted to learn more. Fulvia then sent me texts from an issue of May Revue she had edited on Italian feminisms, around which I set up a reading group and symposium at Goldsmiths. Those events were so powerful the reading group decided to continue to meet outside academia. From this we developed the Now You Can Go programme, to which Fulvia-as a key figure of affidamento, for me-was a keynote speaker. Now Fulvia is editing a follow-up issue of May Revue with contributions from these events. The whole thing has come full circle, in a process of mutual contagion and generation, virtually across time and place, as well as through immediate, embodied encounters. 


\section{Captions}

1 Claire Fontaine, Taci, anzi parla brickbat, 2015. Photo: Courtesy of the artist

2 Venezia, 1976, "Party at the new Jacqueline's flat", Photo by Jacqueline Vodoz, (c) Fondazione Jacqueline Vodoz e Bruno Danese

3 Feeling Backwards, workshop by Nina Wakeford, Raven Row, as part of Now You Can Go, 8 December 2015. Photo: Christian Luebbert

4 In or Out: Leaving the Art World and Other Systems, with Gabrielle Moser (introducing, with image by Feminist Art Gallery) and (from left-right) Raju Rage, Karen Di Franco, Karolin Meunier, and Frances Rifkin, The Showroom, as part of Now You Can Go, 12 December 2015. Photo: Helena Reckitt.

5 A Feminist Chorus for Feminist Revolt, a spoken distillation of texts from the Feminist Duration Reading Group, gathered into a score by Lucy Reynolds, The Showroom, as part of Now You Can Go, 12 December 2015. Photo: Ehryn Torrell.

6 Intimate Acts: A feminist workshop exploring collective acts of annotation, translation, and recontextualisation, by Kajsa Dahlberg and LauraGuy, The Showroom, as part of Now You

\section{Notes}

1 Céline Condorelli, In Support: A Theoretical and Practical Investigation into Forms of Display, unpublished PhD thesis, Goldsmiths, University of London, London, 2014, p. 17.

2 Angela Dimitrakaki, "Troubling Canons: Exhibiting Women's and Feminist Art," Helena Reckitt ed., in Revisioning the Modernist Art Canon, ed. Iskin, Ruth E, Routledge, London, forthcoming.

\section{Bibliography}

Sara Ahmed, Queer Phenomenology: Orientations, Objects, Others, Duke University Press, Chapel Hill, 2006.

Lesley Caldwell, "Courses for Women: The Example of the 150 Hours in Italy," Feminist Review No. 14, July 1983, pp. 71-83.

Adriana Cavarero, "On the Outskirts of Milan," Relating Narratives: Storytelling and Selfhood, Paul A. Kottman, trans., Routledge, New York, 2000, pp. 55-66.

Céline Condorelli, In Support: A Theoretical and Practical Investigation into Forms of Display, unpublished PhD thesis, Goldsmiths, University of London, London, 2014.

Angela Dimitrakaki, "Troubling Canons: Exhibiting Women's and Feminist Art," Helena
Reckitt ed., in Revisioning the Modernist Art Canon, ed. Iskin, Ruth E, Routledge, London, forthcoming.

May Revenue \#04 (Paris, 2010). See www. mayrevue.com.

Milan Women's Bookstore Collective, Sexual Difference: A Theory of Social-Symbolic Practice, Patricia Cicogna and Teresa de Lauretis, trans., Indiana University Press, Bloomington, 1990.

Gayatri Chakravorty Spivak, "The Politics of Translation," in Outside in the Teaching Machine, Routledge, New York, 1993, pp. 179-200.

Video in Common, Now You Can Go (London, Video in Common, 2015). Available at https://www. youtube.com/watch?v=dWaLpqoAVbE

Gabrielle Moser is a writer and curator based in Toronto. She organises exhibitions and events about photography, spectatorship, and pedagogy, and runs No Looking After the Internet, an out-loud looking group. She has curated exhibitions for Access Gallery, Gallery TPW, Vtape, and Xpace. Her writing appears in venues including Artforum.com, Art in America, Canadian Art, Fillip, Journal of Visual Culture and Photography er Culture, as well as in numerous books and exhibition catalogues. Her current curatorial research, focused on the theme of Strike/Work, investigates artistic practices of the exaggeration, refusal, and withdrawal of labour as feminist strategies to critique working conditions. She holds a PhD from the art history and visual culture program at York University in Toronto, Canada, and is a lecturer at OCAD University.

Helena Reckitt is a curator and researcher whose work often explores legacies of queer and feminist art, theory, curating, and activism. She has edited Art and Feminism 2001, Sanja Iveković: Unknown Heroine 2013 and, with Joshua Oppenheimer, Acting on AIDS 1998. Her 2013 essay "Forgotten Relations: Feminist Artists and Relational Aesthetics" appeared in Politics in a Glass Case, edited by Angela Dimitrakaki and Lara Perry. She has held curatorial and programming positions at the ICA, London, Atlanta Contemporary Art Center, Georgia, and The Power Plant, Toronto, and has curated solo exhibitions with artists including Yael Bartana, Keren Cytter, Hew Locke, and Ryan Trecartin (with Jon Davies), and group exhibitions such as What Business Are You In? (2004), Not Quite How I Remember It (2008), and Getting Rid of Ourselves (2014). She is Senior Lecturer in Curating in the Art Department at Goldsmiths, University of London. 


\section{Living the Revolution A Dialogue Between Maura Reilly e Lara Perry}

Lara Perry: You are the Founding Curator of the Sackler Center for Feminist Art at the Brooklyn Museum 1 , where you conceptualised the first exhibition space in the world dedicated exclusively to feminist art. While there you organised several exhibitions, including Global Feminisms (co-curated with Linda Nochlin) and the permanent reinstallation of Judy Chicago's The Dinner Party. What do you think the creation of such a space suggests about the current status of feminism in the art world?

Maura Reilly: I think it represents an enormous achievement. Importantly, its opening in 2007 came at a time when there was a great resurgence of interest in feminist art, exemplified by multiple exhibitions of feminist art worldwide, including Global Feminisms, Wack!, and Kiss Kiss Bang Bang (all in 2007), then Gender Check (2009-10) and Elles (200911), among many others.

Simultaneously, MoMA had launched its "Women Project" (MWP), an initiative begun in 2005, not from within MoMA, but at the suggestion of donor Sarah Peters, with the aim of reassessing the museum's traditionally masculinist canon, and which has resulted in multiple symposia, education programs, a major publication, solo exhibitions of women artists, and numerous acquisitions. A year later, in 2006, I helped establish The Feminist Art Project (TFAP) (along with Arlene Raven, Judy Chicago, Dena Muller, Judy Brodsky, Ferris Olin, and Susan Fisher Sterling), which sought to capitalise on the opening of the Sackler Center, which we all viewed as a groundbreaking museological development. Its initial aim was to spark new initiatives throughout the country that would build on the momentum started by the announcement of the Sackler Center.

The conflation of these exhibitions and projects precipitated a renewed mainstream interest in feminist art-one that I believe continues until today.
LP: In June 2015, you published a widely publicised article in ARTnews, "Taking The Measure Of Sexism: Facts, Figures, And Fixes", in which you explored the statistics of the representation of women artists in various outlets of the art world. Can you say something about the continuing significance of empirical investigation in the work of the feminist curator?

MR: I think empirical investigation is important for all feminists, in any discipline, not just curating. Counting is, after all, a feminist strategy. I've been collecting statistics for over a decade, the Guerrilla Girls since 1984, the Gallery Tally since 2013, and Pussy Galore since 2014. What's clear in all of these instances is that the more closely one examines art world statistics, the more glaringly obvious it becomes that the majority of exhibitions/galleries continue to present art by white, Euro-American, heterosexual, privileged, and, above all, male artists. In its most recent report (2015), for instance, Gallery Tally looked at over 4,000 artists, represented in LA and New York and of those, 32.3\% of them were women. (A recent audit of the galleries in London demonstrates similar figures. In 2013, East London Fawcett (ELF) examined the artists represented by 134 commercial galleries in London and found that $31 \%$ were women.) It's egregious.

Hence the necessity of reminding the art world of these discrepancies because the real problem is that sexism is still so woven into the institutional fabric, language, and logic of the mainstream art world that it often goes undetected. But ignoring sexism certainly won't make it go away. If we cannot help others to see the structural problems, then we can't even begin to fix them. In other words, how can we get people to "think about gender"? How can we get those in the art world to recognize, accept, and acknowledge that there is indeed inequality of the sexes? The question becomes, then, how can we elicit sympathy to point of action? How can we go about educating disbelievers who contend, because there are signs of improvement, that the battle has been 
won? How do we fight against cognitive dissonance? As Franz Fanon explains, "Because it is so important to protect the core belief, they will rationalize, ignore and even deny anything that doesn't fit in with the core belief." So if we present evidence that works against people's core belief, how can we ensure this new evidence is accepted? Or, to put it differently, how do we denaturalize what is perceived as natural? And to do so, don't we run the risk of backlashangry responses, denial, or worse, dismissal?

LP: In that same article in ARTnews, you called for more all-women and feminist exhibitions, in addition to ones with gender parity. Why is the all-woman show an important strategy for feminist curating?

MR: In my effort to encourage more womenonly exhibitions, I'm often asked whether this isn't a ghettoization of women. My answer is that until there is gender equality in the art world, women-only exhibitions will continue to be necessary. I believe firmly that exhibitions focusing exclusively on women (or Latino, African, queer artists) are not ghettoizing those artists but rather attempting to "level the playing field". They are, in essence, curatorial correctives. After all, "greatness" in the art world has been defined since antiquity as white, privileged, Western, and above all male. Not much has changed. Yes, women have made great strides, but we still have a very long way to go-as my stats in $A R T$ news make clear.

Without women artist exhibitions, women will just continue to be invisibilized and marginalized. The key here is visibility, which inevitably helps women in terms of the marketplace and in art history. For instance, one need only think of historical shows like Women Artists: 1550-1950 (1976). Curators Nochlin and Sutherland Harris literally "found" women artists who had been overlooked historically, but who are now highly visible--thanks to their efforts-and who are now featured in art history textbooks, e.g. Lavinia Fontana, Sofonisba Anguissola, etc. These women artists, excavated from museum storage in the U.S. and Western Europeare now taught regularly, featured in dissertations, etc. In short, women-only exhibitions can have a transformative impact.

More recently, I can speak to my exhibition Global Feminisms, co-curated with Linda Nochlin, an all-women show featuring many artists working outside the marketplace, and many who'd never shown in the U.S. before, or rarely (Arahmaiani,
Regina José Galindo, Tomoko Sawada, Parastou Forouhar). Most of these artists now have gallery representation in the U.S. In sum, with a blockbuster show in NYC that received lots of press (NYT, Times, $V V$, New Yorker, etc.), their visibility as artists increased exponentially, and certainly helped some of their careers. Visibility again is the key here. And, as such, hopefully no curator/gallerist/collector can argue they don't have enough knowledge about women artists for inclusion in shows or collections.

Of course, I understand that women-only exhibitions are essentialist. However, until women have a better foothold, we need to preserve the category "woman" (an always already essentialist term). But we must also recognise that we live in an undeniably essentialist world. If we want to "use the master's tools to dismantle the master's house", as it were, then don't we need to use the language of "essentialism" to do so-even at the same time that we realize the term is exclusionary and doesn't account for the important differences between and amongst women?

I suppose I'm thinking here of Gayatri Spivak's concept of "strategic essentialism", which means acting 'as if' identities are stable for political reasons. So, for example, one might temporarily accept the category of 'woman' as a stable unity for the purposes of mobilising women in feminist political action.

My concern, however, with women-only exhibitions is whether we're only preaching to the converted. Who attends these shows? Is it women only and their allies? Is the mainstream public attending? And, if it's the former, then how can we ultimately institute change?

Thus, are exhibitions with gender parity better? What if the Whitney Biennial or Venice Biennale or Documenta were more diverse-in terms of race, gender, and sexuality? What if galleries were? Or, what if permanent collections at museums were more fair and just? Imagine the impact-on the art market, collectors, gallerists, curators, students, etc. Could this be mandated?

Apropos of this, in 2005, feminist curator Xabier Arakistain developed a Manifesto at Arco Madrid, signed by prominent figures from the art world, which mandated that $50 \%$ of the works purchased by the publicly funded Spanish museums be by women artists. The manifesto did not succeed in changing any museum acquisition policies, but it 
certainly raises an interesting question: Should we be advocating for affirmative action curating and collecting?

LP: Do you endorse initiatives like the Moderna Museet's "Second Museum of Our Wishes", which fundraised specifically to extend its collection through the acquisition of works by women artists?

MR: Yes, of course, I endorse any initiative that grants women artists increased visibility. Though, in that instance, I was disappointed that the museum enhanced its collection by only twenty-four works by thirteen artists. And why did the initiative last only two years? Why not fundraise to ensure collecting women in perpetuity? If not, then doesn't the gesture become simply tokenist? And I suppose I wonder, cynically, how often those twenty-four works are exhibited?

LP: Is the status of women artists in the commercial market an important component in rectifying gender inequality?

MR: The commercial market is an arena of the art world where women are particularly unequal. For instance, the highest price paid to date for a living woman artist is \$7.1 million, for a Yayoi Kusama painting, in comparison with an editioned sculpture by Jeff Koons, which sold for \$58.4 million. Likewise, the most ever paid to date for a dead woman artist is $\$ 44.4$ million for a Georgia O’Keeffe painting, versus $\$ 142.4$ million for a Francis Bacon triptych.

To address these wide discrepancies, we must work to create an art world in which high qualities, rather than high prices, are continuously reinforced as the touchstones of success, for men and women equally. Or, as John Spero humorously explained (London Evening Standard, December 10, 2014), the true sign of equality will be "when art by women is just as unaffordable to most as art by men".

LP: In your 2009 interview with Amelia Jones and Connie Butler for the Feminism and Visual Culture Reader (Second edition, London and New York: Routledge, 2009), you make a distinction between curating feminist art, and curating using feminist methodologies. (You give the example of projects you worked on in the Brooklyn Museum with curators from the Egyptian and Ancient Near Eastern departments, which you worked on to explore the meaning of feminist methodologies in collections not easily associated with feminism). Beyond working towards equal numerical representation of women artists and curating feminist content, are there other strategies that you think are important for feminist curating?

MR: Yes. I think it's imperative that we also focus our attention on topics/work that may not be defined as "feminism" per se, but that relates directly to issues of sexuality and gender. We should be advocating for exhibitions of women artists even in the absence of their direct identification with feminism, as well as employing women artists in different kinds of programming and publishing.

We should also be encouraging collectors and gallerists to purchase and represent more women, and museums to change their acquisition policies to ensure gender balance in their collections. We should be insisting on more press coverage on exhibitions of women artists, and continue to produce shows.

\section{LP: In your 2012 talk on feminist and queer} curating at Tate Modern², you introduced a number of independent curators whom you described as making important interventions inspired by feminism in the exhibition programmes of various institutions. Do you understand these independent curators as somehow working in concert to achieve a common goal?

MR: Yes, I do-though not necessarily consciously so. In that talk at Tate Modern, I presented those individuals as "curatorial activists", a term I coined to describe those curators who've made career-long commitments to ensuring that the marginalized are heard-artists of colour, as well as women and LGBTQ artists.

This is the subject of my forthcoming book, Curatorial Activism (Thames \& Hudson, 2017), which investigates contemporary curatorial strategies providing productive alternatives to exclusionary models of collecting and display that continue to re-produce inequality, often under the aegis of the art historical canon. One chapter focuses on the historiography of feminist art exhibitions, and examines the work of several curators who have dedicated themselves almost exclusively to the feminist cause in particular, including Lucy Lippard, Rosa Martinez, Connie Butler, Helena Reckitt, Camille Morineau, Xabier Arakistain, Michiko Kasahara, Juan Vicente Aliaga, and others.

We need more people dedicating their writing, their curating, and their scholarship to feminism, not 
just once, but as a whole life project/mission every day and in every way. We need more curators living the feminist revolution, not just paying lip service to it.

LP: Speaking of "living the revolution", in 2014 you founded the initiative fCU (Feminist Curators United), along with Helena Reckitt and me. How does the $\mathrm{fCu}$ relate to your professional aspirations as a curator? And, why did you feel there was a need for such a network?

MR: My entire career as a curator and scholar has been dedicated to art in/from the marginswhich is to say, art produced by those who cannot be defined as straight, white, and male. Why? Because the majority of mainstream curators focus exclusively on the rest, with often only a tokenist inclusion of "others".

However, there are many curators working worldwide dedicated to feminist activism, including those listed above. I wanted them to understand that they were not working in isolation-and by creating a network we can support each other, e.g. share ideas, research, and suggest venues and artists.

\section{Notes}

1 The website of the Elizabeth A Sackler Center for Feminist Art can be found here https://www. brooklynmuseum.org/eascfa, last accessed March 2016.

2 Maura Reilly delivered the keynote address at the conference "Civil Partnerships: queer and feminist curating," held May 2012 at Tate Modern, London. The videos of the programme can be accessed here: http://www.tate.org.uk/context-comment/video/ civil-partnerships-queer-and-feminist-curating-videorecordings\#open265737, last accessed March 2016.

Maura Reilly, Ph.D. is Executive Director of the National Academy Museum and School in New York. As the Founding Curator of the Sackler Center for Feminist Art, she conceived and launched the very first exhibition and public programming space in the U.S. devoted entirely to feminist art, where she organized dozens of exhibitions, including the permanent installation of Judy Chicago's Dinner Party, the critically acclaimed Global Feminisms (co-curated with Linda Nochlin), Ghada Amer: Love Has No End, Burning Down the House, among many others. She has held Senior Curator positions at the American Federation of Arts and Location One, both in New York
City, and has authored many books and articles on contemporary art. Reilly is the recipient of several prestigious awards, including ArtTable's Future Women Leadership Award and a Lifetime Achievement Award from the Women's Caucus for Art. Her most recent and forthcoming books include Curatorial Activism (Thames er Hudson, 2017) and Women Artists: The Linda Nochlin Reader (Thames er Hudson, 2015). Reilly received her M.A. and Ph.D. from the Institute of Fine Arts at New York University.

For more information, please visit www.maurareilly.com.

Lara Perry is an art historian with specialist research expertise in portraiture, gender, and art museums. She was the leader of an international research network exploring feminist curating practices that ran a programme of symposia and seminars held in locations from Washington, D.C., to Tallinn between December 2010 and May 2012, and was funded by the Leverhulme Trust. She coedited a book of essays on feminism and curating, Politics in a The Sirens' Song: Speech and Space in the Courthouse Imagine Law Glass Case-with Angela Dimitrakaki, a member of the research network. Lara leads the programme in the History of Art and Design at the University of Brighton. 


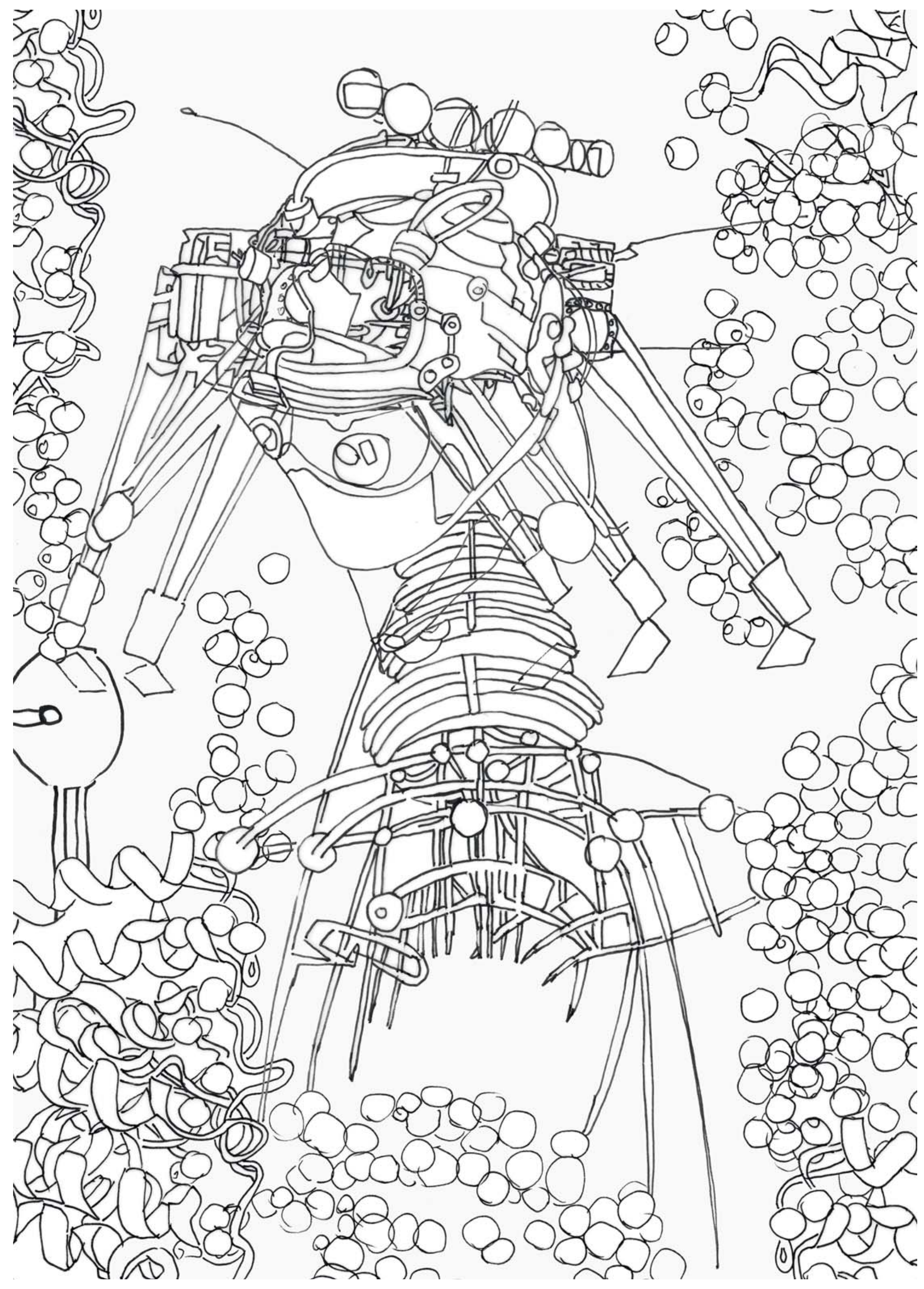




\section{The Biographical Exhibition as a Problem of Feminist Critique and the Case of the Exhibition Marlene Dumas - Female, 2005' Sigrid Schade}

\section{The Success of Biography as a Problem}

Art history is one of the most successful disciplines in the humanities and cultural studies if one traces the success of one its main products-the artist's biography or biographical exhibition-and its effects on various areas of Western societies. No other discipline, it seems, has so few problems communicating its subjects to a broad audience as art history manages to do via its exhibition business. The number of museums, exhibitions, and biennials has grown to such an extent in the age of globalization, and the speed with which contemporary artists are canonized has so increased that it seems there is no need to worry about the future of the profession and the future of countless historical and contemporary artists, nor about that of curators. ${ }^{2}$

The question, however, whether this success-apart from its evident advantages-does not instead pose a special problem for a feminist critique that refers to the ideological constructions of authorship in artists' biographies, which are by no means objective and neutral but rather tied to judgments and contain, among other things, attributions related to gender difference. These constructions, with their gender and national myths, have long since been the subject of critical reflection, not only within the humanities and cultural studies but also on the part of artists themselves.

As a self-reflective discipline, art history, especially in the German-speaking world, has been less successful within the spectrum of the sciences precisely because-this is my thesis-one of its types of texts and exhibitions is too successful and too popular. Questions and methods of art history that could make them attractive and connectible for social discourses are overshadowed to some degree by the artist's biography. ${ }^{3}$ Coming to terms with the ideological construction of creativity as divine gift, brilliant inventiveness, and creatio ex nihilo has been a central theme of feminist criticism for more than thirty years now, which has done us the service of analyzing and showing the essentialist statements about masculinity and femininity that are implicitly formulated in myths of the artists and patterns in artists' biographies. ${ }^{4}$ From that perspective, adherence to and the success of the artist's biography is also a manifestation of resistance to feminist insights that such research uncovered for the entire field and hence in no small measure an adherence to essentialist attributions to "female" or "male" artistry.

Even feminist art history and exhibition policies are not immune to the traditional patterns of the artist's biography and produce parallel biographical writings 
of women artists who have been neglected (thus far) or forgotten in the history of art. ${ }^{5}$ This is possibly the more successful variation on a "feminist" rereading of art history, since the increasing popularization of historical and current women artists represents an opportunity to take up challenges to make those who have been excluded historically visible without having to call into question the constructions of the artist's biography itself. Intentionally or unintentionally, essentialist attributions to a "female" creativity are likewise tolerated or produced. ${ }^{6}$ That conclusion could be reached by observing the present focus of exhibition makers and artists' biographers on women artists. The subject of the present essay will be a classic example of the popularization of a contemporary artist using the means of the artist's biography that updates traditional myths about the artist without problematizing them.

An art history that wants to-and must, if it wants to be contemporaryaddress critical works by contemporary women artists finds itself confronted with a paradoxical task. On the one hand, it must and should make biographical, geographical, and national attributions, since that is in a sense one of its core activities and has (thus far) guaranteed its success. In this way it generates, for example, investments (third-party funding) both from the private and from the state side, which testifies to special interest in constructions of biographical and national identities. $^{7}$

On the other hand, it has also to call into question its methods for producing biographies, catalogues raisonnés, monographic and biographic exhibitions, which to a decisive degree have evaluative and fictive character. One first step in this self-reflection, therefore, would be to admit that artist's biography is fictional and to reflect on the patterns for producing such fictions; a second step would be to reflect on the functions of these fictions. Both things, however, are usually denied or silenced, since fiction is not considered a scholarly form of writing if one clings to traditional ideas of scholarship that claim the universal validity and objectivity as well as apparent neutrality of statements.

I would like to point out in response that it is only the admission of and the analysis of the construction of artists' biographies, for example, that leads to statements that can be regarded today as scholarly, in the sense of situating, contextualizing, historicizing, and analyzing conditions of that which is produced and how.

The most visible and the most widespread production of popularizing and popular art history-namely, the artist's biography or monograph, often in combination with a monographic exhibition-can be regarded as a service for a special interest group within our society. Richly illustrated bestsellers and coffee-table books are found as lifestyle symbols and evidence of connoisseurship in the reception rooms of doctors' offices and business consultants and on the floors of upper management, but also in living rooms in private middle-class homes. Art historical works still convey mostly tales of the life and work of great/brilliant and usually male artists. The involvement of art history in the art world, mediated by art critics and exhibition catalogues, can be described as unconscious complicity with the desires for identification of artists, curators, and the public, who still cling to the model of the exemplary, extraordinary individual. The mirroring of a "community of the initiated" ultimately guarantees the economic success of art history and the exhibition business as a service for a society in which the exhibiting artist has replaced the commissioned artist. ${ }^{8}$ Within the compulsion of self-promotion for the exhibiting artist and the pop star and the hyping of self-employment as part of a neoliberal economic policy to make precarious working conditions seem appeal- 
ing are historically preformulated. They also apply to curators who participate in the success of the artists they exhibit.?

The artist's biography closely dovetails with traditional myths of the artist that structure its narratives and carry on the tradition of models for creativity and artistry derived from art historical writing but at the same time constitutes its material.

The reasons why a majority of art scholars and curators continue to base their work on such models of artist biography seem obvious. Recently, artists' biographies are increasingly being circulated in artists' films, in which they are presented to a broad mass audience. How does a mass audience come to have faith in the patterns of artists' biographies? For that much is certain: in the field of the artist's biography, it is primarily about faith, not knowledge.

Since the early modern era, in which artistic paradigms of craft precision and the fulfilment of common aesthetic norms were replaced by paradigms of the idea and the violation of norms-and artists' myths in the form of creation myths became established ${ }^{10}$-the canonical determination of artists' names and artists' works have the effect of strategies of accreditation in which artists, critics, gallery owners, and curators work together, often without being aware of it. There is constant exchange between these areas. Within the interaction between different types of text and artistic and curatorial activities, a "financial body"11 -as Lacan calls it-forms, becomes established, and becomes more discriminate.

This is an unconscious, ritualized game within which the object of desire, the object that ultimately escapes, the "art(work)", results, and within which the protagonists become privileged people who, as connoisseurs, decide what art is. In other words, this game is about power, about economic success, and, beyond that, about narcissistic gratifications that can scarcely be quantified but can be read from their effects on the self-misjudgment and self-promotion of "paradigmatic subjects". The addressee of such a claim to recognition is still an audience that will perhaps discover the qualities of an artist only posthumously and is de facto comprised of art historians themselves, of whom it is expected that they will write up for posterity artists who are marginalized in their day and hence elevate them belatedly. Within this system, the intertextual and intersubjective connections are repeatedly made unrecognizable and invisible, because the function of the addressee remains invisible in the unconscious structure of narcissism. The blind spot of art history is thus the narcissistic structure of such a financial body itself, which is centred on the fetish of the artist as exceptional subject.

The diversity of artists' myths and their historically and socially motivated applicability is, however, not arbitrary. They are components of the procedures that the discourse formation of art history employs to produce its types of statements. "Discourses are [...] practices that systematically form of the objects of which they speak". ${ }^{12}$ Within the discourse formation, procedures of exclusion operate-including, for example, classification, chronologies, formal analyses, schools, and hierarchies of genre-and one central system of exclusion is precisely the function of the author as well as authorial functions that are appropriated by the actors (artists, curators)..$^{13}$

I would like to work out here a case study of the enduring effect of artists' myths and how art historians, even critical ones, unconsciously push these basic patterns into almost compulsive repetitions. Ultimately, I am concerned to show 
that the apparent continuity of artists' myths contains current interpretations that refer to the changing social conditions of so-called neoliberalism in the age of globalization and enable us to see therein a shift in the meaning and function of artists' myths especially and precisely when they relate to women.

I would like to analyze as my example here the introductory descriptions of the contemporary artist Marlene Dumas that preceded her large monographic exhibition at the Kunsthalle Baden-Baden in 2005. One central aspect of curating is framing exhibitions with texts as well, whether on the home page, in the catalogue, on in other formats.

Between Feminization and Masculinization: The Case of Marlene Dumas

The problem begins with the title. The title of the exhibition in Baden-Baden in 2005, Marlene Dumas: Female, ${ }^{14}$ says a lot and promises a lot: not only does it certify that the artist is, as her name would suggest, a woman, but it also refers to a group of works at the focus of the exhibition that she herself titled Female-a portfolio of 211 works from 1992-93 from the Sammlung Garnatz, which formed the core of the exhibition in Baden-Baden. Marlene Dumas (b. 1953), who had been represented already at documenta VII in 1982 and had become widely known not least thanks to documenta IX in 1992, was also to be certified by this exhibition as an internationally renowned artist. The same was true, as a kind of side effect, of the value of the Sammlung Garnatz. ${ }^{15}$ According to the Kunsthalle's home page, Marlene Dumas "is one of the most important, worldwide renowned women artists who have provided crucial impulses in the last twenty years. A native of South Africa, she has dedicated herself repeatedly in her vital creative work to basic conditions of the human within the frame of reference of sexuality, birth, death, and the relationship between the sexes".16

I do not intend to address here the various allusions to the authentication of the artist as a "global player", even though the fact that she is from South Africaobviously not one of the traditional Western art centres-leads to the equally obvious effort to evoke her worldwide significance in the description. I would like to limit myself to describing the strategies for declaring a woman, a female artist, to be one of the "really big names of the international art scene".

For example, the objects of her art are associated with the "basic conditions of the human within the frame of reference of sexuality, birth, death, and the relationship between the sexes". These basic conditions appear as anthropological constants that (not only) in the West are traditionally regarded as also the core activity of women, which is here considered a "female" choice of themes.

It is about a female artist, a woman, who takes the "feminine" itself as a theme. Where or from whom can we get more authentic information about "femininity and creativity" than from a woman, one could argue. Even if the question is immediately recognizable as a rhetorical one, I do not wish to reduce it to the absurd immediately. Such formulations enable one to consciously run through the inner monologues of art historical prose, especially when it pursues certain goals, and how we are all caught up in the production of gender stereotypes, even if perhaps we do not wish to be and even when we are emphatically pursuing an antithetical strategy. In other words, I am not interested in disavowing specific authors, but rather in revealing the power of discourses to which we all constantly succumb if we do not employ the analytical instruments that are available to us in the meantime. 
To get the desired information about "femininity", art historians might first observe the works and compare them to other works from the art historical tradition and perhaps also with other products of the visual culture around us, for example, series of photographs in magazines, advertisements on television, or even our own snapshots-all things that Marlene Dumas has also employed as models.

If the title of the exhibition promises statements about "femininity", ${ }_{1}^{17}$ it automatically produces a desire in the viewers to see "femininity". How can it be depicted? How do we recognize it? From images of bodies with secondary sex characteristics? From stances, clothing, facial features, or hairstyles? The store of cultural codes we have experienced ourselves, remembered or learned from historical sources are called up in order to use them to test. We know the models of femininity that our cultural tradition makes available; with repetition, they become natural; they provide stability.

Can femininity be found in the style of painted or drawn gestures? And, if so, what are its features? Dexterity, tenderness? Or are they to be found in the themes and subjects of the works? And then which ones would they be? Children, everyday scenes, still lifes, self-portraits, or portraits? Is femininity found in the sensitivity of the artist? What effect would it then have on the works? We are already skating on thin ice with the possible answers: as clichéd as these attributions might be, our perception and idea of others and of ourselves are closely tied to them.

But if looking at the images leaves us helpless, then we ask ourselves: Is perhaps the title Female misleading? Is it conceivable that the title is part of a marketing strategy? Should we be taken in by the promise of seeing authentic femininity? If looking at the images leaves us helpless, we keep searching, for example, in the texts written about the exhibition.

In the foreword to the catalogue and on the home page, ${ }^{18}$ we find the following description by the curators of the exhibition:

Marlene Dumas's importance on today's art scene and for many other artists stems from the fact that her works easily bring together what elsewhere is strictly contradictory. Her presentations of the female frustrate and disenchant in a feminist way, so to speak, the male gaze (insofar as this presumes to be taking possession). Also as a matter of course, and with an almost baroque versatility, the artist adopts the role of the-traditionally patriarchal-artist as creator (God) through her drawings, her painting, her poems and reflections, as well as through her teaching activities.

And it continues:

Marlene Dumas sensitizes our perception by countering the photographic standardization of human appearance in the mass media with artistic precision. She does not present her themes as a know-it-all commentator of human existence but rather develops her drawing ambiguously, on the margins of the namable. In the process, she manages-as in Foreign Thoughts, 2002, and Male Beauty, 2002-to coax by means of subtle nuances of color the sensory presence of the human body from the skin of the paper.

The text delivers an impressive series of statements that can be associated with questions of femininity and masculinity as well as an impressive palette of standard clichés that must be ranked among traditional building blocks of the artist's biography and of artist myths. We can conclude the following from the text: Marlene Dumas is an internationally important artist, in part because she confidently unites contradictions (that is to say, communicative and balancing, socially competent). Not actually feminist but only quasi-feminist, their dramatizations of the feminine-that is to say, we are confronted with a cultural performance of the 
feminine-disillusion and disappoint the male gaze that "presumes to be taking possession". It will not be able to seize any property; it does not offer him the anticipated images-the text says-without making it clear which images that the male gaze seizing a possession expects. Furthermore, just as much a matter of course as when she disillusions, the text states, she adopts the position or role of the traditional patriarchal artist as God the Creator. As a woman, as a female artist, she plays the role of a man, namely, that of the artist as God the Creator, that is to say, she can only play him; she cannot be him. So, it is a role change or the appropriation of a "male" privilege.

The distinguishing features of her art, the text goes on, are, among others, the ability to sensitize our perception, that she is not a know-it-all (that is, she is in fact modest), that she works on the margins of the nameable, and that she does so with artistic precision. Attributing sensitivity and modesty to a "powerful woman" strips her of her threatening, competing quality. That the artistic work or intention cannot be named is an old topos of traditional art history that makes the quality of art that seemingly cannot be translated into language the touchstone for connoisseurship. The forming of myths continues: in the process the artist manages to "coax by means of subtle nuances of color the sensory presence of the human body from the skin of the paper".

There are very many gender definitions here in just a few sentences, some of them consciously chosen, others less so. The last qualification in particular, that the artist's work "coax[es] by means of subtle nuances of color the sensory presence of the human body from the skin of the paper", is citing the classical Ovidian myth of the artist Pygmalion, who fell in love with an ivory sculpture he made himself and, with Aphrodite's help, brings it to life. This traditional myth of the artist is the central one to which the idea of the Creator-like artist clings, and it forms the foundation of the talk of the artist as God the Creator, which has found ever new formulations and, especially since the eighteenth century, become more significant again. The way this idea has inscribed itself in myths of the female artist as well has long since been a subject of research for feminist art history. ${ }^{19}$ Almost seamlessly, one could also pick up the thread of the ancient competition between artists, which was taken up again in the early modern period, in which the perfect simulation of proper, living life by artists became the touchstone for their artistic quality.

Comparing canvas, paper, or other surfaces that serve as a medium of creative artistic processes to skin should also be seen in this context as a traditional topos associated with the artist-creator. Associating skin and canvas is not infrequently used to present female bodies as allegories of painting and has been problematized by women artists since the 1970s, as the art historian Silvia Eiblmayr demonstrated for the modern era. ${ }^{20}$

The home page quotes yet another topos of myths of the artist, namely, the idea that an artist is one "from the beginning", that is, reveals his or her talent already as a child. The deferred action of "discovery" is negated: "Marlene Dumas, who is considered one of the very greats on the international art scene, is introduced by Matthias Winzen, who observes, among other things, that it would scarcely be possible to identify a period that could be seen as a key experience for Marlene Dumas's artistic breakthrough. 'Everything was already there,' he notes and proves it with impressive sketches from the period as a student". The argument is taken from Matthias Winzen's essay "A Portrait of the Artist as a Young Woman"; he comes to this conclusion after viewing earlier works. ${ }^{21}$ 
In any case, the authors seem to consider it necessary, when describing the work of an artist who has gotten herself into the position of God the Creator, or is located there, or should be located there, to tell the old story of Pygmalion in a new version. This is supposed to certify that a role change has taken place and that it was a success. In order to prove that a woman artist can create "like a man", it is necessary to dust off analogies from age-old art historical myths.

I have selected these passages in order to work through how myths of the artist and of gender function, in part because their authors really wanted to communicate something else. As we can read, they too see in Marlene Dumas an artist who does not make use of the traditional expectations of the male gaze. For the expectations of males eager to see (voyeurs who do not want to be seen themselves), the tradition of art history would offer above all erotic female nudes, which were made evident through precise illusionistic perfection. In the opinion of these authors, Marlene Dumas breaks with conventions of seeing and depicting; for that reason, she is also described as-at least almost-feminist, which I can understand if "feminist" is understood to mean a strategy that questions traditional gender patterns, making us conscious of them and thus ultimately trying to thwart them. Matthias Winzen should be given the benefit of the doubt for identifying the feminist deconstruction of relationships of the gaze as a starting point for discourse on Dumas: "At the same time, the to and fro of these gazes takes place within social patterns, and the dominant pattern of the male gaze and the gazed-at female, both in society as a whole and in art, has been analyzed and criticized at great length by feminist and micro-sociological theories of power since the 1970s". ${ }^{22}$ In what followed, however, he equated the feminist position with the identification with the role of the victim, which then enables him to describe Marlene Dumas as someone standing between the male position and the female one and hence at the same time not a feminist. ${ }^{23}$ She is not allowed to be a feminist, because in the history of art this would be understood as a threatening challenge. This example shows that the habit of repeating gender stereotypes as they are inscribed in myths about the artist has such an immense effect in our culture that even those who are trying to avoid them cannot always get out of the habit.

This analysis of the introduction to the Marlene Dumas exhibition clearly shows how gender definitions are produced in art and in the history of art. They have had and still have influence on different forms of creativity and productivity, on how artists see themselves, and, of course, also on the texts written about them in which their work is evaluated: exhibition reviews, catalogue commentaries, newspaper articles, promotional materials for the art market, and scholarly and trade journals.

This question of the effects that gender definitions or even gender constructions have on art is not a new question for art history; it has been asked by art historians in the German-speaking world for thirty-five years, and even longer in the English-speaking community. For a long time, it was a taboo issue. The question of the effects that gender constructions have had on art historical writing was taboo and will remain so as long as art history, like the other humanities, clings to the claim that it makes universally valid, true statements. Only in recent years has it increasingly become a matter of course for that to be recognized as a justified question, and the view that scholarship and its production are also-indeed especially so-guided by claims to power and interests and therefore can only make claims of validity that are particular, perspectival, and historical and therefore temporally limited has largely gained acceptance in discussions of the crisis in the humanities and cultural studies. 
It is, after all, a question of their responsibility to provide insights not only into how we imagine "masculinity" and "femininity" in relation to art objects but also into how we see them in relation to everyday life. Moreover, artists and curators seem to have become a kind of role model as "classical exceptional subjects of the modern era", ${ }^{24}$ and neoliberal ideologies make use of this.

But what is the image of the woman artist? Even today when it seems that all areas of society are open to women, female artists are only exceptionally the focus. ${ }^{25}$ And as exceptions they have the function in art historical writing of proving the rule. As exceptions, they can, apparently, only prove the rule if exhibitions and the art criticism and/or art historical writing that accompany them update the models of the artist's biography and myths about artists in such a way that specific merits can be attributed to female artists without having to question fundamentally the "feminine" or "masculine" aspect of traditional concepts of creativity and of the artist-and hence the concepts themselves. And exhibitions have enormous popular success in doing so. The question is how we deal with the obstructing success of the artist's biography.

\section{Notes}

1 Shortened and adapted version of the text first published as "Künstlerbiografik, Künstlermythen und Geschlechterbilder im Angebot-Fallbeispiel: Marlene Dumas," in Oskar Bätschmann et al., eds., Dienstleistung Kunstgeschichte? Art History on Demand?, 100 Jahre Institut für Kunstgeschichte, Universität Bern, Festschrift, vol. 2, Imorde, Emsdetten, 2008.

2 Horst Bredekamp speaks of this "successful history of art history" in Horst Bredekamp, "Einbildungen," Kritische Berichte 2000, No. 1, pp. 31-37.

3 Examples of connectivity include comparative analyses of iconology, theories of the symbol, concepts in semiology and the theory of perception for the "image" as a component of conscious and unconscious cultural communication. The claim of art studies to be a leading field of scholarship is expressed in the German-speaking world, for example, in the proclamation of an "iconic or pictorial turn", which is a symptom of lost theoretical terrains. On this, see Sigrid Schade, "What Do Bildwissenschaften Want? In the Vicious Circle of Pictorial and Iconic Turns," in Kornelia Imesch et al., eds., Inscriptions/Transgressions: Kunstgeschichte und Gender Studies, Kunstgeschichten der Gegenwart, Peter Lang, Bern, 2008, pp. 31-51. http://blog.zhdk.ch/sigridschade/files/2013/07/WhatdoBildwissenschaftenwant_000.pdf.

4 Among the most important pioneers were Rozsika Parker and Griselda Pollock, Old Mistresses: Women, Art and Ideology, Pantheon, London, 1981. See also the summary in Sigrid Schade and Silke Wenk, "Strategien des 'Zu-Sehen-Gebens': Geschlechterpositionen in Kunst und Kunstgeschichte," in Hadumod Bussmann and Renate Hof, eds., Genus: Geschlechterforschung und Gender Studies in den Kulturund Sozialwissenschaften, Kröner, Stuttgart, 2005, pp. 144-84, chap. 3: "Autorschaft und Autorität: Künstler und Kunsthistoriker im Kampf um die Macht des ZuSehen-Gebens."

5 This debate has been ongoing ever since feminist approaches led to the first large exhibition of women artists. See, among others, Sigrid Schade, "Was im Verborgenen blieb: Zur Ausstellung 'Das Verborgene Museum,'" Kritische Berichte 1988, no. 2:91-96; there are various case studies in Kathrin Hoffmann-Curtius and Silke Wenk, eds., Mythen von Autorschaft und Weiblichkeit im 20. Jahrhundert, Jonas, Marburg, 1997.

6 On this, see Sigrid Schade, "'Künstlerinnen und Abstraktion': Anmerkungen zu einer 'unmöglichen' Beziehung in den Konstruktionen der Kunst- 
geschichte," in Ulrich Krempel and Susanne Meyer-Büser, eds., Garten der Frauen: Wegbereiterinnen der Moderne in Deutschland, 1900-1914, Sprengel Museum, Hanover, and Von der Heydt-Museum, Wuppertal, Ars Nicolai, Berlin, 1997, pp. 37-45, esp. 42. Exhibition catalogue.

7 This is often supported by national institutions such as the Schweizerisches Institut für Kunstwissenschaften (The Swiss Institute for Art Research), which provides funds primarily for research, archives, inventories, and publications related to Swiss artists. This poses a problem for the research horizon of such an institution. Support for artists that is partially funded by the state is always national in orientation; it has to legitimize itself with the argument that it creates potential for identification with the nation. Critics who want to claim competence in their own country or for their "own" art scene abroad write about Swiss, German, French, or South African art or artists (or, less problematically, art or artists from Switzerland, Germany, France, or South Africa) and thus are following the tradition of Nikolaus Pevsner's The Englishness of English Art (1956), that is to say, they find themselves in the dilemma of having to define the specific national characteristic of artistry or creativity-however they are constructed-and hence of making essentialist statements per se.

8 Oskar Bätschmann, Ausstellungskünstler: Kult und Karriere im modernen Kunstsystem, DuMont, Cologne, 1997; see also Sigrid Schade, "Kunstgeschichte," in Wolfgang Zinggl, ed., Spielregeln der Kunst, Verlag der Kunst, Dresden, 2001, pp. 86-99.

9 Marion von Osten made this fact a theme of the exhibition Be Creative! at the Museum für Gestaltung in Zurich: Marion von Osten and Peter Spillmann, eds., Be Creative! Der kreative Imperativ, Museum für Gestaltung, Zurich, 2002. Exhibition catalogue. See also Marion von Osten, ed., Norm der Abweichung, Theorie: Gestaltung 3,Voldemeer, Zurich, 2003.

10 Ursula Link-Heer, "Maniera: Überlegungen zur Konkurrenz von Manier und Stil (Vasari, Diderot, Goethe)," in Hans Ulrich Gumbrecht and K. Ludwig Pfeiffer, eds., Stil: Geschichte und Funktionen eines kulturwissenschaftlichen Diskurselements, Suhrkamp, Frankfurt am Main, 1986, pp. 93-114.

11 Jacques Lacan, "Of the Gaze as Objet Petit $a$," in idem, The Four Fundamental Concepts of Psycho-Analysis, trans. Alan Sheridan, Hogarth, London, 1977, pp. 67-119, esp. 112.

12 Michel Foucault, The Archaeology of Knowledge, trans. Alan Sheridan, Pantheon, New York, 1972, esp. 49. See also Schade, "Kunstgeschichte" (see note 8), p. 96.

13 Michel Foucault, "The Discourse on Language," in idem, The Archaeology of Knowledge (see note 12) pp. 215-37.

14 Matthias Winzen, ed., Marlene Dumas: Female; A Collaboration with the Sammlung Garnatz, trans. Pauline Cumbers, Kunsthalle Helsinki, Nordic Watercolour Museum, Skärhamn, and Staatliche Kunsthalle, Baden-Baden, in cooperation with the Sammlung Garnatz, Snoeck, Cologne, 2005. Exhibition catalogue.

15 The collector is even also allowed to express himself in a "Preface": "Marlene Dumas' art caught the attention of my wife and myself at an early stage, and her works subsequently became one of the main focuses of our collection. Meantime, Dumas is regarded as one of the really big names of the international art scene." See Eberhard Garnatz, "Preface," in Winzen, Marlene Dumas (see note 14), p. 6.

16 The wording found on the home page today is no longer identical to the version of 2006; today it states: "On closer inspection of the works, however, Dumas's refinement is revealed in the simple, her exact calculation in the spontaneous, the breadth of her intellectual interests and points of contact in the frame of reference of sexuality (Leather Boots, 2000), birth (Warhol's Child, 1989/91), 
death (The Missionary (2002-4), and the relationship between the sexes (Immaculate, 2003)." Accessed 17.03.2016. http://www.kunsthalle-baden-baden.de/ programm/show/22.

17 Still on the home page today (see note 16): "In the series Female, for example, she studies in 211 drawings the representability of the feminine." She herself states: "I don't admire only one type of woman-I love many types of women. But it's also not only about reaching to interpreting images of women, it's also about the joy of creating beings that do not exist in real life. It's more about the pleasure, but will always stay unknown."

18 The text on the home page was changed after the exhibition ended and no longer corresponds exactly to what is cited here. [The first quotation ("Marlene Dumas's importance ...") is from the original version of the website; the translation in the catalogue has been adapted accordingly. Trans.] It is a compilation of various motifs that can be found in the texts by several authors in the catalogue, including the foreword of the catalogue (p. 8). In the catalogue, the "frustrate and disenchant in a feminist way, as it were" of the website has been replaced by "frustrate [...] in an almost feminist way." The version quoted by me can be found at http:// hosting.zkm.de/kbb/archiv/arc_dumas.html. note 5).

19 Hoffmann-Curtius and Wenk, Mythen von Autorschaft und Weiblichkeit (see

20 Silvia Eiblmayr, Die Frau im Bild: Der weibliche Körper in der Kunst des 20. Jahrhunderts, Reimer, Berlin, 1993.

21 Matthias Winzen, "A Portrait of the Artist as a Young Woman," in idem, Marlene Dumas (see note 14), p. 36.

22 lbid., pp. 39-40.

23 lbid., p. 40.

24 Sigrid Schade, "Kunstgeschichte," in Wolfgang Zinggl, ed., Spielregeln der Kunst (see note 8), pp. 86-99; Schade and Wenk, "Strategien des 'Zu-SehenGebens'” (see note 4), pp. 144-84.

25 Isabelle Graw, "Es kann nur eine geben: Überlegungen zur 'Ausnahmefrau, ," Texte zur Kunst 11, No. 42, June 2001, pp. 79-88.

Sigrid Schade is Professor and Head of the Institute for Cultural Studies in the Arts ICS, Zurich University of the Arts since 2002. She was professor for Art Science and Aesthetic Theory at the University of Bremen from 1994-2004. Her research includes studies in visual culture, hierarchies in the arts, institutional critique, gender studies, interrelations between the arts, and new media. Selected publications: ed. Vera Frenkel, Ostfildern: Hatje Cantz 2013 (German and English); Studien zur visuellen Kultur, together with Silke Wenk, Bielefeld: transcript 2011; Re-Visionen des Displays. Ausstellungsszenarien, ihre Lektüren und ihr Publikum, ed. w. Jennifer John, Dorothee Richter, Zürich 2008; Ausstellungs-Displays. Innovative Entwürfe für das Ausstellen von Kunst, Medien und Design in kulturellen und kommerziellen Anwendungen. Dokumentation zum Forschungsprojekt 2005-2007, ed. Sigrid Schade, Institute for Cultural Studies in the Arts, Zürich 2007; SchnittStellen, ed. w. T. Sieber u. G.C. Tholen, Basel 2005; Co-editor of the series Studies in Visual Culture, transcript Verlag. http://sigrid.schade.zhdk.ch. 


\section{Feminist Perspectives on Curating Dorothee Richter}

Curating is a form of knowledge production which means, it is also a gendered form of knowledge production, in this talk I would like to ask in the first part: What would make a curatorial project a feminist one and in the second part, I would like to closely look at one case of curatorial knowledge production.

First: what would make a curatorial project a feminist one? I came to the conclusion that four categories should be met:

\section{Categories}

1.The first one should be to consider gender equality in terms of numbers in exhibitions and curatorial projects. I remember that this demand was thoroughly discussed, because of the problem of reproducing a simplistic notion of "male " and "female". We as feminists always fought for a multiplicity of sexes, beyond the binary code of a conventional paradigm. "Normal sexuality is thus, strictly speaking, an ordering, which the hysterics deny (then becoming sick)", following Lacan, has put it. This would mean that it would be a feminist project in art if one could infer from it the ordering of gender, as well as the difficulty or impossibility of this adjustment process, and also make it possible to identify the fictitious category of normal sexuality. This would distinguish an art that criticizes and unsettles existing gender roles from art that, in a proxy function, affirms "sexual fulfilment" and at the same time cements gender order. A conventional affirmative art would basically conceal the splitting of the subject, to make it possible to see entire bodies and idealized images. A critical, feminist, potent art would reveal the splitting of the subject of the gaze; it would have no stress-relieving function. But, also derived from a Lacanian perspective, it is important to be aware of the position of "women" in patriarchy; "women" are denied a subject position in so far that the only possible subject position is that of the dominant male position, of the one who has the phallus. So however creatively we play with gender roles, stealing the subject position by mimicking "male" behaviour or looks, we should be aware of the mimicry and nevertheless still demand from the perspective of lack, from the position of the crossed out subject. In so far as I would, as a political demand, still adhere to the counting of numbers of men and women, especially when in the artistic field-in curating, exhibition-making, art, and universities-the imbalance is still in full bloom, or to put it differently, as long as white men hold the most of the top positions in universities, in ranking lists of the art market, and in institutional jobs. Where there is still an urgent need for the masked Guerrilla Girls! Therefore, I think that the demand for equality of representation has to be maintained, seeing this as a temporarily strategy, a support structure on the way to diversity and multiplicity beyond fixed categories as a horizon.

2. The second would be to cite historical references correctly. Which means, to refer to the movements, not to the singled out artistic geniuses, or stars, a paradigm which the art market prefers. This means in our context to see the revolutionary movements of the '60s like Fluxus, Happenings, Womanhouse, and other feminist group works embedded in a struggle for new forms of communities, new forms 
of working together, new forms of meaning production/organisation that would be later called curating.

Which means to stay with the questioning of paradigms, like authorship, production modes, new forms of distribution and reception. These forms had in mind a specifically changed interrelation between audience and artists, between participants and producers, between high and low cultural production, between "races", and, last not least, between the relations of gendered roles. These transgressive practices from the past are always in danger of being connected back to one author or one artist, which limits their potential revolutionary approach in production, distribution, and reception. For contemporary curating, it means to keep to the approach of transgressive practices, creating new forms referring to archives, community-based projects, concept exhibitions, meeting spaces, and interventions in the public space, and to acknowledge historical forerunners and initiatives in their complexities. ${ }^{2}$

3. The third would be disturbance through the image, through the display. That does not mean, of course, that I see an exhibition as an integrated work of art; it is a specific, very complex narrative. So to disturb an easy narrative would be an important mission. According to Jacqueline Rose, Freud "relates-quite explicitlythe failure to depict the sexual act to bisexuality and to a problem of representational space. [...] A confusion at the level of sexuality brings with it a disturbance of the visual field." ${ }^{3}$ Jacques Lacan differentiates the potential disturbance or calming which can result from art or painting. He sees the mode and manner of an artist in the desire to become visible as an author, to be a subject, to convey in the individuality of style something that gives the viewer the impression of being looked at from within the picture: "[...T] hus they will see in the end, as in a filigree, something so specific for each of the painters, that they feel the presence of the gaze."14 The gaze is here understood as the disturbing, unsettling moment, the recognition of being viewed from the outside.

Transferred to the act of putting up an exhibition, one might say that in curatorial work, the production of meaning can give rise to an encounter that looks at the viewer. In some contrary cases, however, certain painting or exhibition assumes the function of something for the eye to feed on, by which the visitor can lay down his/her gaze (like weapons). This would provide the pacifying, Apollonian effect of painting, which Lacan calls the "dompte-regard", the tamed gaze. The project in the realm of the project Female Coalities (which I curated in 1997) emphasised this taming effect of the visual, but also of an author's name. The artists Isolde Look, Irmgard Dahms, Anne Schlöpcke invited Barbara Bloom, Cindy Sherman and Kiki Smith and put stuffed childrens' animals on an auction with a professional auctioneer in an importang gallery in Bremen, which sold off most of the issues, the sold animals were replaced with a polaroid of the owner with it. ${ }^{5}$ The purchase prices often related to the fame of the respective artist.

This eye trap with its pacifying effect is revealed by the artists in the above mentioned project. This disturbing element would therefore also be unsettling and would call into question each of the categories of race, class, and gender. ${ }^{6}$ 

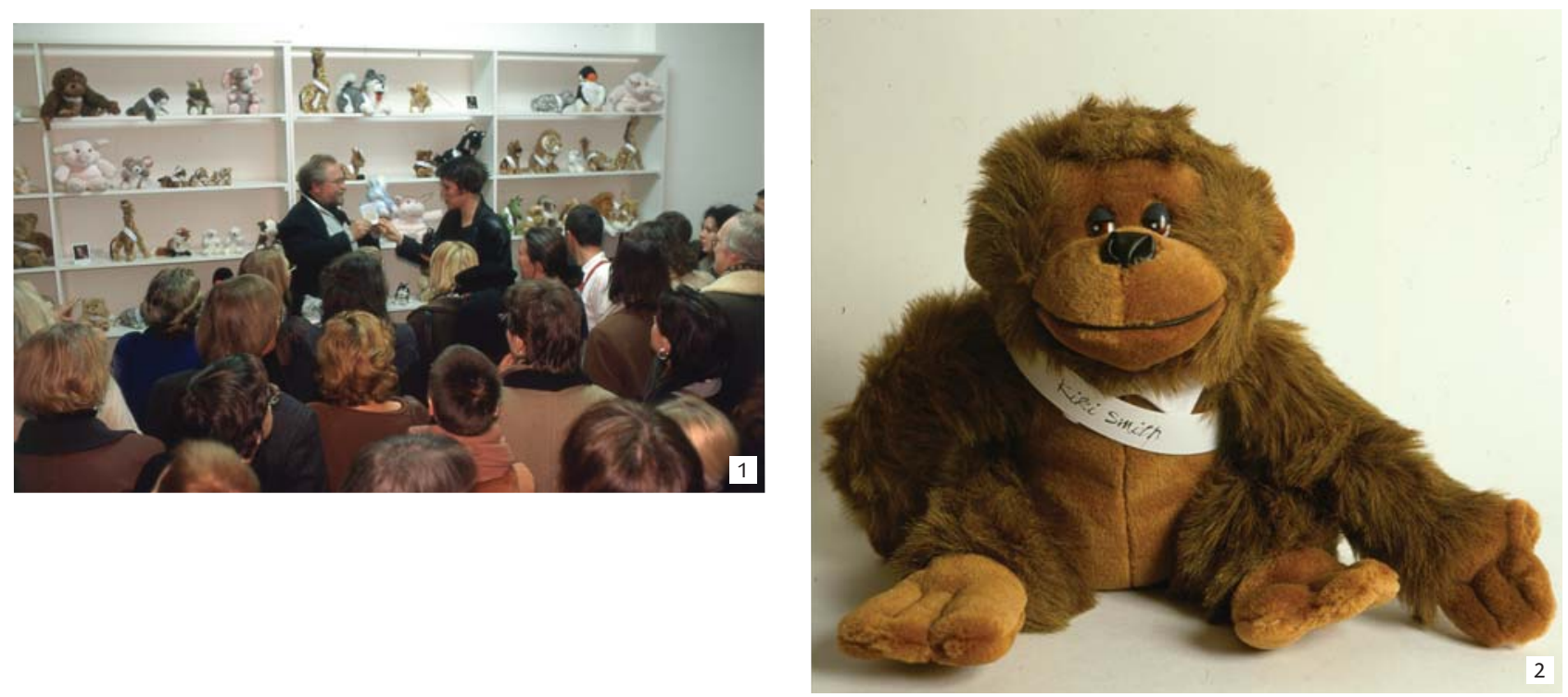

I also suspect that the once hyped notion of "the curatorial" might work as an "(eye) trap". The notion of "the curatorial" implies a problematic ennoblement of curating as a meaning producing activity which takes place (as I see it) in a politically and ideological contested field. Putting "curating" on eye level with philosophy, it is in danger of asking for essentialist, supra-temporal meaning production from curating, which would function outside history. Instead, I would propose staying with re-contextualizing, historicising, localising and being aware of the political demands and alliances. Feminist curating is part of a political movement.

4. Institutional critique: to transfer this to exhibitions would mean always calling into question the context of the exhibition, using curatorial methods to unsettle the curatorial authorship of an exhibition's discourse on truth and the "quality" discourse. Which means from a feminist perspective institutional critique should be embedded in the projects. This would, of course, mean that any hierarchical positioning between curator and artists has to be questioned. As types of naturalization effects in art institutions, Oliver Marchart-citing the museum as an example-singles out four components that each have a gender-specific aspect: firstly, the power to define, which claims that the art institution is a neutral agency of mediation and judgment, is presented as being natural; secondly, the exclusions and inclusions, which make people forget that there are always very specific exclusions; thirdly, the constraints of cultural policy, budget, and similar factors to which the institution itself is subject; and fourthly, its class-based character. ${ }^{7}$ The behavioural norms and built-in ideological concepts which, as subtexts, structure art institutions derive from the interests of a specific group, of which the paradigmatic representative is the white, male, middle-class subject. (In the post-Fordist era, however, a clear classification like this has begun to undergo a shift, given that in the production process the subject is downgraded in favour of group processes. This makes it possible to speculate, for instance, that the middle-class subject is in retreat, as Felix Ensslin has remarked. ${ }^{8}$ ) 


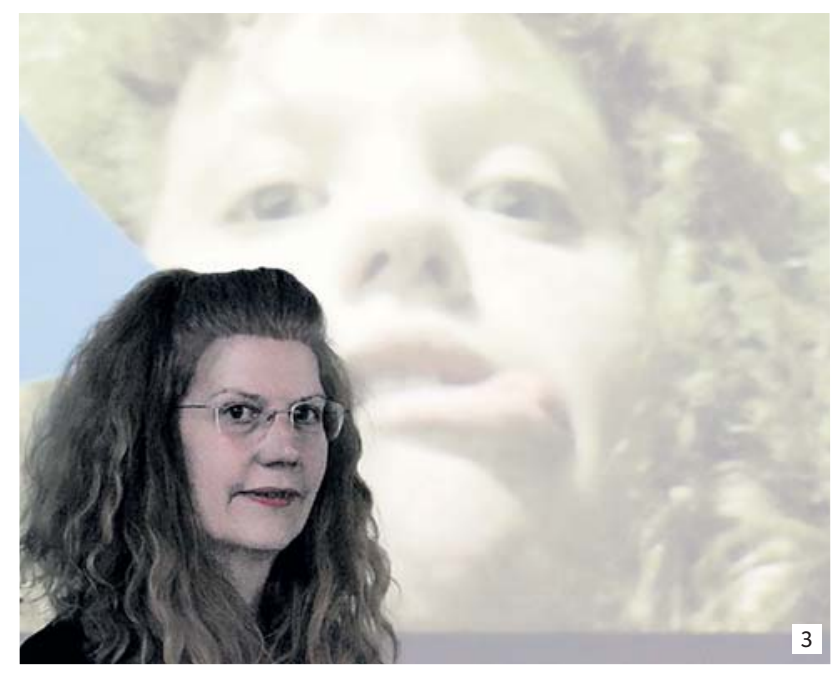

Institutional critique also means that, from a feminist-political perspective, all behaviour patterns are in question as well, all conventions and structures. This is why in some of my talks "False-Hearted Fanny" interferes, demonstrating the multi-layeredness of any discourse; she does not feel bound to institutionalised behaviour patterns and tends to show a subject as a split subjectivity. To take into account the structural and material side of curating means-again-to think of feminist curating as involved in and part of political and economic struggles. In thinking of curating as a form of producing knowledge or, in other words, of interpellations, means consciously taking up a position in an ideologically contested space.

Individual museum presentations and their underlying ideological framework have been discussed and convincingly analysed in detail by Mieke Bal, ${ }^{9}$ Jana Scholze, ${ }^{10}$ Anna Schober, ${ }^{11}$ and also (jointly) by Gerlinde Hauer, Roswitha Muttenthaler, Anna Schober, and Regina Wonisch, ${ }^{12}$ to mention only a few.

Any form of institutional critique should address distribution, production, and reception, all parts of the art system that are still infected with patriarchial orderings. This means that a feminist urgency in curating would have to stay with this thrive to repetition (Wiederholungszwang), in finding other forms of curating, so called non-representationals forms of curating, ${ }^{13}$ which would create space for other forms to live in a curated space, to discuss, to inform, to laugh, to share, to contradict, to infect with an attitude. This was the motivation for the archival exhibition Materials at Kuenstlerhaus Bremen in 1999, featuring thirty feminist artists, art historians, and theorists alongside a symposium on feminist positions in contemporary arts. $^{14} 15$
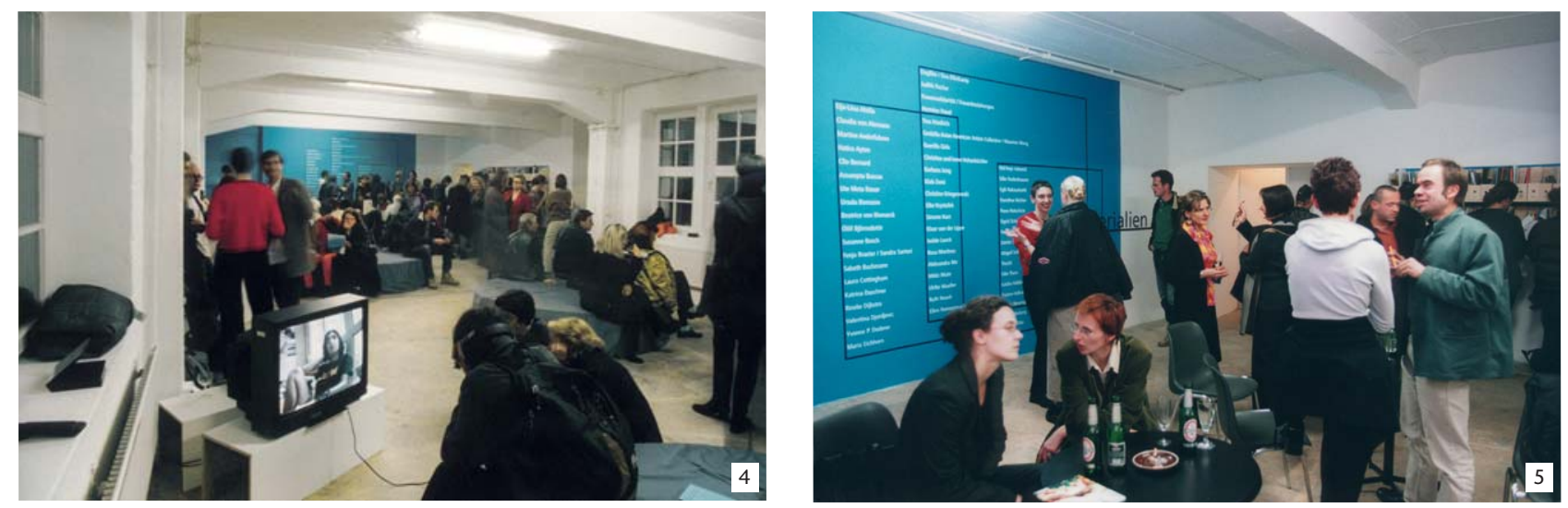
To give you an example that the underlying ordering of gendered roles is also embedded in this new discursive formation called "curating" and how much a critical approach is needed in the field of curating, I would like to anaylse one of these contemporary examples from the sector of publishing in detail:

\section{Case Study: The Exhibitionist}

The birth of the museum is closely related to the burgeoning bourgeois class; it is clearly related to contemporary curating in a historical timeline. The Cristal Palace is described as a paradigmatic site of instituting a new skopic regime. Tony Bennett described the goals related to the famous Cristal Palace in London briefly as follows: "Just as in the festivals of the absolutist court, an ideal and ordered world unfolds before and emanates from the privileged and controlling perspective of the prince, so, in the museum, an ideal and ordered world unfolds before and emanates from a controlling position of knowledge and vision: one, however, which has been democratized in that, at least in principle, occupancy of that position-the position of Man-is openly and freely available to all."16

He continues in a very poignant turn: "It is, however, around that phrase 'at least in principle' that the key issues lie. For in practice, of course, the space of representation shaped into being by the public museum was hijacked by all sorts of particular social ideologies: it was sexist in the gendered patterns of its exclusions, racist in its assignation of the aboriginal populations of conquered territories to the lowest rungs of human evolution, and bourgeois in the respect that it was clearly articulated to bourgeois rhetorics of progress. ${ }^{117}$ As a subject construction, the situation of seeing through a controlling perspective of overview and of being seen, the bourgeois subject has installed the agency of control inside itself-it is controlling itself.

In many ways, curating inherited forms of exclusion. As Olga Fernandez uttered, "Curators' expertise is usually defined by a set of procedural skills and organisational abilities, and intellectual production.." ${ }^{18} \mathrm{Her}$ argument is that this knowledge combination is also a key element in the post-Fordist economy: "The entrepreneurial abilities of the curator and the expanded exhibitions formats are symptomatic of the new economic conditions that require new contexts of collaboration and interaction. ${ }^{\prime 19}$ This means that the fascination and the pre-occupation with curating and exhibition-making of so many countless publications and symposia are partly due to the ideological concept of this figure, the curator, who seems to have gained authorship in this rather confusing new world order with its newly installed infrastructures.

The area of curating therefore provides this imaginary promise and is thus an especially contested field-a special representational battleground-and, as mentioned before, a new discursive formation is therefore installed. This is also why the ideological discussions around curating matter.

As a case study I would like to discuss The Exhibitionist, a magazine published since 2009 by Jens Hoffmann, sometimes with collaborators. In this sceenshot you see the image of the Cristal Palace on the cover in the middle. For the newer issues, it has also been accompanied by a blog. From the beginning, only a part of curating was the topic of this journal, and I quote: "The Exhibitionist does not intend to occupy itself with all forms of curatorial practice. Rather, it is specifically concerned with the act of exhibition making: the creation of a display, within a particular socio-political context, based on a carefully formulated argument, presented through the meticulous selection and methodical installation of artworks, related 


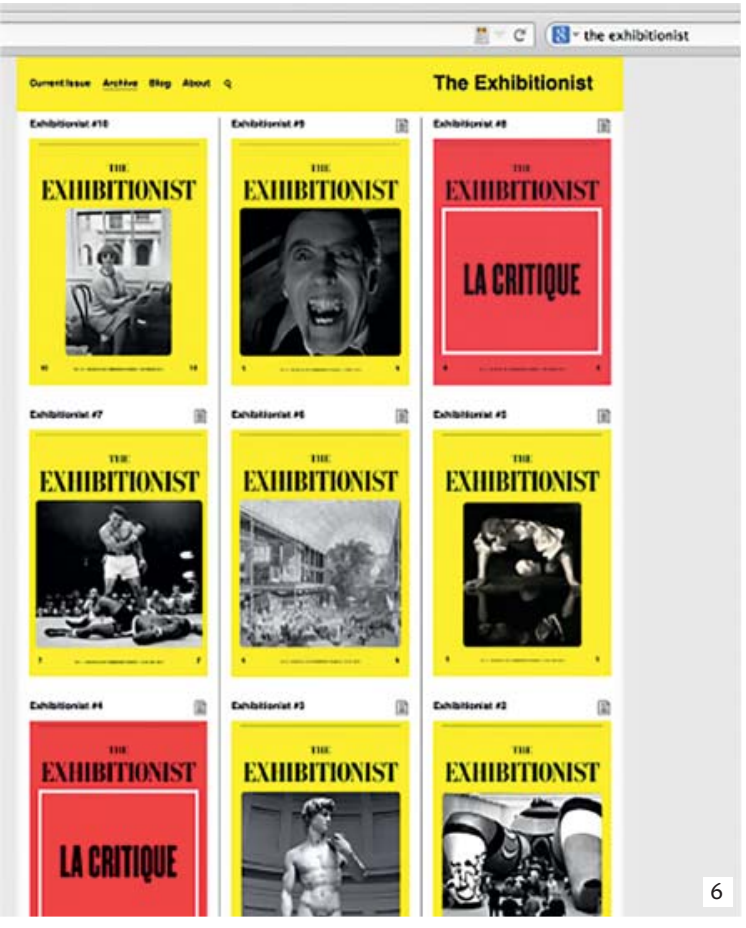

objects from the sphere of art, and objects from other areas of visual culture."20 Just to remind you, dear reader, curating could mean many more different things: publishing, organising symposia, opening up digital platforms, intervening in archives, in radio stations, presenting editions, working in the public space, creating a social space, or social sculptures, or a series of discussions. The main task of the Exhibitionist, according to Jens Hoffmann is therefore as follows: "We concur that the curatorial process is indeed a selection process, an act of choosing from a number of possibilities, an imposition of order within a field of multiple (and multiplying) artistic concerns. A curator's role is precisely to limit, exclude, and create meaning using existing signs, codes, and materials." ${ }^{\prime 21}$ From my perspective, this represents a very narrow concept of a curator or an exhibition-maker: the reduction of the role to an excluding of positions.

Perhaps the name of the journal has to do with this limited concept of exhibition-making; the core issue is therefore also reduced to a specific subject position, which more or less ironically is claimed to be an exhibitionist, which means generally speaking, "A person who behaves in an extravagant way in order to attract attention," as my online translator suggests. ${ }^{22}$ The German and English versions of Wikipedia differ in defining an exhibitionist; while in English the exhibitionist condition could be theoretically subscribed to either men or women, even if more often recognised in men, the German version says bluntly: "An exhibitionist is generally a male person who gains sexual stimulation out of showing his own arousal to normally attractive female persons," in brackets, "showing an erect penis for publicly achieved satisfaction." ${ }^{23}$ It ends with the addition: "In Germany all exhibitionism is prosecutable."

So I suspect that this relation to a clinical sexual disorder, which has its specific life in patriarchy, is programmatically inscribed in some concepts of a curatorial subject. And it might explain why I felt so strangely moved when I recently came across the website of this publication again.

I will show you the covers of the publication online (see image above)-what narrative does this image production offer? You see here, a very prominent the historical example of the Cristal Palace, the reference to a new concept of a bour- 
geois subject, who sees and is to be seen. A subject that will become a well-behaved citizen, because the agency of control is installed inside this subject.

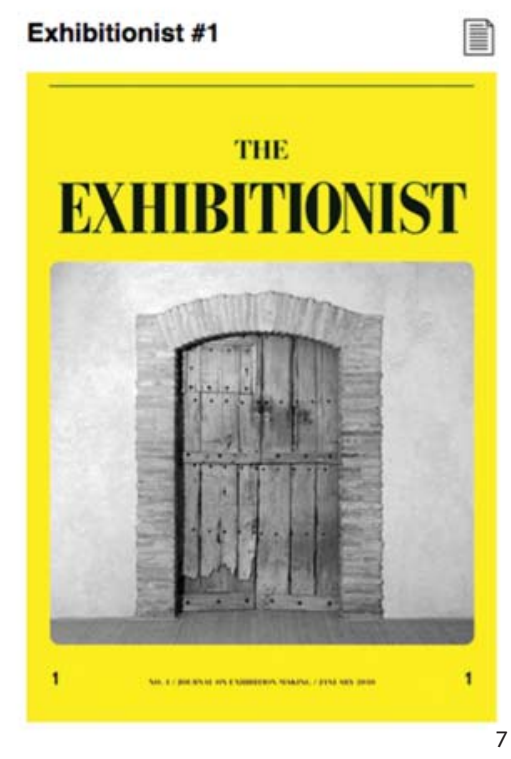

And here, the very first issue, with a specific cover: this somewhat mysterious image is explained in the editorial note: "In homage to Marcel Duchamp we have chosen an image of his final work, Étant donnés (1946-66), for the cover of our first issue.

Anyone familiar with the piece knows that what is shown here, an old wooden door with two peepholes, is only a small part of the full experience of the work. Behind the doors there is an illuminated landscape and a naked woman; the exhibitionism of the scene invites us to look but it also exposes us, standing at the door in the midst of our voyeurism, to the gazes of others just entering the room. The pun of this publication's title speaks to that doubling, to the way in which the curator is not only an exhibition maker but also one who publicly exposes his or her arguments and commitments in a vehemently visual fashion. ${ }^{\prime 24}$
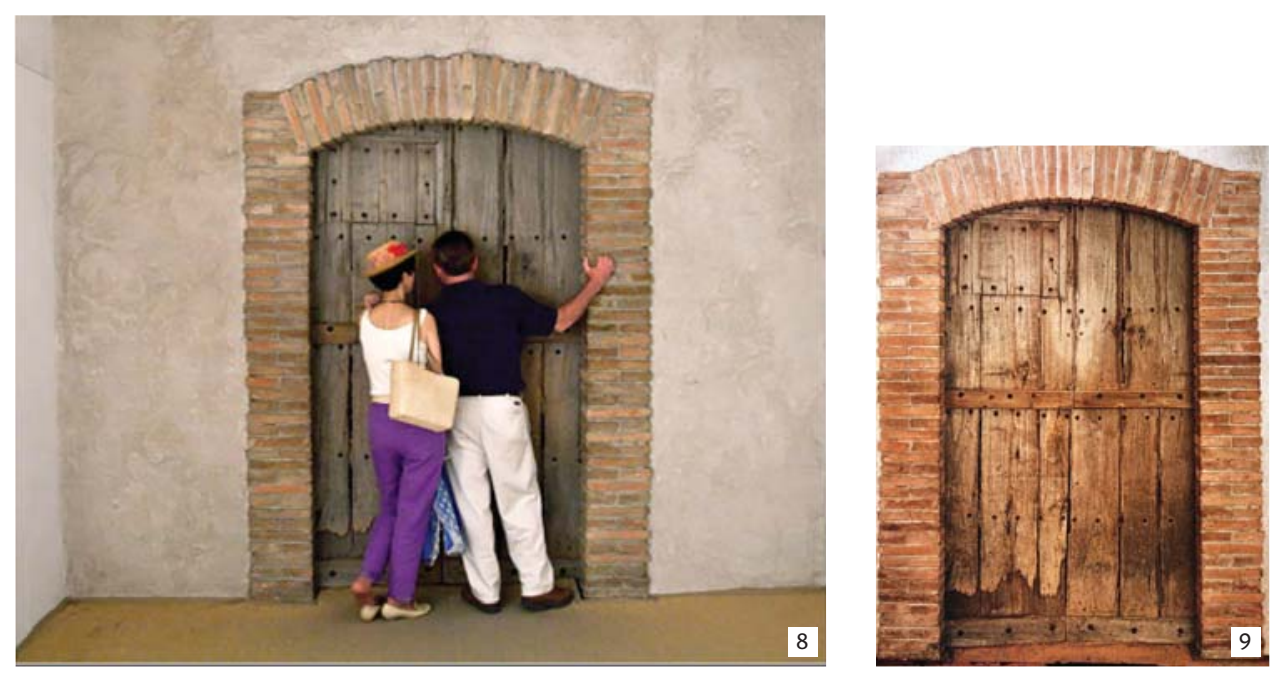

I show here an image from the website of the Philadelphia Museum of Art, where this work is on display. This last work by Marcel Duchamp on which he worked during his last years, when the art world considered him beyond the mate- 
rial production of art, is seen as a double projection of a female-connotated body and the visual field, as Sotirios Bahtsetzis describes. ${ }^{25}$ This transition, or double projection, shows the main characteristic connotation of a space of vision and images of the female body. This transaction, as Linda Hentschel has analysed in depth, ${ }^{26}$ is exactly the moment of production of a technique in the visual field that produces gendered spaces. Hentschel shows that a main structure of Western image production is grounded in this scopic turn in the structure of desire. Hentschel argues (and here I follow also Bahtsetzis) that the historically conditioned construction of gender, and the relation of optical apparatuses, the visual field, and a feminised space, goes hand in hand with an underlying education of seeing as a sexualised activity, an education towards a scopic drive.

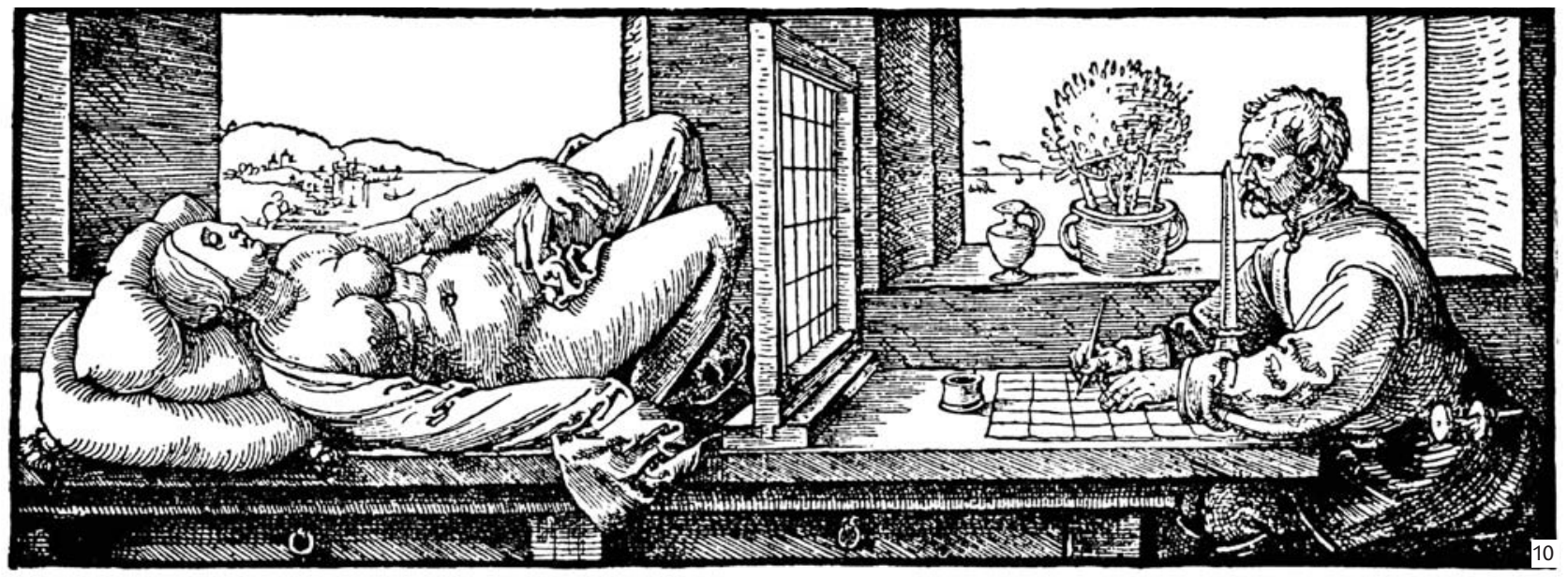

This phenomenon is connected to a scientifically described and controlled space, as presented by the instituting of a central perspective. In this new science, the male and female positions are clearly defined in a hierarchical order. The historical turning point is paradigmatically visualised in this work of Albrecht Dürer: Der Zeichner des liegenden Weibes (The Draftsman of the Lying Woman) (1538). This woodcut was an illustration in a treatise with the title: instruction in measurement. From a feminist perspective, Sigrid Schade and Linda Hentschel showed that the effect of this construction was not only the sexualised visual field but also the creation of a voyeuristic pattern, which was loaded with binary codes: the female associated with nature, the male associated with science; the female with the untamed landscape, the male with cultivated plants; the controlled position and the controller. The demonstration of controlled and subdued female sexuality is obvious. Interesting is the position of the viewer of this woodcut who is denied the viewpoint of the male subject, who instead has the full view of the female genitals, the so-called "beaver

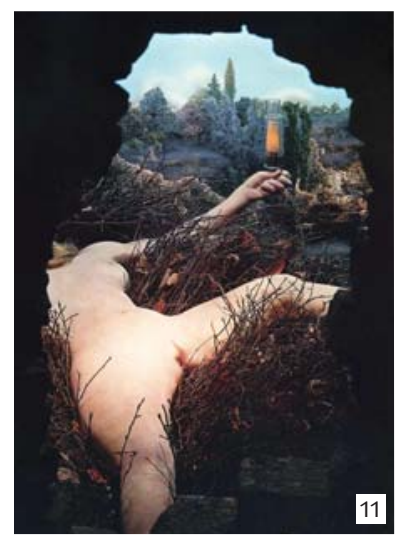


shot." So the moment of presentation and denial is simultaneously inscribed into this image.

To come back to Duchamp's Étant donnés, with the full title: 1. La chute d'eau 2. Le gaz d'éclairage (1. The Waterfall, 2. The Illuminating Gas) (1946-66). In the abovementioned article by Bahtsetzis, he argues that Duchamp was well aware (to use a title by Jacqueline Rose) of sexuality in the field of vision and aimed at a critique of the gendered space. For my argumentation here, I condense Bahtsetzis' lines of thoughts to the conclusion, in which he states that Étant donnés is in this respect a special case of an anamorphic snapshot, as the viewer is excluded from the position of seeing, he has to testify the phallic construction of the scopic regime of modernity. But to cut the discussion short, the damaged body, which was actually put together from casts of Duchamp's secret lover Maria Martins, plus a cast of the arm of his legal wife in later years, and its presentation in the rather bourgeois setting of hiding images suspected of pornography, did from my point of view reinforce this setting instead of questioning it. The scattered body is not shown just in its fragmentation, it is-even if looking violated-holding up a clearly phallic shaped lamp-'honi soit qui mal y pense'-by the arm cast of Duchamp's legal wife. The piece does show an uneasiness about the "real", an uneasiness about what Lacan calls "jouissance" (the 'female' sexual pleasure), and an effort to maintain the phallic position.

Let's go back to the initial presentation of this hiding door as a cover of the first Exhibitionist. We see the door of this scene, which may or may not double the structure of contemporary visual settings: the engendered space, the scopic structure which presents a clear hierarchy of gendered spaces, of relations between an objectified position and a subject in its full rights. What does it initiate in the row of covers we see here, which all revolve around the bourgeois setting of the Cristal Palace?

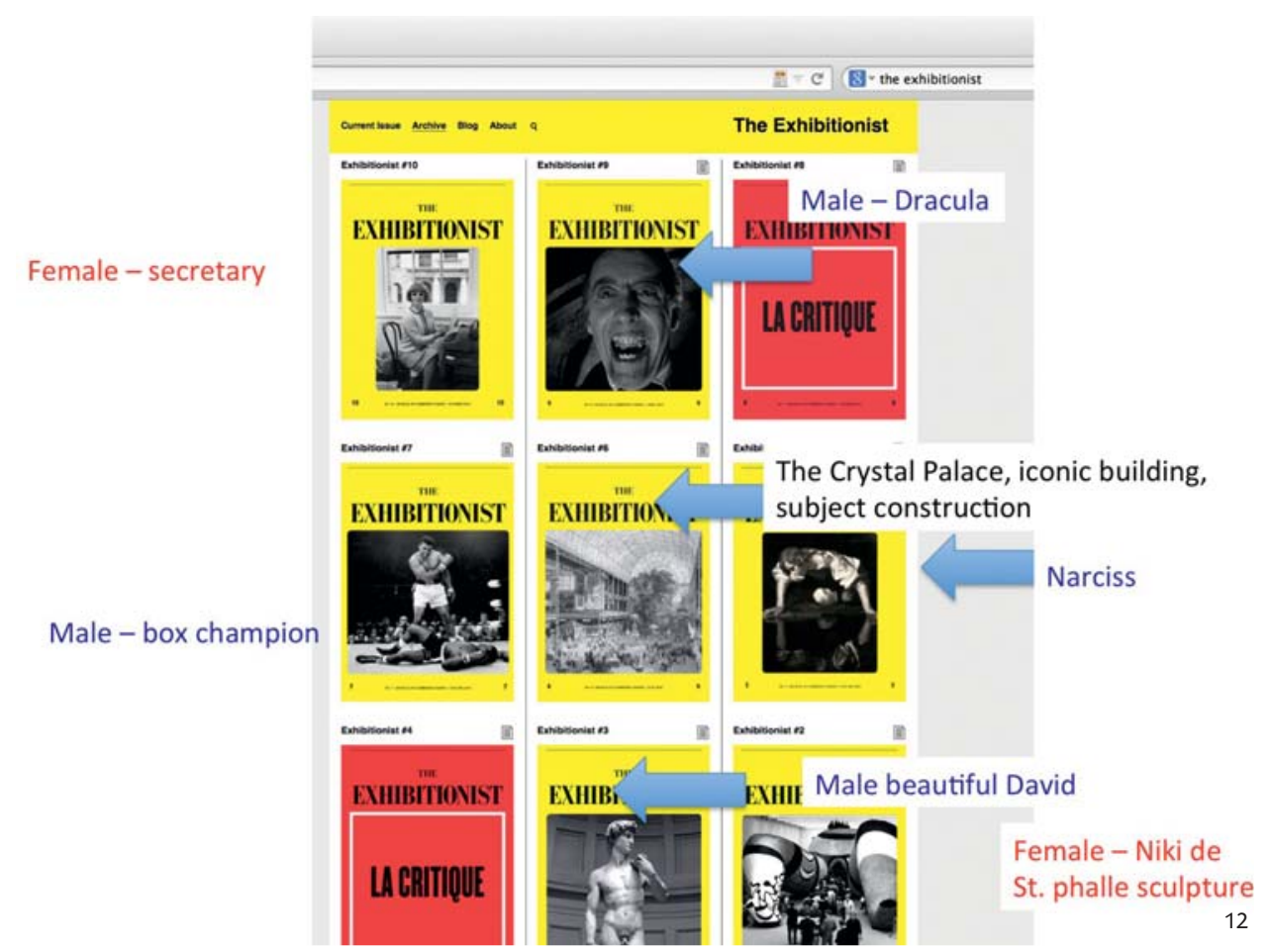


We see the representation of a secretary (a work by Cindy Sherman) and another beaver shot, if one wants to put it like that, a work that was intended to be a feminist commentary on sculpture by Niki de Saint Phalle. We see as male representations a dangerous looking Count Dracula, a beautiful Narcissus, endangered of drowning himself because he is so much in love with his mirrored face, a strong boxing champion, and a beautiful oversized sculpture of David by Michelangelo. I am very much aware that each of these covers could be interpreted in detail with all their underlying meanings and connotations, but in this case I would like to stay focused on the brief overview of male and female stereotypes, which, as I see it, present a narrative in this configuration of a row of covers: they define the framework of the curatorial subject for the already very gendered figure of the exhibitionist. The repetition of these stereotypes double and redouble the traditional

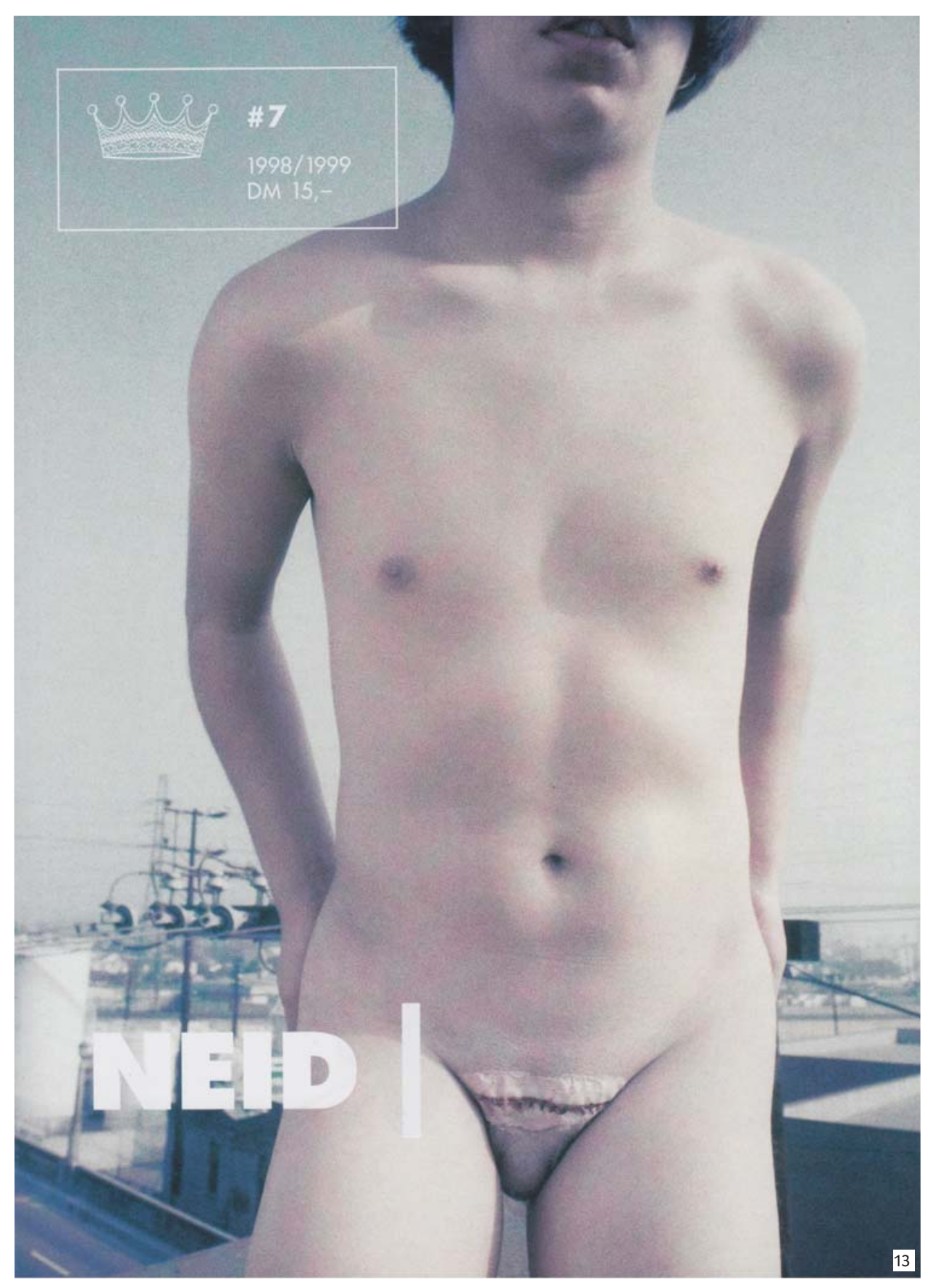


gender roles, even if the original artwork was intended to criticise gendered spaces. The slightly sarcastic attitude that is also conveyed does not question this in an in-depth way; instead, the traditional roles are presented with a subtle smirk. In this way, The Exhibitionist presents what it stands for: a traditional concept of exhibition-making, which of course goes hand in hand with a conservative gendered space in the visual field. The content often also centres on exhibition-making as an associative visual format that does not need too much theoretical insight.

Just as an interlude in terms of how a cover could function, maybe not as an artwork as such, but as a cover, it is also important to be aware where, how, and for whom an image works. It can, as Roland Barthes has discussed intensively, always be de-historicised and put together to generate a myth, an ideological construction.

This cover was put on the famous journal NEID ("envy" in English) by artist and D-Jane Ina Wutdke and shows a work by Claudia Reinhardt, an injured body, the hidden anxiety of patriarchy of castration quite openly addressed. ${ }^{27}$ This image shows the the gaze of the other that is deemed threatening, since that would be able to disorganise the field of vision. As Margaret Iversen demonstrates, Barthes' "punctum" is a reference to Lacan's concept of the gaze, and by the very use of the terms, the sting, wound, and puncture, which can be recognised as a relationship to deficiency as a result of the symbolic threat of castration and which indicates the disturbing incursion of the "real" into the consciousness of the subject. ${ }^{28}$

\section{Captions}

1, 2 Exhibition in the framework of "Female Coalities" curated by D. Richter, artists: Isolde Look, Irmgard Dahms, Anne Schlöpcke with Barbara Bloom, Cindy Sherman and Kiki Smith, Galerie Cornelius Hertz, Bremen, 1996.

$3 \mathrm{Me}$ and False Hearted Fanny, talk at Hochschule fuer Gestaltung Karlsruhe, photograph published in Karlsruher Nachrichten, 29th of May 2015.

4, 5 Materialien / materials, an archive, exhibition at Kuenstlerhaus Bremen, accompanying a symposium on feminist positions in contemporary art with 30 folders with information (catalogues, articles, Dvds, Videos) by artists, theoreticians and curators understanding themselves as feminists, curated by $D$. Richter, 1999. 2015.

6 Screenshot Website of Exhibitionist, accessed

7 Screenshot, Cover Exhibitionist 1, accessed
June 2015

8 Screenshot Website Philadelphia Museum of

Art

9 Screenshot Website Philadelphia Museum of Art, showing a couple before Duchamp's Étant donnés.

10 Albrecht Dürer, Der Zeichner des liegenden

Weibes (The Draftsman of the Lying Woman), 1538

11 Behind the door: Marcel Duchamp,

Étant donnés, 1. La chute d'eau 2. Le gaz d'éclairage

(1. The Waterfall, 2. The Illuminating Gas), 1946-66.

12 Comments on screenshot of the Exhibitionist.

13 NEID \# 7, Cover, 1998/99, Hrsg. Ina Wudtke, Fotocredit: Claudia Reinhardt "Ezikiel" 1996 L.A.

\section{Notes}

1 Jacqueline Rose, Sexualität im Feld der Anschauung, Turia und Kant, Vienna, 1996, p. 57.

2 This is why we (Ronald Kolb and I) published the film Flux Us Now. Fluxus Explored with a Camera with eleven chapters, one of which refers particularly to gender in Fluxus; it follows up on some of the political agendas of Fluxus and emphasises the complexity and the contradictions of the movement. See www.fluxusnow.net.

3 See Jacqueline Rose, p. 229.

4 Jacques Lacan, "Linie und Licht," in Gottfried Boehm, ed., Was ist ein Bild?, Munich, 1994, p. 70.

5 Exhibition at Gallerie Cornelius Herz, Bremen; in the framework of the project female coalities, curated by D.Richter, 1996.

6 See also Dorothee Richter, "In conversation with False Hearted Fanny, Feminist Demands on Curating," in Elke Krasny, ed., Women's: Museum. Curatorial Politics in Feminism, Education, History, and Art / Frauen: Museum. Politiken des Kuratorischen in Feminismus, Bildung, Geschichte und Kunst, Vienna, 2013, pp. 75-83.

7 Oliver Marchart, "Die Institution spricht," in Beatrice Jaschke, Charlotte Martinez-Turek and Nora Sternfeld, eds., Wer spricht? Autorität und Autorschaft in Ausstellungen, Turia $\mathrm{e}$ Kant, Vienna, 2005, pp. $39 \mathrm{f}$.

8 Felix Ensslin, on the occasion of my lecture on artistic authorship at the Kunstakademie Stuttgart, Dec. 2015.

9 Mieke Bal, 'Telling, Showing, Showing off', Critical inquiry, 18 (1992), 556-94.

10 Jana Scholze, Medium Ausstellung. Lektüren musealer Gestaltung in Oxford, Leipzig, Amsterdam und Berlin, Transcript, Bielefeld, 2004.

11 Anna Schober, Montierte Geschichten. Programmatisch Inszenierte Historische Ausstellungen, Dachs Verlag, Vienna, 1994.

12 Gerlind Hauer, Roswitha Muttenthaler, 
Anna Schober, and Regina Wonisch, Das Inszenierte Geschlecht. Feministische Strategien im Museum, Böhlau, Vienna, et al., 1997.

13 Non-representational forms of curatingthis notion is obviously a contradiction in itself, because the so-called non-representational forms also represent, but it is worth thinking of what is actually happening in an exhibition space and about what a project represents.

14 The symposium "Dialogues and Debates Feminist Positions in Contemporary Art", which I curated, was held at the artist residency Die Höge; the accompanying archive/exhibition was shown at Kuenstlerhaus Bremen. I asked all speakers to name at least five artists, theoreticians, or curators for the archive. The contributions to the symposium were published in Dorothee Richter, Die Höge, eds., Dialoge und Debatten - Symposium zu feministischen Positionen in der zeitgenössischen bildenden Kunst, Verl. für Moderne Kunst, Nürnberg, 2000 (German/English).

15 At Kuenstlerhaus Bremen I also co-curated (with Sigrid Adorf and Kathrin Heinz) a series of talks on feminist issues in the visual field, which was published later in Sigrid Adorf, Kathrin Heinz, Dorothee Richter, guest eds., Frauen Kunst Wissenschaft, Im (Be)Griff des Bildes, Heft 35, Marburg, June 2003. This series was often combined with exhibitions inspired by a feminist approach, for example an exhibition by the artist group De Geuzen, see also Dorothee Richter, Programming for a Kuenstlerhaus, Institut für zeitgenössische Kunst, Nürnberg, 2002. Curating from a feminist perspective inspired the exhibition series with the provocative title Feldforschung Hausfrauenkunst (field research in housewifery), (see Dorothee Richter-Glück, Kulturzentrum Schlachthof, eds., Feldforschung Hausfrauenkunst, Bremen 1992. Exhibition catalogue.), and the project female coalities, with exhibitions, dinners, screenings, talks, and performances in different venues all over Bremen (see Dorothee Richter-Glück, Zentralstelle für die Verwirklichung der Gleichberechtigung der Frau, eds., female coalities, Bremen, 1997. Exhibition catalogue.

16 Tony Bennett, The Birth of the Museum, History, Theory, Politics, Routledge, London, New York, 1995), p. 97.

17 Bennett, Tony, The Birth of the Museum, History, Theory, Politics (London, New York: Routledge, 1995), p. 97.

18 Fernández, Olga, "Just what is it, that makes 'Curating' so different, so appealing?" in Institution as Medium, Curating as Institutional Critique, Part 1, OnCurating Issue 8, 2011, p. 40. 19 lbid.

20 Jens Hoffmann, 2009. "An overture," The Exhibitionist, Issue 1. Accessed 09.03.2015. http:// the-exhibitionist.com/archive/exhibitionist-1/.

21 lbid.

22 See https://de.wikipedia.org/wiki/Exhibitionismus, accessed 09.10.2016.

23 Translation by D. Richter.

24 Hoffmann, "An overture".

25 Sotirios Bahtsetzis, "Die Lust Am Sehen Marcel Duchamps 'Étant Donnés': Zwischen Der Skopisierungs Des Begehrens Und Der Feminisierung Des Bildraumes," The Marcel Duchamps Studies Online Journal, 2004, 1-18. <http://www.toutfait.com/ articals.php?id=4418 $>$.

26 Linda Hentschel, Pornotopische Techniken des Betrachtens: Raumwahrnehmung und

Geschlechterordnung in visuellen Apparaten der Moderne, Jonas Verlag, Marburg, 2001.

27 NEID \# 7 Cover, 1998/99, ed. Ina Wudtke; Fotocredit: Claudia Reinhardt "Ezikiel" 1996 L.A., Neid (Envy) was founded in 1992 by Ina Wudtke, Heiko Wichmann, Hans Christian Dany and Claudia Reinhardt, 1995- 2004 edited by Ina Wudtke. See http://www.inawudtke.com/html/arbeiten/neid. html, accessed 09.04.2016.

28 Margret Iversen, "What Is a Photograph?," in Art History. Vol. XVII, No. 3, September 1994.

Dorothee Richter is Professor in Contemporary Curating at the University of Reading, UK, and head of the Postgraduate Programme in Curating, CAS/ MAS Curating at the Zurich University of the Arts, Switzerland; She is co-director with Susanne Clausen of the Research Platform for Curatorial and Cross-disciplinary Cultural Studies, Practice-Based Doctoral Programme, as well as the publisher of the web journal OnCurating.org; Richter has worked extensively as a curator: she was initiator of Curating Degree Zero Archive, which travelled to 18 venues in Europe; Curator of Kuenstlerhaus Bremen, at which she curated different symposia on feminist issues in contemporary arts and an archive on feminist practices, including Materialien/ Materials; recently she directed, together with Ronald Kolb, a film on Fluxus: Flux Us Now, Fluxus Explored with a Camera (Staatsgalerie Stuttgart 2013, Akademie der Bildenden Künste in Wien, 2014, Kunsthochschule Hamburg 2014, Gesellschaft für Aktuelle Kunst, Bremen, 2014, Kunstverein Wiesbaden 2014, University of Reading 2013, Migros Museum für Gegenwartskunst, Zürich, 2013; Kunsthalle Sao Paolo, 2014; Ostwall Museum Dortmund, 2015, Kibbutz College Tel Aviv, 2015; Universität Lüneburg; 2015; Museum Tinguely in Basel, 2015, Lentos Museum in Linz, 2016), and she is working at the moment on a video archive on curatorial practices together with Ronald Kolb, a collaboration with the ZHdK and the ZKM Karlsruhe. 


\section{In Search of the Feminist (in the) Institution Stella Rollig in conversation with Juliane Saupe}

Juliane Saupe: For twelve years now you have been the director of the LENTOS Kunstmuseum Linz as successor to Peter Baum, who held that office for thirty years. How would you describe the changes due to a feminist being in this position?

Stella Rollig: I was influenced by the politicization, the New Institutional Critique, and the Context Art of the late 1980s/1990s. I am not an art historian, but originally a critic. For many years of my career I worked outside of institutions. This may indicate something of my background. The changes when I took over as director were major ones, perhaps also because museum work on the whole and the art business have changed massively and continue to change.

JS: Your first collection presentation in 2004 was a strong feminist statement: for Paula's Home you chose exclusively female artists from the holdings. Women only-was that your motivation?

SR: After six months at LENTOS, I had grasped that the structures are marked by patriarchy. The concept for Paula's Home was developed quickly and reactively. The new LENTOS building opened in 2003, accompanied by an advertising campaign that referred exclusively to male artists in the collection. The slogans for LENTOS were "Andy's Home" (Warhol), "Egon's Home" (Schiele), "Gustav's Home" (Klimt). The city's art collection was represented as being wholly without women. Activists from fiftitu\%, a network association for women artists and cultural producers, carried out a funny anti- or commentary campaign then-a survey of passers-by in front of LENTOS: "Name three women artists". The deplorable results of this survey were published as a video. I took up the activist protest by fiftitu $\%$ as an impulse in the institutional work and asked the two museum curators, both of them women, to do a collection exhibition solely with women artists. This became an extensive show, which we called Paula's Home as an homage to Paula Modersohn-Becker. This was also the first exhibition by the two curators, Elisabeth Nowak-Thaller and Angelika Gillmayr, where they were credited by name. That was not usually the case before I became director.

\section{JS: Would you do that exhibition again today?}

SR: No. It was a statement at a certain historical moment. As you probably know, the Centre Pompidou realized the same concept with elles@centrepompidou in 2011, seven years later, but with a far greater public resonance...

JS: That was also an exhibition showing exclusively female artists from the collection. Could that be a concept of feminist curating: women-only exhibitions?

SR: I was asked about the concept of feminist curating primarily because of three exhibitions: because of my first exhibition in a museum, hers. Video als weibliches Terrain / Video as a Female Terrain in Graz in 2000, then Paula's Home, and finally the most recent LENTOS exhibition Rabenmütter / Mother of the Year in Fall 2015. The latter contrasted the manipulation of mothers through discrimination, political, social, and economic interests with a free, self-determined understanding of motherhood, to put it briefly. In my curatorial work those are certainly important projects, but I would prefer to discuss a broader approach to feminist curating.

\section{JS: So not just women only, but rather...?}

SR: I am interested in gender politics as an essential part of social politics, and I am interested in artistic positions that engage with issues of gender and society. The focus often stems from the artists being personally affected-although a queer sexual 

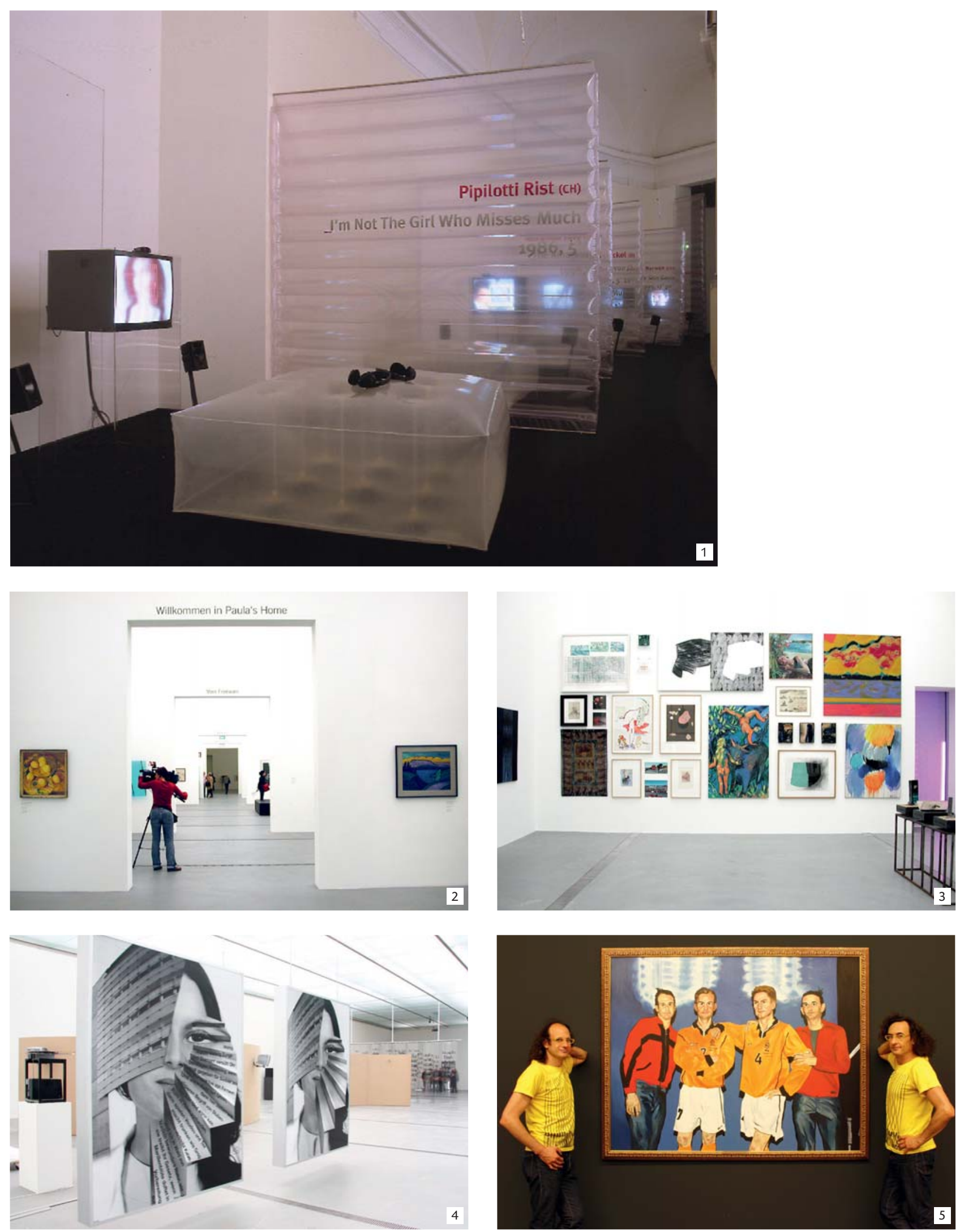
identity is not a precondition for making queer art. In any case, we have worked together with many artists who represent feminist and/or gay positions, such as VALIE EXPORT, Mathilde ter Heijne, Ursula Mayer, Anetta Mona Chișa \& Lucia Tkáčová, Gilbert \& George, Gil \& Moti, EVA \& ADELE. I would like to claim that feminist curating is distinguished by showing marginalized, resistive, deviating, other positions.

Following from this, what currently occupies me is the question of "showing". I am aware that the act of showing constitutes a subject-object position. This is usually the blind spot of curating, and I admit I have not yet thoroughly investigated it.

JS: Would you say that an intersectional concept of feminism enters into your practice, that museum-critical theories, queer theory, or post-colonial theory also influence your work?

SR: Looking at my past, also in connection with the Depot in Vienna, I can agree with that. Today I would say that the way I proceed is very intuitive. I cannot read and mentally process theoretical and philosophical writings to the same extent as in the past. I regret that, but after long days with lots of administration and communication, in the evenings I prefer to read literature rather than an academic book. My decisions and my practice come from a political stance. I know, without having to provide copious footnotes, how I would like our society to be-and the way it appears today does not correspond with my ideal.

The artists I work with and whose work, world views, and aesthetic language I would like to give a platform and an audience, stand for openness, diversity, and self-determination, which I wish for all of us, for myself, and for our society. Freedom from fear, too, and courage-fear is constantly overused today to legitimize exclusion and hostility. I often see freedom from fear in the artistic positions of gay artists, women artists, artist-couples. In other words, in the work of people whose self-understanding is different from that of the male master artist. For example, EVA \& ADELE, who are often falsely perceived as flamboyant, as apolitical, or as an event. The way they thwart all expectations regarding gender identity, even queer identities - which of course have their own stereotypes-is wonderful, and courageous, too, since they are no longer young. They risk something, just like Gil \& Moti, gay Jewish artists, who go into Palestinian territories and offer cooperation. I am also interested in these artists, because their work additionally includes style, an extreme styling of their external appearance, with which they expose themselves to unpredictable reactions.

JS: So your policy for inviting artists is one of your feminist strategies. You also invite artists, couples, or collectives to intervene in the collection exhibition. Are there any other measures you take to proceed against the white, male genius idea that still predominates in museums and in the art market?

SR: On the whole, this view is simply not strengthened. That doesn't mean that no male, white, heterosexual artists can be exhibited in LENTOS. We also make use of self-controlling, by the way: genderbudgeting is an important instrument, gender reports-as far as purchases are concerned we are doing quite well with gender equality, not only in terms of the number of female artists, but also the amount of money, which is the more difficult part, as we all know. Yet despite all this, we are conscious of the fact that we have shown more major solo exhibitions of male artists than of female artists in the last twelve years.

\section{JS: What is the reason for that?}

SR: The reason is the game rules and compulsions imposed on the institution from the outside. These involve a set of interests on the part of politics and the public, which are expressed in a (literally) "horrifying" number: visitor statistics. This is an instrument that is tremendously powerful in its destructiveness, and it can be used to make people small and discouraged - think about attacks in the media. Now male "master artists" are still privileged in the market and in the whole art business, and it is mostly men who are famous. Of course, this has an impact on the visitor statistics and conversely on programming decisions.

The institution has an inherent strength of its own. You push against it, you want to pull it to your own utopias, and you can even move it a bit. But at the base of its essence, the institution is conservative and far more resistant to change than you initially thought.

JS: That brings us to the problems of the everyday practice of a feminist museum directorship that I want to ask you about. 

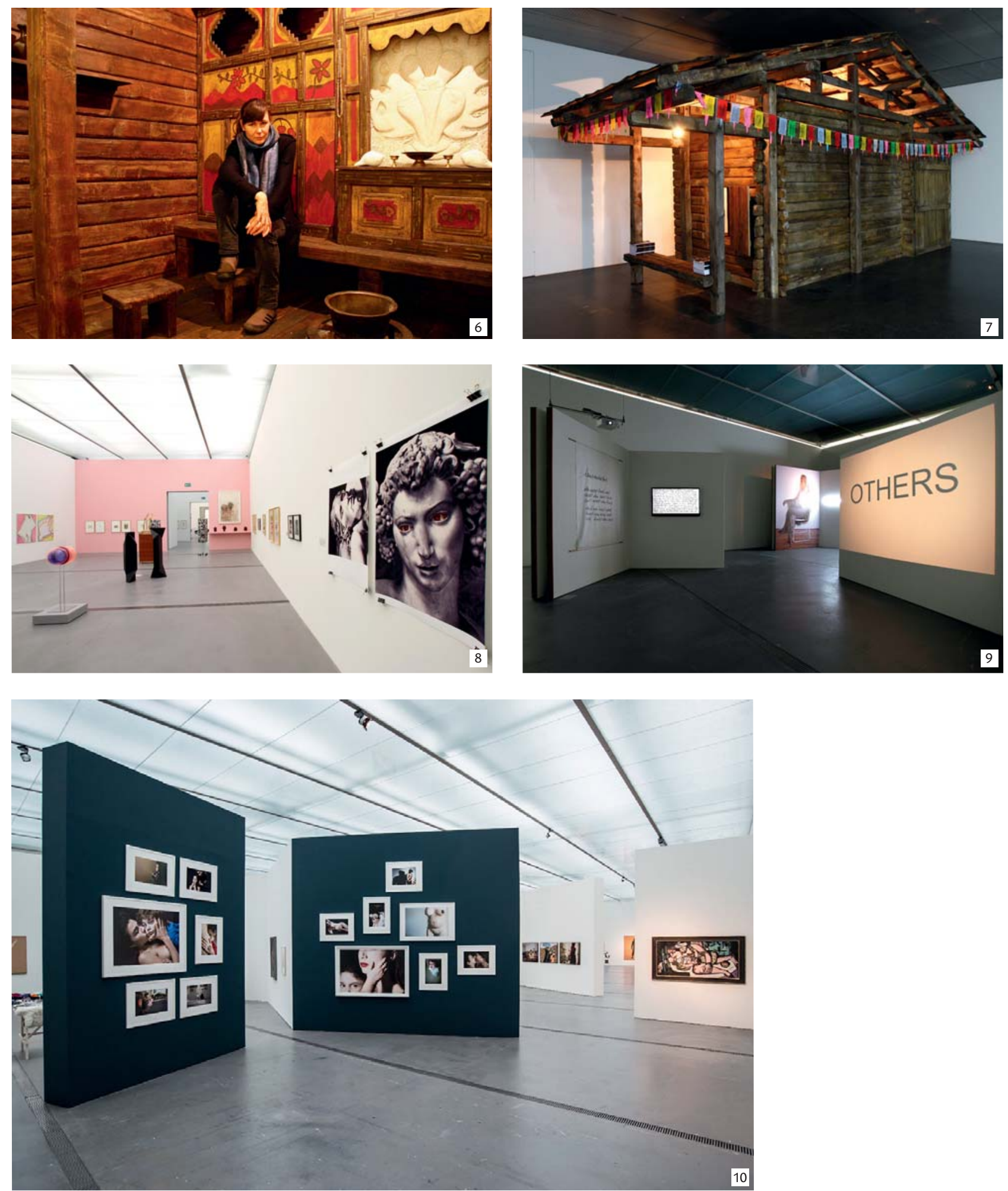

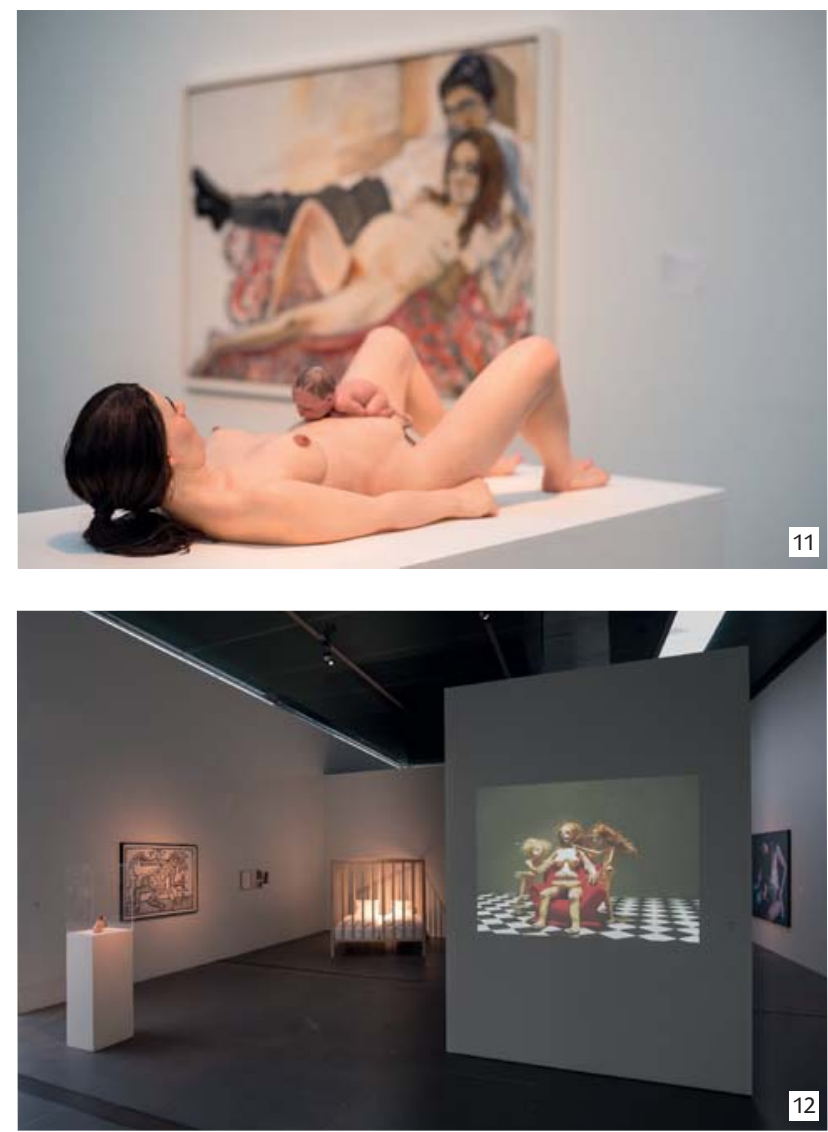

SR: There are problems. One of them is that, in my understanding, feminism and representation are opposed to one another. I am not really interested in providing a stage in the art museum, upon which the class, educational, and economic differences of a hierarchical understanding of society are celebrated, and where a so-called elite affirms itself. I am not interested in promoting that for the museum, nor for myself personally. And that is not easy, because I am not the director of an off-space or a project group; LENTOS is a large institution. It was built as a flagship for the city of Linz and arouses very specific expectations of glamour, representation, and affirmation. The rulebook of representation is anti-feminist. For me, feminism means using a minoritarian standpoint to be able to act more freely.

JS: Something I wonder about again and again is whether there can even be an institution that operates in a feminist way. Can there be a museum with a feminist agenda that is not the Elizabeth A. Sackler Center for Feminist Art, also not an off-space, but rather a museum, such as LENTOS, for example?

SR: I wonder about that, too-and tend to think that institutional action and feminist thinking have to be in friction and learn from one another in an ongoing process, but that a reconciliation will not take place until some point in eternity. The bad news is: there is no feminist institution. And the good news: but there are feminists in the institutions.

The conversation was conducted in January 2016. Translation: Aileen Derieg

\section{Captions}

1 <hers> Video as a Female Terrain, Steirischer Herbst, Graz, 2000. Photograph: private.

2, 3 Paula's Home, LENTOS, 2004. Photo: 4 VALIE EXPORT, Time and Countertime, LENTOS, 2010. Photo: LENTOS/MaschekS

5 Gil er Moti, Totally Devoted To You, LENTOS, 2012. Photo: LENTOS/MaschekS

6, 7 Mathilde ter Heijne, Any Day Now, LENTOS, 2011. Photo: LENTOS/MaschekS

8 EVA \& ADELE, Their room in the collection, LENTOS, 2013. Photo: LENTOS/MaschekS

9 Anetta Mona Chisa er Lucia Tkácová, Their room in the collection, LENTOS, 2013. Photo: LENTOS/ MaschekS

10, 11, 12 Rabenmütter / Mother of the Year, LENTOS, 2015. Photo: LENTOS/Reinhard Haider

Stella Rollig has been the director of LENTOS Kunstmuseum Linz since 2004, and since 2011 of NORDICO Stadtmuseum as well. She studied German literature and art history at the University of Vienna. She is a writer and curator who has taken teaching assignments in Graz, Linz, Munich and Banff/Canada. As Federal Curator for Visual Arts, in 1994 she founded Depot. Art and Discussion in Vienna. She is the author of numerous publications. She lives in Linz and in Vienna.

Juliane Saupe is a cultural producer, cultural scientist, and writer. In 2016, she will complete the Master's program Critical Studies at the Academy of Fine Arts Vienna. She is a co-founder of Open Studio Days Istanbul, and co-curator of Prosperous Poison. On the Feminist Appropriation of the Austrian Unconscious (2015/16) at mumok, Vienna, as well as co-editor of the accompanying publication (2016). 


\section{It's Time for Action! Heike Munder}

\section{Insouciant Monster Women}

It's Time for Action (There's No Option) was the title Yoko Ono gave a pop song she recorded in 2000, in which she called everyone to action: Every day - any way. The song reflects her life's motto: not to remain in the present or the past, but to look forward. Ono became famous as an artist, musician, and then as the wife of John Lennon, and in all roles she flouted socially constructed role models of the 1960s and 1970s. She has never spoken explicitly about the role of women or equal opportunities, but instead lives out hert notion of feminine identity with every breath of her body. She has approached the theme directly in many of her works. Her most famous work, Cut Piece (1965), was a performance in which visitors, bit by bit, cut pieces of her clothing away with a pair of scissors, right down to the bra. It was a voyeuristic act-afflicted by the gaze on her body and her facial expressionwhich focused in an exemplary manner on the object-emphasized nature of woman, proceeding to the very limits of pain. Her 1969 film Rape is a similar work, shot in collaboration with John Lennon. Here, the camera follows a young woman who at first flirts with the camera, but shortly after becomes irritated and maddened, and finally crumbles into hysterical panic, reduced to a threatened animal in the corner. In her private as well as her public life, Ono does not care one jot for the conventions and expectations that surround her being a woman, married or otherwise. She intervenes in all kinds of situations, whether political or artistic. She is a solo warrior of the view that speaking in public about her position as a woman implies admitting woman's inferiority in the system. To ignore it and simply take her rights for granted makes far greater sense to her. But even today transgressions of existing codes of social behaviour are punished by isolation and sometimes ostracism, in her case evidenced most famously by the fact that she has been demonized by so many for the breakup of the Beatles.

A younger generation of female musicians have marvelled at Ono, admiring her behaviour and her hoarse screams in her early improvised music pieces, and regarding her as one of their most inspiring role models. This generation draws on the energy of punk rock music and the idea of the body as an object with which to attract attention. As Pil $\Theta$ Galia Kollectiv, friends and collaborators of Chicks on Speed, commented in their booklet for the Girl Monster-CD (2006): "The girl monster is hysterical, neurotic, satanic and hers is the kind of hysteria that cannot be maintained and suppressed with consumerism or idol-worship." ${ }^{\prime 1}$ This self-description works with the negative attributes of classical female psychology-hysterical, neurotic, satanic-and uses the terms as a surprise attack. They hope both to slip away from authoritarian analysis by turning it around and thus demanding from the audience and listeners ambivalent ways of reading, and above all to attract great attention to their shows and gestures. Through the reference to the monstrous (Girl Monster), the Pil $\Theta$ Galia Kollectiv channel and enthral the gaze of the public, at the same time drawing on Donna Haraway's famous treatise Cyborg Manifesto as an attempt to circumvent the attribution of the binary comparison with the masculine. ${ }^{2}$ These girls know the power of the gaze their transgressions can trigger during their shows. They link the fun had in that provocation to the admission that in our society some things change only slowly, yet do so continuously. The dynamic in the group lightens the process for them. As early as the beginning of the 1990s, young 


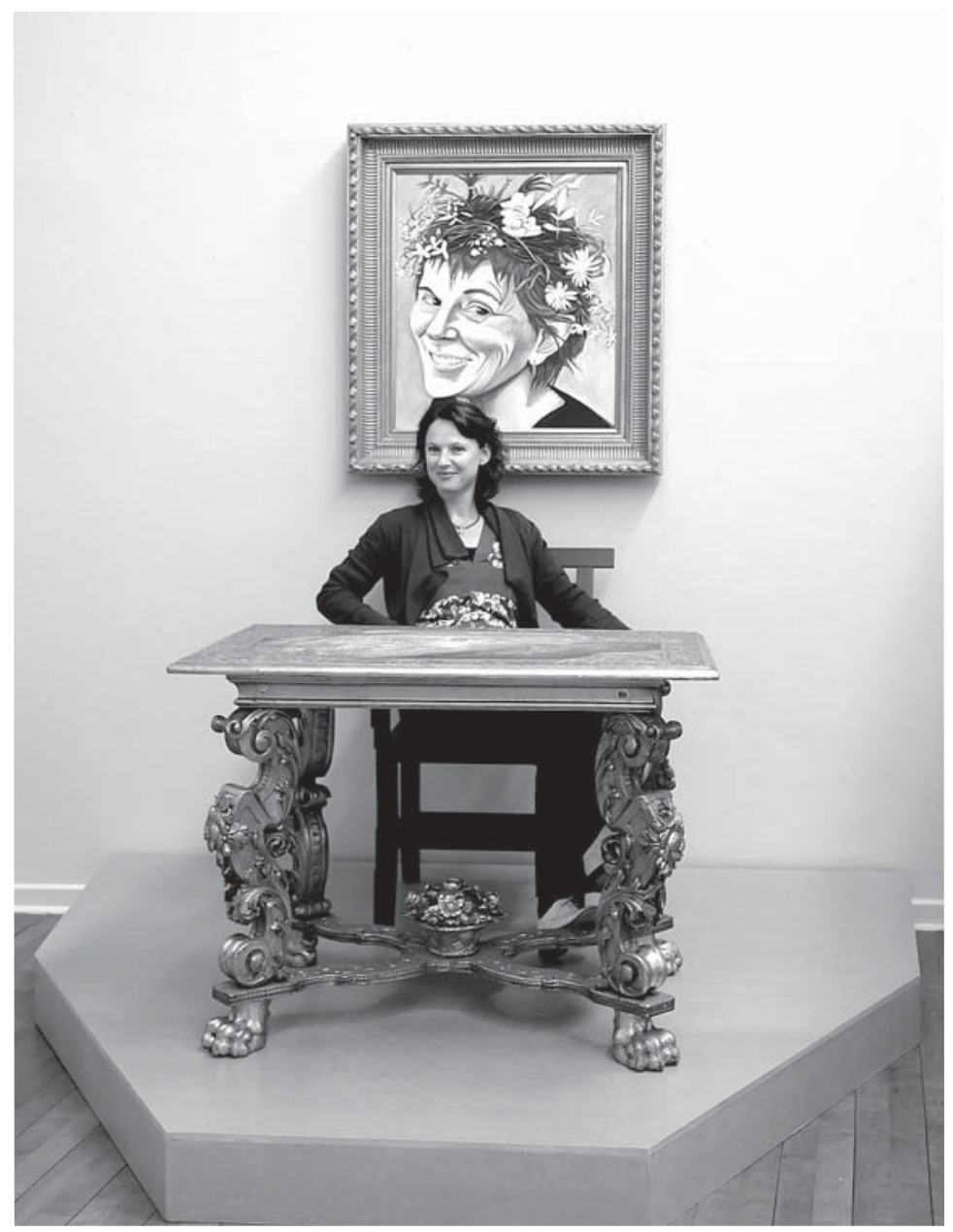

women from all countries involved in the punk and hardcore scene organized the Riot-Girrrl movement in a grassroots style, as a reaction against the lack of representation of female musicians, and to give a platform to their rage about such circumstances. Among them were groups like Bikini Kill, Sleater Kinney, and Le Tigre. Le Tigre, Chicks on Speed, and Peaches take great care to attempt a correcting of music history by performing cover songs, by sometimes almost forgotten female protagonists, in an effort to bring them back to the public consciousness and reintroduce continuity. ${ }^{3}$

In the visual arts the strategies of continuity are similar, and in this case it is frequently not just the quote, but also the (female) originator who surfaces and is discussed and forms an intertwining of generations. This is one of the approaches used in It's Time for Action. It encompasses female artists of the first, second, and third waves of feminism. Various atmospheres, generations, and themes are consolidated: generating a head of steam through the voyeurism the works trigger-always on the trail of the enforced ego, the Girl Monster in us, born of the self-conception of each of their generations, a lust for life, the use of art as symbolic representation, and the conviction that in an active movement everything can be possible.

\section{Role Models}

One concern of mine is re-examining the theme of feminism, which appeared to have been discussed enough at the end of the 1990s and early 2000s, and for a brief period drew increased attention to it. We are talking about feminism. In the late 1990s when the active period of girlism had come to its end, femi-
Portraits Behind the Desk Performative Portraits, 2005/06 Courtesy of the artist Photography by Johanna Rylander/ Malmö Konstmuseum 
nism was more than just old hat; it no longer appeared attractive to a younger generation of women, or it served only as an identification model. Aside from which many believed they could rest upon the successes of the first and second generation. From a superficial point of view, the situation of women in the middle of this decade could be said to be in really good shape, with women occupying key political positions, and women in the artistic field surfacing increasingly frequently in art's rankings. But precisely at this point, when as bosses or leading figures women should have a role-model function, looking more closely one realizes that those very female success stories distinctly lack female role models of their own. And all that in the face of the many role models that cultural history has to offer: Gertrude Stein, VALIE EXPORT, Aretha Franklin, Kara Walker, Yayoi Kusama, Agatha Christie, Cleopatra, Marie Curie, Bette Davis, Patty Smith, Debby Harry, Kim Gordon, Indira Gandhi, Greta Garbo, Mae West, Rosalind Krauss, Judith Butler, Andrea Fraser, Anaïs Nin, Yoko Ono, Alice Neel, Joan of Arc, Marlene Dietrich, Eleanor Roosevelt, Susan Sontag, Virginia Woolf, Peggy Guggenheim, Frida Kahlo, Martina Navratilova, Kate Moss, Björk, Martha Rosler, Pipilotti Rist, Christa Wolf, Amelia Jones, Catherine David, Missy Elliot, Grace Jones, Annie Lenox, Courtney Love, etc. The list goes on and on. But we marvel at these women far more for their aura and their cultural achievements than for their actual lives as examples to be followed.

A method of covering one's back-quite literally-is to have a choice of suitable role models that can be referred to in the form of a photograph on the wall behind one's desk. This was the idea of American artist Mary Beth Edelson (born 1933), when she became aware of the fact that the media presentation of women in professional fields usually took place without the support of such a role model image. On the other hand, in the male workplace, a portrait of a famous man was usually to be found mounted proudly on the wall behind the boss's desk-with the effect that the power of the role model is incorporated into his identity, often augmenting or even doubling the sense of his own individual authority. Female portraits are rarely to be found, and if they are they are family portraits that demonstrate class and prestige. Unless one counts the pin-up illustrations adorning many workplaces during World War II, illustrations of women as figures of authority in public life are more the exception than the rule. As a result of this observation, in 2005 Mary Beth Edelson asked women to name one hundred female role models that could be hung representatively behind the work desk. Here are a few examples of their choices to give an impression: Marina Abramovi D, Mata Amritanandamayi Devi (Amma), Hannah Arendt, Emily Brontë, Maria Callas, Colette, Angela Davis, Pat Hearn, Rosa Luxemburg, Iris Murdoch, J. K. Rowling, Alice Schwarzer, Katharina Sieverding, and Valerie Solanas. Edelson portrayed the named models by following a dogma of her own, through which she attached and undermined the classical rules of painting. ${ }^{4}$ The completed portraits were exhibited under the title Portraits Behind the Desk Series (2005/6) as an ancestral gallery in the Malmö Konstmuseum. On the opening night, guests were photographed with a role model behind a mighty desk, and a print was sent to each of those who had been portrayed.

To gain attention for women and to secure them a place in history was also a concern of artist Mathilde ter Heijne (*1969), when she researched her work Women to Go (2006). She looked for biographies of women who, in spite of immeasurable contributions to history, have not found an adequate place within it. As a result, her work deals with constructed role models. The title can be understood quite literally: the visitor had a choice of over 300 different postcard motifs displayed on postcard stands, and could take them home. The front side of the post- 
card showed portrait photographs of anonymous women who had lived or had been born between 1800 and 1900. On the reverse side, short biographies were provided, of women whose lives during those times can be described as extraordinary, but hardly any of whose biographies are widely known. Image and biography do not concur, yet the postcards still generate identification and admiration. The cards were collected with great enthusiasm by the visitors.

\section{Sexual Self-Empowerment}

The liberalization of sexuality and the liberation from social rules were the foundational pillars for many women as well as men in the 1970s. They wanted to live out their desire, and no longer permit their desires to be taboos or simply concealed, as they had been in the extremely prudish post-War period. In Switzerland, the artist Manon played a significant role. She displayed her most intimate desires to the public, and the moralistic discourse of the period castigated her as a "fallen angel". Her most important work and first art action was the Das lachsfarbene Boudoir, created in 1974. The boudoir is a replica of Manon's bedroom (from the original period), a site full of fetishes with an erotically charged atmosphere. The work was a provocation much intensified by dubbing the room a "boudoir": in historical terms the boudoir is an embodiment of female architecture, and as a private retreat serves as a pendant to the gentleman's chamber. The boudoir, which by the beginning of the 20th century gradually disappeared, is a room in which the feminine is embodied and idealized, disclosing a panopticon of feminine topography. Manon's cabinet-like, luxuriously lined, and erotically charged room was full of distressed salmon pink silk satin, champagne bottles, dirty washing, horns, seashells, mirrors, lipstick, as well as personal letters and photographs of her companions of that time such as Urs Lüthi or Jürgen Klauke. Sensual delights were placed provocatively in the foreground.

Sometimes, strategies are difficult to reconstruct in retrospect, for certain realizations and accomplishments are nowadays taken for granted, which in that period were yet to be fully asserted and required a definitive carrying through. One such example is the active work in the (soft) porn industry of the 1980s, such as that carried out by Cosey Fanni Tutti and others. Cosey Fanni Tutti's work was an attempt to devise her own sexuality actively, not only privately, but also to live it out precisely where the purest masculine voyeurism is encountered, and furthermore to maintain it. A precursor of this was the American artist and "whore" Annie Sprinkle (*1954), renowned for her performance Public Cervix Announcement (19901995), in which the public were invited to observe her cervix with a speculum and electric torch in order to "demystify the feminine body." Her infectiously good humour made it possible for Sprinkle to turn society's greatest sexual taboo on its head, an achievement for which she is revered by many. Moreover she was extremely politically active, campaigning for the rights of sex workers and their medical care. Sprinkle was one of the major protagonists of the "sex positive" movement of 1980 s feminism.

Cosey Fanni Tutti (*1951), who is known more as a musician than an artist, counts amongst the idols of recent music history. Her work in the industrial noise band Throbbing Gristle (TG) and her performance group Coum in the 1970s has led to her being named by the Girl Monsters as a representative of the monstrously feminine. Cosey Fanni Tutti shocked the art scene in England with the appearances of her performance group Coum, in which openly acted out sexuality, which sometimes went as far as anal intercourse, was a regular occurrence on stage. The actions were spontaneous, but provocations were very well designed, reaching their climax in the legendary and scandal-inciting exhibition at the London ICA in 1976. 
Here Cosey Fanni Tutti presented a show that interwove her various occupations as photo model for men's adult magazines and professional striptease artist with art and music. The artist harvested a great deal of rejection-most significantly for her unbowed reinterpretation of her pornographic activities into art, but also from the many feminists who were prejudiced against the sex industry per se.

\section{Body Shells}

Here, we return to role models and remain concerned with the illustration of the body. It is significant that works in the feminist field continually return to the illustration of the body, in spite of all the attempts to negate it that took place in the riotous 1970s and 1980s. For the body is, as the British social anthropologist Mary Douglas described, the venue and symbol of society. Through bodily behaviour and the acting out of rituals, rules and limits, social rules and hierarchies within society are clarified. ${ }^{6}$

Furthermore, the banishing of the body was also a banishing of individual sexuality, and desire emanating from the love of life. At the end of the 1980s the provocative author Camilla Paglia, despised by many feminists, shocked readers with her biological comparisons and uninhibited marvelling at male flesh, a desire she supported with de Sade. According to Paglia: "Feminism has, due to its actual task of striving for political equality, exceeded it and has got off course in the denial of the contingency of life." ${ }^{17}$ She brought her opponents to incandescent rage with her sentence, "Leaving sex to the feminists is like letting your dog vacation at the taxidermist. ${ }^{8}$ Quoting Paglia provided a satirical barb against the dogmatism of some feminists; in the 1990s their strict codex was broken by a young light-hearted generation.

It was the age of girlism, a loose network of young women, who entered the arena charged with humour and spawned a line of unheeding women-for example Pipilotti Rist, Chicks on Speed, or Patty Chang. They defied the victim role of the constructed view and won their audiences over with an infectious delight in the world. The strategy-also a subversive act-was successful, and an entire generation followed along.

One of their major protagonists is Pipilotti Rist, who has established herself with video works such as Pickelporno (1992) or Ever is over all (1997). Here the female beholder is inspired by watching a young woman in a swaying dress nonchalantly smashing the windows of parked cars with a metal pipe, an act usually carried out at night by riotous gangs of male youths, and certainly not by a single woman in the broad light of day. It is obvious that this generation of women, the girlists, have taken an important step toward liberation and self-empowerment, with a resounding assertiveness that has never existed before. Pipilotti Rist displays this dilemma precisely in one of her older video works, (Entlastungen) Pipilottis Fehler ((Absolutions) Pipilotti's Mistakes)) (1988). Here, Rist treats the eternal struggle for an unreachable inner and outer perfection, and the attempt to escape this torturous non-attaining and the guilt feeling resulting from one's own inadequacy-inflicted through the societal power structures of the normative, the legislative body, and its enforcement. Three scenarios present this attempt at flight and the hopelessness of its striving. Thus the female figure attempts, in vain, to overcome obstacles-for instance something fence-like-or in a swimming pool tries to fight against her hand being forced under the water and escape the situation by passing out, a reaction that links her to the psychoanalytically bound conception of hysteria as the physical transformation of an unsatisfied female psyche. In Rist's work the acceptance of this struggle as well as her own defect/mistake are earmarked as possible solutions. 
A further option is the exaggerated attribution of vulnerability and active exhibition of the body exemplified by female artists such as VALIE EXPORT with her Tapp- und Tast-Kino (1968) or Hannah Wilke in her S.O.S. Starification Object Series (1975) of the 1970s. Accordingly, the artist Patty Chang ( $\left.{ }^{*} 1972\right)$ was aware that the body, in spite of all the theoretical attempts of the 1980s and early 1990s to deny it, is inescapable-too many questions vital for survival are acted out upon it. Chang became renowned for her solo performances, in which the psychological inner and the physical exterior of the body take centre stage. The spectator oscillates between nausea and voyeurism. In her 1998 video work Melons (At a Loss), Chang, dressed in a tight bodice, looks straight ahead into the camera and tells of her aunt who has died of breast cancer. Using a knife she cuts through the cup of a bra. Instead of a mutilated breast, a half melon becomes visible as a metaphor. Chang takes it out with a great deal of noise and proceeds, with a spoon, to rake out the flesh and eat it, continuing to speak with great exertion. The treatment itself is grotesque and is a direct reference to the black humour of the Girl Monster musicians.

\section{Self-Conception}

The world is certainly still shaped by heterosexual constructions of male norms, which can only be ignored or broken with great difficulty. In his book Male Domination, the French sociologist Pierre Bourdieu wrote that the power maintenance of the patriarchy belongs to the "paradoxical submission" of women. ${ }^{9}$ This presupposes woman's anticipatory submissiveness and implicit knowledge of structures of order. As a result of this a taken-for-granted grand entrance of women in public life is broadly absent, and is evidently not always valued positively-as already seen in case of Yoko Ono and many others.

In fiction, on the other hand, such an entrance has long since taken place. In her book Pin-up Grrrls (2006), Maria Buszek dedicated her work amongst others to the pin-up illustrator Alberto Vargas, who is regarded as having gallantly succeeded in combining self-assuredness with sex appeal. His perfect combination of feminine and masculine ideals was admired by men and women, both hetero and homosexual, and copied in equal measure by both. Originally, the Vargas girl rose to fame in the American magazine Esquire during the 1930s and 1940s, among other things keeping American soldiers' spirits up during World War II. But the Vargas girl was not esteemed only by men, for she possessed enviable qualities: she was not passive, but highly self-aware, extremely self-secure, and enormously sexy. Unfortunately, after World War II women again experienced a setback, and the newly gained self-image was only sustained for a brief period. However, the Vargas girl was to keep her female admirers over the following decades. It survived also those of Laura Mulvey as masculine-coded "gaze" and essentialist spurned interpretations. Female artists like Annie Sprinkle or Manon, and also Mary Beth Edelson or Patty Chang, take these images on. Sprinkle uses them in order to expose her physical qualities in Anatomy of a Pin-up (1984-2006), and Mary Beth Edelson to demonstrate her admiration for film divas of history and to create portraits from them of what they would have really liked to have been, but could not be.

Like Ono, artist Katharina Sieverding (*1944) perfectly controls the self-confident entrance in her life and in her work. She is renowned for her large-scale photography, as well as for works rooted in the fields of body art, performance, and experimental film. As early as the 1970s, Sieverding used photography as a major medium and took it on accordingly-contrary to the view of many artists of the period for whom it was only a means of documenting their actions and performances. Usually a self-reflexive gaze at her own physiognomy forms the centre 
point. Sieverding's works are situated at the cutting edge between society and the individual, and react shrewdly to dominant societal conditions. Implementing provocative images such as Deutschland wird deutscher (German will become more German), in which she responded to the extreme right-wing reaction after the fall of the Iron Curtain, she has generated public and political scandal. The work Transformer (1973) shows a likeness of the artist in double exposure, which she over-laid with that of her partner, Klaus Mettig, creating a fictive androgynous face which, by means of various forms of lighting, different poses, and contrasts, changes continually. With every minimal change she exhibits a new expression. The face appears akin to a sphinx-like spectral mask or androgynous indefinite held in an unswerving transformation of changing identities. Sieverding is aware that art is not a real holding place for politics; nevertheless it is an important symbolic representative that she uses for her messages.

Stagings are of great importance and provide the opportunity to reveal and recognize contradictions and ambivalences. The images that are created can likewise be hedonistically consumed, like utopian stimuli, and increase the potential for exercising influence on the current stagings of gender. This can culminate in stage entrances of infectious energy. ${ }^{10}$ In Anat Ben David's performances, the Israeli artist is aware of precisely this potential when she covers and censors the intimate areas of her body with gaffer tape, takes the stage, and begins the show in a white dandy suit. Her pieces are fed by punk elements, combined with Dada poses and graphics, which she introduces with her videos. Together with Chicks on Speed they bear a message to the world, which appeals for self-confident role models, and their fragmentation is formulated as the message:

We are many

We are prepared

We are linked

We have a program

We have methods

We are female pressure

We share political thinking

We are avant-garde

We are a social mobile

We are critics

We are shoe maniacs

We have a message

(Chicks on Speed)

Differing strategies lead on; the world needs more Girl Monsters!

Translation from German by James Rumball.

A version of this essay was first published in Heike Munder, ed., It's Time for Action (There's No Option). About Feminism, JRP|Ringier, Zurich, 2007, pp. 167-189.

\section{Notes}

1 Pil and Galia Kollectiv, "Girl Monster vs. Fembot", liner notes for Chicks on Speed present Girl Monster (a compilation featuring 60 women from punk and modern music on Chicks on Speed Records), Berlin: Chicks on Speed Records, 2006. 
2 See Donna Haraway, "A Cyborg Manifesto: Science, Technology, and Socialist-Feminism in the Late Twentieth Century," in Simians, Cyborgs and Women: The Reinvention of Nature, Routledge, New York, 1991, pp. 149-181.

3 See Christiane Erharter and Elke Zobl, "Mehr als die Summe der einzelnen Teile. Über Feministische Fanzines, Musiknetzwerke und Ladyfeste", in Female Consequences. Feminismus, Antirassismus, Popmusik, ed. Rosa Reitsamer and Rupert Weinzierl, Löcker, Vienna, 2006, pp. 17-30.

4 See http://www.dogme95.dk/the-vow-of-chastity/. Accessed March 2016.

5 See http://www.anniesprinkle.org/html/writings/pca.html. Accessed March 2016.

6 Mary Douglas, Purity and Danger. An Analysis of the Concepts of Pollution and Taboo, Routledge, London/Boston, 1966. Quoted from Janet Wolff, "Reinstating Corporeality: Feminism and Body Politics", in The Feminism and Visual Culture Reader, ed. Amelia Jones, Routledge, London/New York, 2003, pp. 414-426.

7 Camille Paglia, Sexualität und Gewalt oder: Natur und Kunst, DTV Deutscher Taschenbuch, Munich, 1996, p. 9 (trans. by James Rumball).

8 Ibid. (trans. by James Rumball).

9 Pierre Bourdieu, Masculine Domination, trans. by Richard Nice, Stanford University Press, Stanford, CA, 2001.

10 See Stephanie Kiessling and Nina Stastny, "Let's get physical. Körperinszenierungen zwischen Pop $\circlearrowright$ Rock", in Female Consequences. Feminismus, Antirassismus, Popmusik, Rosa Reitsamer and Rupert Weinzierl, eds., Löcker, Vienna, 2006, p. $41 \mathrm{f}$.

Heike Munder studied cultural studies at the Leuphana University of Lüneburg. She has been the director of the Migros Museum für Gegenwartskunst in Zurich since 2001. She co-founded the Halle für Kunst Lüneburg e.V., which she co-directed between 1995 and 2001. Previously curated exhibitions include Resistance Performed (2015), Dorothy lannone (2014), Geoffrey Farmer (2013), Ragnar Kjartansson (2012), Tatiana Trouvé (2009), Tadeusz Kantor (2008), Rachel Harrison (2007), It's Time for Action There's No Option (2006), Marc Camille Chaimowicz (2006), Yoko Ono (2005), and Mark Leckey (2003). She teaches regularly, including at the Leuphana University of Lüneburg, Goldsmiths College (London), the University of Bern, the Zurich University of the Arts, and the Jan van Eyck Academy (Maastricht). Since 1995, she has written extensively on art in catalogues and art magazines. In 2012, she was on the jury of the Turner Prize. 


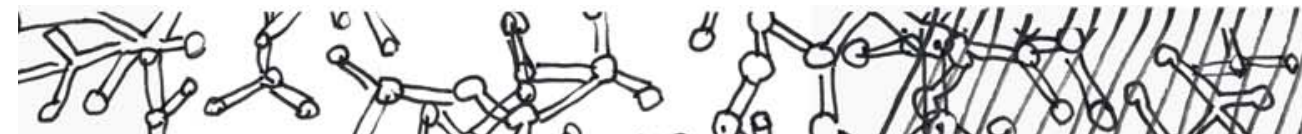
o.

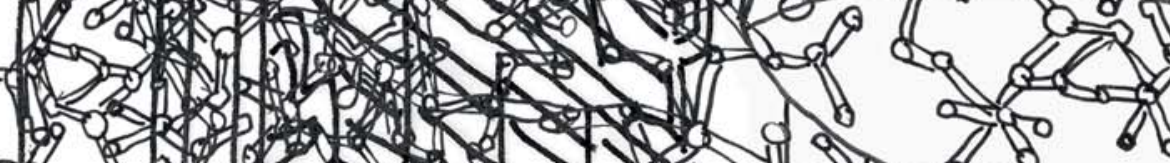

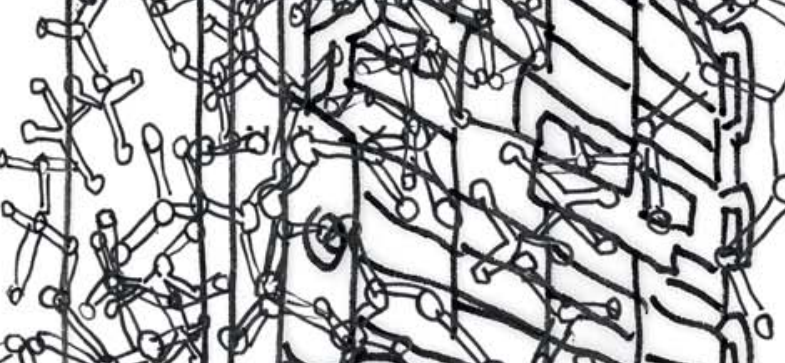
gol a $\leftarrow$ o d a

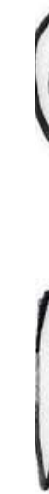
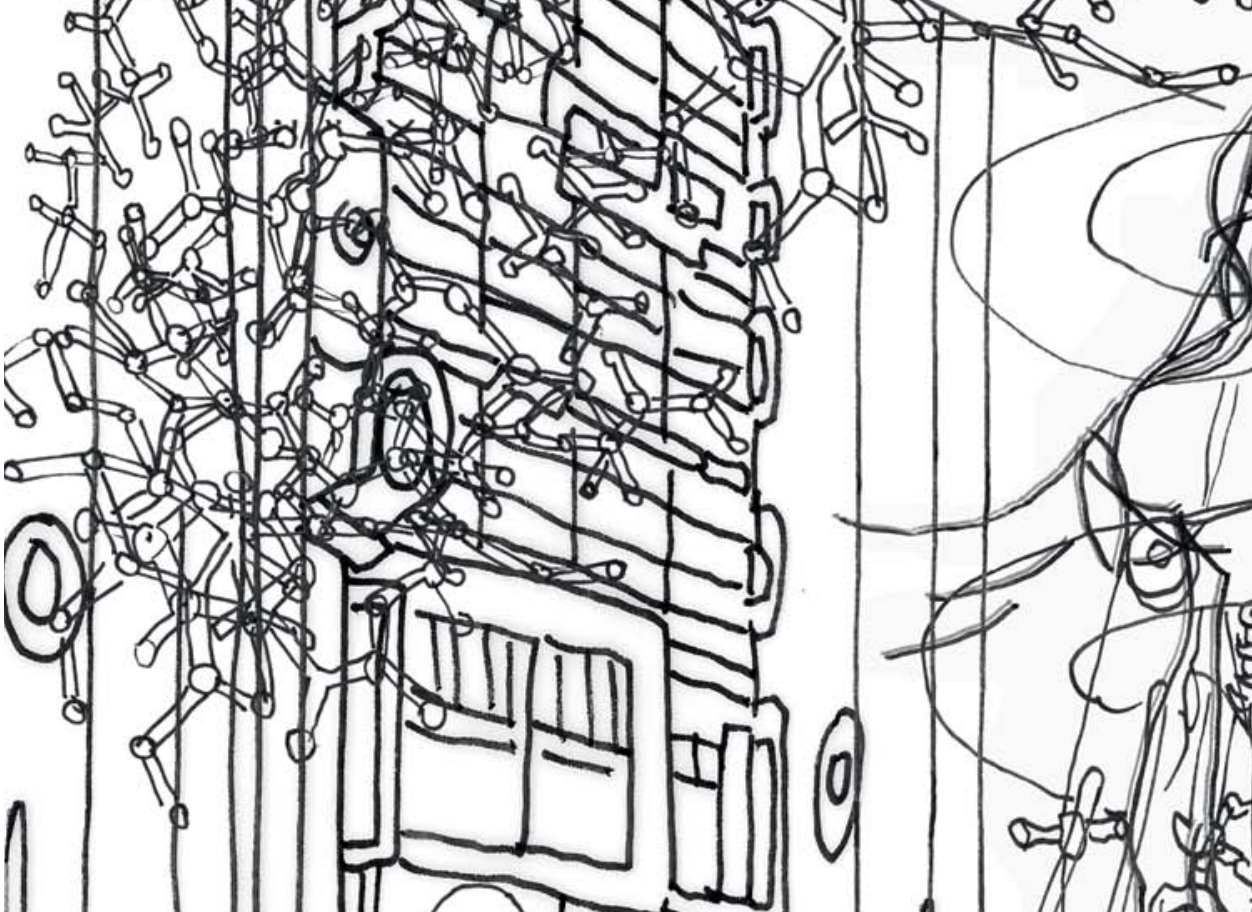
(1) 


\section{Public Service Announcement: On the Viewer's Role in Curatorial Production Lara Perry}

As many have observed, recent decades have seen the transformation of the role of the curator from someone who is primarily concerned with building knowledge about and preserving a collection, to someone whose primary responsibility is for interpretation and public engagement. The rationale for this development is ostensibly the privileging of democratized access to public collections, but can also be accounted for as a function of neoliberalization, in which 'public service' is conceived as services provided to individual beneficiaries rather than for a collective public good'. The 'curatorial turn' of the last twenty years can be understood as a reconfiguration of the labour of the curator from the work of preservation to the work of presentation. This work has a gendered dynamic which has been increasingly explored by feminist critics of the curatorial function; but it also has a reciprocal relationship with another form of labour which has received less attention in the curatorial literature, the work of consumption performed by the audience that the curator addresses. This work also has a gendered dimension that may illuminate the transformations at play in the making of art exhibitions.

In Helena Reckitt's 2013 essay "Forgotten Relations: Feminist Artists and Relational Aesthetics" and in other essays in this volume, this transformation of the labour of the curator is considered in relation to gender and especially the question of care labour ${ }^{2}$. The labour of care, which is sometimes referred to as the labour of "social reproduction", is the primary form of adding value through labour in a post-Fordist economy, although traditionally an unwaged form of labour allocated to women ${ }^{3}$. Rather than fulfilling the author (or auteur) function normally accorded to the (male) exhibition curator, the curator in the new service-based economy is understood to be tasked with performing the social labour that is required to mediate the artist and her artworks for the exhibition's audience. This labour is partly necessary because of the context of the growing pressures on art institutions to demonstrate their value to individual users. Concomitantly (and perhaps not accidentally), the audience is increasingly involved in the realisation of the artwork itself, in an era when contemporary art is commonly constituted directly through immaterial and social exchanges.

The nature of these engagements between the art institution (within which the curator works) and its audiences can be thought of as two complementary or even integrated forms of labour. Normally understood as the necessary binary function to production, consumption is a highly gendered form of labour that has been structured through capitalism to correspond with new forms of production: for example, the invention of department stores to distribute mass-produced ready-to-wear clothing in the nineteenth century, which displaced the production of bespoke garments in the home or by individual makers ${ }^{4}$. Consumption in the form of shopping for ready-made goods is the form that domestic labour increas- 
ingly takes in industrialized economies. As home food-raising, home cooking, and sewing are replaced by the use of ready-made clothing and ingredients, or indeed whole meals, the purchase of commodity forms replaces the production of goods in the household. A historical continuity between these quite different functions has been created by ensuring that both are typically gendered female. Whether the provision of everyday needs takes the form of the production or the acquisition of domestically consumed items (in Britain at least, and I believe in other industrializing economies also), the labour involved continues to be scripted as part of women's household labour, even when it primarily-and contradictorily-takes place in the 'public' sphere of urban commerce.

There is an analogous relationship between consuming art in exhibitions and consuming household goods that should not be ignored, especially when we consider the nature of the labour involved. The processes of viewing, judging, selecting according to practicality and 'taste' are equally at play in the visiting of an art museum as they are in a trip to the supermarket or department store. The importance of the museum collection as a mechanism to educate consumers in the characteristics of good design was a recognized function of both the Victoria and Albert Museum in London and the Museum of Modern Art in New York (which is also a museum of design, as visitors to the shop understand). This manifests itself both in the collections, which include objects for domestic use, but also in the character of the displays. As Julia Noordegraaf, Charlotte Klonk, and others have written, there is an observable traffic between the design of museum displays and that of retail spaces 5 . As I have written elsewhere, the strategy of associating Tate Modern with routine and familiar leisure consumption by imitating retail forms of branding was deliberate. The frequent co-location of art museums and galleries with commercial districts and vice versa, affirms the relationship between the production and exhibition of art and its commodity status. For example, the Burlington House / Burlington Arcade / Bond Street axis, which associated the Royal Academy in London with luxury retail from its removal there in 1838 , sustained the evolution of nearby Bond Street as a luxury trading district incorporating art auction houses and independent galleries through the nineteenth century and into the present.

That shopping for consumer goods and visiting art exhibitions are both popularly constructed as forms of leisure rather than forms of labour should be considered in relation to their feminization. Read through Sylvia Federici's argument, one could say that these are forms of labour that have been exempted from the wage economy, in order that the capital that accrues from them can be more easily appropriated from the labourers. But should we consider the purchase of oranges and the contemplation of a Whistler exhibition equally as forms of value production? David Graeber has suggested that the widespread use of the terminology of consumption-suggesting a metaphor for eating or a literal appropriation-to describe a range of cultural activities which extend far beyond the use of materials is itself an effect of capitalism, which demands that social relations be always reimagined as property relations. The constant recourse to 'consumption' as an analytical term indicates the extent to which every form of human activity has been subjected to the language of commodification, even when it is not part of a system of profit-bearing production, or may even resist such processes ${ }^{6}$. His preferred perspective is to consider 'social life' as having the purpose of the 'mutual creation of human beings', which is a position which most of us would share, although he leaves untouched the question of the historic and enduring gender inequalities of that work. 
It may be that viewing art in an exhibition format is an excellent example of an activity that is neither production nor consumption (Graeber's example is a baseball game). One could argue that the process of putting art in an exhibition/ museum context is to withdraw it from the world of commerce, and to protect it (through rules about touching and taking) from any literal material use that Graeber suggests is entailed in processes of consumption properly observed. But the exhibition/collection is also, of course, a kind of advertising for artists and their dealers, and read through a more complex account of the production of commodity value, the exhibition may not be so removed from its processes. Pierre Bourdieu's account of the formation of cultural capital and other accounts of the world's 'hidden curriculum' would tend to confirm that visiting exhibitions and commanding the vocabularies that art introduces can be converted into a form of capital' ${ }^{7}$. Institutions, artists and curators can be complicit in fostering these different forms of capital value even as they deny them, challenge them or refute them ${ }^{8}$. The work entailed in the 'mutual creation of human beings' or the labour of 'social reproduction' is more complex and extensive than the provision of consumable food and clothing, even if capitalism might wish that work into a profit-generating mode of commodification.

That the work of intellectual, emotional, and social cultivation that takes place through the enjoyment of art should be designated as leisure, or consumption, or via a new category of immaterial or social labour, is a symptom of the extent to which such labour is always the negative partner in the binary systems of valuing labour or 'production'. Attempts to account for the political consequences of looking are equally subject to being expressed in an unstable gendered dynamic. At the same time that Laura Mulvey was formulating her pioneering account of the (male) gaze which objectifies the representation of the (female) subject ${ }^{9}$, the Italian art critic Carla Lonzi proposed the opposite formulation, that the viewing subject was typically gendered female to sustain the authority of male cultural production. Giovanna Zapperi explains Lonzi's position:

As Lonzi tried to explain her abandonment of art criticism, she insisted on her refusal to play the role of the artist's spectator, thereby introducing the problem of the artistic gaze. Contrary to the then (almost) contemporary theorizations in the Anglo-American context, for Lonzi the woman is not the object but the spectator of the artwork; it is she who passively observes and thus legitimizes male creativity through her exclusion ${ }^{10}$.

Lonzi's account of the viewer as gendered feminine against the masculine authority of the artwork, or the exhibition, or the museum, is consistent with interpretations of the museum like Carol Duncan's essay "The MoMA's Hot Mamas"11, which also positions the museum exhibition format as an assertion of (masculine-gendered) authority invested in the artwork; or in my account, of the (masculine-gendered) authority of the curator and the museum, which assume responsibility for conserving and interpreting the items in their care.

The relation between the curator and the artist is normally the binary within which the role of the curator is framed; the argument that I have been developing here is that the relationship between the curator and her audience is equally significant-although the nature of a feminist analysis of this relationship is, for me, not yet obvious. As the work of the curator devolves from a role of authority over the artwork to one of social mediation and affective labour, is this gendered dynamic between the exhibition and the audience also subject to transformation? If so, how can we theorize the nature of the relation between the (feminized) curator and the (feminized) audience for her work? Studies of visitors in museums tend to be for- 
mulated in quite empirical terms, although even empirical studies of the gender of visitors are hard to locate (though families are present in that literature). My concern is not that art might be increasingly appropriated as a practice through which women* might enter into dialogues with one another about their social labour, but that the whole endeavour might be consequently under- or de-valued through its location in the realm of the unprofitable. If it is the work of capitalism to reimagine social relations as property relations, then the feminization of the exhibition may be a symptom of the relegation of art and (some of) its enterprises to the margins of the globalised economy. How we can mutually reclaim and reassert the importance of these dialogues should be a central concern of the feminist curator.

*inclusively defined to include LGBT+ women

\section{Notes}

1 For the debate over the curatorial function, see James Cuno, ed., Whose Muse? Art Museums and the Public Trust, Princeton University Press, Princeton, 2004. Karsten Schubert's The Curator's Egg: The Evolution of the Museum Concept from the French Revolution to the Present Day (Ridinghouse, London, 2009) gives an account of the neoliberalization of national art collections.

2 Helena Reckitt's essay appears in Angela Dimitrakaki and Lara Perry, eds, Politics in a Glass Case: Feminism, Exhibition Cultures and Curatorial Transgressions, Liverpool University Press, Liverpool, 2013.

3 Associated with feminist critiques of Marxism, the thesis of 'social reproduction' as a form of overlooked production has informed various feminist historical and social analyses. Sylvia Federici's Caliban and The Witch (Autonomedia, New York, 2004), a synthetic account of women's 'social reproduction' labour in capitalism, is a recent and influential account.

4 See for example Philippe Peron, Fashion and the Bourgeoisie: A history of Clothing in the Nineteenth Century, Princeton University Press, Princeton, 1994.

5 Charlotte Klonk, Spaces of Experience: Art Gallery Interiors from 1800-2000, Yale University Press, New Haven, 2009; Julia Noordegraaf, Strategies of Display: Museum Presentation in Nineteenth- and Twentieth-Century Visual Culture, NAi Publishers, Rotterdam, 2004.

6 David Graeber, "Consumption," Current Anthropology, Vol. 52, No. 4, August 2011, pp. 489-511.

7 See Felicity Allen's introduction to her edited volume Education (Whitechapel, London; MIT Press, Cambridge, Mass., 2011, pp. 14-15.

8 There is a growing interest in examining the interface between the commercial market for art and the non-commercial aspects of art practice. For a critique of the current situation, see the final pages of Andrea Fraser, "L'1\%, C'est Moi," first published in Texte zur Kunst, 83, September 2011, pp. 114-27. http:// whitney.org/Exhibitions/2012Biennial/AndreaFraser, accessed 21 March 2016.

9 This, of course, is the position initiated by Laura Mulvey's groundbreaking essay "Visual Pleasure and Narrative Cinema", published in the journal Screen in 1975 and widely reproduced. It has been subject to wide-ranging criticism and supportive reformulations of her thesis-see, for example, Mandy Merck, ed., The Sexual Subject: A Screen Reader in Sexuality, Routledge, London, 1992.

10 Giovanna Zapperi, "Challenging Feminist Art History: Carla Lonzi's Divergent Paths," forthcoming in Vicky Horne and Lara Perry, eds, Feminism and Art History Now, Intellect, Bristol, 2016.

11 Carol Duncan, "The MoMA's Hot Mamas," Art Journal 48(2), Summer, 1989, pp. 171-178. 
Lara Perry is an art historian with specialist research expertise in portraiture, gender, and art museums. She was the leader of an international research network exploring feminist curating practices that ran a programme of symposia and seminars held in locations from Washington, D.C., to Tallinn between December 2010 and May 2012, and was funded by the Leverhulme Trust. She co-edited a book of essays on feminism and curating, Politics in a Glass Case-with Angela Dimitrakaki, a member of the research network. Lara leads the programme in the History of Art and Design at the University of Brighton. 


\section{Curatorial Materialism. A Feminist Perspective on Independent and Co-Dependent Curating Elke Krasny}

The late 1960s and early 1970s witnessed the emergence of a new type of work that was about to radically transform the art world and, maybe even more importantly, how art relates to the world. This transformation concerned the production, distribution, dissemination, study, and reception of art. This emergent way of working in a different way went beyond the then given narrow confines of the art world and was extended to social and political contexts. This work has been identified as independent curating.

With respect to the early history of independent curating, I want to raise the following two points here. Firstly, independent curating was crucial to transforming modern art into contemporary art. Secondly, many of the independent curators who were profoundly shaping this transformation were feminists, active as feminist artists, art historians, activists, thinkers, and public intellectuals. These two points taken together allow us to see, in historical hindsight, that the emergence of feminist curating was crucial to transforming modern art into contemporary art. With this historical knowledge in mind, we need to raise the question: what are the current transformations initiated by feminist and queer-feminist curating whose politics and practices we witness today telling us? Is the new type of work that feminist and queer feminist curating performs today, and which I conceive of to be co-dependent much rather than independent, crucial to an ongoing process of transformation from contemporary art into a not-yet-named art? The term independent points to the relation of a cultural practice, like curating, to political and economic struggles and thought, including feminism. Terms like modern and contemporary point to the relation between cultural practices, like art, and their histories as produced via their respective academic disciplines such as art history/art histories. The questions raised here concern the complex relations between practices, theories, and historiographies. They extend to political and economic struggles and thought and ask how theorization within and through practices such as curating moves forward? Equally, these questions raise concerns as to the epistemologies and narratives produced via academically disciplined knowledge production. And, what could a theoretical framework be that makes it possible to approach such questions in a critically nuanced way that is most sensitively alert to historical and present transformation emerging through practice, and in particular curatorial practice?

\section{Curatorial Materialism}

Let me suggest at this point that a curatorial materialism would allow for practicing theory in such a way as described above. A materialist approach ensures awareness for the material interactions and their inherent political and economic 
struggles. A curatorial approach takes into account relatedness to the world as a way of producing, including the production of new epistemologies and emergent histories. My suggestion of a curatorial materialism is owed to the concept of museum materialism introduced by Angela Dimitrakaki and Lara Perry. In 2013, Dimitrakaki and Perry called for the critical practice of a "museum materialism: a politically mindful, theoretically alert investigation of feminist confrontations with the complex actuality and conditions of art-world institutions. ${ }^{2}$ Following their call for a museum materialism, I suggest here a curatorial materialism as a critical investigation into the conditions and means of curatorial production, including self-organised and self-initiated productions, along with the access to infrastructures and institutions, the relations between curators, artists, technicians, builders, educators, intellectual producers, government officials, sponsors, donors, and supporters, and the engagement with the public. I see thinking from a position of relatedness as central to curatorial materialism. As I pointed out earlier, early feminist curatorial practices transformed the way in which art relates to the world. It is precisely this practice of relatedness, and the way the practice of curating transforms the ways in which these relations are shaped and allowed to happen, to which curatorial materialism has to be theoretically astute.

\section{Feminist Independent Curating}

I will now briefly discuss three different models of feminist independent curating from the late 1960s and early 1970s. I discerned these feminist examples of models that can be understood to have transformed the conditions of production and distribution of art in the work of Lucy Lippard, Ida Biard, and VALIE EXPORT. Between 1969 and 1974, American art critic Lucy Lippard realized a series of Number Shows, titled after the number of people living in the cities where the shows took place. ${ }^{3}$ In 1972, Zagrebian art historian Ida Biard initiated La Galerie des Locataires in her Paris apartment with its window doubling as exhibition venue. ${ }^{4}$ In 1975, Austrian artist VALIE EXPORT realised the exhibition MAGNA. Feminism: Art and Creativity. A Survey of the Female Sensibility, Imagination, Projection and Problems Suggested through a Tableau of Images, Objects, Photographs, Lectures, Discussions, Films, Videos and Actions. The project ran counter to disciplinary categorizations and connected visual art, film, poetry, music, and also a theory through a symposium and lectures. ${ }^{5}$ These curatorial models re-defined the use of infrastructures and institutions just as much as they created new public approaches to art-making on both a conceptual and a political level. Art historical scholarship, and in particular feminist art historical scholarship, has recently begun the historical project of mapping out and analysing the changes owed to feminist curating. ${ }^{6}$ Much of this analysis has foregrounded the following aspect of the curatorial work-the exhibitions through which the changes regarding the conceptual, im/material, and political dimensions of art were shown. What needs more future analysis is how feminist curating changed the way art relates to the world and how the transformation of the conditions of production and distribution and a feminist politics of defining this transformation is paramount to transforming these relations. In what follows, I will outline the contours of a curatorial materialist analysis of Lippard's, Biard's, and EXPORT's practices with a specific focus on production and distribution and its politics of access to resources, infrastructures, and institutions.

The curatorial model of Lucy Lippard's Numbers Shows 1969-74 relied on the creation of networked relations between small-scale institutions, different venues in cities, and the contributing artists. Lippard's strategy effectively redefined the relation between the work of curating and the work of art-making. The Number Shows' catalogues of $4 \times 6$ index cards attest to this, often citing instructions by the artists as to how the curator was to execute the art work on site. This strategy 
effectively transformed the conditions of production with regard to the division of labour between the work of the artist and the work of the curator. Here, the curator appears as the one who produces and makes the artwork in order for it to become public via the exhibition format. The status of the artwork was also effectively challenged. Very often the work was ephemeral and only existed on site for the duration of the exhibition. "The number shows were low-budget and for the most part physically easy to transport, in part out of necessity, given the dictates of the smaller, sometimes marginal and generally under-funded institutions where they took place. [...] The majority of artworks she solicited were, if not easily transportable, easily produced on-site at the instruction of the artists and often in their absence. The works were frequently ephemeral and intended to be dismantled after the exhibition." ${ }^{\prime 7}$ Even though one could suggest that this strategy of working is solely due to the small budgets available at the institutions with whom Lippared collaborated, I argue here that working in such a way is a conceptual strategy that transformed the relations between curator and artist and rendered them transparent as division of labour relations. Lippard worked with small-scale or marginal institutions and showed the artworks in a number of venues spread over the cities in which the exhibition took place. The Numbers Shows reveal a profound understanding of how material and immaterial elements are assembled through logics of production and the division of labour. The title does not refer to the number of artists involved or to the budget figures. Rather, the title refers to the number of inabitants in each of the cities where the respective exhibition venues were located: 557,087 (Seattle), 955,000 (Vancouver), 2,972,453 (Buenos Aires), and c.7,500 (Valencia). This demonstrates that sites, and this includes institutions, were not only conceived of as physical spaces, but as spaces constituted by social relations. By referring to a city via its number of inhabitants, its potential public, a city is read in its social production of space. It is the people who are, who make Seattle, Vancouver, Buenos Aires, or Valencia. The choice of title clearly points out that Lucy Lippard's feminist curatorial strategy understands the relations enabling access to institutional rescources and their infrastructures, that is, as relations to people who produce these institutions.

Ida Biard's La Galerie des Locataires presents a curatorial model based upon resource autonomy and the self-definition of the conditions and distributions of production. Biard redefined the relation between curator and exhibition space and, by extension, the division of labour between curator and artist. By declaring her own apartment, the space that made it possible for her to live and work in Paris, as the space that made it possible to support the communicating of the works of others, Biard shared her spatial and infrastructural resources. The gallery's motto read as follows: "The artist is anyone whom others give the opportunity to be an artist. $^{\prime \prime}$ Biard's curatorial approach made conceptual use of the infrastructure of the postal service. The address of her private apartment in Paris was declared the destination for mail from artists practicing in different parts of the world. What arrived by mail was then carried out by the curator. "Artists from all over the world were invited to send their works by mail, to be exhibited in the window of Biard's apartment, or realized, according to artists' instructions, in public spaces of different cities, and in the framework of various exhibitions and projects." ${ }^{\prime \prime}$ In 1976, Ida Biard used her space and the credentials of her past practice to demonstratively go on strike. She chose to discontinue her curatorial services in order to express her dissatisfaction with the "current system of the art market."10 Her own apartment and its postal address had provided the means for the production and distribution of art. The very same resource that she had made available within the art-context through her curatorial practice then became a resource for going on strike by taking this resource out of the production and distribution of art. 
VALIE EXPORT's exhibition MAGNA is a curatorial model based upon inserting feminist practice into the hegemonic art world by using its existing institutions and infrastructures, but on one's own feminist terms. The MAGNA exhibition project introduced the feminist artist as curator and as contemporary art historian, effectively redefining the relations between curating, art-making and art history writing. In 1972, EXPORT had written a manifesto for women's art with the title The Future of Women is the Future of Art History. Her curatorial project attests to her manifesto's goal of defining the future (of) art history through art produced by women. The curatorial strategy employed for MAGNA relied on finding an institution ready to host an independently conceived of and curated international feminist group show. EXPORT set out to find a well-established and prominent hosting instituiton. She describes her work, including her correspondence and her travels to secure funding and an exhibition space, as follows: "I had already developed the concept for the exhibition in 1972. An international exhibition was planned. And I was travelling around in 1972. Looking for other places for the exhibition, such as the Lenbachhaus in Munich or somewhere in London. I travelled around quite a bit, and there was also a lot of correspondence about it. The standard answer was, 'Very interesting, but who would be interested in it?'"11 MAGNA was eventually shown at Galerie nächst St. Stephan, Vienna, in the rooms that since 1923 had been the Neue Galerie run by Jewish gallerist Kallir-Nirenstein and which, beginning in 1954, came under the directorship of Monseigneur Otto Mauer, who dedicated the space to avant-garde art. Using the gallery institution and its infrastructures, EXPORT's curatorial strategy firmly inscribed feminist art practices in the avant-garde tradition and introduced them as the avant-garde of contemporary art-making.

The examples given here can only serve as an introduction to a comprehensive curatorial materialist study of early feminist independent curating. Much of the recent feminist art historical research and theoretical analysis on early feminist independent curatorship has paid very close attention to inscribing this work into the the emerging body of scholarly work on the histories of curating. This scholarly work allows us to understand how the work of feminist independent curators like VALIE EXPORT, Lucie Lippard, and Ida Biard was central to ushering in the shift from modern art to contemporary art, in particular regarding the transformations of the conceptual, im/material, and political dimensions of the artwork. Yet, much less attention has been paid to how the feminist notion of independence may have impacted the shaping of the type of work that led to the establishment of independent curating at the time. The idea of independence, in particular the quest for economic and political independence, is part of feminism's legacy. ${ }^{12}$ How this legacy informed the notion of independent curating warrants further analysis. Therefore, what I have elaborated here is to be understood as a research outline for a comprehensive curatorial materialist study of independent curating, with a particular, yet not exclusive, focus on feminist curatorial projects, and a focus on the question of how feminist economic and political thought on independence informed the concept of independent curating that ushered in the transition from modern art to contemporary art.

\section{Feminist and Queer Feminist Co-Dependent Curating}

I now wish to complicate the notion of independence, and I will do so by presenting some of my current research on feminist and queer feminist curatorial collectives. The examples chosen include the collective practices of Red Min(e)d and Queering Yerevan. Seen through a feminist curatorial materialist perspective, the practical and theoretical work of Red Min(e)d and Queering Yerevan attests to their profound awareness of the human and non-human co-dependencies in the work of curating. 


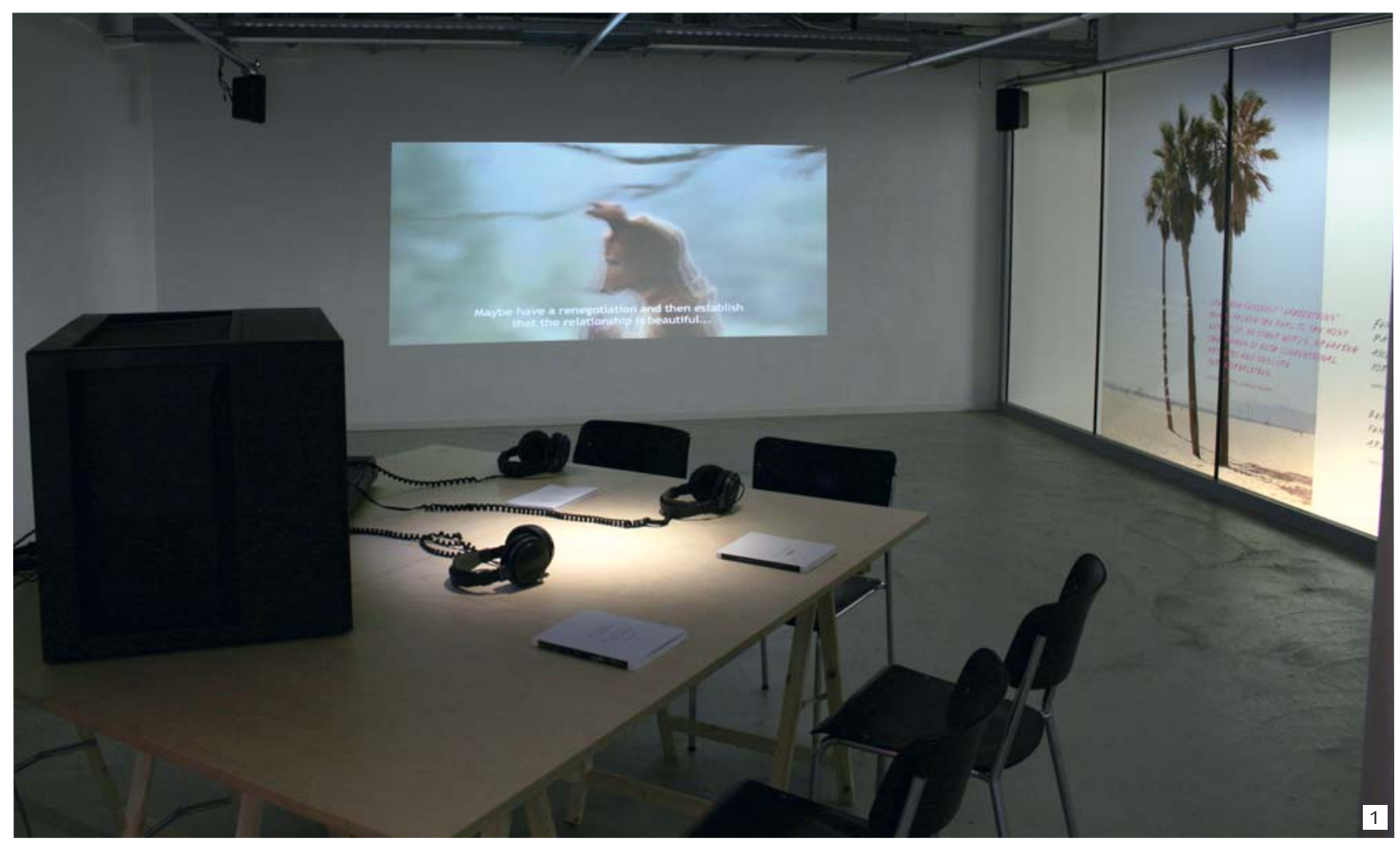

Red Min(e)d is self-identified as a "feminist curatorial collective"13 active with(in) and beyond the post-Yugoslav space. Starting from shared experiences of transitionality from the Socialist Federalist Republic of Yugoslavia to post-socialist globalisation, and based upon shared beliefs in curating feminist knowledge, friendship, and solidarity, the group started Red Min(e)d as well as their ongoing Living Archive project, which began in 2011. The four members, Jelena Petrović, Katja Kobolt, Danijela Dugandžić Živanović, and Dunja Kukovec, come from different backgrounds that include feminist theory, contemporary art, cultural production, and activism. They live in different places: Ljubljana, Sarajevo, Belgrade, and Munich.

"In the beginning of the Living Archive [...] we agreed that whatever happens we will focus on LOVE, on the politics of love. Putting FRIENDSHIP and LOVE first and before all misunderstandings, disagreements, and problems was the best thing we could do for us, for the Living Archive and for all the people involved in the process.."14 They practised the Living Archive together with a number of activists, artists, authors, curators, and scholars in art venues in cities like Zagreb, Sarajevo, Vienna, or Stockholm. They not only situated pasts, presents, and futures via feminist durationality, but also produced and shared solidary knowledge on women's art and feminist art in the post-socialist post-Yugoslav situation. They established relationships of trust and friendship with the people involved. The Living Archive is an exhibition laboratory and a public living archive with an Audio/Video booth that documents and presents live artist's talks, discussions, and interviews, the Perpetuum Mobile with a growing collection of video and other media art, and the Reading Room where one can fill out the feminism and art questionnaire. ${ }^{15}$ $\operatorname{Red} \operatorname{Min}(e) d$ not only make their working relations transparent, they equally make public aware of their embodied, lived and felt precarious working conditions. "What we have known since the first edition of the Living 
Archive is that most artists, curators, and authors, just like each one of us, have no salaries, no health insurance, have no savings, have no studios, no security, and no plans for future. They produce hungry, tired, love sick, homesick, lonely, with friends, using the equipment and skills of their friends and giving their lives, time, and energy to produce art knowing that most of the people around them believe that art is just a commodity." ${ }^{16}$

In 2013, Red Min(e)d were nominated as curators of the prestigious October Salon. Initiated in 1960 by the City of Belgrade, the Salon is the oldest and most prestigious institution of contemporary visual art in Belgrade. Red Min(e)d inserted the Living Archive into the October Salon. "In June 2013, when we got appointed as the curators of the 54th October Salon [...] we searched for a public museum or a gallery in Belgrade that would be big enough to host over 40 artistic positions, have at its disposal an operating license to be able to welcome the public, be open and available in autumn and have heating and electricity in the whole building..17 They found none. They decided that the 54th October Salon would take place in the former KLUZ department store and factory, originally built as a military salon, currently owned by Zepter. They knowingly risked of being accused of co-optation or capture. The exhibition No One Belongs Here More than You tested, and resisted, used, and subverted, the precarious space of a so-called private-public partnership afforded within the conditions of "neoliberal predatory capitalism and aggressive Orthodox Christianity. ${ }^{118}$ Red Min(ed) exposed their dependence on available spaces and resources. They chose to radically expose this co-dependence as part of their feminist curatorial practice under the precarious present conditions.

Red Min(e)d state that their work is not about changing the "(art) world". What they aim to do is "to build an emotional space for processing what we feel matters most. [...] We have been working on the basis of solidarity and consensus. We are four and we are constantly shifting power between us [...] we have been builidng a truly safe space of belonging. ${ }^{\prime \prime 9}$ During the October Salon exhibition, to make manifest the labor of art together with the labor of curating, "... the 54th October Salon showed the labor, the work behind each artwork, the tears, the feminist agendas, the sociality, and the affect as well as the living in the Living Archive." ${ }^{20}$

Queering Yerevan is self-described as "a collaborative project of queer and straight artists, writers, cultural critics, and activists to be realized within the framework of the QY collective. It takes as its point of departure concrete mnemonic experiences of concrete queer artists in a specific time and space: Yerevan, 2000 s. $^{\prime 21}$ Starting from shared experiences of transitionality from the Union of Soviet Socialist Republics (USSR) to the Republic of Armenia, marked by post-Soviet globalisation, exchanges with the Armenian diaspora, conditions of prevailing homophobia and patriarchy, and the powerful influence of the Armenian Orthodox church, the collective of Queering Yerevan, originally active under the name WOW, Women Oriented Women, began to work in 2007. In the absence of infrastructure readily available for the production, distribution, and reception of contemporary art in Yerevan, the three core members- Arpi Adamyan, Shushan Avagyan, and lusine talalyan-organize and provide infrastructures for artistic production and public exchanges. They put together events, exhibitions, happenings, film screenings, workshops, run a blog, and publish books. They apply for or crowdsource funding. Taking all these material and immaterial, emotional and cognitive labours together, they curate. Coming To You To Not Be With You was their first exhibition. In 2008 , they opened the garden of Zarbuyan 34 as the physical site for the exhibition and as a gathering space for connectivities and exchanges with other artists, activ- 
ists, curators, theorists, and with the audience. "Since our group consists of people working in different genres and with different mediums, one of the main objectives of the group is to be affected by each other's issues and be influenced by each other's aesthetics and methods, ideas and practices: to see how our work can change in the process. ${ }^{122}$

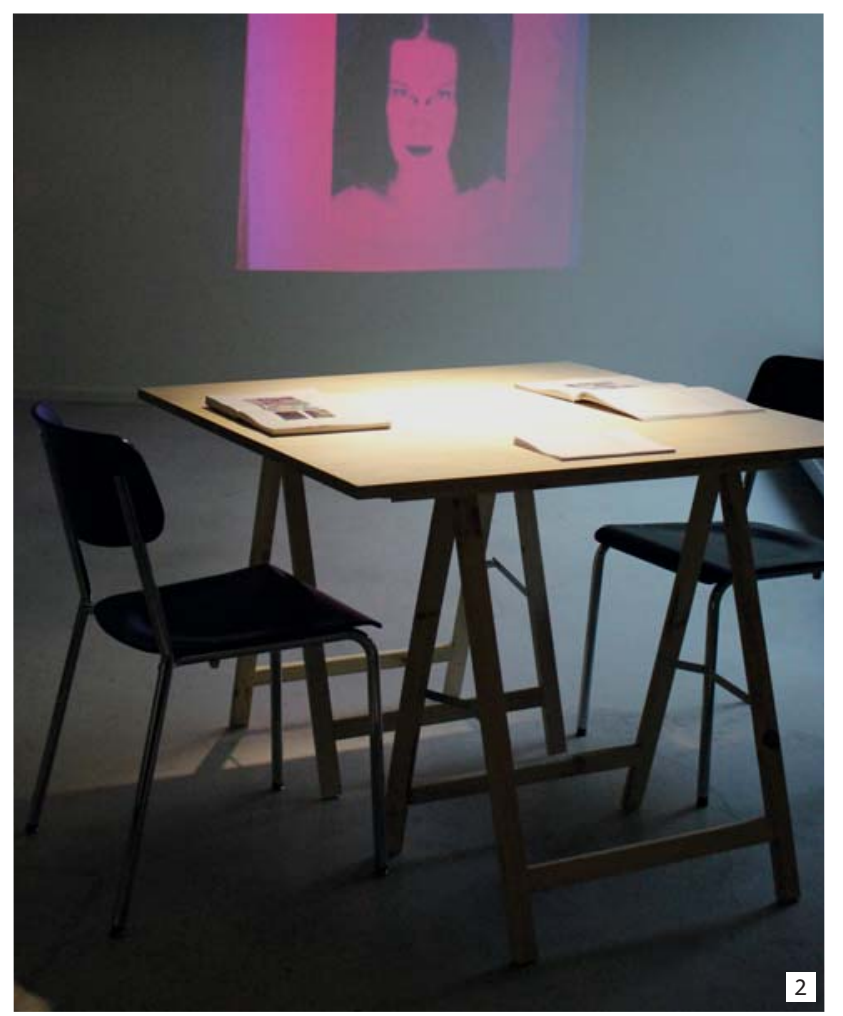

In their first published book, Queered: What's To Be Done With Xcentric Art, they combine experimental, poetic, and theory-based writing with the e-mail correspondence that both instituted and constituted the formation of the loose, local, and diasporic network of queer and feminist Armenian artists and intellectual producers active around the QY collective. The book exposes the potentialities, contradictions, and conflicts inherent in the affective labour of curating-as-caring. Filled with debates, conflicts, and emotions, it also makes public the work of funding applications. ${ }^{23}$ Angela Harutyunyan, art historian and curator, who is part of the Armenian diaspora, describes QY's first exhibition: "What I had in mind was to recuperate this collective experience of labor, precisely the experience of producing art as a laborious collective process, which resulted in an intersubjective exchange between the participants in terms of constructing relationships, strengthening and rearticulating friendships." ${ }^{\prime 24}$ She emphasizes having experienced "dissensus" rather than "consensus" and describes the exhibition as "attempts of subjectivization and its very failure." 25

The book not only mixes different formats of writing, but also the languages and alphabets of Armenian and English. Therefore, the book itself can be understood as a living archive-to borrow the term from the practice of Red Min(e)dand, paradoxically, even though a book is conventionally considered a finished and finalized product, as an open-ended space for affective labour, queer feminist durationality, and the sharing of knowledge in transnational solidarity with each other and with future readers. The book crosses between the private and the public, between the here and now, the there and then, between Yerevan and the Arme- 
nian diaspora. The book also includes "a two-year conversation" that took place on a list server via e-mail. Curating-as-caring also means taking care of fleeting fragments of solidary knowledge production, of making the commitment to transition from a list server to print, and to endure the conflicts arising within this affective labour. "The goal is to archive a two-year conversation that has been most productive to us, in various ways-if not collectively, then alternatively, individually and otherwise. This 'unspace' has been the most real space and it's created possibilities. We need a record of that, not in the form of a pdf, or a blog, not in the form of censored and cut up pieces, but boldly, in boldface, on paper, thick and heavy, as our conversations have been. ${ }^{\prime 26}$ The e-mails fill the printed pages with affective relations, conflicts, desires, identifications, and disillusionment. "That is I don't want anything I wrote to the listserv to be published. [...] Decisions should be made collectively and the needs and concerns of all should be taken into account." [... "I agree, the book is open-ended, like you said, at least for me it is. ${ }^{117}$ Queering Yerevan build their own support structures and platforms of sharing their work, be it in a garden as a temporary exhibition venue, or via a listserv or in a book. Equally, they make public their co-dependency within their own community as well as from funding bodies or other supporters. They show that their work emerges through co-dependencies.

\section{Too Early to Conclude}

The feminist and queer feminist collectives I have described here make temporary use of existing art infrastructures and/or establish self-initiated, self-sustained, changing, or mobile infrastructures such as a garden, a blog, a book publication, or an archive on wheels. By way of making public their dependence on spatial, infrastructural, economic, and affective resources, they point out that the term "independent" actually conceals that curatorial work is constituted by relations and always dependent upon the exchange and collaboration with other human and non-human actors. Such curatorial work relies on the contributing work of artists, archivists, historians, intellectuals, researchers, technicians, theorists, and, in some cases, on many other museum workers, funders, or government officials. It equally depends on economic, material, infrastructural, institutional, and technological resources. The feminist and queer feminist collectives whose work I presented here establish such material and immaterial infrastructures as part of their work, which enables them to also continue their work and their exchanges with many others. These opened-up physical or digital spaces are understood as emotional spaces, discursive spaces, and spaces of emerging knowledges. Theirs are responses to hegemonic conditions of the globalised art world context, not altering them, but creating within them material and emotional spaces of feminist and queer feminist solidarity. Curatorial materialism allows us to understand that these collective practices are, in fact, new forms of co-dependent curating. Feminist independent curating was part of paving the way from modern art to contemporary art. It is too early to conclude what name will be given to the kind of art that is currently in the making through feminist and queer feminist co-dependent curating.

\section{Acknowledgements}

I am grateful to members of Red Min(e)d and Qeering Yerevan for answering my questions about their practice in personal conversations, via Skype, or over the phone, and also via extensive e-mail communication. I am also grateful for their generously granting me the right to publish photographs showing their work. 
Notes

1 Angela Dimitrakaki and Lara Perry, eds. Politics in a Glass Case. Feminism, exhibition cultures and curatorial transgressions. Liverpool University Press, Liverpool, 2013.

2 Angela Dimitrakaki and Lara Perry, eds. Politics in a Glass Case. Feminism, exhibition cultures and curatorial transgressions. Liverpool University Press, Liverpool, 2013, p. 1.

3 On Lucy Lippard's Numbers Shows, see Cornelia Butler et al.: From Conceptualism to Feminism: Lucy Lippard's Numbers Shows 1969-1974, Afterall Books, London, 2012.

4 On VALIE EXPORT's curatorial work, see Monika Kaiser, Neubesetzungen des Kunst-Raumes. Feministische Kunstausstellungen und ihre Räume 1972-1987, transcript Verlag, Bielefeld, 2013.

5 On Ida Biard, see Ivana Bago, "Strike by Galerie Les Locataires." Accessed 03.01.2016. http://tranzit.org/exhibitionarchive/tag/ida-biard/; and Ivana Bago, "A Window and a Basement. Negotiating Hospitality at La Galerie des Locataires and Podroom - The Working Community of Artists," Art Margins, 1: 2-3, 2012. Accessed 03.02.2016. text.pdf.

http://www.delve.hr/file/files/2012\%20lvana\%20Bago_Artmargins\%20

6 The following publications attest to this emerging field of scholarship: the 2006 n.paradoxa special issue on Curatorial Strategies, the 2006 essay "Issues in Feminist Curation: Strategies and Practices" by Katy Deepwell, the 2010 essay "How to Install Art as a Feminist" by Helen Molesworth, the 2010 volume of Feminisms is Still Our Name: Seven Essays on Historiography and Curatorial Practices, edited by Hedlin Hayden and Sjöholm Skrubbe, the 2013 Politics in a Glass Case. Feminism, Exhibition Cultures and Curatorial Transgressions, edited by Angela Dimitrakaki and Lara Perry, the 2013 Working with Feminism: Curating and Exhibitions in Eastern Europe, edited by Katrin Kivimaa, the 2013 Women's:Museum. Curatorial Politics in Feminism, Education, History, and Art, edited by Elke Krasny and Frauenmuseum Meran.

7 Cornelia Butler, "Women - Concept - Art: Lucy R. Lippard's Number Shows," , in Cornelia Butler et al., From Conceptualism to Feminism: Lucy Lippard's Numbers Shows 1969-1974, Afterall Books, London, 2012, p. $24 \mathrm{f}$.

8 Ivana Bago, "A Window and a Basement. Negotiating Hospitality at La Galerie des Locataires and Podroom - The Working Community of Artists," Art Margins 1: 2-3, 2012, p. 22.

9 Ivana Bago, "Strike by Galerie Les Locataires." Accessed 28.03.2016 http:// tranzit.org/exhibitionarchive/tag/ida-biard/.

10 ibid.

11 Stella Rollig, VALIE EXPORT, Gudrun Ankele, and Petja Dimitrova, "Collection Strategies and Interventions in the Canon," in Elke Krasny and Frauenmuseum Meran, eds., Women's:Museum. Curatorial Politics in Feminism, Education, History, and Art, Löcker Verlag, Vienna, 2013, p. 47.

12 For example: In 1898 Charlotte Gilman Perkins wrote the book Women and Economics - A Study of the Economic Relations Between Men and Women as a Factor in Social Evolution. In it, she speaks of women's economic independence as key to the improvement of marriage, motherhood, domestic industry, and racial improvement.

In 1949 Simone de Beauvoir's Le Deuxième Sexe appeared, in which she devotes an entire chapter to "La femme indépendante". In her 1963 book, The Feminine Mystique, Betty Friedan stipulated that women's full identity and freedom is linked to economic independence. Marxist feminist Silvia Federici describes the 
need to make oneself independent as follows: "The Second World War was important for the development of feminism in Italy because it marked a moment of rupture of the relation of women to the State and the family, because it made women understand that they needed to make themselves independent, that they could not put their survival in the hands of men and the patriarchal family". Accessed 02.03.2016. https://viewpointmag.com/2015/04/15/witchtales-aninterview-with-silvia-federici/.

13 Red Min(e)d, "Production in times of trouble," in Red Min(e)d (Jelena Petrović and Katja Kobolt, Danijela Dugandžić Živanović, Dunja Kukove ) in collaboration with Jelena Vesić, eds., No One Belongs Here More Than You. The Living Archive: Curating Feminist Knowledge. 54th October Salon, Cultural Center of Belgrade, Belgrade, 2014, p. 203.

14 lbid.

15 My description is based upon a number of different websites containing information on Red Min(e)d's Living Archive, such as: http://www.vbkoe. org/2012/09/28/the-bring-in-take-out-living-archive---vbkoe-edition/?lang=en (last accessed in March 2016), http://minainstitute.wordpress.com (last accessed in March 2016) and https://bringintakeout.wordpress.com/category/news/page/3/ (last accessed in March 2016)

16 "Production in times of trouble," p. 204.

17 Red Min(e)d, "Where and what is a museum?", in Red Min(e)d (Jelena Petrović and Katja Kobolt, Danijela Dugandžić Živanović, Dunja Kukove ) in collaboration with Jelena Vesić, eds., No One Belongs Here More Than You. The Living Archive: Curating Feminist Knowledge. 54th October Salon, Cultural Center of Belgrade, Belgrade, 2014, p. 28.

18 Erić Zoran, ed. Differentiated Neighbourhoods of New Belgrade, MOCAB Museum of Contemporary Art Belgrade CVC Center for Visual Culture, Belgrade, 2009 , p. 10.

$19 \operatorname{Red} \operatorname{Min}(e) d$, "No one belongs here more than you," in Red Min(e)d (Jelena Petrović and Katja Kobolt, Danijela Dugandžić Živanović, Dunja Kukove ) in collaboration with Jelena Vesić, eds., No One Belongs Here More Than You. The Living Archive: Curating Feminist Knowledge. 54th October Salon, Cultural Center of Belgrade, Belgrade, 2014, p. 15.

20 Red Min(e)d, "The Living Archive: Curating Feminist Knowledge," in Red Min(e)d (Jelena Petrović and Katja Kobolt, Danijela Dugandžić Živanović, Dunja Kukove ) in collaboration with Jelena Vesić, eds., No One Belongs Here More Than You. The Living Archive: Curating Feminist Knowledge. 54th October Salon, Cultural Center of Belgrade, Belgrade, 2014, p. 205.

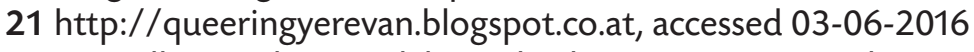

22 QY collective, lusine talalyan, shushan avagyan, arpi adamyan, eds., Queered: What's to be done with XCentric Art?, QY Collective, Yerevan, 2011, p. 12.

23 Timothy D. Straight, Norwegian Honorary Consul in Armenia responds to a funding request as follows: "While the issue of sexual minorities is an important one for Armenia, there were so many applications on so many pressing issues that all of the could not be chosen, unfortunately." (Queered: What's to be done with XCentric Art?, p. 247.)

24 Ibid., p. 200.

25 lbid., p. 201.

26 lbid., p. 318.

27 Ibid., p. 321. 
Elke Krasny is Professor of Art and Education at the Academy of Fine Arts Vienna. Her work as a curator, cultural theorist, and writer focuses on architecture, urbanism, politically conscious art practices, and feminist historiographies of curating. Krasny holds a Ph.D. in Fine Arts from the University of Reading, Department of Art, Research Platform for Curatorial and Cross-disciplinary Cultural Studies.

In 2016 she taught at the Post Graduate Program on Postindustrial Design at the University of Thessaly, Volos; 2014 City of Vienna Visiting Professor at the Vienna University of Technology. In 2012 she was Visiting Scholar at the Canadian Centre for Architecture in Montréal. In 2011 she was Visiting Curator at the Hongkong Community Museum.

Recent curatorial works include On the Art of Housekeeping and Budgeting in the 21st Century, curated together with Regina Bittner, Suzanne Lacy's International Dinner Party in Feminist Curatorial Thought at Zurich and Hands-On Urbanism. The Right to Green which was presented at the 2012 Venice Biennale. Her 2015 essay Growing the Seeds of Change was included in Jordan Geiger's volume Entr'Acte, Performing Pulbics, Pervasive Media, and Architecture. She co-edited the 2013 volume Women's:Museum. Curatorial Politics in Feminism, Education, History, and Art, the 2012 volume Hands-On Urbanism. The Right to Green and the 2008 volume The Force is in the Mind. The Making of Architecture. 
IIIIII

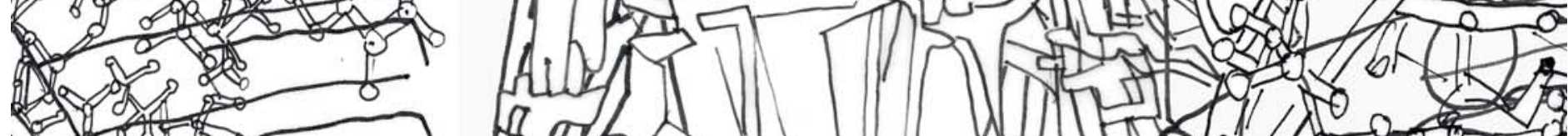

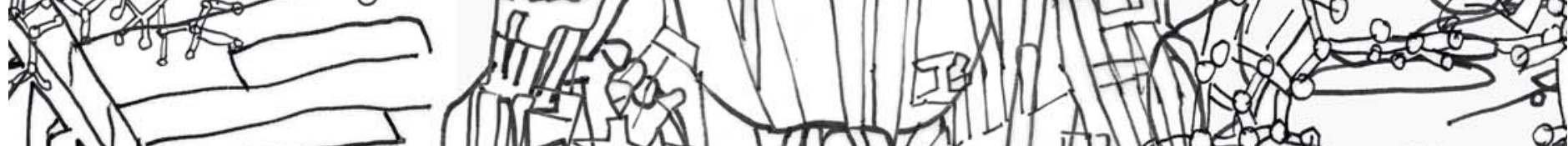

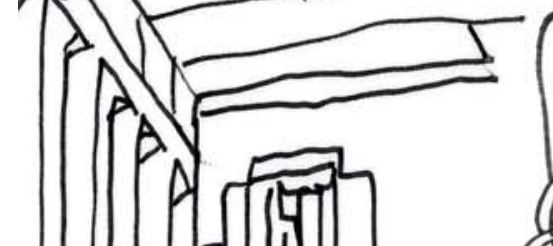

5 - 120
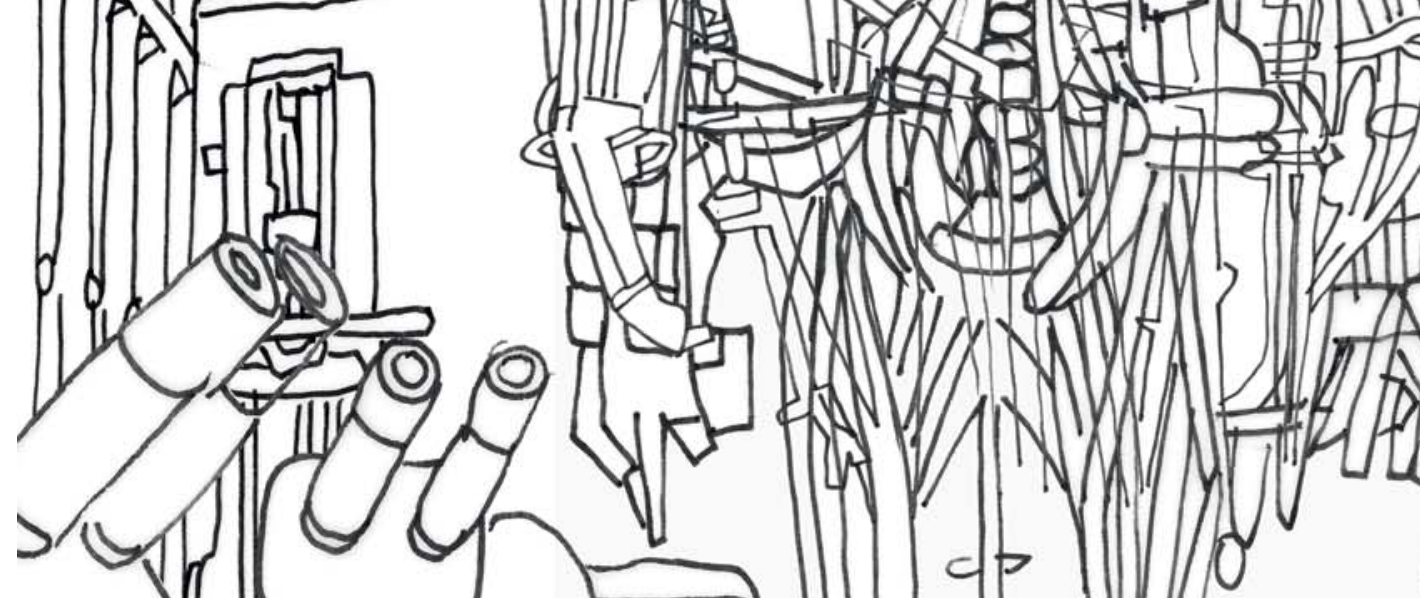


\section{Performing Feminism 'Badly': Hotham Street Ladies} and Brown Council Laura Castagnini

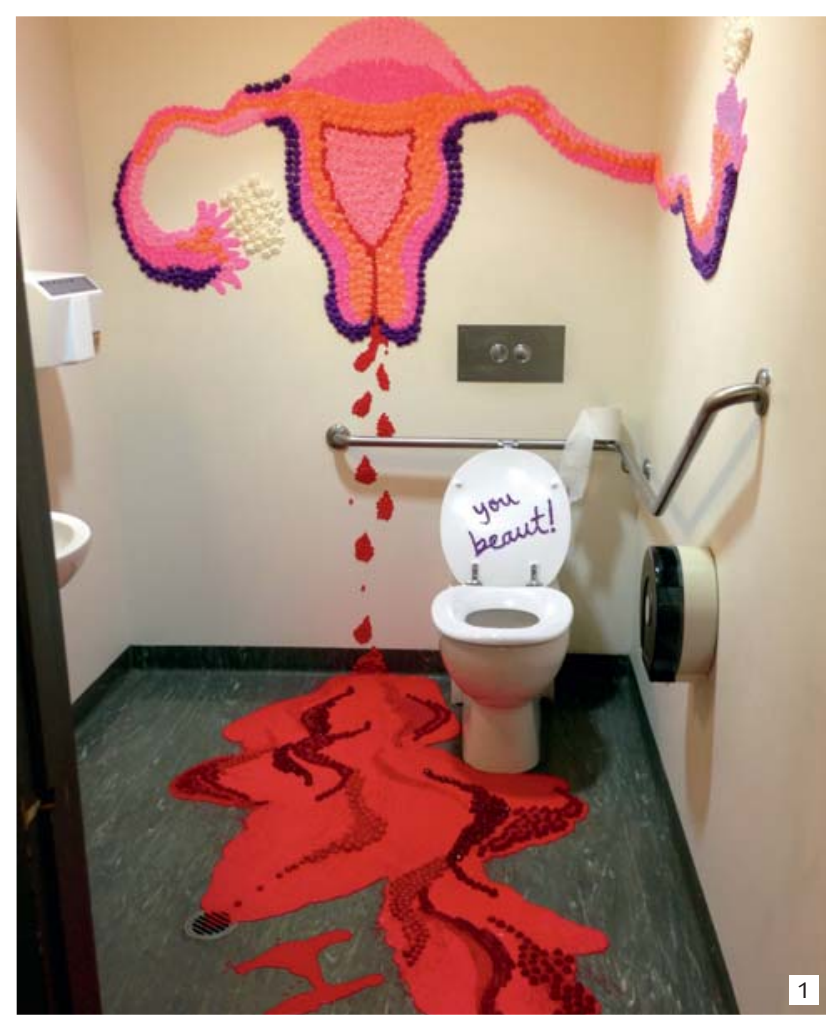

If you needed to pop to the loo during my curated exhibition Backflip: Feminism and Humour in Contemporary Art, you would have stumbled across a cake-frosted uterus spurting sugary menstrual blood all over the gallery toilet floor. ${ }^{1}$ The gooey site-specific installation, entitled You Beaut! (2013), was the handiwork of Melbourne art collective the Hotham Street Ladies and created entirely from edible cake decorations, including icing sugar, sprinkles and raspberry lollies (for the... err... clots). As well as rendering Margaret Lawrence Gallery's bathroom inoperative for the show's duration, You Beaut! provoked a series of interrelated questions that I would like to explore in this article. What does it mean for female artists to insert menstrual blood-the female grotesque par excellence-into the gallery more than four decades after the emergence of such subject matter in the
Women's Art Movement? Why might contemporary feminist artists work collaboratively, use domestic techniques and materials and, in doing so, appropriate second wave feminist methodologies? Finally, what's so funny about this approach?

I will suggest that the humorous and revisionist tendencies evident in You Beaut! can be characterised as 'parafeminist parody'. Situated within the post2000 s resurgence of interest in feminism worldwide, parafeminist parody refers to the current trend in contemporary feminist art to mimic or cite aspects of earlier feminist practices. Parafeminist parody is an interpretation of art theorist Amelia Jones' conceptual framework of "parafeminism" read through the lens of Linda Hutcheon's revised theory of parody, and intends to explicate the forms of humour currently emerging in contemporary practices such as the Hotham Street Ladies.

The term parafeminism, first articulated in Jones's groundbreaking book Self/Image (2006), uses the prefix "para" to denote a model of contemporary art practice that runs "parallel to," rather than "post," earlier forms of feminism: it is "a conceptual model of critique and exploration that is simultaneously parallel to and building on (in the sense of rethinking and pushing the boundaries of, but not superseding) earlier feminisms." ${ }^{2}$ It characterises an intersectional form of feminist art practice that refutes coalitional identity politics and adopts a "rethinking" and expansion of second wave feminist methodologies. ${ }^{3}$ Another aspect of parafeminism is that it belies conflicting attitudes and proximities to feminism: to use Jones' words, it "embrace(s)" the confusion of "the meaning, significance, and status of feminist-or parafeminist-visual practice today."

I would like to further Jones' theory of parafeminism by arguing there is parodic potential in its historical homage, when read through the lens of 
Hutcheon's theory of parody. Hutcheon differentiates parody from satire: a form of humour which, she argues, is always mocking, while parody's definition includes works that mimic, refer or pay homage through their utilisation of irony which "can be playful instead of belittling. ${ }^{15}$ The etymological root of the prefix 'para,' which is shared by parafeminism and parody, provides the foundation for Hutcheon's theory. She argues:

The prefix para has two meanings, only one of which is usually mentioned - that of "counter" or "against"... However para in Greek can also mean beside, and therefore there is a suggestion of an accord or intimacy instead of a contrast. $^{6}$

The doubleness of parody's root 'para' leads Hutcheon to a new definition of parody which, I suggest, is particularly relevant to parafeminism:

Parody... is repetition with difference. A critical distance is implied between the background text being parodied and the new incorporating work, a distance usually signalled by irony. But this irony can be playful instead of belittling: it can be critically constructive as well as destructive. The pleasure of parody's irony comes not from humor in particular but from the degree of engagement of the reader in the intertextual "bouncing" (to use E.M Forster's famous term) between complicity and distance.

While Hutcheon's insights broaden the term parody to include "beside", and thus account for strategies of complicity and homage, I reverse Hutcheon's logic to argue that parafeminism can be expanded to include the term "counter", and thus account for strategies of distance and critique. This methodology elucidates two important elements of parafeminism: firstly, Hutcheon's insights convey that the term parafeminism etymologically has two contradictory meanings pertaining to complicity and distance. Thereby, I extend Jones' theory to ascertain that parodic pleasure in reading parafeminist practices is produced by the viewers' engagement in "bouncing" between complicity and distance. ${ }^{8}$

Secondly, I argue that the parafeminist strategy of "rethinking" earlier forms of feminism can be read, through Hutcheon's theory, as a parody of the past. Thus contemporary feminist art-or parafeminist art-can be considered as a temporal parody of previous "waves" of feminism: embodying both homage to second wave strategies of the 1970s and, as will be later discussed, inversion of the 1990s Bad Girls phenomena.

In this way, parafeminism enables contemporary feminist practitioners such as Hotham Street Ladies to own and build upon the history of feminist art through parodic strategies of homage and citation.

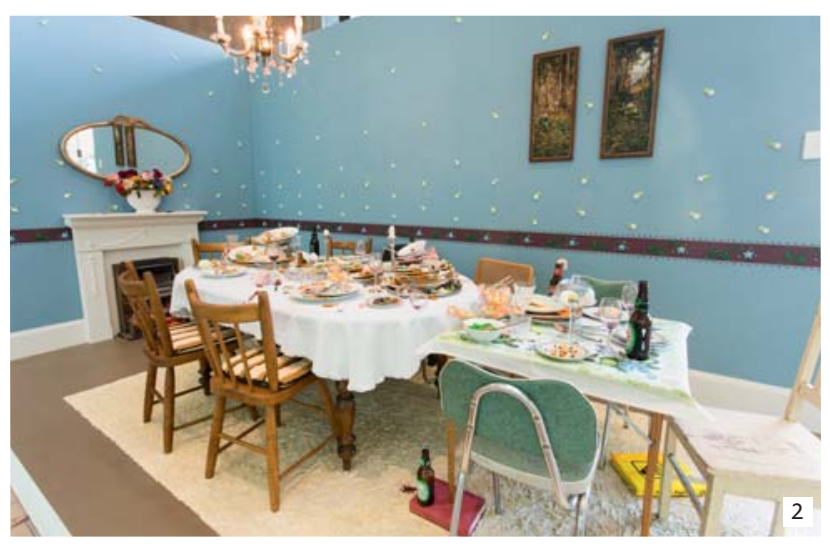

Rethinking Earlier Feminisms

Parafeminist parody reveals itself in the work of the Hotham Street Ladies (HSL): Cassandra Chilton, Molly O’Shaughnessy, Sarah Parkes, Caroline Price, and Lyndal Walker. The collective, all of whom lived at one time in a Melbourne share house in Hotham Street in Collingwood, cite their inspiration as "groups such as mother's auxiliaries and the Country Women's Association. They also come together out of necessity to make things for the enjoyment of their community and for the enrichment of girly chat." HSL pay homage to women's collectives of the past through their titling as "ladies", their celebration of female friendship, and enjoyment of traditional domestic activities of baking, cake decorating and craft. However, HSL's practice exploits the grotesque elements of food and share-household living to present incongruities between ideals of femininity and the Ladies' lived experience as women today.

HSL's first collective effort was The HSL Contribution Cookery Book (2004), a community recipe book, after which their work has traversed a broad range of materials and contexts including: Hotham Street House Cake (2008), a cake creation of the original sharehouse exhibited in a gallery; Frosting, (2008-), an ongoing series of street art rendered in icing; Green Bin (2011), an oversized public sculpture of a recycling bin; and their most ambitious project to date, At Home with the Hotham Street Ladies (2013), an installation that transformed the foyer of the National Gallery of Victoria into two comically messy domestic 
living spaces meticulously crafted through cake decoration. HSL's representation of the abject-food, mess, and bodily functions-is offset by their skilful mimicry of middle-class femininity through craft and baking techniques.

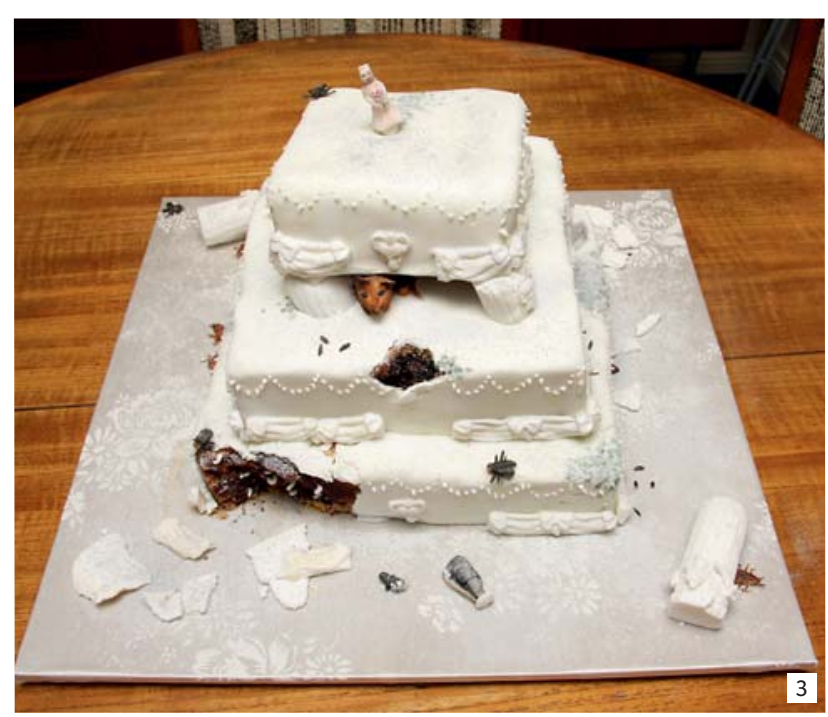

For three years in a row, from 2009-2012, HSL submitted absurd entries to the Royal Melbourne Show Cake Decorating competition. Their first effort was Pizza Cake (2009): a crude cake creation that depicted two pizza boxes emblazoned with a HSL emblem as well as half eaten crusts, an ashtray, and a remote control. They didn't win, but the following year the collective offered Miss Havisham Cake (2010) for the contest: a destroyed three tiered wedding cake which included fake mice scampering throughout detritus of broken columns and a missing plastic groom that was inspired by the unhinged female character in Charles Dickens' Great Expectations. Much to the artists' amusement, the second cake was disqualified for being "in bad taste."10 The judges' comments read: "Be aware that the exhibit is in bad taste. You are presenting something that is food-based and should be pleasing to the eye. A nice idea but not suited for a major competition." ${ }^{\prime 11}$ In response, in 2011 HSL presented Amy Varden (2011), a cake that depicted the recently deceased pop singer Amy Winehouse.

HSL's cake contest performance enacts parody on a number of levels: it mocks the notion of competition based on women's domestic prowess through presentation of crude imagery in a medium that, according to the judges, "should be pleasing to the eye."12 The subversive element of these works relies on the mimesis of a constructed femininity, based on the view that gender is instilled by behaviours regu- lated by societal norms, and the subsequent failure to conform. At the same time, however, the cakes are meticulously detailed and demonstrate enormous technical skill: suggesting a sincere celebration of the women's work displayed at the Royal Melbourne Show. Further, HSL pay tribute to female characters and artists, thus remixing and presenting them in divergent cultural contexts. Therefore a dialectic of critique and homage operates within HSL's parodic performance, demonstrating Hutcheon's argument that parody can include "critically constructive" strategies of homage. ${ }^{13}$ The cakes demonstrate comic theorist Simon Dentith's argument that within parody "the polemic can work both ways: towards the imitated text or towards the 'world."'14 Thus, to use Dentith's logic, HSL draw on the authority of precursor texts (the cake contest, the novel, the singer) to attack and satirise elements of the broader "world" (gender stereotypes). ${ }^{15}$ I want to characterise the dialectic between critique and celebration of women's work that emerges in HSL's work as a distinct strategy of parafeminist parody that relates to its "rethinking" of earlier feminist histories. However, before we can answer the questions posed at the beginning of this article in relation to HSL's installation You Beaut! (2013), the performative element of this temporal parody needs to be further elucidated. To this end, I will draw upon the work of another Australian feminist art collective who combine cake and collectivism to restage earlier feminist histories.

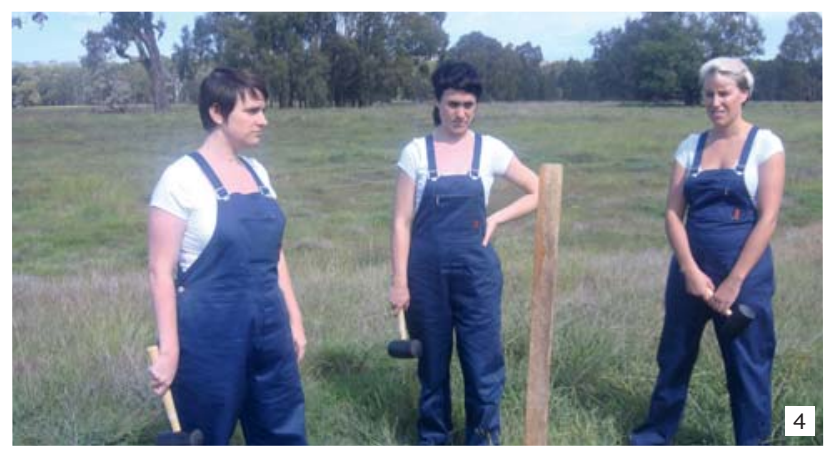

\section{Performing "Badly"}

Brown Council's work responds to the physical and historical context of performance to "critique why and how it is that we perform", 16 according to the artists. Brown Council's members-Frances Barrett, Kate Blackmore, Kelly Doley and Diana Smith-met during their studies at College of Fine Art (COFA), a Sydney art school known for its ability to operate at the nexus of performance and visual art, and their collaborative work continues to straddle gallery and stage contexts. Often combining absurd humour with temporal citation, Brown Council's work operates as a 
multi-directional parody that I characterise as explicitly parafeminist. Through analysis of their oeuvre, I ask: how does parafeminist parody operate when its restaging of the past is considered a deliberately "bad" performance?

Brown Council's early video works exaggerated elements of sexist popular culture to create grotesque presentations of its members' exhausted bodies through durational performances. Milkshake (2007) depicts the artists, who are wearing homemade skeleton suits, drinking one litre of milk before attempting an energetic choreographed dance routine to Kelis' song "Milkshakes." Similarly, Runaway (2008) presents a female figure (played by all four artists interchangeably) running towards the camera in slow motion. The dramatic soundtrack builds tension, lights flash onto her face and body, until suddenly the protagonist is squirted with (fake) blood and climactically rips off her singlet to expose a tan-coloured t-shirt with huge breasts drawn in black marker. From these early works, Brown Council undertook an intensive period of research into the form and functions of comedy itself. They developed a four-hour live performance, $A$ Comedy (2010), in which the artists interrogate power dynamics in performance by placing themselves at the mercy of the audience; Big Show (2009), a video which documents the artists' durational performance of clichéd comedic gags; and One Hour Laugh (2009), in which the artists filmed themselves laughing continuously for one hour. ${ }^{17}$ In all three performance-based works, the members of Brown Council sport a costume of dunce hats and bibs hand-crafted from primary-coloured paper. This DIY style of costume, which reappears throughout Brown Council's early works, takes pleasure in sabotaging the markers of quality and taste that uphold discourses of "high art". Thus, I would suggest, these Brown Council works revel in "the queer art of failure", theorised by Judith (or Jack) Halberstam as the subversive potential that lies in resisting markers of "success" in a capitalist and patriarchal society. ${ }^{18}$ Failure is a strategy that circulates through the work, often to grotesquely comic potential: the Milkshakes performance is disrupted by bumps and cramps, the jokes told in A Comedy are often terribly bad, and the endurance tasks set in Big Show result in retching, pain, and boredom. In their emphasis on bodily functions, Brown Council image what literary theorist Mary Russo termed "the female grotesque": using laughter, to borrow Russo's phrase, as a strategy to "expose and subvert the impasse of femininity."19 However, unlike their "bad girl" feminist predecessors of the 1980s and early 1990s, Brown Council filter the female grotesque through a parafeminist lens: a blend of self-conscious failure and irony that results in a parody of comedy itself.

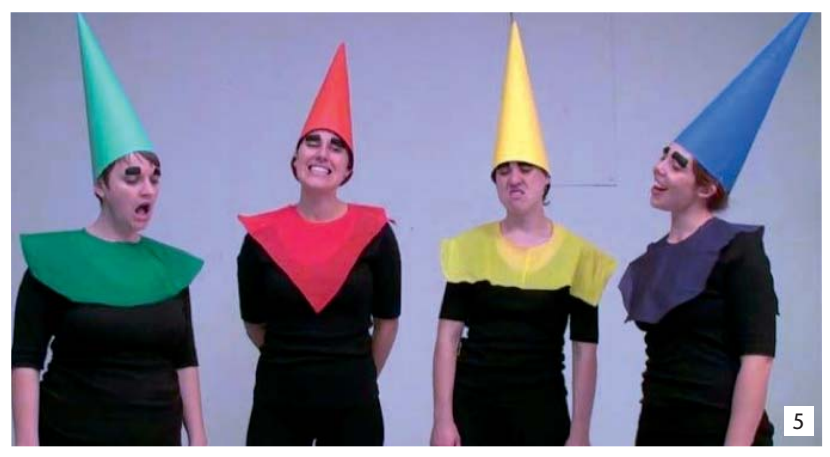

More recently, Brown Council have turned their attention to the legacy of their preferred medium: durational performance. These works investigate the idea of "the artist" as well as the construction of performance and art histories, including, of course, earlier forms of feminism. This interest is exemplified in works such as Dance Work (2009), in which Brown Council hired a dancer to perform a striptease at an exhibition opening; Photo with the Artist (2011), in which the public were invited to buy a photo of themselves with the four artists outside the Museum of Contemporary Art; Performance Fee (2012), in which the collective sat blindfolded in Queensland's Gallery of Modern Art and sold kisses for \$2; and the ongoing project, Remembering Barbara Cleveland (2011-), in which Brown Council honour the life and work of a fictive 1970s Australian female performance artist named Barbara Cleveland. ${ }^{20}$ Such works operate to deconstruct the conditions-financial, symbolic, and gendered-of performance. However, they also borrow from the aesthetics of early feminist practices (black and white footage), specific artworks (Orlan's 1977 performance The Artist's Kiss), and key figures (the popularity of the name "Barbara" in an earlier generation of feminists in Australia: Barbara Campbell, Barbara Hall, Barbara Creed, Barbara Bolt). Citation escalates into parody in the endurance performance video Work in Progress: Dawn to Dusk (2010), in which the four artists, dressed in blue overalls, silently hammer a wooden post into the ground for sixteen hours. As the critic Pip Wallis noted: "With tongue-in-cheek humour, Dawn to Dusk references performance art and its intertwined history with feminist art of the 1960s and 70s." ${ }^{21}$ That is to say, Work in Progress: Dawn to Dusk cites the aesthetics of feminist art history through their employment of durational performance, grainy grey-scale footage and costuming, but filters their homage through an added layer of absurdity: a "repetition with critical distance" that challenges the accomplishment of 
women's labour rights. Through their aesthetic homage and conceptual critique of earlier forms of feminism, Brown Council's work presents a dialectic of proximity and distance to history that is intrinsic to my notion of parafeminist parody.

Australian feminist art historian Catriona Moore cited Work in Progress: Dawn to Dusk as an example of contemporary artists "performing feminism badly". In a brief talk at the LEVEL ARI symposium in Brisbane, Moore argued: "Today I see in a lot of contemporary practice feminism being performed in very funny ways, sometimes being performed badly." ${ }^{\prime 22}$ Moore has questioned the aesthetic and conceptual purchase of such an approach, most recently in her essay "Feminist Aesthetics, Then and Now" (2013), Moore writes:

Then, as now, feminist artists do not feel comfortable with any set formal or stylistic lexicon. Hipster feminism instead cheerfully embroiders, playfully unravels or badly performs the baser depths of feminine sensibility. Maybe this is another case of strategic essentialism, in this case feminist aesthetics, turned inside out and replayed in decadent, camp and provocative form. ${ }^{23}$

In her attempt to theorise the aesthetic productivity of feminist revisionism, Moore barely hides her disappointment in mourning the loss of the political potency of earlier practices. ${ }^{24}$ In this, she echoes an argument made by Amelia Jones in her article "1970/2007: The Return of Feminist Art":

"Recent practices seem to appropriate strategies from earlier feminisms without sustaining the politics these strategies aimed at promoting. And the strategies are replicated either without knowing of the earlier models or by knowingly repeating them, but in new contexts in which they do not have the same political effect."

However, other critics have argued that contemporary mimicry of earlier feminist aesthetics could potentially function as gateway drug to feminist politics. In her oft-cited essay "Extimacy: A New Generation of Feminism" (2009), the critic Alexie Glass writes: "In recent practice feminism is often claimed as a site of discourse which has become actively recharged via appropriations of feminist visual language." 25 This "recharging" of feminism through artistic appropriation simultaneously gives weight to history, as Bree Richards argues in her article "Doing, Being, Performing". Reviewing the "resurgence" of performance art by women artists in Australia, through the insights of Glass, Richards argues: "Their collective sidelong glances, quotations, nods, random encounters or riffs on the multi-layered histories of the body and the performative in art history gives presence to the past, reimagining the terrain for new parallels." ${ }^{\prime 26}$

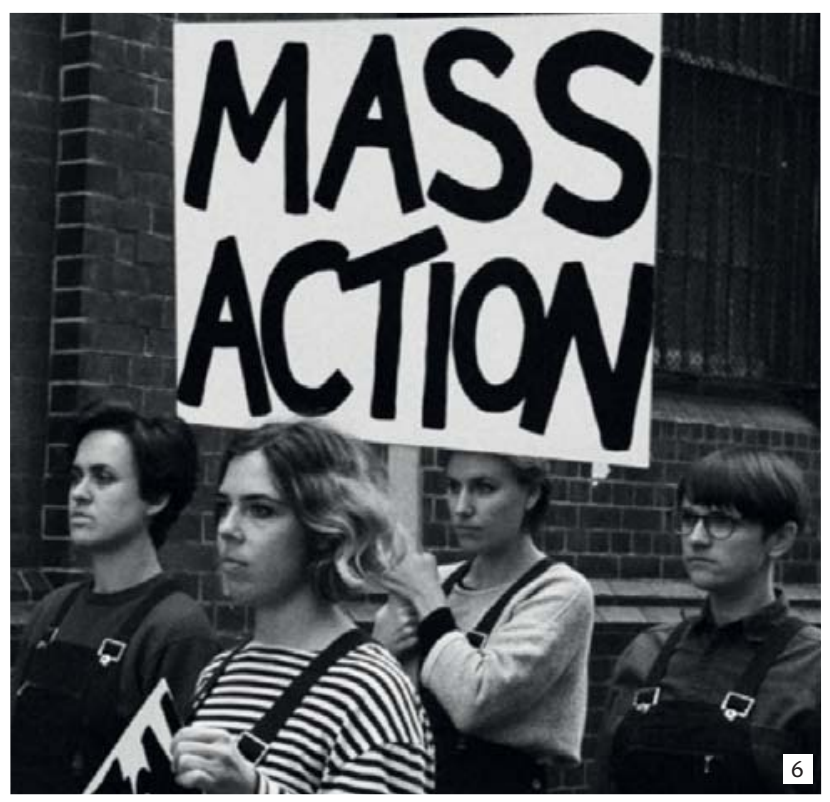

I suggest that, to use Moore's words, "performing feminism, and performing it badly", ${ }^{27}$ might be a productive way to consider the emergent strategies of historical revisionism and aesthetic citation that I am characterising as parafeminist parody. As a case study, let us consider the live performance Mass Action: 137 Cakes in 90 Hours (2012), in which Brown Council undertook a 90-hour "bake off" in the headquarters of Sydney's Country Women's Association (CWA). CWA is the largest women's organisation in Australia, known for its support of rural women through fundraising activities such as the Country Classics Cookbook series and female-only hostel accommodation in major cities, and is tied to a particular generation of predominantly white middle-class women's Anglo-Christian values of respectability and goodwill. Brown Council's durational performance saw the artists attempt to cook every recipe in CWA's Country Classics Cookbook without stopping for three days, while the action was broadcast on the internet through a live video feed and updates by invited bloggers. Thereafter, the artists offered the cakes to a judging panel and held an afternoon tea for CWA members. ${ }^{28}$ By exaggerating the CWA's mission through repetition and exhaustive performance, Brown Council's premise illustrates Hutcheon's notion of parody as "repetition with critical distance". 
However, the titling and promotion of Mass Action denotes the performance as a protest. Brown Council's grey-scale publicity shot clearly channels the aesthetic of 1970s feminist protest actions, depicting the serious-faced, overalls-clad collective marching in the streets carrying a placard with the text "Mass Action". Historically, feminist protests usually involved withdrawing from domestic work; however, Brown Council inverted this logic by doggedly baking an enormous amount of cakes. Brown Council's refusal to present a clear-sighted target for their Mass Action protest reflects strategies of broader political movements such as Occupy, whose open-ended agenda has been praised by critics as resistance to its conclusion, and presents issues of women's labour as an ongoing and multifarious battle. ${ }^{29}$ Thus, in its simultaneous functions of feminist critique and celebration of women's work, Mass Action exemplifies the broad range of parody articulated by Hutcheon's definition: including works that mimic, refer or pay homage through their utilisation of irony which "can be playful instead of belittling". ${ }^{30}$

Brown Council's restaging of earlier strategies of feminism, or to use Moore's phrase, "performing feminism, and performing it badly", ${ }^{31}$ presents a parafeminist "rethinking" 32 of durational performance and women's histories and thus operates as a parody of second wave feminist methodologies. This temporal parody, I argue, is politically and aesthetically productive in reimagining new terrain for (para)feminist practice.

Coming to Terms with the Weight of the Past

As I have examined in this article, both Brown Council and Hotham Street Ladies have made performance-based work that utilises domestic strategies of food preparation to enact various types of feminist critique and homage: of femininity, women's work, and the politics and practices of an earlier generation of feminist performance artists that includes Barbara Campbell, Lyndal Jones, Bonita Ely, and Joan Grounds. Indeed, the feminist strategy of performing with domestic materials to render the female grotesque, shared by the artists I have selected for analysis, was developed in the 1970s; notable performances include Bobby Baker's invitation for audiences to eat life-sized cake versions of her family members in The Edible Family (1976), the Waitresses' performance of a many-breasted torso waitress The Great Goddess Diana (1978), and Bonita Ely's cooking demonstration Murray River Punch (1980) in which she served "punch" with ingredients of pollutants in Australia's Murray River. ${ }^{33}$ The interjection of food into discourses of gender and performance allowed a previous generation of feminists to understand the way that systems of labour and value influence the codification and regulation of women's bodies according to patriarchy, ${ }^{34}$ as well as to rework models of female desire and pleasure towards inter-subjective forms of exchange. ${ }^{35}$ Thus works by Baker, the Waitresses, Ely, and others, functioned to simultaneously celebrate women's work and critique the subjection of women through domestic roles, while relishing in the corporeal pleasure of grotesque food behaviours.

By re-presenting these second wave strategies in the 2010s, Brown Council and the Hotham Street Ladies are part of a new generation of feminist artists employing strategies of parody as defined by Hutcheon: they possess a "critical distance" to their predecessors and are "repeating with difference" earlier feminist agendas. ${ }^{36}$ Such work demonstrates not only contemporary artists' continued commitment to addressing gender inequality but also their subtle homage to earlier feminist artists through parafeminist "rethinking" and extension of earlier strategies: thus their presentation of a simultaneous proximity and distance to history that shifts the terrain of feminism towards new dimensions of practice. ${ }^{37}$ I suggest this strategy is the defining feature of our contemporary moment in feminist art history.

In this article I have focussed on the work of Brown Council and Hotham Street Ladies, however my argument could be easily extended to a number of Australian feminist artists including Catherine Bell, Emily Floyd, Danielle Hakim, Alice Lang, Eugenia Lim, Hannah Raisin, Salote Tawale, Inez de Vega, and Kalinda Vary, among many others. I suggest that the citational and historicising project of these parafeminist practices allows the corporeal preoccupations of live and video art to be restaged: both more proximally and playfully, and at a distance from, the explicit politics of the past. At the same time, parafeminist parody can be considered a parodic inversion of the 1990s Bad Girls phenomenon, which disassociated humorous forms of gender-based practice from their feminist predecessors, since contemporary artists are including homage as a central element of their subversive feminist humour. The pleasure produced in such parafeminist practices demonstrates the value of parafeminist parody to a new generation of feminist artists, enabling them to assess both the gains and losses of their foremothers and, in doing so, negotiate new possibilities for feminist practices and ideology. Hutcheon suggests the "critical distance" that enables parody is usually presented through irony, however: 
"Irony functions, therefore, as both antiphrasis and as an evaluative strategy." 38 Therein, I read contemporary feminist art as a parody of earlier forms of feminism, with the "critical distance" between the text being parodied and the new, incorporating, work signalled by an irony that is both critical and evaluative.

To conclude, I will return to the delightfully disgusting work mentioned in the introduction to this article, You Beaut! (2013). I began with this artwork to open up questions about humour in contemporary feminist art and the associated strategies of parody and historical homage, and I asked more specifically what kinds of conclusions can be drawn when artists render abject female bodily fluid in a medium usually reserved for domestic pleasantries. From the outset, HSL's presentation of menstrual blood as feminist subject matter demonstrates the continued constraints and expectations that surround women's bodies. However, it further recalls the centrality of this subject matter in feminist exhibitions of the 1970s. ${ }^{39}$ The Ladies' rendering of female bodily fluid through cake decoration (itself a parody of another second wave methodology) exaggerates the work's feminist politic to the point of exaggerated cliché. Through the insights developed in this article, I propose that You Beaut! parodies the very notion of a feminist exhibition: both the predictability of feminist art conventions as well as their continued relevance after forty years. It revels in menstrual blood, parodies (both in the sense of critique and celebration) women's work, and delights in the viewer's shock; and in doing so, it laughs at how very clichéd this performance is. At its critical peak, this multi-layered parody asks of feminism: how far have we really come? Thus, You Beaut! instantiates Hutcheon's claim that parody is "one of the ways in which modern artists have managed to come to terms with the weight of the past." ${ }^{\prime \prime 0}$

This article was first published in n.paradoxa: international feminist art journal, No. 36, July 2015, Humour, pp. 23-31.

\section{Captions}

1 Hotham Street Ladies, You Beaut! (2013), site-specific installation for Backflip: Feminism and Humour in Contemporary Art, Margaret Lawrence Gallery, Victorian College of the Arts, Melbourne

2 Hotham Street Ladies, At Home with the Hotham Street Ladies (2013), installation in the foyer of lan Potter Centre: NGV Australia, Melbourne.
3 Hotham Street Ladies, Miss Havisham Cake (2010), entered in 2010 Royal Melbourne Show cake contest.

4 Brown Council, Work in Progress: Dawn to Dusk (2010), HD video, 8:51 mins.

5 Brown Council, One Hour Laugh (2009), HD video, 60 mins.

6 Brown Council, Mass Action: 137 Cakes in 90 Hours (2012), promotional image.

\section{Notes}

1 Laura Castagnini, ed., Backflip: Feminism and Humour in Contemporary Art, Margaret Lawrence Gallery, Victorian College of the Arts, University of Melbourne, Melbourne, 2013.

2 Amelia Jones, Self/Image: Technology, Representation, and the Contemporary Subject, Routledge

London and New York, 2006, p. 213.

3 lbid.

4 lbid., 217.

5 Linda Hutcheon, A Theory of Parody: Teachings of Twentieth Century Art Forms, Methuen, New York, 1985 , p. 32.

6 Ibid.

7 lbid.

8 lbid.

9 The Hotham Street Ladies, see http://www. hothamstreetladies.com.

10 lbid.

11 Undecipherable author, "Royal Melbourne Show judging comments: Hotham Street Ladies," September 9, 2010. Original scanned and emailed to the author by Lyndal Walker, February 15, 2014.

12 lbid

13 Linda Hutcheon, A Theory of Parody (1985), p. 32.

14 Simon Dentith, Parody, Routledge, London and New York, 2000, p. 17.

15 Ibid.

16 Brown Council website: http://browncouncil.com/about

17 For more on this body of work, see Anneke Jaspers, "Brown Council: Critical Comedy," Runway, 18 (2011); Megan Garrett-Jones, "Just for Laughs: Brown Council's A Comedy," Das 500, published September 3, 2010, http://www.dasplatforms.com/ writing/just-for-laughs-brown-councils-a-comedy

18 Judith Halberstam, The Queer Art of Failure, Duke University Press, Durham, 2011.

19 Mary Russo, The Female Grotesque: Risk, Excess, and Modernity, Routledge, New York and London, 1995, p. 73.

20 The video This is Barbara Cleveland (2013) is 
the latest instalment in the project.

21 Pip Wallis, "The View From Here: 19 Perspectives on Feminism: Exhibition Review," Next Wave Text Camp Reader, Next Wave Festival, Melbourne, 2010.

22 Catriona Moore, "Introduction: Performing Feminisms", MP3 sound recording, 4:41 mins, from a paper presented at LEVEL - Feminism and Art in 2013 Forum at Queensland University of Technology, Brisbane, March 9, 2013, http://www.ciprecinct.qut. edu.au/archive/2013/feminism-art.jsp

23 Catriona Moore, "The more things change... feminist aesthetics, then and now," Artlink, 33.3, 2013, p. 24.

24 Amelia Jones, "1970/2007: The Return of Feminist Art," X-TRA, 10.4, 2008, http://x-traonline. org/article/19702007-the-return-of-feminist-art/.

25 Alexie Glass, "Extimacy: A new generation of feminism," Art er Australia, 47.1, 2009, p. 135.

26 Bree Richards, "Doing, Being, Performing," Performa Magazine, Posted January 24, 2013, http:// performamagazine.tumblr.com/post/41227948102/ doing-being-performing. My emphasis.

$27 \mathrm{lbid}$.

28 Documentation can be viewed at the project's website: http://browncouncil.com/massaction/.

29 Hito Steyerl, "Art as Occupation: Claims for an Autonomy of Life", e-flux, 30.12, 2011, http:// www.e-flux.com/journal/art-as-occupation-claimsfor-an-autonomy-of-life-12/

30 Linda Hutcheon, A Theory of Parody (1985), p. 32 .

31 Catriona Moore, "Introduction: Performing Feminisms" (2013).

32 Amelia Jones, Self/Image, p. 213.

33 This strategy is also evident in photography; see Lee Miller's surrealist cakes of the 1960s and 1970s.

34 Mary Douglas's work was particularly influential in this area; Mary Douglas, Purity and Danger: An Analysis of Concepts of Pollution and Taboo, Routledge, London and New York, 1966. Key exhibitions include The D'Oyley Show: An exhibition of Women's Domestic Needlework (Sydney: Watters Gallery, 1979); Women at Work: A week of Women's Performance (Melbourne: George Paton Gallery, 1980); and internationally Dirt er Domesticity: Constructions of the Feminine (New York: Whitney Museum of American Art, 1992).

35 Rachel Fensham, "An Appetite for Trapeze," Performance Research 4.1, 1999, p. 142-50.

36 Linda Hutcheon, A Theory of Parody (1985), p. 32
37 Amelia Jones, Self/Image, p. 213. Other local examples of contemporary artists that incorporate cake into their feminist art are: Madeline Kidd's glossy sculptural and painting arrangements; Heide Holmes' video CAKE (2010); Damp's The Damp Pie Chart (2009); and most pertinently Kalinda Vary and Ebony Gulliver's recent performance Food for Thought (2014) in which they offered to their audience a choice of home-made cakes with satirical names such as: "The Obedient Wife" (crushed nice biscuits, no fillings, just the shell); "The Julie Bishop/Margaret Thatcher Tart" (Zesty lemon tart in flaky pastry case) and "Pussy Riot Tart- Vladimir Putin with cream on his face" (Caution: Contains unpalatable, indigestible elements.)

38 Linda Hutcheon, A Theory of Parody (1985), p. 53. My emphasis.

39 For example the Feminist Art Program's iconic exhibition Womanhouse (1972) which included Judy Chicago's installation Menstruation Bathroom. 40 Linda Hutcheon, A Theory of Parody (1985), p. 29.

Laura Castagnini is an Australian curator and writer interested in the performance of feminist, queer, and anticolonial histories. Recent curatorial projects include our word is our bond (West Space, Melbourne, 2015); Alice Lang Originals (Sydney College of the Arts, 2014); Backflip: Feminism and Humour in Contemporary Art (Margaret Lawrence Gallery, Melbourne, 2013); and Memory Screens (co-curated with Eugenia Lim, Australian Centre for Contemporary Art, 2013). As well as in numerous exhibition catalogues, her writing has appeared in Frieze magazine, n.paradoxa: international feminist art journal, Australian and New Zealand Journal of Art (Routledge), and Artlink journal. She is currently Programme Coordinator at Iniva (Institute for International Visual Arts) in London, and Secretary of fCu (Feminist Curators United). 


\section{Taking Care: Feminist Curatorial Pasts, Presents and Futures Victoria Horne, Kirsten Lloyd, Jenny Richards and Catherine Spencer}

This conversation took place electronically in March 2016 between four art historians and curators who have been involved with the Edinburgh-based reading group "Social Reproduction in Art, Life and Struggle". Established in 2014 by Victoria Horne and Kirsten Lloyd, our discussions have so far ranged from witch hunting and the refusal to reproduce, to the politics of communal housing and debates about "dual systems theory" in feminism. Questions concerning the feminist commons have recurred, as has the theme of labour. In the exchange that follows we draw from the debates that emerged through both these meetings and a series of research workshops organised by Victoria Horne, Kirsten Lloyd and Catherine Spencer that dealt more explicitly with the practical and conceptual aspects of curatorship and exhibition-making: "Curating Materiality: Feminism and Contemporary Art History" and "The Fabric: Social Reproduction, Women's History and Art" (both University of Edinburgh, June 2015); "Archive Materials: Feminism, Performance and Art History in the UK" (University of St Andrews, October 2015); and "Writing/Curating/Making Feminist Art Histories" (University of Edinburgh, March 2014).

We each come to the topic of "curating in feminist thought" from different perspectives: Victoria and Catherine have a background in the university and their knowledge has been formed primarily through exhibition histories and academic discourse; Kirsten is an independent curator and contemporary art historian; Jenny Richards is currently the co-Director of Konsthall C in Stockholm. Together with Jens Strandberg she runs the programme Home Works responding to the institution's location within a com- munity laundry, and questions surrounding the politics of domestic work and the home.

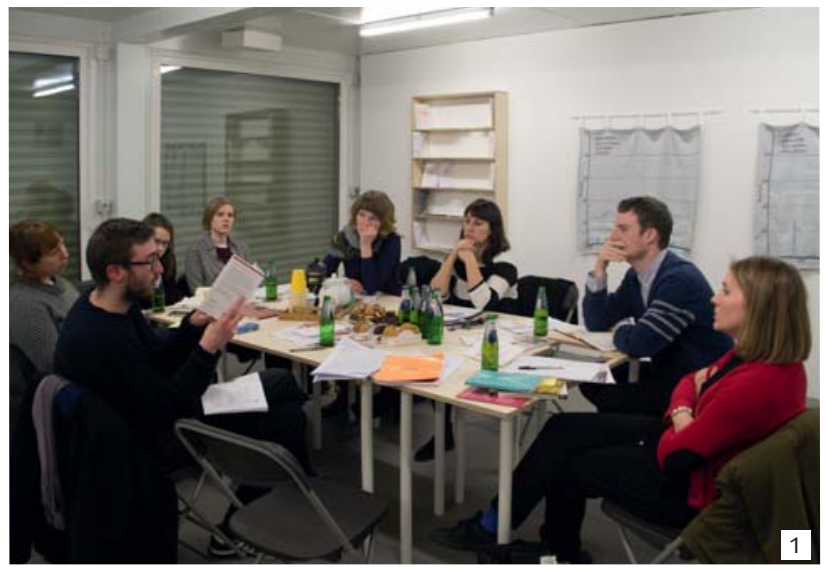

\section{1: Curatorial Histories, Curatorial Labour}

Victoria Horne: It's revealing that the second issue of Hilary Robinson's Feminism-Art-Theory anthology contains a section on "Curating Feminisms", which the first issue did not ${ }^{1}$. This reflects a generally heightened visibility that is most immediately attributable to the increased market interest in feminist art and the number of historical exhibitions mounted between 2005 and $2012^{2}$, but is also (we hope) due to a renewal of feminist and left popular politics in the wake of the 2008 financial crises.

Catherine Spencer: The impact of these latter elements also informs recent contributions to the field such as Angela Dimitrakaki and Lara Perry's edited volume Politics in a Glass Case: Feminism, Exhibition Cultures and Curatorial Transgressions ${ }^{3}$. 
VH: Yes, these publications alert us to the contradictory position of feminist critique now that art associated with the feminist movements of the late 20th and early 21 st centuries is being collected, exhibited and even commissioned by large-scale institutions. But from another perspective we can say that we have access to an increasingly comprehensive history of feminist exhibitions and feminist organising in the arts. My question is this: if we recognise that the history of feminist curatorial practice is still comparatively lacking, is this neglect mainly attributable to the difficulties (or impossibilities) inherent to writing such a history?

CS: Processes of exhibition making and display have been fundamental to the histories of feminist art production - the two have developed in tandem as works have entered, altered, and resisted or rejected museum and gallery institutions. I agree though that there are perhaps less well-defined histories of "feminist curating", and that such histories would need to look beyond recognisable and traditional institutional roles, while simultaneously recovering the work that has been done through established channels, but which has needed to remain hidden so that it can operate. And equally acknowledge that a feminist practice may be pitted directly against received notions of curatorship.

Kirsten Lloyd: I agree that the conception of the curator as an individual invested with the authority to select, operating at a distance from the process of production or even action is insufficient, particularly in this context. Though there have been a few calls recently to bind the definition of curating exclusively to exhibition-making, here we have to expand beyond the perimeters of the display space, or at least appreciate their porosity ${ }^{4}$. To my mind we need to develop a more nuanced understanding capable of addressing the curatorial function in social practice (or indeed curating as social practice), as well as the complexity of durational feminist curatorial entanglements with smaller, more experimental institutions. In other words activities that intervene in, reimagine, or remake structures.

Jenny Richards: The task of charting the effects these artistic and curatorial practices have had in shaping institutions is also far from simple, particularly as the resonances of this work operates according to temporalities that do not align with a chronological lineage. It makes me think of Mierle Laderman Ukeles' The Keeping of the Keys: Maintenance Art as Security (1973) created at the Wads- worth Atheneum in the U.S.: Ukeles took the museum guards' keys and locked and unlocked different galleries and offices, blocking access to rooms as they became designated as sites of "maintenance art". As Helen Molesworth notes, her role as artist "allowed her to explore the ramifications of making maintenance labour visible in public", yet crucially that labour was made visible to the institution as well ${ }^{5}$.

VH: Your comments remind me of a 1992 essay by Griselda Pollock where she suggests that, in direct opposition to modernism's privileging of the studio as the primary space of creation, materialist feminism focuses our attention toward the gallery, exhibition-making, criticism, etc., as "interdependent moments in the cultural circuit of capitalist production and consumption" ${ }^{\prime \prime}$. Undoubtedly, the decades since have seen art history place far greater emphasis on these very processes. Yet while Pollock's suggestion has been formally acceded, we could argue that the expanded notion of the "curatorial" has been reframed as another primary, creative act performed by a re-imagined romantic subject.

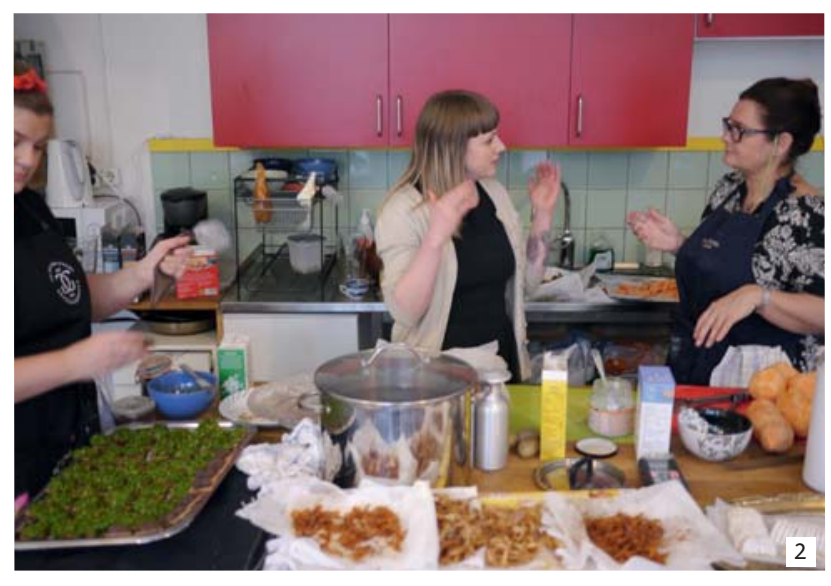

KL: Yes, I think it was Ruth Noack who observed that we are in the midst of a "curatorial epidemic". And this diagnosis can easily be confirmed by a glance at the swelling ranks of postgraduate cohorts on curatorial programmes, or the widespread appropriation of the term across disciplines and sectors. Of course this ascendancy of the curator can be framed as an economic symptom; her rise beautifully aligning with the demand for entrepreneurship, precarity, networks, and mobility. These arguments are by now well-rehearsed. Vesna Madžoski describes the lot of this new breed of "she-curator" as a precarious "girl for all", capable of performing a multitude of formerly distinct tasks by herself 7 . The feminisation not only of labour but of survival springs to mind here. Jenny, you 
recently used a phrase that really struck a chord with me: "the coping curator". Can you expand on this? What are the realities of curatorial labour today? Service provider? Professional carer? Hostess? ${ }^{8}$

JR: Where to begin! The coping curator is what we are all meant to be right? That woman who looks great, perfect lipstick, never needs to sleep and as Arlie Hochschild says, "offering only the clean house (gallery) and welcoming smile" . But of course that figure doesn't exist-well she doesn't live in me! Instead, to meet the demand, one must split oneself, pushing - as Hochschild highlights - the messy, difficult, undesirable work into the background, in order to leave a cleansed version of that role in the public. In efforts to critique the gendered categorisation of work and its expansion, you often come to perform the very figure you are trying to examine and erode. It is really hard to try and change this pattern. This form of self-exploitation and the slippage into this role is something that I try to address through expressing the marked paradox of this work publicly. For example, if Konsthall $\mathrm{C}$ is asked to make a public presentation then Jens and I make a point to talk about our role as "directors" as that of janitor / chef / cleaner / therapist / friend / organiser / builder / teacher / administrator / artist, etc. These are all roles and forms of work crucial to curating and being able to organise and work together, but often not articulated. Following the work of Silvia Federici and the strategies of the Wages for Housework campaign, the act of exposing the culturally hidden aspects of our role is important to how we can better understand the underlying exploitative structures of our working.

VH: I feel wary of claiming endurance predominantly for curators, or creative labourers more generally. Angela McRobbie recently published an article called "Notes on the Perfect", where this perfection functions not only to exacerbate competition between women, but to produce a heightened self-beratement which she locates as the direct outcome of (punishment for) the gains of second-wave feminism ${ }^{10}$. As a set of descriptors I find her article painfully accurate (as is your quip about great lipstick, Jenny!) and from discussions I've had with friends I know it to be true across disciplines/careers. Perhaps the gift-or curseof curating and writing is that it gives us a context to actually reflect on these unattainable demands? And perhaps then we need to consider the potential of work-refusal, or try and take seriously the "good enough" attitude of ordinariness ${ }^{11}$. Of course that's easier said than done.
JR: Yes, absolutely, this of course isn't limited to creative labourers but felt across different sectors and working (and non-working!) positions. Sophie Hope and I run a project called Manual Labours that explores physical relationships to contemporary work. Here we try to find ways to connect with workers in other fields of work with very different circumstances and conditions. Within this project the practice of saying NO to work-or as you say Vicky "work-refusal"- has arisen as a strategy to address the fragmenting and disempowering effects that current (often precarious) working conditions produce. We're currently working on a stage of the project called The Complaining Body that looks at the world of workplace complaints with call centre workers, university staff and commuters. Rather than investigating complaining bodies, we found instead a plethora of uncomplaining bodies; individuals who were unable to find a way to articulate their work struggles or to say "no" to working unpaid overtime. The reasons given ranged from fear of losing their job to more gendered perspectives on complaining, including appearing like the stereotypical nagging woman. This is a feeling Sarah Ahmed brilliantly analyses in Feminist Killjoys ${ }^{12}$. So how do we find ways to critically and practically disrupt the working conditions that we inherit and perpetuate?

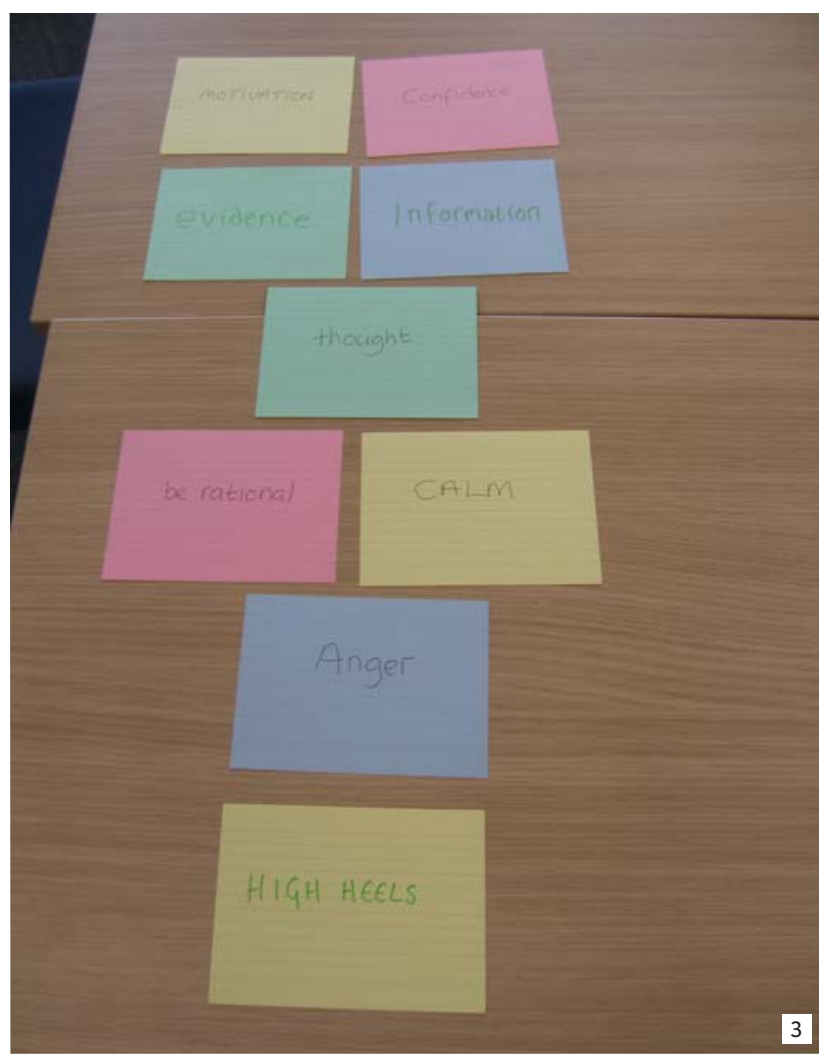


KL: All of this puts me in mind of something that I've been concerned with for some time now, which is the value that concepts of social reproduction elaborated in feminist political economy can bring to analyses of contemporary art and curatorship. Though recent literature has expanded the term's scope, historically it has referred to the "labour of love" traditionally performed for free by women in the home to sustain and replenish the working population. Kathi Weeks's observations on the interpenetration of production and reproduction seem to describe perfectly the shift in emphasis that you described earlier Jenny, and it is one that I have certainly experienced in relation to my own work. In her words: "Not only is reproductive labour more clearly productive today, as evidenced by its many waged forms, but productive labour is increasingly reproductive in the sense that it often creates not only strictly economic goods and services but also social landscapes, communicative contexts, and cultural forms ${ }^{\prime \prime 13}$. So while a great deal of attention has been given over to curatorial knowledge production, this perspective really begins to open up the potential to examine other important-yet deeply connectedaspects of the curatorial process including the complexities of care and the creation of socialities.

VH: Returning to Kirsten's observation on the increased professionalisation of curators, primarily through postgraduate programmes; Felicity Allen gave a talk recently in which she noted that these processes of professionalization are often exploited to exclude certain people. I'll quote her at length as I think it offers a very useful historical dimension to the discussion we're having:

"The histories of curating produced as a result of the need for reference books to teach with ... have yet to recognise the work of the mostly anonymous and female gallery educators who preceded them, while a heroic avant-garde is celebrated .[...] I have argued that the continuing negation of gallery education as a specific form of radical curation in Britain since the 1980 s is comparable to the negation of women's reproductive labour; that is, I am referring to the 1970s analysis of women's domestic labour which showed it was systematically unrecognised and unpaid - it [gallery education] was in fact a model of life as work and, sometimes, art as life. While gallery education has frequently been paid, contracts have often been precarious and, crucially, it is-accurately or not-associated with women and children"14.
CS: This links up with what you were saying at the beginning of our discussion, Vicky; in terms of the last two decades at least (if not longer), histories of feminist curating would need to account for the work done in education departments, often by predominantly if not entirely female staff as Allen points out. In major institutions (such as Tate and the National Gallery) education departments are structurally demarcated as separate from the curatorial departments, even if there may be significant overlaps in actual working practice-particularly, for example, in commissioning social art practice as you mentioned, Kirsten. And, of course, since 2008 gallery education work has become increasingly precarious and under-funded.

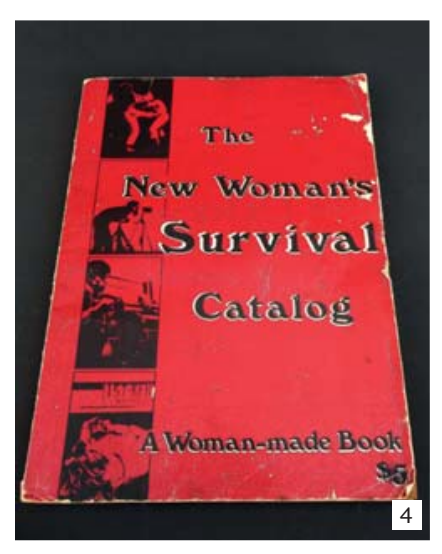

\section{Feminist Politics and the Institution}

VH: Since the 1990s (and especially the mid2000s), the increased absorption by museums of art associated with the feminist movement has coincided with a massive expansion of those same institutions. It seems we urgently need to trace and theorise more comprehensively the contradictions of these coincident developments. If we listen to Hester Eisenstein's arguments about feminism's "seduction" by corporate interests, we start to understand how feminist ideals can be used to refurbish rather than revolutionise the museum $^{15}$.

KL: These questions about the "compatibility" of feminism and the museum, as well as the latter's neutralisation of politics, have of course been around for some time, but I agree that it needs to be reconsidered in relation to current circumstances.

VH: Indeed, and whether institutional opposition results in neutralisation, or co-optation. When 
thinking about feminism's beleaguered relationship with the museum, we can look to the long history of protest against those institutions; not only from within the post-war cultural sphere, but even thinking back to Mary Richardson slashing the Rokeby Venus, or Mary Wood attacking Singer Sargent's portrait of Henry James. In Wood's words, "I have tried to destroy a valuable picture because I wish to show the public that they have no security for their property nor their art treasures until women are given political freedom".16 This reveals the impasse between feminist politics and a particular kind of institution, at least in patriarchal-capitalist conditions, which serves to shore up economic value and gendered distinction.

JR: Yes, there are institutions that engage periodically with feminism as an "issue", and then there's the question of what does - or might - a feminist institution look like? And what tools are needed to build it? I'm thinking about grassroots cultural productions that attempt to build entirely new forms of culture from the bottom up. The New Women's Survival Catalog is a brilliant feminist manual from 1973. Fed up with efforts to change "the master's house" from the inside, they sought to grow a new type of culture based on the need, desires and experiential knowledge of their collective. Six women travelled over 12000 miles to research, meet, document, and share thriving feminist practices across the U.S. For me there seems to be something critical in the "doing", in trying things out. The New Women's Survival Catalog took shape through the practices it drew from and, in turn, supported and inspired further activity. Is there something to be learnt from this approach, the potential in the material and physical efforts of making, that maybe can equip us with some new tools for imagining other models? In practical terms there are many complexities presented by institution building, some we've already touched upon-namely economy and time (two things we all seem to struggle with).

VH: Do you think the museum itself retains any potential? Might we see it as a place that not only shores up the existing social order but provides an opportunity to create new publics or new horizons? Or will a "feminist" art museum or curatorial practice always be necessarily compromised? Here I'm interested in the institutional operations (funding, access) that might act to re-secure power even against the exhibition/artworks on display. So, for example, what does it mean to display The Hackney Flashers' activist documentary project Who's Holding the Baby? (1978) in a contemporary art museum? And if that museum provides a free crèche (as the collective first demanded in a 1979 exhibition at the Hayward), does that institutional change evidence some measure of success in their artistic critique?

CS: Who's Holding the Baby? was included in a show at Nottingham Contemporary called Somewhat Abstract in 2014. It was a really interesting show that featured items from the Arts Council Collection, and it was great to see Who's Holding the Baby? within that context, but the crèche element was missing, so it could be argued this was an example of a feminist work not actually being curated in a feminist way. Which goes back to the point that while we may feel we have increasing access to a history of feminist art-making, the ways in which that has both been interlinked with and helped to inform feminist curatorial practice (as well as how feminist production might be hampered by traditional curatorial practice) are perhaps still less immediately clear.

VH: Helen Molesworth evidences this conceptual difficulty, when she honestly admits: "I feel fairly confident that I know how to write an essay as a feminist, less sure I know how to install art as one ${ }^{\prime \prime 17}$. Is there a friction between theory and practice, about how to translate fairly abstract ideas about politics into the material space of the exhibition?

$\mathrm{KL}$ : In many ways I don't find this admission surprising, after all the essay is by definition an exploratory, provisional form, an arena to test ideas. If the museum's literary equivalent is the encyclopaedia, the "laboratory" approaches associated with new institutionalism seemed to offer something more akin to an essayist practice, yet this moment has now pretty much passed. In thinking about feminist curatorial futures and, in particular, their association with the institution (broadly defined), where might we go from here? Jenny, going back to your question as to what constitutes a feminist institution, what are your thoughts on this? Your programme at Konsthall C is clearly aligned with your feminist politics, but I wonder if its impact has gone beyond the visible curatorial themes and specific artistic projects to influence structures, approaches, and ways of working as well?

JR: This is a really important point, and something we think about a lot. It links to some of the earlier points on how to expose the hidden labours of the institution in order to reorganise and value labour differently. On a structural level, details such as having a flat pay structure, so that everyone working at Konsthall $\mathrm{C}$ is paid the same, is fundamental 
in practicing the politics we try and discuss through the programmes (credit should go to Anna Ahlstrand and Kim Einarsson who instituted this during their tenure). It provides the foundation for a more collective approach to working, where our politics can't just be gesturally explored in the content of exhibitions. We also rotate our work tasks so that everyone is involved in the different jobs at the Konsthall. Jens also has an app on his phone called "hours tracker" that records the time we spend working. Whilst the demands of the Konsthall mean that we can't be paid for the real hours we do, we can still measure and communicate them to the board and our funders.

KL: So you see a future for the feminist institution more generally then? I'm also interested to hear how such internal structural adjustments resonate with (or impact upon) those whom your activities are designed to engage with and indeed how you engage with them.

JR: I see a future in people playing with institutions. For example when Konsthall $\mathrm{C}$ was set up by the artist Per Hasselberg and the neighbourhood council of the area "Hökarängens Stadelsrådet" they decided to call the space Konsthall C. This naming act was a performative gesture to allow what was essentially in the beginning an art project to access institutional funding. Looking back now, continuing to think of the space as an evolving public artwork is conceptually fruitful; it encourages us to push the space in directions other than the standardised development art organisations are expected to follow. Building on from that, I think this play between structure and audience is important to examine. How much of your organisational working bleeds out into the space; into the way the audiences experience the exhibitions? I see it happening on different levels. In Konsthall C's case, one part is the different audiences that come to connect to the programme. Our explicit commitment to challenging the devaluation of domestic labour propels our programme to find ways to work with audiences and groups that are engaged in these politics, too. For example the last two projects with Ciara Phillips and Stephan Dillemuth have tried to find ways to support the activist group Hemtjänstupproret, an organization of home care workers challenging their oppressive working conditions. We began a relationship with them last year when we organised a discussion between the writer Gunilla Lundahl and Clara Lindblom-Stockholm's councillor responsible for elderly care-which drew on Lundahl's research into the monitoring of home care workers through a GPS app. Representatives from the union Kommunal and activists from Hemtjänstupproret were invited to discuss the regulatory scheme and argue for the changes that could be made. This event became really important in how the activities inside the Konsthall can go beyond this site to support and care for those struggles happening in the private homes around the gallery.

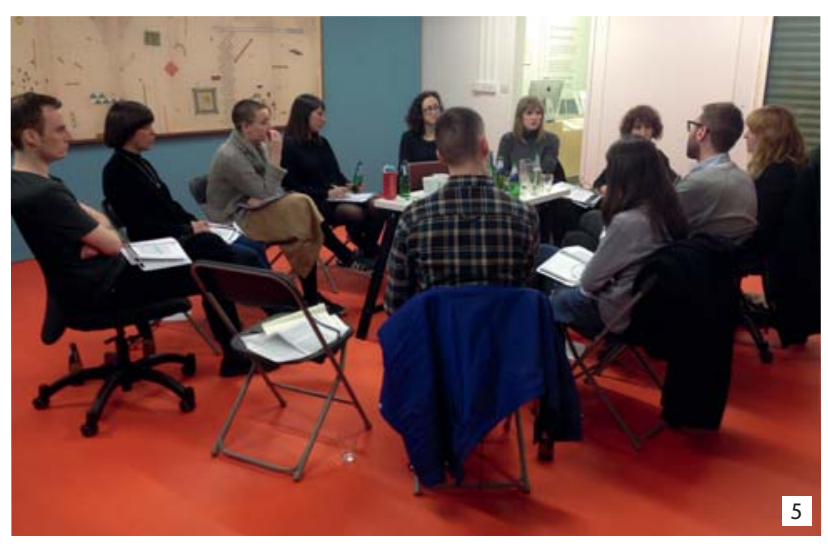

\section{Feminist Temporalities and Duration}

CS: One of the threads running through our discussions and events has been temporality. This relates to debates about social reproduction, in terms of hidden time and hidden labour, but also models of durational and generational time. Duration offers one alternative to cyclical time or the "waves" model of feminism, and might ensure that longer histories are not lost, but don't become constricting. This is signalled by, for example, the title of the Feminist Duration Reading Group in London ${ }^{18}$. The temporality of the reading group, as an organisation that must of necessity take time and evolve at a gradual but ideally accumulative pace, could be a useful model for curatorial practice. Equally, the sometimes recursive, sometimes discursive temporality of the reading group model has connections with the pedagogic time of the seminar room, and also perhaps offers a slightly different perspective on the intense interest in re-performance and restaging in relation to both feminist art and curatorial practice during the 2000s.

VH: For some time now I have had a niggling thought that the reading group format bears some relation to the broader historical operations of re-performance, re-enactment, and turn to the historiographical or archival in contemporary art. That in an increasingly digital age we frequently find ourselves returning to forms of communication and print cul- 
ture (the reading group, the fanzine etc.) which were actually very significant to feminist political organising in the late 20th century. (I don't want to suggest they even went away entirely of course). These forms seem unmistakably to offer means of community-building and sharing that can be great sources of strength in our precarious working environments today.

$\mathrm{KL}$ : The importance of sharing "real time" in terms of creating the conditions for solidarity.

JR: Definitely, or the workshop format that creates the conditions for being together but also for making things together.

CS: Yet at the same time there is a need to acknowledge the potentially exclusive operation of group formation, and the privilege that can coexist with precarity. Those two things often oscillate, sometimes with productive, sometimes deeply destabilizing effects, in our professional relationships with institutions both academic and artistic.

VH: That's very true. Perhaps this contradictory "oscillation" is matched by feminism's broader struggle between critique and complicity in relation to art's institutions. Jo Freeman's powerful essay "The Tyranny of Structurelessness" is perhaps an important reference point also for thinking about collective organising and the impossibility of total freedom beyond existing operations of power-the idea that structurelessness is not only impossible but would in all likelihood also be repressive ${ }^{19}$. More recently Andrea Fraser has comparably reminded us that "we" are the institution also and cannot escape $i^{20}$.

CS: Agreed; these were important debates that happened during and as a result of the women's movement in the 1970s, and it would be a shame to repeat those conversations (though I don't get the sense we are, or at least hope not). But there is also a feeling of not wanting to assume knowledge, perhaps, that leads to the kind of repetition you were just talking about Vicky-or the "re-performance" of knowledge. So it is not simply fetishization on the one hand or ignorance on the other, but combined with worries about imposter syndrome, being somehow behind and needing to "catch up".

VH: Imposter syndrome is certainly a factor! I also think there's a link to be drawn here to what Jenny said earlier about "coping" and the demands of perfectionism. The association between this neverending drive and repetition, or the inability to move forward, is one that I hadn't considered before. Think- ing cynically, that inwardness, or backwardness in terms of the archival turns in contemporary art and academia, might imply a temporal stagnation or an inability to imagine a future ${ }^{21}$.

CS: Which links back to the danger you noted before that the reading group structure might inadvertently throw up some of the issues that have been very usefully interrogated in relationship to feminist re-performance. While many of these (I'm thinking of a project like re.act.feminism \#2 - a performing archive) have been incredibly valuable for our understanding of feminist art histories, in 2011 Helena Reckitt expressed a degree of wariness about reenactment within contemporary art more generally: "Where once I greeted news of such projects with anticipation, now a sense of ambivalence, even scepticism, mutes my response. Re-enactment, I fear, is in danger of becoming just another aesthetic trope, a backward glance that fails to shed light on why and how we remember and represent the present" 22 . So there is definitely a question around how we handle the temporalities of re-performance and repetition (and the work of an artist like Sharon Hayes is extremely interesting for the complexity with which it addresses these returns), which might lead us back again to the idea of durationality as something that has a sense of layered sedimentation rather than disjointed citation.

KL: In terms of this idea of durational engagements, I can see similar tendencies (and associated issues) in a number of projects or programmes that explicitly state their commitment to slower, more consciously iterative forms of curating ${ }^{23}$. They too prioritise spending time together and creating safe spaces for exchange. Clearly, this entails a different type of interaction with institutions and there often appears to be a strong desire to flee visibility; to place value instead on the temporal shadows of curatorial production, or at least to emphasise that any publicfacing facets only constitute a small element of much deeper (and longer) endeavours. I read an interesting article recently that was collaboratively written by a group of academics from North America who call themselves the Great Lakes Feminist Geography Collec$t_{i v e}{ }^{24}$. They call for a feminist politics of resistance predicated on slow time-on taking time. Though their aim is to counter the relentless acceleration of time(lines) in the neoliberal university, the same pressures and velocities can be witnessed across a range of fields, including of course the curatorial sphere. Fast and frequent production is an essential component of visibility. But I would be wary of associating 
what we might call "relational curating" to political drives to slow things down. As far as I can see the demand to keep up with accelerated rates of production remains and, as we know, the nurturing of relationships-whether with communities, allies or loved ones-requires a great deal of intensive labour!

VH: Yes, the demands of an "accelerated rate of production" names it precisely. As much as I enjoy our reading group(s), this is the contradiction that I'm aware of. While in one sense these are "slower" forms of interpersonal communication, the growth of temporary, transitional, relational feminist events is precisely due to lack of time. The lack of lack of slow research development that would allow us to organise or "curate" less temporary formats or produce work on a longer scale. Whether this is because of the accelerated demands of contemporary academia, or because of the sheer excitement and motivation around these topics at present, is something I don't have the answer to. Probably a bit of both. operate?

\section{KL: How would those less temporary formats}

JR: It actually makes me think of your own approach Kirsten, especially your project ECONOMY with Angela Dimitrakaki and its evolving exhibitions, commissions, online platform, and publication, each constructing different temporalities and modes of engagement ${ }^{25}$. I suppose you could also think about a project like The Grand Domestic Revolution (GDR), which began in 2009, co-curated by Binna Choi and Maiko Tanaka at Casco, Utrecht. They develop what they term "living research", or a collective exploration into the contemporary condition of the private home, where "living together" became their research methodology, to be practiced in and around the home ${ }^{26}$. Collaboration and living together demand time, to build relationships and to experiment with different ways of being together. Yet, within this structure there were very different temporalities operating simultaneously, which tie with your point about the intensity of the labour a durational approach requires. It feels like there are different strategies at play; there is the formulating of open-ended durational frameworks that insist on evolving according to their own temporality, and slowness more as a mode of attention to particularities within that framework?

CS: The idea of "relational curating" feels like a suggestive, if potentially provocative, one. This might both seek to address the elisions of feminism within "relational aesthetics" (as Helena Reckitt has shown) and the need to negotiate the tension between solidarity and nepotism that we've often discussed ${ }^{27}$.

VH: I suppose I'm thinking about how that attention to the relational, the hidden affective networks and so on, how that work can be made more permanent for future "readers". When I'm thinking of "longer term" preservation work, writing books, or the curating of permanent installations, collections, archives, etc., is this actually where slower research can take place? But we first need feminist archives and funding in existence to allow this. Having worked on the history of feminism and encountered the gaps in that archive, or experiencing as I am the daily struggle of funding and job applications, I am aware that these are necessary conditions for slow, thoughtful reflection. The sort of reflection that feminist history deserves. Rather than the temporary, episodic work we are compelled to do at present because of tenuous financial arrangements and the desire to always "keep up".

JR: Exactly, and within current cultural funding the short-term project still reigns. At Konsthall C we try and work with different temporalities and cultivate a framework for a slower mode of commissioning. Our programme Home Works runs for two years (as that is the length of our contract) and so we invited two practices-Joanna Lombard's and Gunilla Lundahl's-as two-year commissions. Rather than placing an expectation on what this commission might produce (a solo exhibition, a film etc.), the invitation is based on the work they've carried out already, the themes and questions their work interrogates and inspires. Their respective practices offer a framework for other exhibitions and events to evolve from. By centralising the artistic practice, rather than the format funding structures cultivate, we hope to be more responsive in finding the best conditions to support their work. Thus far, it has been refreshing to see how an organisation can support the development of practices in different ways, from helping writing a $\mathrm{PhD}$ application to inviting an artist to develop an exhibition whose work informs questions Lundahl or Lombard are considering. Yet, the struggle in finding funding to create this framework is constant.

CS: Perhaps there is also something to be said here in terms of large-scale curatorial projects like Wack! Art and the Feminist Revolution (2007). I completely understand the criticisms that have been made of shows like this, but the legacy of this exhibi- 
tion does seem to be doing something useful in terms of enabling lateral connections both temporally and geographically. Exhibitions might allow for a form of rapid translation, or a different kind of translation to the linguistic, which has also been valuable for thinking about feminism transnationally. There are also examples where technology can help create what, in a different but related context, the scholar Mechtild Widrich has called a "delayed audience" ${ }^{28}$ such as the re.act.feminism \#2 website ${ }^{29}$. Perhaps the curatorial can do a certain kind of work in this respect, which it is very useful to hold on to, despite the attendant dangers of collapsing difference.

VH: In a related vein (particularly for a show like Wack! which many of us talk about without having experienced), the issue of translating, or reproducing, knowledge is of course a crucial one. This forces us to consider the limited timeframe of the event in comparison to the time of the collection/archive/catalogue. How do we record and translate the spatial and affective experiences of the curated exhibition across time? This relates back to my initial question of whether attempting to write histories of curating is an endeavour bound to failure?

CS: So one of the main ideas within some of this thinking is that it could be argued feminist curating needs to be open to anachronism and to re-discovery, while remaining attuned to the problematic lacunae that inform these modes of thinking. Equally, might feminist curating, in a durational mode, offer an alternative to the jumps and starts inferred by re-performance?

JR: I wonder if the feedback loop is useful as well in visualising what this curatorial approach would look like?

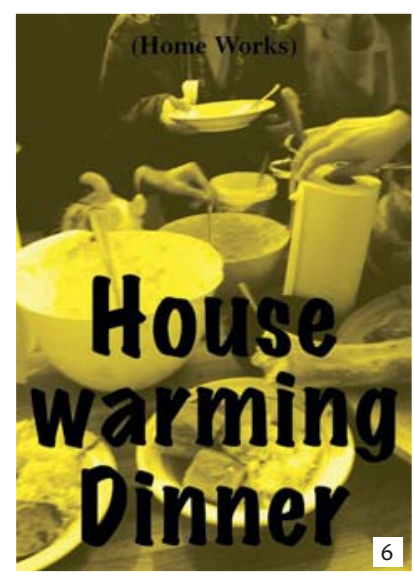

\section{Postscript: Care and Collaboration}

KL: This seems like a good juncture to ask a tricky question: what might we understand by a "feminist" curatorial approach or methodology? A lot of ideas have come up here: addressing power and taking care to power, transparency and opacity, pedagogy and solidarity, duration and excavation, structures and alliances. The concept of "care" also certainly appears to be attracting a lot of attention at the moment and it's a big theme in your programme at Konsthall C Jenny-perhaps it provides one possible aspect of what we might start to think of as a feminist curatorial methodology.

JR: There are two points when considering care: there is the care of the organisation, in terms of both how we care for each other as workers now and how to help the organisation to persist into the future; then, connected to this is the care of the programme and its meeting with a public. To address the second part; care is taken in how the exhibition can be developed as a site of activation. How do the objects or materials within the exhibition operate to create moments of negotiation, discussion, and togetherness? But in order to create the conditions for taking care within the programme, we must first consider what urgencies need to be addressed for its users and locality. What is interesting about working around questions of domestic labour and social reproduction is that everyone can relate to it. We all have to clean, cook, and care (some more than others of course). From there we develop exhibitions that derive from a question, which we invite other artists and contributors to speculate around. In our methodology, Lundahl poses the questions to work on, which we then are able to tailor to the issues that matter in our locality. This follows what Elke Krasny describes as the long history of activating "the question as a method" in feminist thought ${ }^{30}$. In terms of caring for particular subjects or contributors to the programme, for us it is crucial that domestic workers or in our case home care workers from the activist group Hemtjänstupproret are invited to join us in this work. We are not the experts nor do we have the experiential knowledge of the conditions of domestic workers, but we can invite others in with that knowledge to shape how this inquiry develops to better support and care for their working struggle.

KL: Yes, I think it's fair to say that you take a different approach to the "taking care" of artworks than the etymological roots of the verb curare is usually taken to imply. My own experiences in curating 
artworks that are often categorised as "social practice" have shown me that "care" passes from a concern with the object of art to care for the relations involved and the "project" as a whole. An important part of this process has often involved encouraging the ongoing cooperation of the institution, as I'm often not necessarily a salaried member of staff but a freelance individual with pretty limited authority to act. I don't think I'm alone in this-as Katy Deepwell has observed the majority of feminist curating is done on a freelance basis ${ }^{31}$. So in thinking about the present position of the institution, perhaps we need to go back to the emergence of the women's art movement and the absence of the external curator-the majority of these projects were self-organised and were often committed to forging new structures. If today the curator is not fully absorbed into (and secured by) the institution, she instead frequently works "in the thick of it" as Alex Farquharson suggests - with all the precarity and need for solidarity that implies ${ }^{32}$.

JR: I think your point on how the term "curate" has expanded to deal with not only caring of objects but the caring of subjects is really important Kirsten. I've always been anxious about using the term curate in my own work, nervous of its connection to a historical trajectory I don't feel part of, and a set of practices and power relations which I try to work against. Yet to expand the term from its etymological root seems to offer new potential. Maybe it can be taken further to not only reassert the significance of care in this role for objects and now subjects but also the responsibility to bring a reflective perspective on the durational caring labour the role demands?

KL: So, returning to Weeks's observations, can we view reproductive work as both thoroughly enmeshed with the demands of capital and as offering potential grounds for counter struggle? What do you all think about the development of a feminist politics of care, and, what can this mean in the context of curatorship?

JR: Silvia Federici springs to mind here: "Through my experience at home [...] I also discovered what I now call the 'double character' of reproductive work, as work that reproduces us and valorises us not only in view of our integration in the labour market but also against it." ${ }^{33}$ She argues that the space of the home and the work performed there has a double character-simultaneous to the invisibility of labour and power relations, it offers a space of potentiality where other relationships and modes of communication can be formed. For me this connects to another key question for feminist curating and that is how to mobilise collectivity around feminist struggles when the categories of work and gender that we formerly might have gathered around have radically eroded. This question has become particularly pertinent since Home Works' investigation into the Icelandic Women's Day Off, a mobilisation that happened in Iceland in 1975 to raise the visibility of female labour (both paid and unpaid), which brought the whole country to a standstill. Investigating this inspiring event now can feel disempowering as the possibility to come together and collectivise around an issue is increasingly harder-a point raised by many of those involved in the 1975 strike. With precarious contracts and freelance working there is no shared employer to unite around, and, quite rightly, the homogenous term "women" is not necessarily one we all want to identify with. So I wonder if we can add this to your question, Kirsten, as another concern to take away from this conversation: how to care for the fragmented, singular subject that we all inhabit? How do we find ways to unearth its double character or potential to form other alliances from within this site of contradiction, paradox, and struggle?

KL: To bring this text to a close, then, perhaps we could briefly reflect on the writing process itself. Inviting you all to participate in this conversation came out of a desire to extend our live interactionsto precipitate another iteration as it were-but it was also a conscious move to avoid the usual singleauthored text format. We touched earlier on the potentially exclusive operations of group formation, and indeed, given the links between us all, this article could be seen as yet another example of "cronyism, nepotism, and feminism" ${ }^{34}$.

VH: Your words remind me of a wonderful article written by Meredith Brown about AIR Gallery in 1970s NYC, which reminds us of the importance of "contact capital" and the building of networks, among women, through extra-institutional spaces, cooperatives and galleries ${ }^{35}$. We champion or celebrate these peripheral networks, live them ourselves to an extent, and yet at what point do we start to criticise them as "cronyism"-once they become institutionalised? As Catherine mentions above, the forming of our reading group should involve an awareness of privilege...

CS: There is the politics of the "informal chat" format we have embraced here, even though it has 
involved a lot of editing and shaping...so it's debatable precisely how informal it is.

JR: Definitely and beyond the structure of this article what about the language and textures we have used to try and capture feminist curatorial practices? What forms of feminist articulation have we worked with that seek to expand the limiting mode of expression through which we are pushed to valorise ourselves? This is something I often am vexed by. At the same time our approach of writing together has required us to be somewhat vulnerable, to expose the usually hidden bad spelling or the unpolished confused comment. I mentioned the possibility of printing some of our Skype chat alongside this conversation as a means to expose the messy but intimate side this text has produced. A side that perhaps better illustrates the care we are cultivating and the contradiction we are working under?

VH: Our reflection upon the politics and status of discourse has of course a long history in the humanities. I have great fondness for Irit Rogoff's feminist celebration of gossip: "An alternative history in which the concept of Modernism gets undone not necessarily by a parallel cultural heroism gendered female but by a set of small-scale actions and receptions taking place at the margins; the pleasures of conversations, the conflicts of domesticity, the agony of rejection and failed love, the spreading of rumours, all the low moments which invariably follow the high moments" ${ }^{\prime \prime 6}$.

CS: We've debated about whether or not we should end this conversation with someone else's words, but I actually think it's very fitting in terms of our thinking around the reading group structure, durationality, the need to take time to listen, care, and respond, the exchange of knowledge, and the writing of histories. Sara Ahmed talks about the importance of feminist citational practices, so this feels like a fitting point to end! ${ }^{37}$

All: We would like to acknowledge and thank our fellow reading group participants for exploring with us the politics of conversation: Frances Stacey, James Bell, Harry Weeks, Glyn Davis, Jennie Temple, Laura Guy, Kirsteen MacDonald, Catherine Street, Georgia Horgan, Angela Dimitrakaki, Angeliki Roussou, Fiona Anderson, Denisa Tomkova, Ben Nichols, Kirstie Skinner and guests including Petra Bauer, Katie Schwab and Akiko Kobayash.

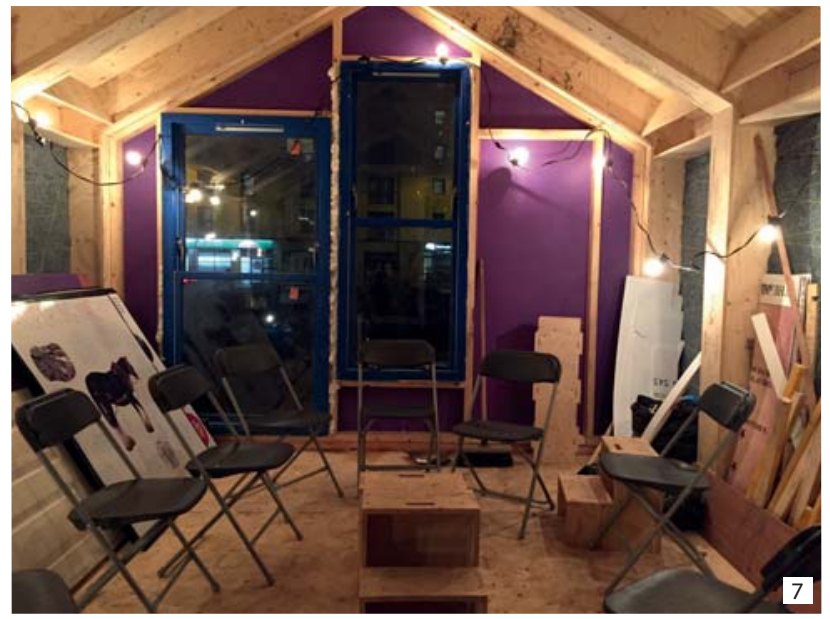

\section{Captions}

1 "Social Reproduction in Art, Life and Struggle" Reading Group \#3 at Collective in the context of Gorgia Horgan's exhibition Machine Room (2015) (http://www.collectivegallery.net/archive/2015-georgia-horgan) holm

2 Home Works 2015-2017, Konsthall C, Stock-

3 'Manual Labours: The Complaining Body, What do you need in Order to Complain? Workshop exercise with University Workers, Northern England 2015

4 The New Woman's Survival Catalog, 1973 by Kristen Grimstad (Editor), Susan Rennie (Editor)

5 "Social Reproduction in Art, Life and Struggle" Reading Group \#7. Sewing and Sex Work: Organising Labour at Collective with Petra Bauer. Organised by Frances Stacey. (2016)

6 House Warming Dinner Home Works 20152017, Konsthall C

7 "Social Reproduction in Art, Life and Struggle" Reading Group \#6: "The man-made environment and the politics of communal living" at Fountainbridge Community 'Wikihouse' with Akiko Kobayash from Assemble Collective Self Build (http://assemble-csb.co.uk/\#). Organised by Frances Stacey. (2016)

\section{Notes}

1 Hilary Robinson ed., Feminism-Art-Theory (John Wiley er Sons, Hoboken, 2015) and (John Wiley er Sons, Oxford, 2001).

2 Hilary Robinson discusses these developments in greater detail in "Feminism Meets the Big Exhibition: 2005 onwards," Anglo-Saxonica Vol. 3 No. 6, 2013, pp. 129-152.

3 Angela Dimitrakaki and Larry Perry eds., Politics in a Glass Case: Feminism, Exhibition Cultures and Curatorial Transgressions (Liverpool University Press, 
Liverpool, 2013).

4 See for example Jens Hoffmann and Maria Lind, "To Show or Not to Show." Mousse Magazine No. 31. Accessed 23.3.2015. http://moussemagazine.it/ articolo.mm?id=759

5 Helen Molesworth, "House Work and Art Work," October Vol. 92, Spring 2000, p. 79.

6 Griselda Pollock, "Painting, Feminism, History," in Destabilising Theory: Contemporary Feminist Debates, Michèle Barrett and Anne Phillips, eds., Polity Press, Cambridge, 1992, pp. 138-176, p. 146.

7 Vesna Madžoski, De Cvratoribvs: The Dialectics of Care and Confinement, Atropos Press, New York and Dresden, 2013.

8 See Elizabeth MacGregor, "The Situation of Woman Curators" in New Feminist Art Criticism: Critical Strategies, Katy Deepwell ed., Manchester University Press, Manchester, 1995, pp 70-75.

9 Arlie Hochschild, The Managed Heart: The Commercialization of Human Feeling, University of California Press, Berkeley, 1983, p. 167.

10 Angela McRobbie, "Notes on the Prefect," Australian Feminist Studies Vol. 30, No. 83, 2015, pp. 3-20.

11 This phrase derives from the psychoanalyst D. W. Winnicott's influential theorisation of the "good-enough mother". D.W. Winnicott, The Child, the Family, and the Outside World Penguin, London, 1973.

12 See Sara Ahmed, The Promise of Happiness, Duke University Press, Durham, NC, 2010.

13 Kathi Weeks, The Problem with Work: Feminism, Marxism, Antiwork Politics, and Postwork Imaginaries, Durham and London, Duke University Press, 2011, p. 141.

14 Felicity Allen, paper given at KEYWORDS, Edinburgh College of Art, 8 March 2016. Quoted with kind permission of the author. For more information on the KEYWORDS project, see www. keywordscontemporary.com

15 Hester Eisenstein, Feminism Seduced: How Global Elites Use Women's Labor Power and Ideas to Exploit the World, Routledge, London, 2009.

16 Anon., "Academy Outrage," The London Times, 5 May 1914.

17 Helen Molesworth, "How To Install Art as a Feminist," in Modern Women: Women Artists at the Museum of Modern Art, eds. Cornelia Butler and Alexandra Schwartz, Museum of Modern Art, New York, 2010, pp. 498-513, p. 499. Exhibition catalogue.

18 In 2015 this group collaborated on the Now You Can Go programme of events. Accessed 24.6.2016. http://nowyoucango.tumblr.com/programme
19 Jo Freeman, "The Tyranny of Structurelessness," 1972. Accessed 22.03.2016. http://www. jofreeman.com/joreen/tyranny.htm.

20 Andrea Fraser, "From the Critique of Institutions to an Institution of Critique," Artforum VOI. XLIV, No. 1, September 2005, pp. 278-283.

21 For more on the historiographic turn, see Dieter Roelstraete, The Way of the Shovel: On the Archaeological Imaginary in Art, University of Chicago Press, Chicago, 2013.

22 Helena Reckitt, "To Make Time Appear," Art Journal Vol. 70, No. 3, Fall 2011, pp. 58-63, p. 60.

23 See, for example, the current series developed by the Arika collective entitled Episodes, which takes a deliberately episodic approach to artistic production. Accessed 25.03.2016. http://arika.org. uk/

24 Alison Mountz, Anne Bonds, Becky Mansfield, Jenna Loyd, Jennifer Hyndman, Margaret Walton-Roberts, Ranu Basu, Risa Whitson, Roberta Hawkins, Trina Hamilton, and Winifred Curran, "For Slow Scholarship: A Feminist Politics of Resistance through Collective Action in the Neoliberal University," ACME: An International E-Journal for Critical Geographies Vol. 14, No. 4, 2015, pp. 1235-1259.

25 See www.economyexhibition.net and Dimitrakaki and Lloyd (eds.) ECONOMY: Art, Production and the Subject in the 21st Century, Liverpool University Press, Liverpool, 2015.

26 See www.gdr.cascoprojects.org. Accessed 27.03.2015.

27 See Helena Reckitt, "Forgotten Relations: Feminist Artists and Relational Aesthetics," in Politics in a Glass Case: Feminism, Exhibition Cultures and Curatorial Transgressions, ed. Angela Dimitrakaki and Lara Perry, Liverpool University Press, Liverpool, 2013, pp. 131-156.

28 Mechtild Widrich, Performative Monuments: The Rematerialization of Public Art, Manchester University Press, Manchester, 2014, p. 8.

29 Re.act.feminism \#2 - a performing archive website. Accessed 25.03.2016. http://www.reactfeminism.org/

30 Elke Krasny, "Feminist Thought and Curating: On Method," In On Curating. Accessed 20.03.2016 www.on-curating.org/index.php/about. html\#.VvhCnEtRduY

31 Deepwell also notes the institution's reliance on such individuals to introduce "groundbreaking" scholarship and the demand for creativity. Katy Deepwell, "Feminist Curatorial Strategies and Practices Since the 1970s," in New Museum Theory and Practice: An Introduction, ed. Janet Marstine, John Wiley er Sons, Oxford, 2006, p. 65. 
32 Alex Farquharson, "I Curate, You Curate, We Curate," Art Monthly 269, 2003, pp. 7-10.

33 Silvia Federici, "Revolution from Ground Zero: Revolution, Reproduction and Feminist Struggle," Autonomedia 2012, p. 2.

34 A. L. Steiner, Eve Fowler and Emily Roysdon discussing their 2007 Shared Women project, quoted in Reckitt "Forgotten Relations," p. 148.

35 See Meredith Brown, "The Enemies of Women's Liberation in the Arts Will be Crushed": A.I.R. Gallery's Role in the American Feminist Art Movement," Archives of American Art, Smithsonian Institution, 2012. Accessed 22.3.2016. http://www. aaa.si.edu/essay/meredith-brown

36 Irit Rogoff, "Gossip as Testimony: A Postmodern Signature" [1995], in Amelia Jones ed., The Feminism and Visual Culture Reader, Routledge, London, 2003: 268-276.

37 See for example Sara Ahmed, "Making Feminist Points," 11 September 2013. Accessed 27.03.2016. http://feministkilljoys.com/2013/09/11/ making-feminist-points/

Victoria Horne teaches at the University of Edinburgh and is a 2015/16 Postdoctoral Fellow with the Paul Mellon Centre for British Art. Her research charts the transformation of British art history in the late twentieth century through its periodical cultures and reading communities, and traces the reshaping of the discipline from the pressures of feminist politics, new critical directions, and the emergence of digital platforms. Previous writing can be found in Feminist Review, Radical Philosophy, and the Journal of Visual Culture. In 2016, IB Tauris will publish her co-edited book, Feminism and Art History Now.

Kirsten Lloyd is an independent curator and Teaching Fellow in Curatorial Practice at Edinburgh College of Art where she is also a PhD candidate. Her research focuses on late 20th and 21 $1^{\text {st }}$-century art, including lensbased practice, participatory work, the art document, and realism, as well as curatorial theory and practice. In 2013 she co-curated ECONOMY with Angela Dimitrakaki (www.economyexhibition.net). Presented at Centre for Contemporary Arts (Glasgow) and Stills (Edinburgh), the exhibition investigated the production of subjectivity through a capitalist economy in the 21st century. Their co-edited book, ECONOMY: Art, Production and the Subject in the $21^{\text {st }}$ Century, included her chapter 'Being With, Across, Over and Through: Art's Caring Subjects, Ethics Debates and Encounters' (Liverpool University Press, 2015). Her chapter 'If You Live Here... : A Case Study on Social Reproduction in Feminist Art History' will appear in the forthcoming IB Tauris volume Feminism and Art History Now (V. Horne and L. Perry, eds.).

Jenny Richards' research, writing, and projects focus on the categorisation of labour and the politics of the home. She is currently co-director of Konsthall C, Stockholm, a public art gallery located within a community laundry where together with Jens Strandberg they develop the exhibition programme Home Works. She also works with Sophie Hope on the project Manual Labours a practice-based research project exploring physical relationships to work. The project is currently in its second stage: Manual Labours: The Complaining Body, which investigates the world of workplace complaints with artist Sarah Browne, Hamish MacPherson, and Ivor Southwood and will be presented at The Showroom this April.

www.manuallabours.co.uk www.konsthallc.se

Catherine Spencer is a Lecturer in the School of Art History at the University of St Andrews. Her research focuses on performance art in the 1960s and 1970s and its relationship with sociology, including the use of sociology as a specifically feminist strategy. Her writing has been published in Art History, Tate Papers and British Art Studies; she also writes exhibition reviews for publications including Apollo online and Art Monthly. Between her $M A$ and $P h D$ she worked briefly in gallery education at Orleans House Gallery in Richmond. 


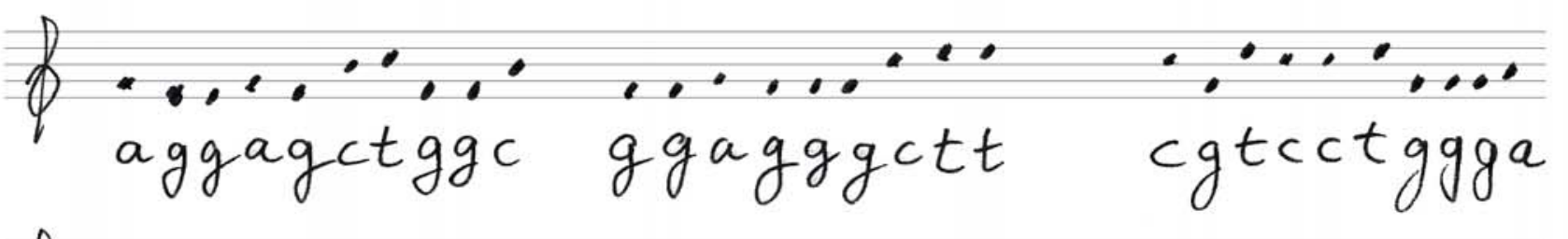

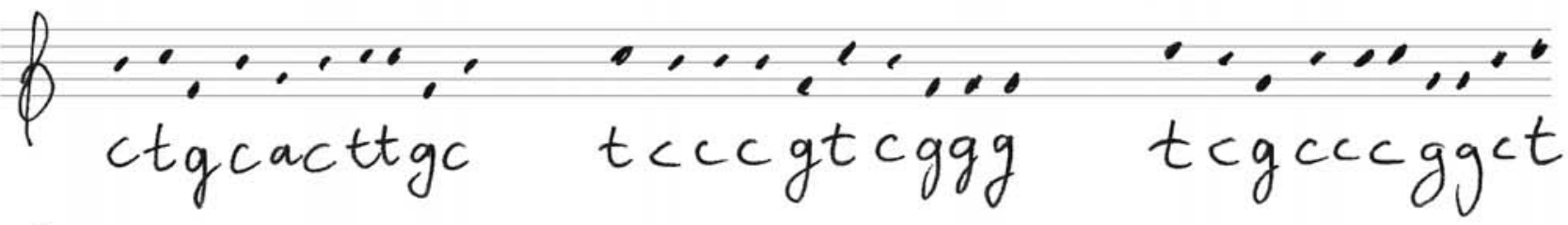
ctgcacttgc $t<c c g t c g g g \quad t c g c c c g g c t$ tcaccggace cgcaggctcc cggggcaggg $f \ldots, \ldots, \ldots, \ldots, \ldots, \ldots, \ldots$, ccggggccag agctcgcgtg toggcgggac

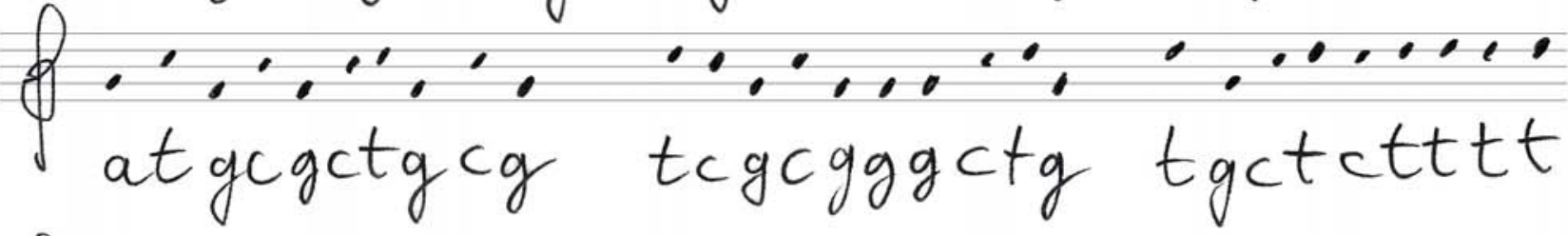
$\left\{\begin{array}{l}\ldots \ldots, \ldots, \ldots, \ldots, \ldots, \ldots \\ \text { cctcgggctg ccaggtggcc cgccggttc }\end{array}\right.$ $\left\{\begin{array}{ccc}\ldots, \ldots \ldots & \ldots \ldots, \ldots & \ldots \ldots \ldots \\ \text { tgagccttct gccetgcggg } & \text { gacacggtct }\end{array}\right.$ $f, \ldots, \ldots, \cdots, \ldots, \ldots,, \ldots, \ldots, \ldots$

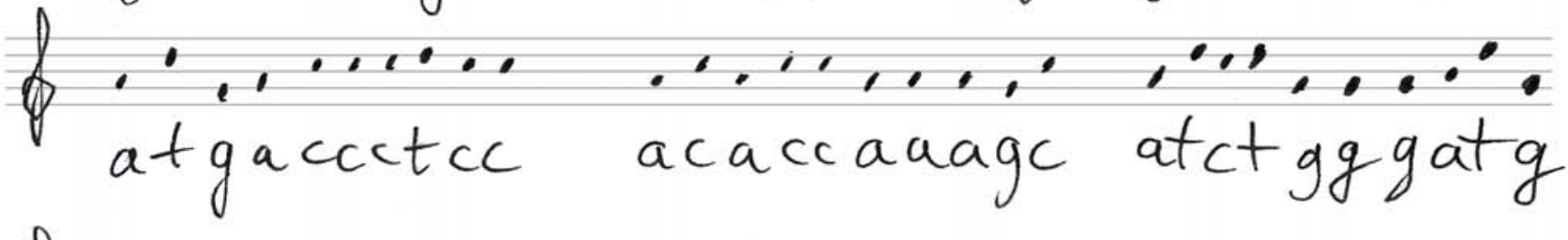

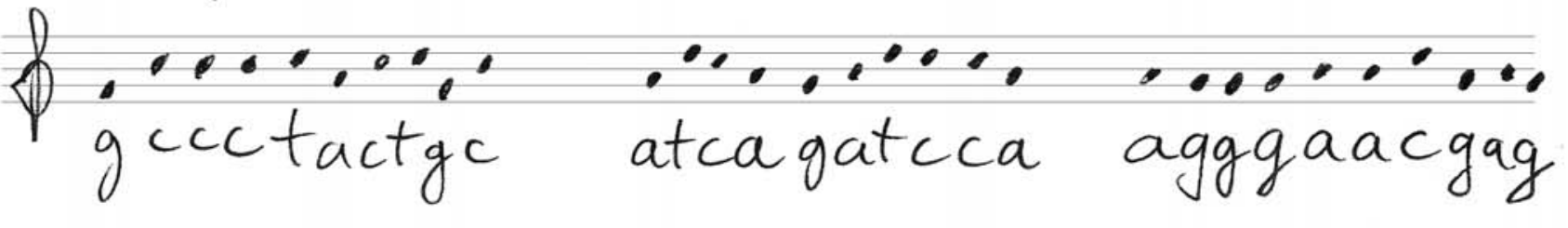
Homo sapiens estrogen teceptor transcript (ESR1) 


\title{
"We falter with feminist conviction". Lina Džuverović and Irene Revell
}

\author{
Notes on Assumptions, Expectations, Confidence, and Doubt in the Feminist Art \\ Organisation
}

To talk about our organisation, Electra, founded in 2003, we will first, briefly, turn the clock back to a moment in London thirty-five, or so, years earlier, when a group of women couldn't help but query and intervene into the problematic process in which art history was being constructed before their very eyes. This initiative led to the foundation of Circles, an artists-run distribution and production organisation focused on women's filmmaking. When seen from the perspective of Electra, this earlier moment foregrounds certain historical continuities and shared inter-generational concerns, which can either be seen as a source of strength for younger feminists, or (depending on one's point of view) frustration at how slowly structural change happens and how hardy its protagonists must therefore be. We would like to note that almost all of the references we make in this text, both historical and current, refer to the local situation in London, from within an immediate or extended community around the organisation(s).

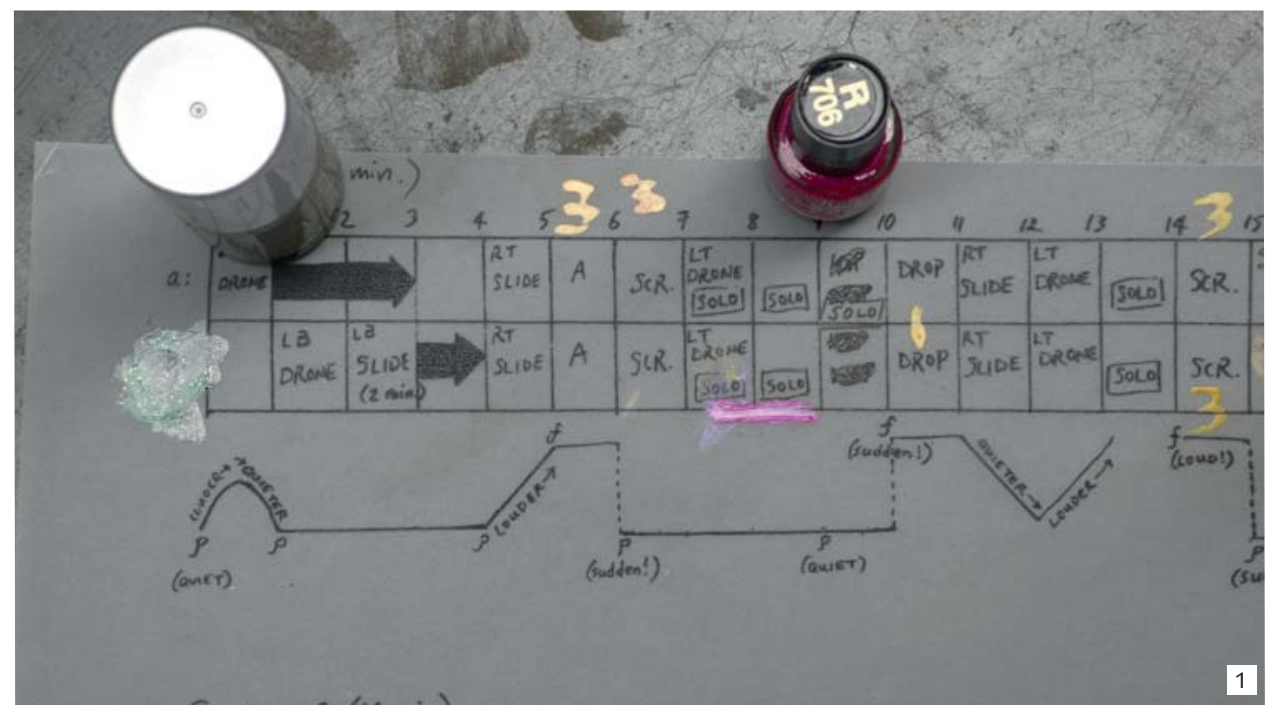

\section{A Crumpled Heap}

Circles was founded in the late 1970s by some of the female members of the London Film Maker's Co-operative. There is an associated founding myth, an event that was by no means the only catalyst for the creation of Circles, but remains informative in seeking to understand what is at stake in the articulation of such a feminist organisation. This story begins with the withdrawal of a group of women filmmakers-Annabel Nicolson, Felicity Sparrow, Jane Clarke, Jeanette Iljon, Lis Rhodes, Mary Pat Leece, Pat Murphy, Susan Stein-from the canonical 1979 Hayward Gallery, London exhibition Film as Film, which sought to map the entire history 


\section{Expectations / assumptions of a feminist art organisation}

- $\quad$ that everyone cares about what they do

- that there is a certain shared sense of a 'common good', the building of a common resource for the good of the organisation and its community/ies

- that your work and social life will be connected and will enhance your life by being interesting and enriching

- $\quad$ that you will like the people you work with

- $\quad$ that you will become friends with artists you work with (get closer to your heroes/heroines)

- that those heroes/heroines will like you and respect you

- $\quad$ that you will like and respect them

- $\quad$ that people will credit and acknowledge each other accordingly

- $\quad$ that a community will be formed around the projects

- that such a community will last

- that people you work with will have a certain sense of loyalty, duty or responsibility or gratitude and that they will remain faithful to the organisation, continue to promote it, or express some form of solidarity

- $\quad$ that those you work with share a similar outlook/politics/vision

- $\quad$ that everyone will give more than they are paid for even though the organisation is trying to challenge free labour (conflictual at the very core)

- that it is commonly known that you have put in hundreds of unpaid hours/gone out of your way to make things happen many times over

- that money is important but other things (solidarity, loyalty, belief in projects and people) are important too and not in conflict with survival

- $\quad$ that community and belief can protect you from living in the real world

- $\quad$ that a certain corporate language will be avoided (seen as inappropriate) yet its strategies appropriated when useful (brand, strategy, creative industries, profit, power, networking)

- that the business side is a 'put on' for the purpose of funding

- that alternative languages and approaches will be nurtured and cherished and not de-valued as inferior to the 'proper'

- that despite clear hierarchies the organisation will be non-hierarchical (conflictual and confusing from the outset)

- $\quad$ that the longitudinal will trump the latitudinal: that depth of interest and engagement will automatically be more highly validated

- that single individuals will not derive more value from the collaborative venture than is 'fair'

- that the 'group' or collaboration will be acknowledged in each future instance where its works / projects are referred to, not just those individuals who become more 'successful'

- $\quad$ that the work of the group will still be respected, and furthermore, understood as the precursor, when its primary discourses and aims are taken up by larger institutions

- $\quad$ that feminist curating is not only a numbers game (ie curating with more women artists) but a systematic and self-reflexive ongoing challenge that feminist curating will produce feminist art and feminist exhibitions

- that feminism is intended intersectionally with a host of other struggles: including but not limited to class war, anti-racist, queer, trans, crip activism inter alia

- that feminism is a radical anti-capitalist force-field that will dismantle the Master's House, not merely grease the career path of a few already-privileged women 
of almost a century of artists' moving image. The story, then, underscores the "problems of history", as Rhodes termed it.

Aware that the development of the exhibition had been hitherto heading towards producing a vastly male history of artists' film in the 20th century, the organising committee invited Lis Rhodes, an artist filmmaker, to contribute to the exhibition's curatorial research, in particular to research the history of women in film. It is worth noting that the invitation was to a single woman, presumably deemed of sufficient status to contribute to such 'important' work. Crucially, Rhodes chose to complicate this invitation, offering a diffractive ${ }^{2}$ approach to multiply the question of representation at the very first turn. That is, she extended the invitation to a wider group of fellow women artists, already complicating the authorial grounds of curatorial knowledge-production. The group set about to research a number of hitherto completely obscure figures-Maya Deren, Germaine Dulac, Alice Guy, Lois Weber-searching for historical precedents for their own work. When it came to the exhibition itself, the group chose to withdraw this research, arguing that the rigidly canonical framework presented by Film as Film was counter to their feminist impulses. They explained this withdrawal in a text, Women and the Formal Film ${ }^{3}$, which was displayed in the exhibition space itself, and its catalogue. Instead, their research fed into the foundation of Circles, an organisation that literally took their own work, and their own sense of historical context, into their own hands-underscoring the crucial role of historical precedents in tunderstanding one's own practice-especially in such uncharted feminist organisational work.

Published alongside this group-authored text there is a more personal account by Lis Rhodes entitled Whose History ${ }^{4}$. In her text Rhodes elegantly describes her painful alienation in the face of an art-historical canon:

It is as though a line could be drawn between the past and present, and pieces of a person's life and work pegged on to it; no exceptions, no change - theory looks nice - the similarity of the item reassuring - shirt to shirt shoulder to shoulder - an inflexible chain, each part in place. The pattern is defined. Cut the line and chronology falls in a crumpled heap. I prefer a crumpled heap, history at my feet, not stretched above my head.

This statement, and the context behind its writing, speak of the ongoing problems of history and feminist organisation: the need to search for historical precedents to inform one's own work. There is a joyful exuberance to the realisation that this might 'merely' constitute a crumpled heap, a celebration of a crumpled heap as an end in itself.

\section{Assumptions and Expectations}

Thirty-five years later, it was some of the same concerns/questions that fuelled the foundation of another arts organisation, Electra. Whilst Circles emerged quite directly from the London Film Maker's Co-op, with many parallel members of both organisations, Electra was founded in close proximity to the Lux Centre, the organisation that had emerged from the merger of London Film Maker's Co-op and London Electronic Arts, together forming the Lux Centre, later to become LUX. Through conversations that emerged in relation to an ongoing programming strand "Interference" that took place at the Lux Centre, 1998-2001, the two curators of the series, Anne Hilde Neset and Lina Džuverović (Džuverović also a staff member of Lux Centre) perceived an overwhelmingly male bias in their own series, and rather than complicitly continuing such work, took matters into their own hands and began the curatorial/research project, Her Noise, which sought to 
address the "historical blind spots" of women in the history of 20th-century sound practice(s), and their contemporary successors. Electra was founded in 2003 initially out of necessity and pragmatic need to enable this curatorial project to happen. The desire to seek out historical exclusions, and the need to foster new forms of organisation to do so clearly resonates across these two histories.

What does it mean, then, to run a feminist/collaborative/collective organisation that challenges dominant structures, methodologies, and goals? What acts of self-sacrifice may be embedded in such a claim? How can a feminist organisation/ action exist in neoliberal precarious market conditions? How often are these questions articulated and outlined at the inception of such organisations-or can they be? What are the invisible assumptions in working in an arts environment with a certain ethical code?

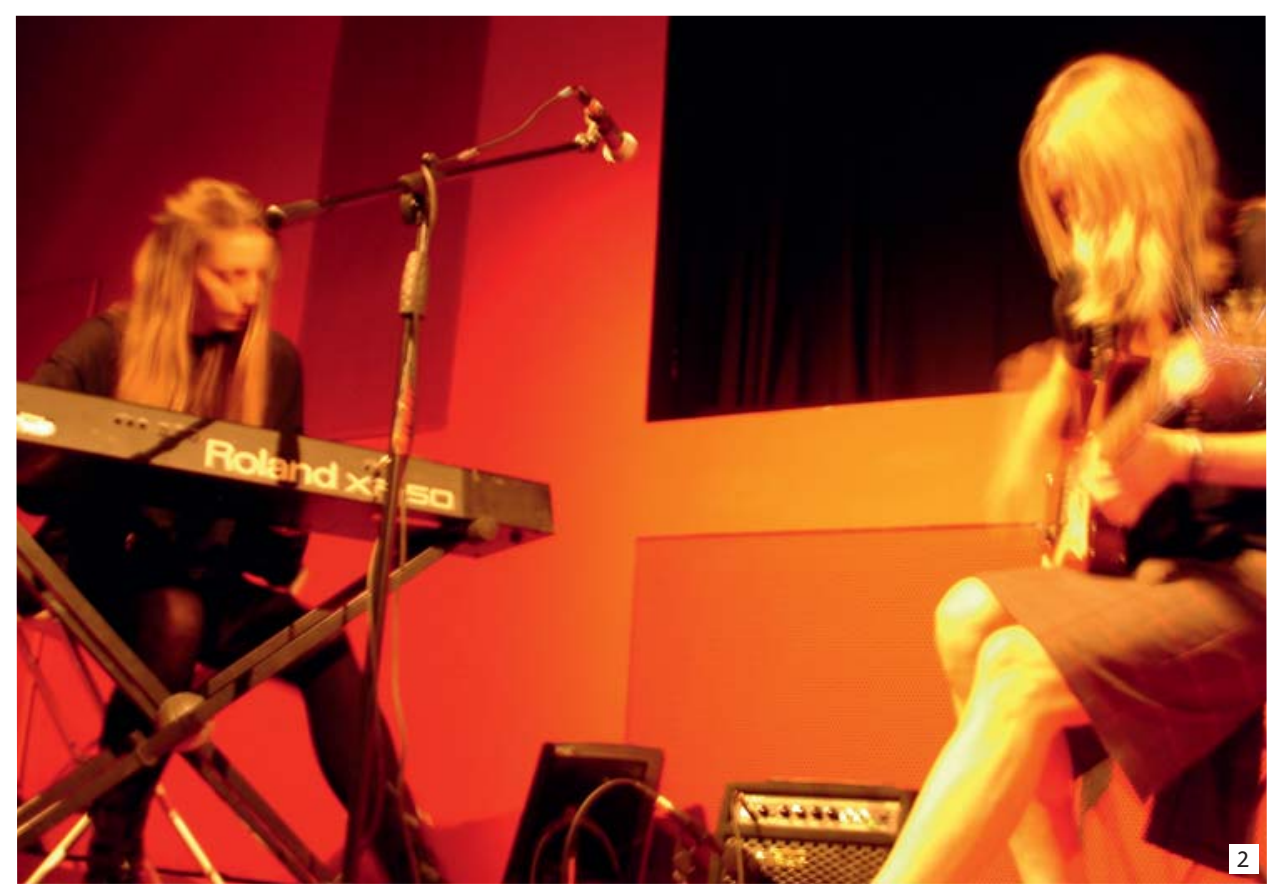

'Feminist' seems to have become, in recent years, a hackneyed term for curators, a magic protective cloak that shields the curator, an adjective so consensually positive and useful beyond question that it can be applied at ever-increasing frequency to confer adherence to an ill-defined consortium of loosely liberal values. We're ever faithful to it, but how certain are we in what we mean when we use it, especially in this particular art/curating context? Does 'feminist curating' refer to curating feminist work, by feminist artists, work that embraces feminism(s) in its form and/or content? Is it a way of making feminist statements in the curatorial process, or does it involve incorporating feminist politics into the working process and infrastructure of the curatorial work itself? And in the case of the latter, how easy is it to define the feminist art organisation, its work and infrastructure, moreover perform this work?

Effective feminist curating might require clearing the decks of multiple meanings of both curating and feminism, and drawing upon one's own ethical vision. Alternatively, a meandering curatorial practice with an emphasis on difference and social justice, a desire to rethink histories, acts of fandom, all coupled with a sense of urgency, could equally amount to what could be termed 'feminist curating'. It was the combination of the latter that brought Electra into existence. By 
using Electra as a central case study, an organisation in which we were both involved (and continue to be so), this text explores questions that arise in an attempt to undertake 'feminist curating', drawing on personal experience with some provisional theoretical suggestions. In what began as an exercise in seeking further definition towards an 'ethical code' for feminist curating, we would like to note that what follows is by no means a definitive history of the organisation, conspicuously lacking discussion of any individual project and rather focusing in this instance on the organisational framework, a series of points drawn from our own experiences.

In parallel with this discussion, we offer an index of 'expectations/assumptions' (see fig. 1) of a feminist organisation, that we share as a means to providing a general 'key' to the highly specific points that follow. These expectations frequently exist but are not articulated, or cannot be articulated, written into a contract, or even verbalised, nor may it be desirable to do so even if it were possible. Yet, they are essential in the running of such organisations, ambiguously and almost invisibly underpinning their work and decision-making, with little articulation. Of course, these are only our own assumptions, and by no means exhaustive, but we hope the list extends towards a useful articulation of what might foreground a feminist art organisation, at least in our experience of it.

\section{Electra: a feminist organisation finding its feet in a neoliberal climate of overproduction}

The arts organisation Electra ${ }^{6}$, founded in 2003, provides a personal insight for both of us into possible methodologies, and curatorial positions, as well as challenges and pitfalls, of an attempt to 'perform' (undertake) what might be termed 'feminist curating' in a particularly competitive, fast-moving, production and output-centred environment in London in the early 2000s through to the present.

In the space of less than six months Electra developed from a platform for delivery of one project, Her Noise, primarily driven by a curatorial desire (and vague ambitions and hopes of continuing beyond this one project), to a fully functioning arts organisation. The reasons behind this shift, and the sudden and rapid rethink, were, unsurprisingly, economic in nature. Realising that the organisation we had founded had the potential to become a long-lasting, potentially sustainable initiative, and provide not only our livelihoods but also a space for further action, meant that we quickly 'shifted gears' to meet the requirements imposed by our potential funders. Despite the fact that our desire for this work stemmed from curatorial interests, and the ethics of DIY grassroots artistic communities, we quickly learned to adapt, to speak the language of 'small business', rising to the challenge of having to appear to be a bon a fide arts organisation. From thinking of Electra as a small project with a relatively modest purpose and infrastructure-a bank account, a desk in a shared office, and a rudimentary website-we quickly adapted to appear to be running a fully-fledged arts organisation.

By Spring 2005, Electra had rapidly, and to an extent artificially (by moving too fast), succeeded in becoming an Arts Council England Regularly Funded Organisation, with a business plan, financial and organisational commitments, an artistic programme scheduled for three years ahead, an Advisory Board, an Executive Board of Directors, an accountant, and soon, a host of freelance staff. This was by no means an unwelcome development. In fact, we were delighted that these opportunities arose, but it was sudden and we responded as best we could, frequently feeling we were committing to delivering a programme beyond our means 
(in terms of time and resources) or wishes, but nevertheless eager to grab the chance that had unexpectedly arisen, to establish something long-lasting and full of potential, that we still hoped we could mould into a shape that captured some of our visions.

The way the organisation developed meant that its structure, its methodologies, its ethos and its running became a hybrid of the ethical, curatorial, and practical ideas we believed in and had brought with us from previous experiences, and on the other hand, the pragmatic, strategic decisions we needed to make in order to fulfil the criteria that would ensure our entry into the world of 'bigger players'-regularly publicly-funded arts organisations in London. As a result, what had started out as a grassroots initiative, tentatively initiated by two curators with a particular research question about feminist history and omission (the question behind $\mathrm{Her}$ Noise), grew into an arts organisation almost overnight, along with an immediate tension between a DIY anti-authoritarian impulse, and the professionalised rules of the output-driven mainstream 'art world'. To be regularly funded, it seemed, we needed to aspire to certain normalising features (needing to aspire to larger rather than smaller audience numbers, active audience development, diverse forms of income, with an increasing emphasis on private streams, et cetera), which we continued to attempt to resist, with varying levels of success. Our belief in fostering smaller communities through a depth of engagement proved to be generally at odds with the growth mindset of public funding. In what follows we discuss, through a series of points, this hybrid model that Electra inhabited, a model that sought to bridge our ethics with the pragmatic demands we were facing. Some points are more of a matter-of-fact, while others we unpack, sometimes making prescriptions and/or speculations about further areas of inquiry.

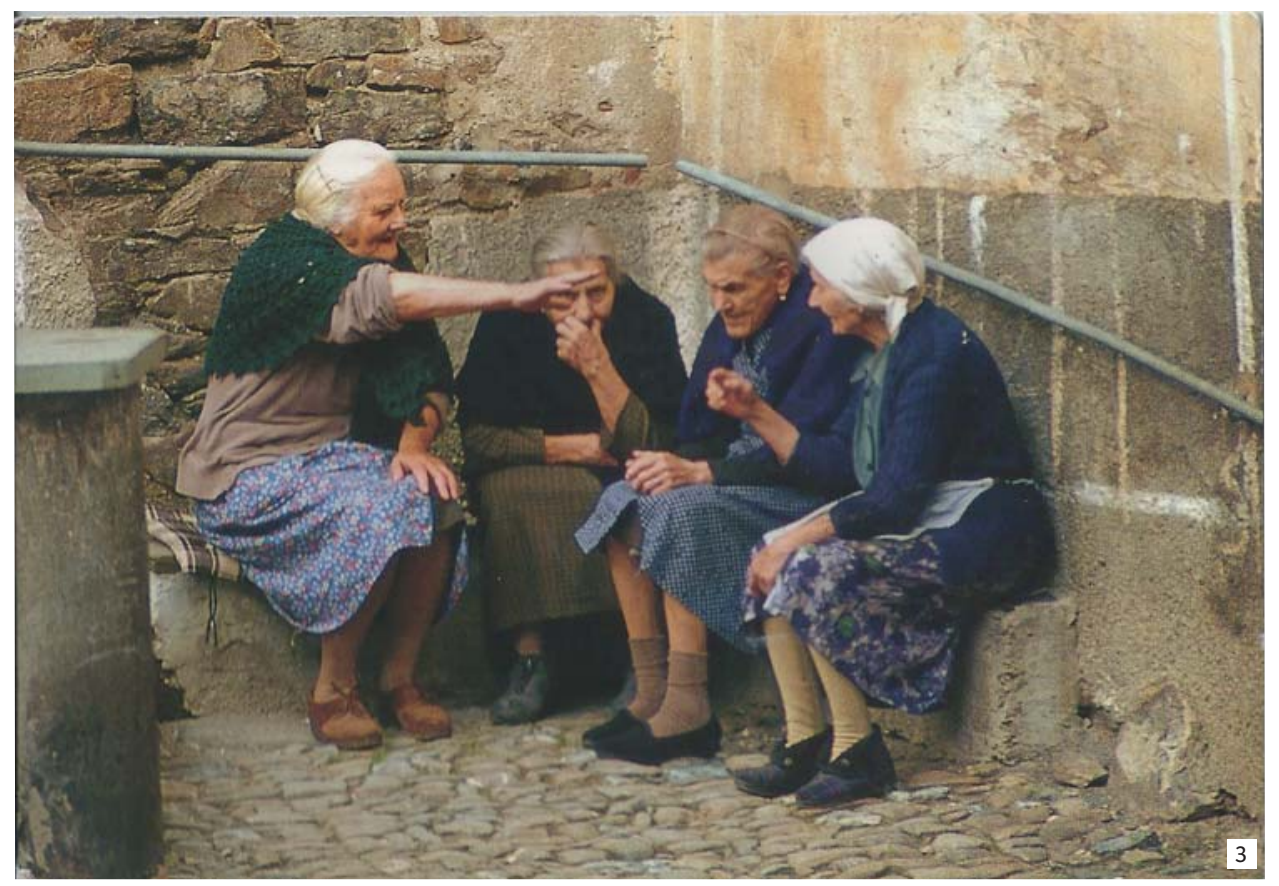

\section{Labour/governance}

Electra was initiated on the firm belief that we would only undertake projects in which everyone would be treated and paid fairly. This meant that there would be no unpaid work, artists would always receive per diems, have their transport and accommodation paid, and receive a fee. A project would not be taken on until it was clear that these conditions could be adequately met. 
Electra was hierarchical. We had job descriptions and job titles, and our salaries reflected this. It was never a collective, in the 'traditional' egalitarian sense, and the hierarchies were evident in our day-to-day running, decision-making and 'perks' (for instance research travel). This structure was intended as a way of reflecting seniority in terms of experience and length of commitment. Nevertheless transparency and a horizontal dialogue were encouraged, with a desire to include all staff in key discussions and decision-making.

Electra was set up as a limited company, with three main shareholders, the two founders, Lina Džuverović and Anne Hilde Neset, as well as Irene Revell who joined the organisation in 2004. The ownership percentages reflected the amount of investment (unpaid time, paid time, 'risk', expertise) each of us had invested, at the point of its division, or an attempted version of this split. In addition, others who have made a significant contribution to the organisation over the years as freelance staff in a variety of curatorial and production roles, include Fatima Hellberg, Holly Ingleton, Sinead McCarthy, Ash Reid, Lisa Rosendahl, Dawn Scarfe, and Lucy Shanahan.

Each project would contribute $20 \%$ of its overall budget towards core costs of the organisation. Though in reality, especially in latter years of Electra's activity, this varied wildly (mostly downwards) in each situation, against a pervasive economic shift that saw many earlier sources of funding dry up in an economy that was shrinking overall at the same time as facing an increasing demand from ever-growing numbers of small-scale initiatives and new organisations.

\section{Care}

Our belief in fair payment was part of a wider ethos of taking a greater level of care and attention to detail at every level than we felt was customary in arts production at the time. This reflected our interest in fostering a community, rather than simply producing and staging some art. Through close, slow collaboration with artists and other partners with whom we worked, we sought to create a space in which practice could be speculative, take risks, take its time, without being entirely output-driven. These methods were a result of prior experience in larger institutions with an endemic culture of carelessness and, at times, exploitation. We still strive to reject the insidious over-production and exhaustion of the ego-obsessed mainstream art world. Yet, of course, given our own excitement and ambitions, coupled with a rather slender infrastructure (two to four freelance members of staff at any time), we often did 'punch above our weight' in ways that were both essential to the organisation's development and outward visibility, but ultimately personally exhausting and, at times, soul and health-destroying.

\section{Curatorial vision and the 'Inchoate'8}

The curatorial vision was not clearly articulated. This lack of articulation was initially due to the aforementioned speed with which opportunities had arisen, but also an effect of a desire to not be self-limiting, and a desire to resist the categorisations that we felt to be so problematic in canonical art history. In this sense, the organisational thinking went very much hand-in-glove with the ethos of the individual projects and research, which often sought to expose or undermine these rigid structures. Our projects all shared an inherent interest in historical 'blind spots' (both within, and beyond art history) twinned with inter-generational approaches to curating, those that consider the influences of particular histories on contemporary practice. 


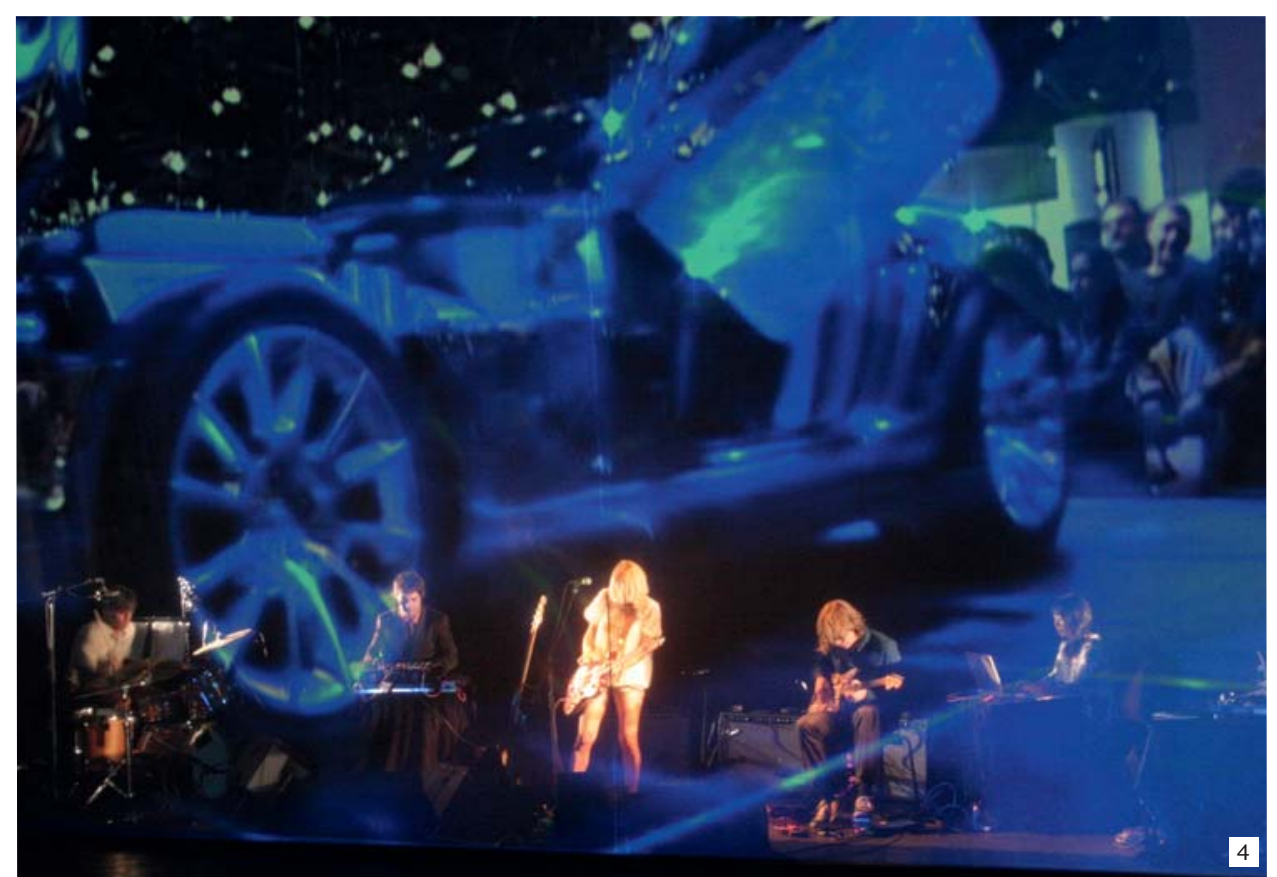

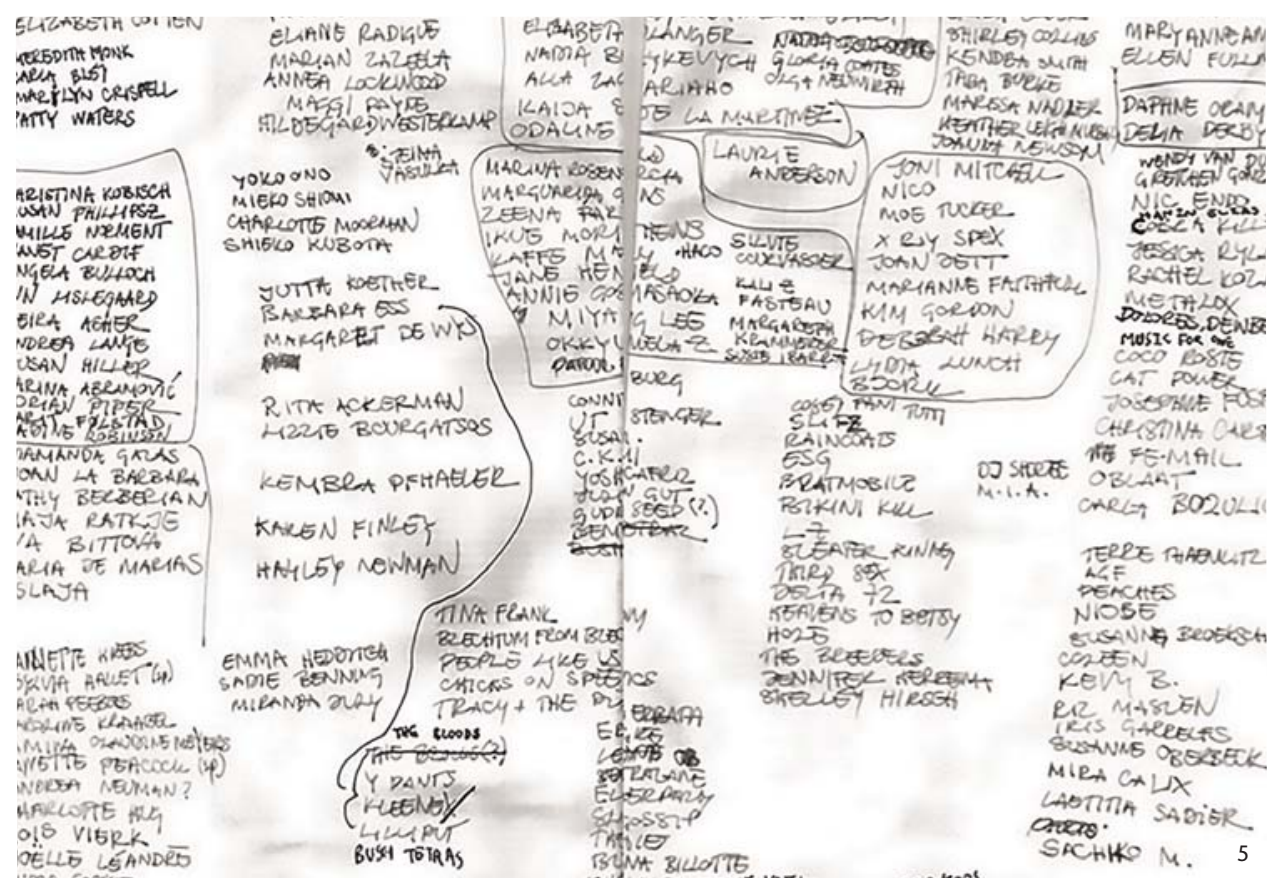

Even today, a precise definition of the curatorial vision of Electra may elude us, but we could say that its ethos lies at the intersection of the self-organisational ethos shared by Fluxus, No Wave, Punk, Riot Grrrl, and their contemporary legacies, although the wish to avoid precise taxonomies and categories altogether remains central to the organisation. Electra's curatorial vision was always more centred on the type of process and engagement we wished to be living, than the products of that engagement. Described at one stage as 'working with artists who work across sound, performance, moving image and text on questions of political and social urgency', provided an improvement on the earlier, even more wilfully vague, tagline which read 'Commissioning, Curating, Producing'. 
Our approach to feminist politics, and practices, was discussed in detail in a text entitled "Twice erased: The Silencing of Feminisms of Her Noise", which explored the ways in which feminism was articulated (or rather not articulated, but implied) in Electra's methodologies, via the Her Noise project. It is worth noting that whilst a clear articulation of feminist, post-colonial, and other critical approaches to historicisation in what we might broadly term 'intermedia' might seem like a reasonable proposition in 2016, we struggled for a viable way to describe these impulses that was not instantly toxic (damaging due to the unpopularity of such a discourse in general terms) for the organisation in 2005, or even 2010. Whilst we would eschew the notion of 'waves' of feminism that obscure the continuous and ongoing developments of feminist practice(s), it is true to say that never in our working memory has there been a greater acceptance of these terms than in the present (and yet never has there been more ambiguity in the intentions of their use).
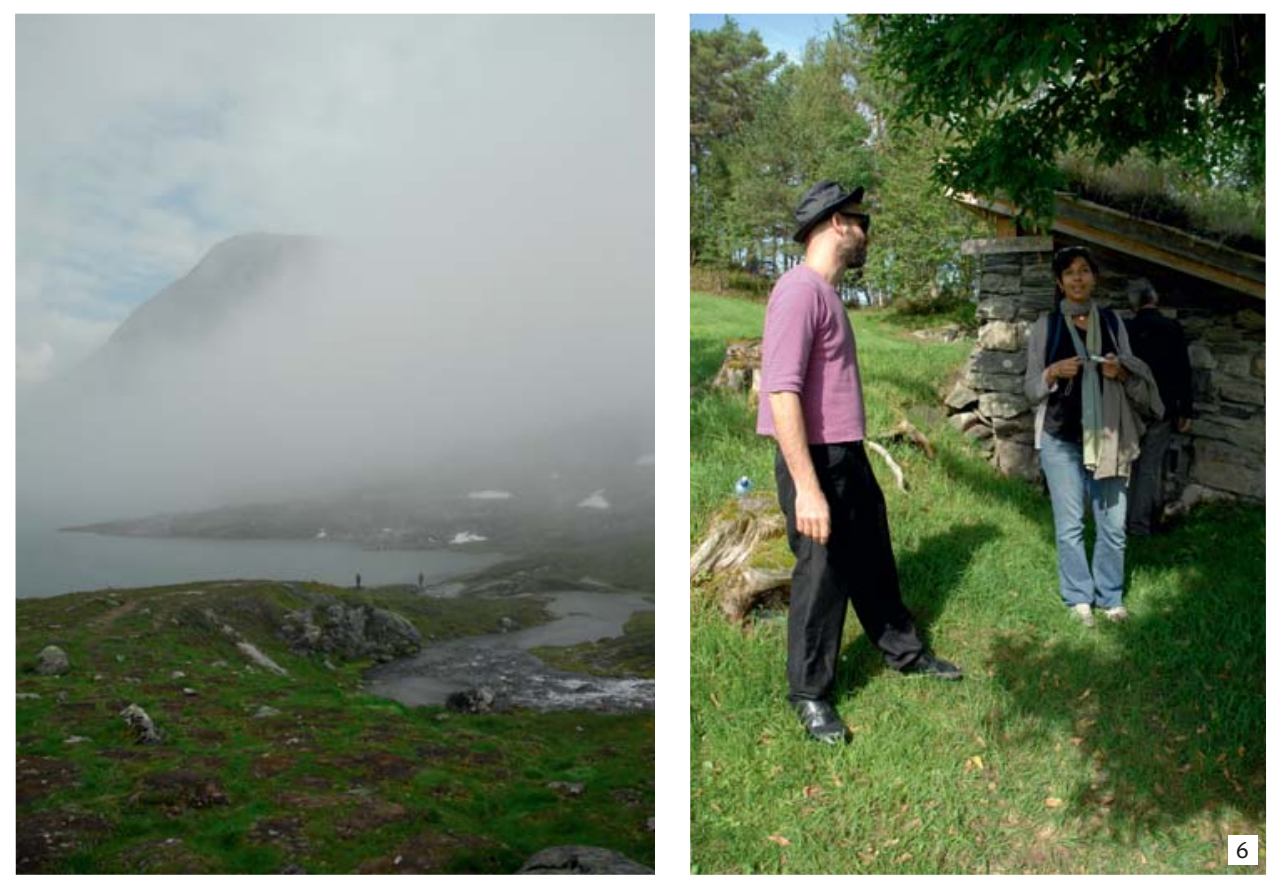

\section{Curator as Fan, Curator as Friend}

Many of Electra's projects emerged from a sense of 'fandom' towards certain protagonists or areas of work, or at times towards particular ways of articulating politics, rather than a more 'academic' position. We are indebted to art historian Catherine Grant's thinking in this regard in her paradigm-shifting 2011 essay "Fans of Feminism"10. Grant's text rethinks the model of intergenerational influence within feminist practices through the queer figure of the 'fan'; a joyous accounting for these desirous modes of identification that might take an informal, non-institutional, or even amateur route to knowledge-production, allowing for the fact that seeking out such obscured histories requires a level of ardent yet almost always innovative dedication.

In effect, the curatorial red-thread was more readily associated with our experiences of certain communities and subcultures than an academically acquired rationale, in line with this notion of the 'fan'. One point for further consideration of the 'curator fans of feminism' might be how this model operates for more than one such fan-for instance in a collective, group, or organisational setting. How much 
must, or even can, fandom be shared, or at least overlapping? And how in turn does this operate amongst audiences?

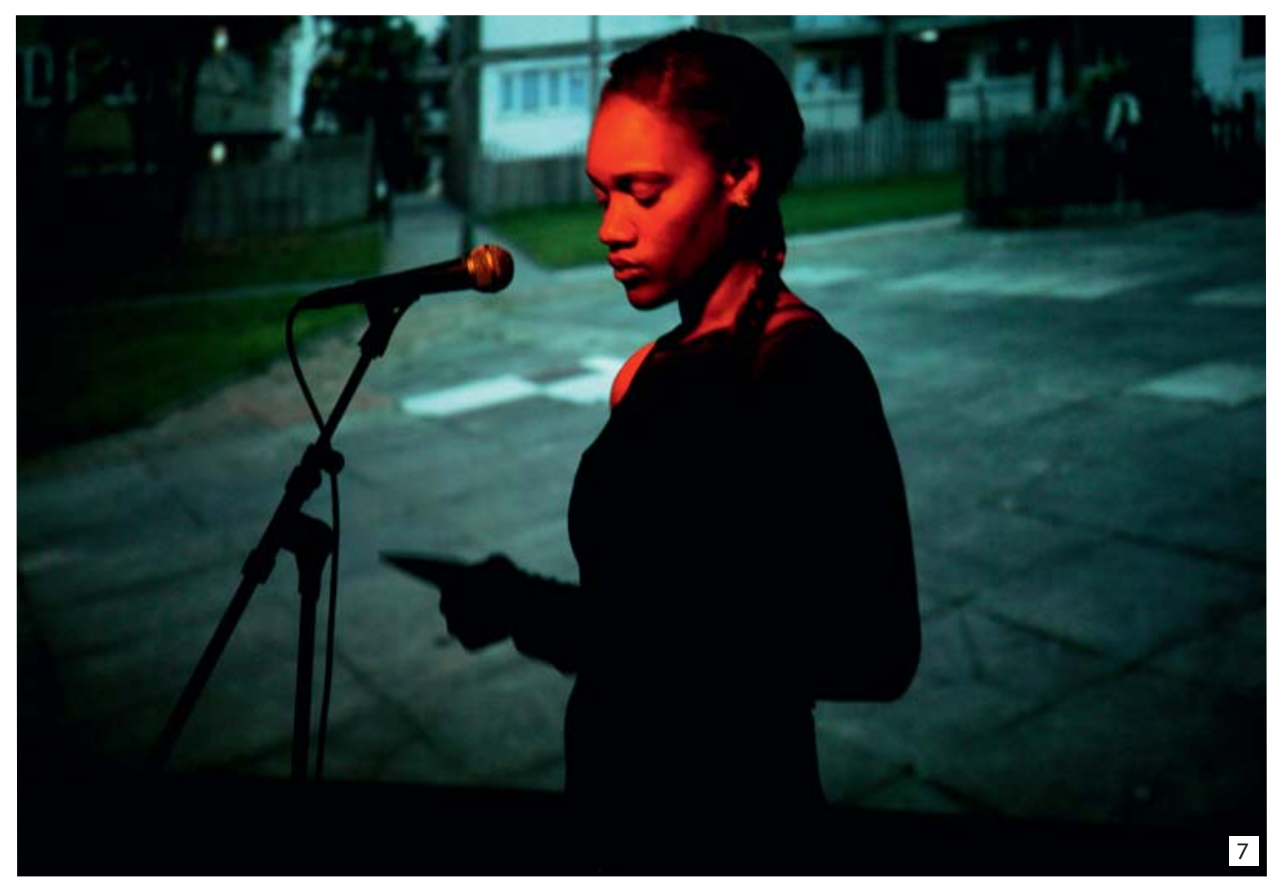

A different, but not unrelated, model with equal relevance to Electra's modus operandi was articulated by curator Viktor Misiano in his 1998 text "The Institutionalization of Friendship ${ }^{\prime \prime 11}$, in which he foregrounds links between disparate artistic communities in different cities, united by no other force but friendship. Turning to sociology, Misiano explains that, "The only type of a social link not determined by some regional or family relationship, professional cooperation, ideological solidarity, or erotic attraction is friendship". He goes on to qualify friendship as "a type of serial solidarity" different entirely to the lovers' need for togetherness, the familial bond, the repeated production-driven togetherness of those joined by work, or the shared ideological goals of political togetherness. Friendship is unregulated, self-instigated over and over again, and excludes personal gain.

But in DIY communities, it is precisely friendship, the "serial solidarity" that begins to give way to something more like work-joint, exciting, and inspiring work. Electra incorporated elements of what happens when friendship imperceptibly migrates into a different form of togetherness, because shared interests and ideas often lead to 'doing something together'.

\section{Fidelity, or, 'The Ethical Slut'}

Some firmly stated commitments from the outset were based around a belief in longer-term, often ongoing, relationships with artists. Accordingly a depth of engagement was prioritised in our fields of research that was in opposition to the time-scales imposed by the exhibition cycle of larger, mainstream institutions. Initially we even toyed with the idea of 'representing' artists whose work was too non-commercial or marginal for gallery representation, echoing the historical impulses of organisations such as Circles and the London Film Maker's Co-op, or the Women Artists' Slide Library. Electra's ongoing and often multi-annual research process, though no means unique, remains far from dominant models of ' $f a s t$ ' curating, today best exemplified by the widely adopted 'name-check' curatorial model of the Serpentine Gallery marathons (and their legacy, already proliferated 
globally) which feature dozens of artists' and thinkers' contributions in a short time, and other ways of relaying content that seem to push for this inhumane scale. We felt disturbed by the dominant curatorial 'colonial' drive to 'claim' artists, the more obscure and unknown (exotic) the better, and as many as possible, without any clear commitment to a depth of engagement. This 'virgin' narrative seems an ugly remnant at the heart of mainstream curating, perpetuating its often-violent colonial histories. In a regime where success is so strongly predicated on volume and speed of production/output, one of the most radical gestures might be to adopt an understanding of 'fidelity', or in rejecting the heteronormative associations of such a term, at least giving some consideration to the question of how to be an 'ethical slut $^{\prime 12}$.

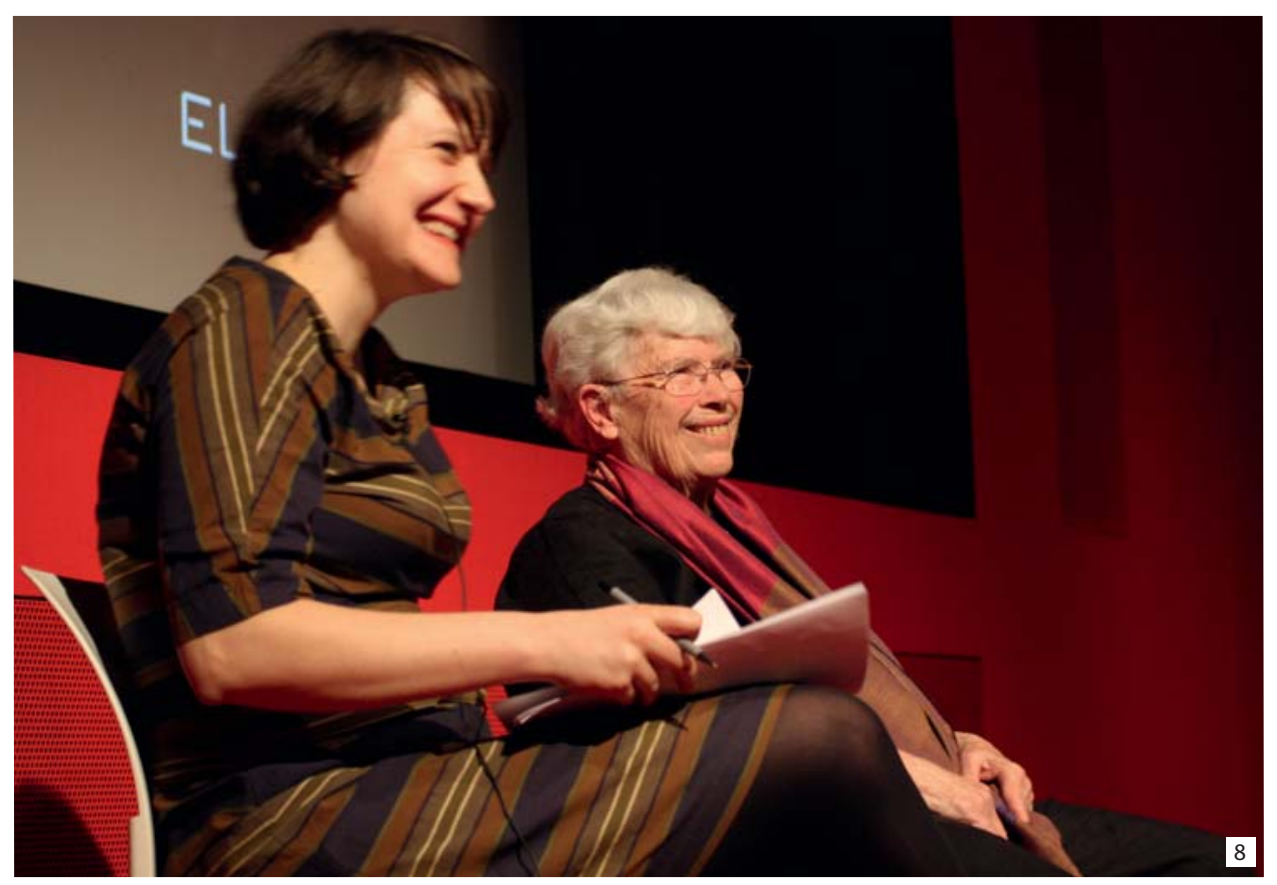

\section{Subsumed, Co-opted-Nice, But Not Essential}

The enormous diversity of Electra's projects-each intended to find its own specific output, presented (ideally) in its own best-suited context(s), with its own time-scale and budget-makes it difficult to point to a 'typical' Electra project. This form of site-specificity and context-sensitivity, while curatorially ambitious, holds two distinct disadvantages for the organisation. Firstly, a small organisation that resists the idea of a 'signature output' and always works in partnership, is likely to struggle to attain visibility or even discernibility in a landscape increasingly dominated by branded entities (artists and arts organisations both adopting the corporate model of having 'signature', easily recognisable outputs, styles and visual identities), particularly when working with larger institutional partners (13). Secondly, a bigger, and perhaps more ethically rooted concern emerges out of a growing sense that Electra was increasingly offering well-packaged artistic products to large mainstream institutions, resulting in a sense, at its most extreme, of grassroots communities being co-opted and instrumentalised to serve momentary interests and trend-driven agendas of mainstream institutions seeking access to new audiences and 'emerging' practitioners without having to 'get their hands dirty' (fleeting engagements with, for instance, feminist discourses, sound-based practices, queer politics). 
The relationship with the institution remains conflictual for us to this day, in particular with regard to the question of co-option in curatorial practice. Whilst Electra's relatively marginal curatorial agendas were readily afforded a platform in larger institutions, providing the organisation with a certain amount of perceived mainstream success, the long-term benefits of these sporadic instances remain questionable to us. Our "curatorial and production services" (to use the output-driven language the organisation had adopted) rarely led to fundamental shifts or long-term engagement on the part of our partners, institutions that hosted Electra-produced and curated projects. The stakes could be wiped clean as soon as our collaboration would be over and as soon as the audiences would depart (but not before the event would be fully 'claimed' through documentation, marketing, and social media by the host institution). Particular 'niche' practices, questions, methods or politics-central to Electra's operation-became usefully appropriated by a host of mainstream agendas that had little to do with the communities and histories in which Electra was invested. This outsourcing model frequently served as a way of bringing in new audiences, reaching out to specific communities for the large institution-a key operational model in the insufficiently thought-through inclusion rhetoric of New Labour of the early to mid-2000s. The longevity of such initiatives was of little concern to the institution, as long as their reach and audiences could be documented and recorded for funding purposes. Where there has been deeper, more ongoing commitment from institutions, this, in fact, is usually tied to single individuals, rather than being more widely embedded: individuals who may leave their post for another institution, perhaps in another country or continent.

At the same time, the model of collaborating across a wide range of different exhibition partners does have an interesting effect in its heterogeneity: neither ruling out this liberal game of infiltration/high visibility (for all of its quandaries), nor the more radical/intimate alternatives.

Electra's intrinsically anti-patriarchal model of resisting dominant structures, fostering and nurturing marginal communities, and attempting the creation of a 'safe space' positioned on the sidelines of the whirlwind of action-packed London overproduction, eventually yielded an unsurprising conclusion on the part of our funders. The work of an organisation which deliberately strove to contribute to niche communities and small audiences, and its refusal to play the numbers game of working with more artists and seeking larger audiences, led to the conclusion that such an organisation was no longer necessary. "There are lots of larger institutions doing this work now" was part of the logic that may have contributed towards the ending of a ten-year-old regular funding contract with Arts Council England in 2014. Notions of care, long-term commitment, attention to detail, and slow, well developed outputs all stem from the socially undervalued realm of unpaid, traditionally female labour (the domestic) in which well-being emerges from process, not grand gestures and bombastic events.

\section{Does this sound simple? / Fuck you! ${ }^{14}$}

By way of conclusion, we return to what remains one of the most complex aspects of running a feminist, grassroots organisation-the process of articulation itself. This becomes explicit in the exercise of writing a text such as this one, an act of looking backwards: both in the sense of having to search for histories that "one was not told"15, but also in the act of back-projecting meaning onto what was difficult to describe, and continues to be so. The connections we make here are ones we have made through the process of working things out over thirteen years of Electra, not through some perfectly formed pre-emptive gesture. 
In a recent essay on the theme of confidence, feminist philosopher Sara Ahmed argued that:

"The more a worldview is supported, the less confidence you need to uphold

it. There is confidence in the system. If you are trying to challenge that system you might need even more confidence than you would otherwise have needed. You face resistance and ridicule. The walls you come up against don't even appear to others. The wall you speak of becomes a phantom wall. You have to hold on harder, be firmer in your conviction, because your conviction brings you up against a world"16.

She goes on to warn that "[th]ere is no guarantee that in struggling for justice we ourselves will be just. We have to hesitate, to tamper the strength of our tendencies with doubt; to waver when we are sure, or even because we are sure. A feminist movement that proceeds with too much confidence has cost us too much already."

Ahmed's assessment of confidence-both the difficulty of its desperate lack in the face of doing this work, yet the continual need to challenge it as a currency in the first place-resonates with us throughout our work, and its articulation.

As much as an attempt to determine what might constitute a 'feminist art organisation' is desirable from the outset of such an endeavour, we also wish to emphasise that this must be an ongoing and self-reflexive process; that understandings, language, historical references might only emerge through this process. Sometimes the difficulty of articulating these notions is a matter of being "up against a world" that offers little more than a veiled cynicism or outright derision.

Put in other terms, it's questionable whether a feminist art organisation that we could have neatly packaged-up-for the consumption of funders, the funding system, wealthy collectors, et al.-would be an organisation worth faltering to create. We stand with Lis Rhodes in favouring the "crumpled heap", and as Ahmed concludes her text, "We falter with feminist conviction. As we must."

\section{Captions}

1 Marina Rosenfeld, Sheer Frost Orchestra, 2006 performance (part of the Cage Musicircus), Turbine Hall, Tate Modern, curated and produced by Electra. Image: Shirley O'Loughlin

2 Jutta Koether and Kim Gordon performance and talk, Tate Modern, 2005 (part of Her Noise). Image: Lina Džuverović 2005)

3 "I tried to tell them about Electra" (postcard from Lina to Irene, August,

4 'Perfect Partner' performance, commissioned by Electra, 2005, Barbican Centre, A film by Kim Gordon, Phil Morrison and Tony Oursler. Image: Tony Oursler

5 Her Noise Map (Anne Hilde Neset and Lina Džuverović), part of the Her Noise project (2005)

627 Senses residency, August 2006, Schwitters' Hytte, Hjertoya, Norway and surrounding area (I-r: Jutta Koether and Carl Michael von Hasswolff; Kenneth Goldsmith and Lina Džuverović ). Image: Simon Wagsholm

7 Claire Hooper, Eris: the path of ER, 2012, film and live performance with Danielle-Marie Shillingford, MC Lioness and Beatrice Dillon (for LUX / ICA Biennial of Moving Image), live performance commissioned by Electra. Image: Christa Holka

8 Irene Revell in conversation with Pauline Oliveros, Artist Talk and Perfor- 
mance: Pauline Oliveros, Tate Modern as part of Her Noise: Feminisms and the Sonic, 2012, curated by Electra in collaboration with CRiSAP (Creative Research into Sound Arts Practice, University of the Arts London). Image: Katie Snooks

\section{Notes}

1 Lis Rhodes, "Whose History", Film as Film: Formal experiment in film 19101975, Arts Council England, London, 1979. Exhibition catalogue.

2 We use the term diffraction in light of post-humanist understandings. For discussion see Karen Barad, "Posthumanist Performativity: Toward an Understanding of How Matter Comes to Matter," Signs Gender and Science: New Issues Vol. 28, No. 3, Spring 2003, pp. 801-831.

3 Annabel Nicolson, Felicity Sparrow, Jane Clarke, Jeanette Iljon, Lis Rhodes, Mary Pat Leece, Pat Murphy, Susan Stein, "Women and the Formal Film," Film as Film: Formal Experiment in Film 1910-1975, Arts Council England, London, 1979. Exhibition catalogue.

4 Lis Rhodes, ibid.

5 The Interference series ran bi-monthly for three years at the LUX Centre for Film, Video $e$ Digital Arts in London, and presented seventeen events between March 1998 and March 2001. The series was conceived by Lina Džuverović (then working as Education Co-ordinator at the Lux Centre) in collaboration with The Wire magazine (represented curatorially by Anne Hilde Neset, with substantial curatorial input from Rob Young) as a way of connecting discourses around moving image work and sound-based practices. The series of talks, performances, screenings, and panel discussions featured, among others: Brandon Labelle, Terre Thaemlitz, David Toop, Philip Jeck The Scratch Perverts, Erik Davies, Robin Rimbaud- Scanner, Kodwo Eshun, Thomas Koner, Jurgen Reble, Add n to X, Vicki Bennett - People Like Us, and Kaffe Matthews.

6 Electra was legally founded in May 2003 in London, by Lina Džuverović and Anne Hilde Neset as an organisational structure that would enable the production and delivery of the curatorial project Her Noise.

7 Electra had responded to an 'Invitation to Tender' from Arts Council England, who wished to take on three new 'media arts' agencies-at a time when the discourses of 'media arts' were still poorly understood within larger institutions, and in parallel a more general interest amongst funders in smaller models such as the 'agency', footloose, with low overheads and supposedly entrepreneurial potential.

8 We borrow this term from David Toop's description of certain researchled practices that that do not seek determinate outcomes (he includes in this term artists Annabel Nicholson and Marie Yates).

9 Džuverović, Lina; 'Twice erased: The Silencing of Feminisms in Her Noise', Women and Music: A Journal of Gender and Culture, University of Nebraska Press, Issue 20, 2016, forthcoming

10 Catherine Grant, "Fans of feminism: Rewriting Histories of Second-wave Feminism in Contemporary Art," Oxford Art Journal 34 (2), 2011, pp. 265-286.

11. Dossie Easton and Catherine A. Liszt, The Ethical Slut, Greenery Press, San Francisco, 1997.

12. As in Vivan Ziherl's eloquent discussion of "If I Can't Dance" in Curating Research, Paul O'Neill and Mick Wilson, eds., Open Editions, London, 2015. Ingleton.

13 Hernoise.org, which was created in 2012 by Her Noise archivist Holly

14 Lyric by Kim Gordon, taken from 'The Sprawl', Sonic Youth, Daydream Nation, 1988.

15 Lis Rhodes, ibid. 
16 Sara Ahmed. 2016. "Losing Confidence". Feminist Killjoys blog. Accessed 24.03.2016. http://feministkilljoys.com/2016/03/01/losing-confidence/

Lina Džuverović is a curator and Lecturer at the Department of Art at the University of Reading. Formerly she was Artistic Director at Calvert 22 Foundation (2011-2014) and Director of Electra, a London-based commissioning organisation, which she co-founded in 2003. She is also a PhD candidate at the Royal College of Art and Tate, researching Pop Art in the former Yugoslavia. Selected curatorial projects include Monuments Should Not Be Trusted (Nottingham Contemporary, 2016), Sanja Iveković -

Unknown Heroine (South London Gallery and Calvert 22, 2013); IRWIN - Time For A New State er NSK Folk Art (Calvert 22, 2012); 27 Senses (Chisenhale Gallery, London, 2010), Favoured Nations, Momentum, 5th Nordic Biennial of Contemporary Art

(2009), Her Noise (South London Gallery, 2005).

Irene Revell is a curator and writer who has been working across professional and 'DIY' registers over the past sixteen years. Her work seeks out new contexts and connections for practices with challenging social and political implications. She is Director of Electra; a member of the Cinenova Working Group; and Visiting Curator on the MA Sound Arts, UAL. Recent collaborative projects include Cinenova series Now Showing (2015-); The Multiversal Score, Wysing Arts Centre (2015); Someone Else Can Clean Up This Mess, Flat Time House (2014). Recent writing includes a forthcoming contribution to Women Artists, Feminism and the Moving Image (ed. Lucy Reynolds, I.B.Tauris, 2016), Caesura/ Accesso (forthcoming), Camera Austria (with Kerstin Schroedinger), NOIT, Psykick Dancehall, and The Wire magazine. She was associate editor of Aftershow: Pauline Boudry/Renate Lorenz (Sternberg, 2014). 


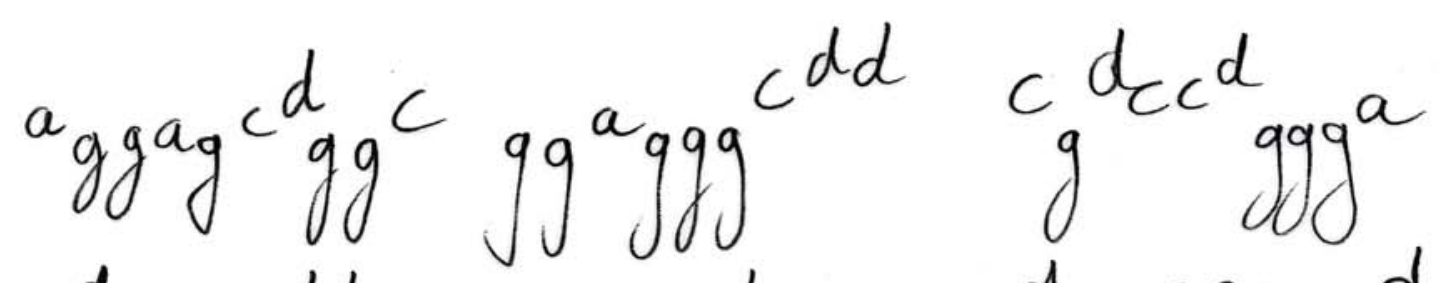

$c_{g}^{d} c_{a} c d d c d_{c c c}{ }^{d} c_{g g g} d_{c} c c c c d$ g g g

$d_{a}{ }^{c c} g g^{a^{c c}} c_{g} c_{a g g}{ }^{c d} c c \quad c_{g g g g} a_{g g g}$

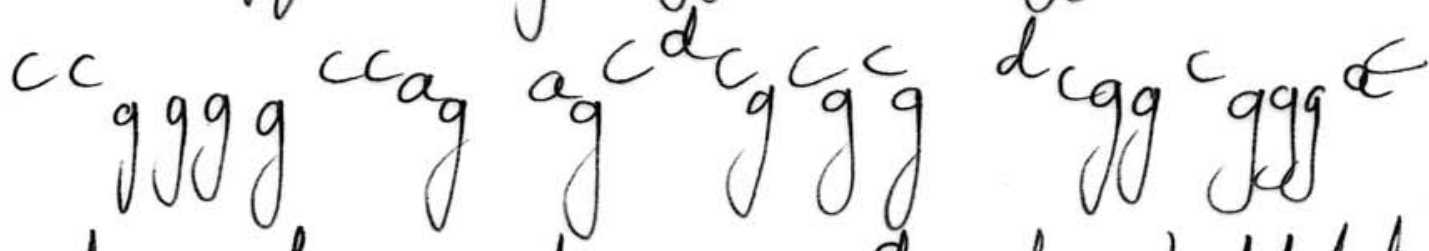

$a^{d} c_{g} c_{g} c d_{c} c_{g g g} c_{g}^{d} d_{g} c d c d d d d$

$c_{g d c} c^{d} c_{a g g} c_{g g c c} c_{g} c c d d d$

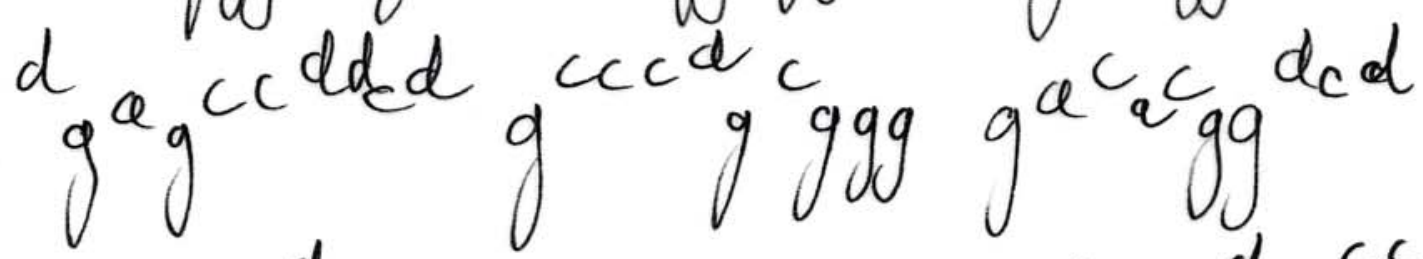

$g^{c_{a} c c c} g^{d} c c \operatorname{cog}^{c} g^{c c} a^{c} g g^{a c c a d} a^{a^{c c}}$

$a^{d} a^{c c c d} c c$ a $a^{c} c_{a a a_{j}} a^{d} a^{d} g g g^{d} g$

$g^{c c c^{d}} c^{d} g^{c} a^{d c} a_{g} a^{d c_{c}}$ agggaa $g a^{a_{g}}$

(ESR1) 


\section{Angels in the White Cube? Rhetorics of Curatorial Innocence at dOCUMENTA (13) Nanne Buurman}

\section{Introduction}

Recent years have seen a tremendous boost in feminist curating. While problematizations of sexist representation, canon critique, and quotas for women have been around for a while, exhibitions dedicated to feminist and queer issues or the work of women artists are currently proliferating. Yet, despite this increased feminist concern with the gendered content of exhibitions, which is also mirrored in the accompanying literature, ${ }^{1}$ the specific relationship between gender and curatorial authorship remains largely a blind spot or tends to link curatorship with masculinity. ${ }^{2}$ This is surprising because the curatorial field is increasingly dominated by women. It is all the more remarkable because - complementary to stereotypical associations of artistry with masculinity - structural analogies may be drawn between traditional scripts of femininity and widespread curatorial codes of conduct. Beyond the shared etymology of care work and curating in the Latin curare ('care'), they have in common an emphasis on modesty, restraint, and the negation of authorship, as well as an emancipatory historical trajectory from behind the scenes to centre stage.

Well into the twentieth century, curatorial care for collections and the self-negating housekeeping usually performed by women may be compared as backstage agencies that had few public merits but adhered to a separation of spheres, in which the author-ity and autonomy of artists and men was secured by the invisible care labours performed by curators and women respectively. ${ }^{3}$ The ideology of the white cube, which veils curatorial agency in favour of a purported autonomy of the artworks, thus corresponds with nineteenth-century ideals of pure femininity, personified by the Victorian Angel in the House, who was expected to perform her domestic duties quietly to provide the backdrop for her husband to stage himself as the head of the house. Still today, the figure of the Angel in the House, famously criticized by Virginia Woolf (1942), has its counterparts in curators who modestly declare their innocence. In a manner befitting the Victorian ideal of the desexualized hostess and mother, who labours invisibly in the background to care for her loved ones and guests, curators of all genders claim that they merely prepare the stage for the artists as the protagonists and do not have any authorial ambitions of their own. This conception of non-authorial curatorial agency sometimes even manifests itself in generalizing normative codes of modesty. In 1978, for example, the curator Alanna Heiss observed: "While the demands of art centered on the meaningful expression of the self, the demands of curating predominantly included the ability to absent the self, to provide the neutrality of context necessary to artists and audience [...]" (2012: 491). ${ }^{4}$

Since Brian O'Doherty's (1976) critique of the pseudo-objectivity and virginity of the white cube, the conception of a neutral exhibition has no longer 
been tenable. Nevertheless, the topos of curatorial innocence paradoxically seems to have become all the more important after figures such as Harald Szeemann called into question the traditional backgrounding of curatorial agency by articulating authorial claims. Before the late 1960s, curators had been conceived of as custodians operating primarily behind the scenes of museums, their chief responsibility being the care of collections as well as the study and preservation of art, whereas its mediation and exhibition had only been of secondary concern. In their article, "From Museum Curator to Exhibition Auteur. Inventing a Singular Position", Nathalie Heinich and Michael Pollak (1996) write that pre-authorial custodian curating was characterized by "the tendency towards the erasure of the person in the post", partly as a consequence of dealing with artists as "an extremely individual lot" (ibid. 234). They find "[t]races of this form of abnegation" in "the voluntary assumption of those traits deemed appropriate for a curator - reserve, modesty, discretion" as well as "sacrifice of wealth and fame" which they link "to the high proportion of women curators [...]" (ibid.). Against this background, the author-ization [sic!] of the curator as an (independent) exhibition-maker, who owes his authorship not least to an analogy with traditional conceptions of artisthood as sovereign creation (Grammel 2005, von Bismarck 2005: 177), can also be understood as a 'masculinization of curating'. Analyzing the iconic photograph that shows Harald Szeemann surrounded by artists at the occasion of documenta 5, Dorothee Richter points out that, "Szeemann's pose is a distinctive positioning, based on historical schemata, especially of the curator as a god/king/man among artists" (2012: 232).

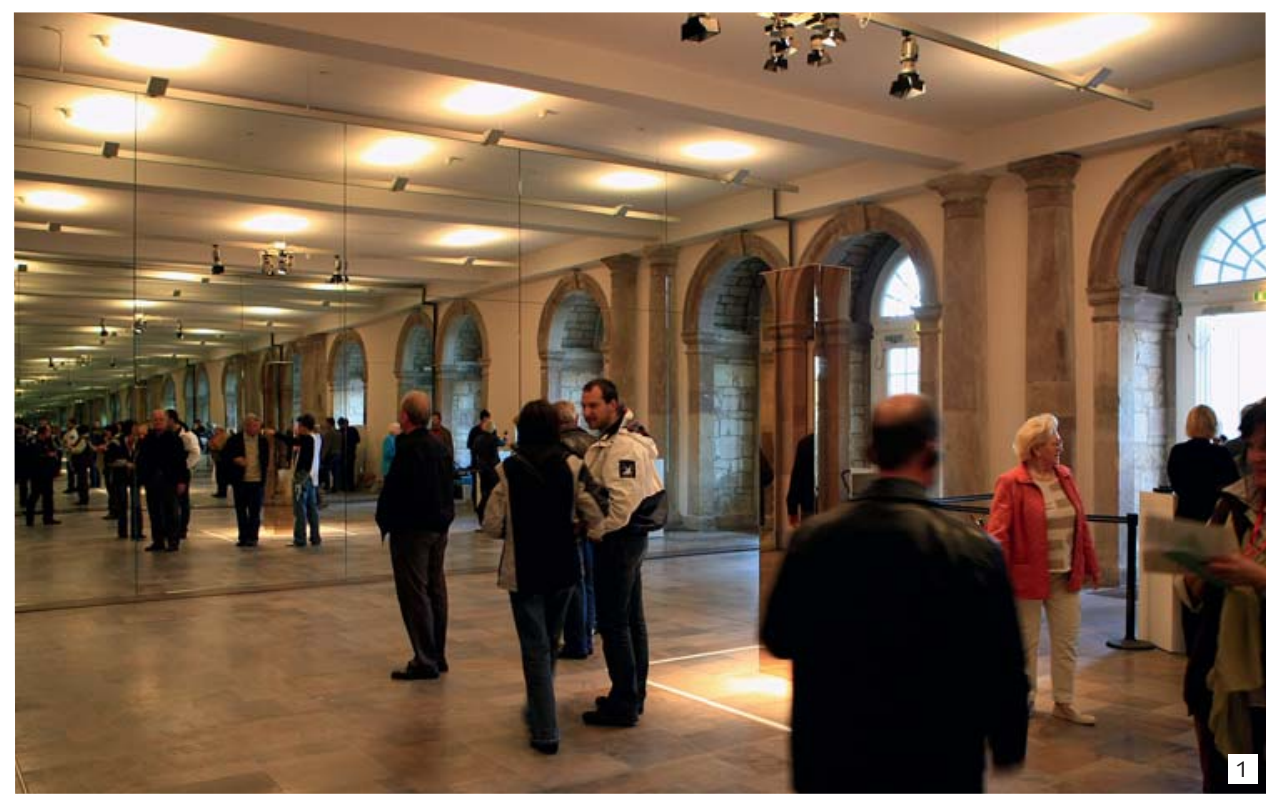

Since the 1990s, this heroization of individual charismatic curators has been relativized by media-reflexive approaches to curating that address exhibitions as social spaces in which a large number of actors and agents contribute to the production of meaning. Indebted to traditions of artistic institutional and representational critique, discourses of critical curating have called attention to expository practices, modes of "giving to see" and the powerful effects of curatorial constellations. In other words, rather than focusing on curators' singular personalities, issues of contextualization, staging, display, and the ways in which visitors are addressed have since come under scrutiny (e.g. John/Schade/Richter 2008). Hence, diverging from the above-cited claims of innocence, the author-ity of exhibiting was not rejected, but reflected upon, decentralized, and differentiated. In the curatorial field, the crisis of representation thus first became apparent during the late 1960s, 
when the author-ization of the curator and the subjectivization of exhibitionmaking called into question the notion of expository neutrality that had for so long gone unchallenged. From the 1990s onward, critical reflections on the mediality of exhibitions have proliferated, leading to an increased awareness of the aesthetic, epistemological, and social effects of curatorial framings. This includes a growing recognition of the constitutive role of the visitors - as manifested in the controversies over the issue of participation - so that, from about 2010 onward, there is even talk of an educational turn in curating (e.g. O'Neill/Wilson 2010). ${ }^{5}$ Whilst proponents of post-representative curating conceive of exhibitions as inherently political social spaces where the meaning of exhibits is constantly negotiated (e.g. Sternfeld/ Ziaja 2012), some neo-objectivist curatorial tendencies - much in line with currently influential post-humanist theories - claim to let exhibits of human and non-human provenance speak for themselves. ${ }^{6}$

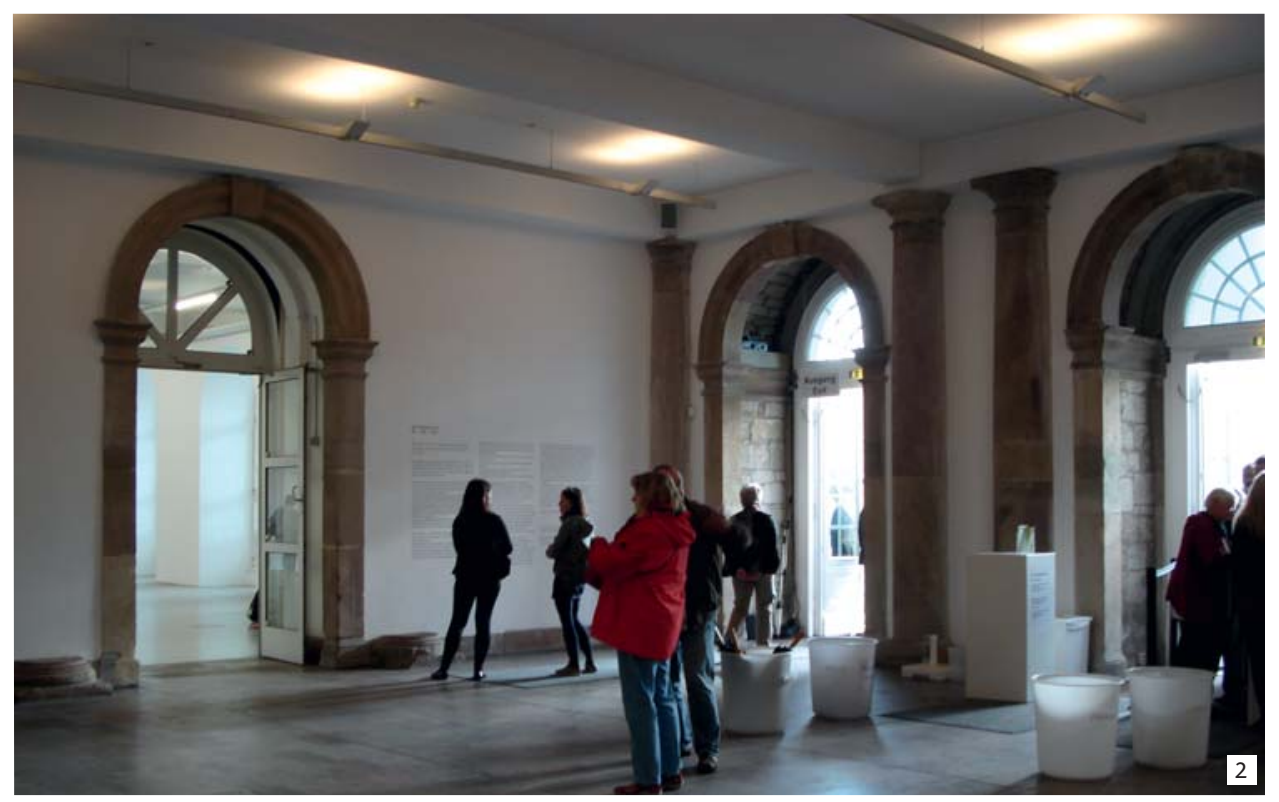

The developments roughly outlined above can also be observed with regard to the various editions of documenta. Founded in 1955, the institution was described by Arnold Bode in the catalogue of documenta III (1964) as a "museum of 100 days". However, this recurring large-scale exhibition differs from museums in that it is not devoted to the collection, care, and study of objects, but above all to the exhibition and mediation of contemporary art. Accordingly, the documentary claim to representativeness inscribed in the institution's name was challenged from the first documenta onward (see Schwarze 2006: 9-13). This became most explicit in documenta 5 (1972), because its curator Harald Szeemann replaced the scholarly-objective approach with his ostensibly subjective curation of what is canonized as one of the first thematic exhibitions ever (see Germer 1992). Akin to the traditions of representational critique and media-reflexivity, documenta 12 (2007) eventually exhibited the act of exhibiting itself as a governmental practice (see Buurman 2009). This essay discusses dOCUMENTA (13) (2012) as an example of how the power inherent in the dispositives of showing (once again) became (or was rendered) invisible by verbal and visual rhetorics of innocence. In the following, I specify the ways in which the political dimension of exhibiting (e.g. von Bismarck 2008) - i.e. "the power of display" (Staniszewski 1998) and the hierarchization of visitors and exhibits implied in their constellation (see Beck 2007) - was deproblematized. 


\section{Curatorial Authorship at dOCUMENTA (13)}

One of the chief concerns proclaimed by artistic director Carolyn Christov-Bakargiev was the critique of anthropocentric worldviews, which was to be achieved by an expansion of cultural agency to include scientific researchers, political activists, animals, plants, and inanimate objects. Despite this radically inclusive approach, dOCUMENTA (13) was in many respects characterized by a recentralization of authorship on exceptional humans. Whereas the preceding documenta 12 (2007) - with its ostentatious mise-en-scène - had shifted the attention away from artist-subjects and contexts of production towards the context of reception, the effects of display on the perception of objects, and the experiences of visitors, $d(13)$ 's display, in contrast, was curbed in favour of centring the attention on the artists as its primary authors. Thus, $d(13)$ countered the reflection of exhibitionary mediality and author-ity, epitomized in $d 12$ by the mirrored entrance hall (fig 1 ), by once again re/turning to the model of the white cube (fig 2). Due to this adherence to the notion of curatorial objectivity, not only was the constitutive role of the visitors' corporeal and mental presence in the space largely ignored, but the ways in which exhibitions shape meaning, mediate reality, direct the visitors' attention, and influence their experiences were also almost completely subdued. The outward appearance of the curator as an 'innocent angel' - suggested, for example, in the repeated emphasis on Christov-Bakargiev's "friendliness", her "optimistic smile", and her "curly blonde hair" (Schlüter 2012a: 23) in various mainstream media portraits with such telling titles as "Die Heilerin", i.e. "The Healer" (Rauterberg 2012), and "Madame Maybe" (Schlüter 2012a) - however, has to be put into perspective. Aside from the discrepancy between the curator's verbal claims of non-intervention on the one hand and the power relations inherent in every actual staging of a show on the other, DOCUMENTA (13) is also marked by a number of other inconsistencies - for example, contradictions between the post-humanist stance and the focus on the lives of the artists, or between the critique of logocentrism and the strong role played by texts. Not least, curatorial authorship oscillated ambivalently between a compliance with the model of the invisible female hostess and the (re) centring on the curator as an object of attention. ${ }^{7}$

\section{Rhetorics of Curatorial Innocence in Texts by Christov-Bakargiev}

In her curatorial essay, Christov-Bakargiev (2012a) postulated that, "A holistic and non-logocentric vision [...] makes us more humble, able to see the partiality of human agency, encouraging a point of view that is less anthropocentric" (2012a: 31). Nevertheless, the curator's manifold declarations of modesty were performatively contradicted in her programmatic texts as well as by her public appearances, lectures, and interviews given in an assertive style and remarkably self-confident demeanour. In fact, her verdicts on the curatorial and her critiques of anthropocentrism, digitization, and cognitive capitalism are presented quite authoritatively. Famous as an eloquent celebrity curator herself, Christov-Bakargiev, for instance, repeatedly criticized the popularity of curating in favour of advocating for a concentration on the art and the artists. In volume one of the three-volume catalogue, The Book of Books, for example, she writes: "After more than a decade of these discourses, mainly dedicated to curatorial practices or to broader cultural studies and postcolonial theory, it is pleasurable to reread, for example, Rudolf Arnheim (1904-2007) and the gestalt theories of the perceptual psychologists." (Christov-Bakargiev 2012b: 650) Christov-Bakargiev sides with Arnheim's diagnosis that: "'Art may seem to be in danger of being drowned by talk."' (Christov-Bakargiev 2012a: 38). She joins him in his critique of the "excess of art criticism and theory" (ibid.) because "often, these writings do not speak about the artworks themselves, but about curatorial positions in art today, constituting a meta-artistic discourse" (Christov-Bakargiev 2012b: 650). 

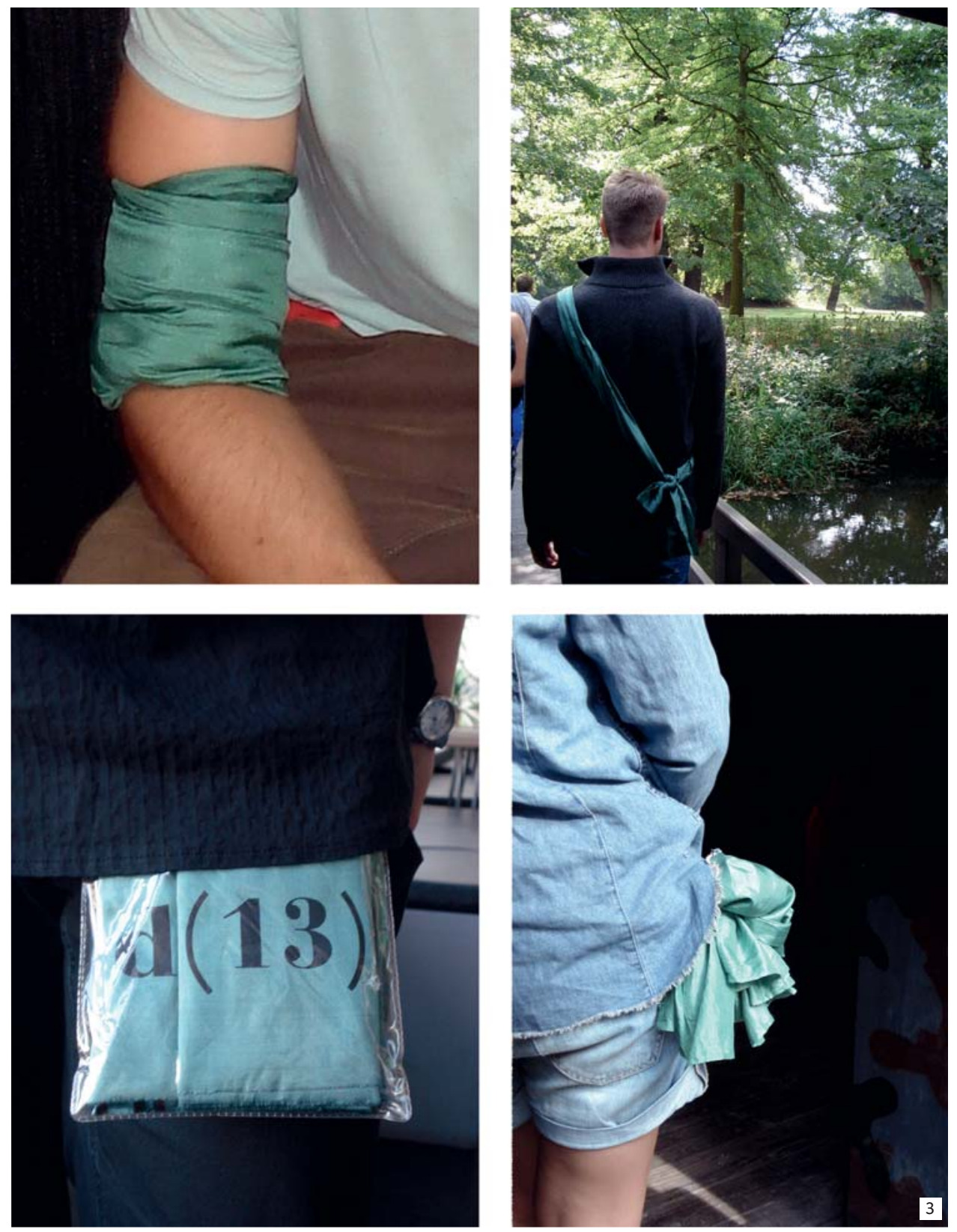

In interviews with representatives of the media, Christov-Bakargiev likewise repeatedly emphasized her interest in artists while explicitly asserting a lack of interest in matters of mediation, display, and the positioning of audiences. As she explained in a conversation with Kia Vahland (2012: n.p. orig. German) in the Süddeutsche Zeitung: "The more you think about display, the less you permit visitors to enter into dialogue with the [artistic] research." Furthermore, in an interview with Ralf Schlüter for Art magazine (2012b: 96), she explicitly distanced herself from the authorial concept of the curator, particularly criticizing the idea of the curator-as-artist (ibid; idem in: Rauterberg 2009). According to Christov-Bakargiev, curators are responsible for the fact that "even the artists no longer feel at home in large-scale exhibitions" (ibid., orig. German). Hence she expressed her aspirations for a "hospitable" dOCUMENTA (13) (ibid.) and demanded strengthening "the authority of the artistic" (idem in: Schlüter 2012b: 96, orig. German). Christov-Bakargiev's rhetoric thus complies with the codes of modesty cited at the beginning of this text. Her insistence on restraint evokes the idea of curatorial innocence and 
the possibility of direct access to the exhibits, untainted by curatorial framings or medial interferences of the exhibition: "A documenta is a membrane between the audience and the world behind the exhibition: artists, intellectuals, technicians. I tend to concern myself more with the world behind the exhibition than with the audience [...]. It's been my experience that if I don't think so much about the visitors, people are the happiest. They have the feeling of being granted undistorted insights into this other world behind the exhibition" (Christov-Bakargiev in: Vahland 2012: 11, orig. German). Moreover, she conspicuously often spoke of her "humility", "humblenesss", and "modesty" as an initiator of (artistic) processes and emphasized the importance of curatorial "care", "concern", and "commitment" for objects (Christov-Bakargiev 2011: 5, 2012a: 34ff., idem in: Jocks 2012: 369ff.), thereby evoking the pre-authorial understanding of curating as a custodial-conservatorial caring of collections. Her rhetorics of humility thus contributed to playing down the curatorial powers of meaning-making.

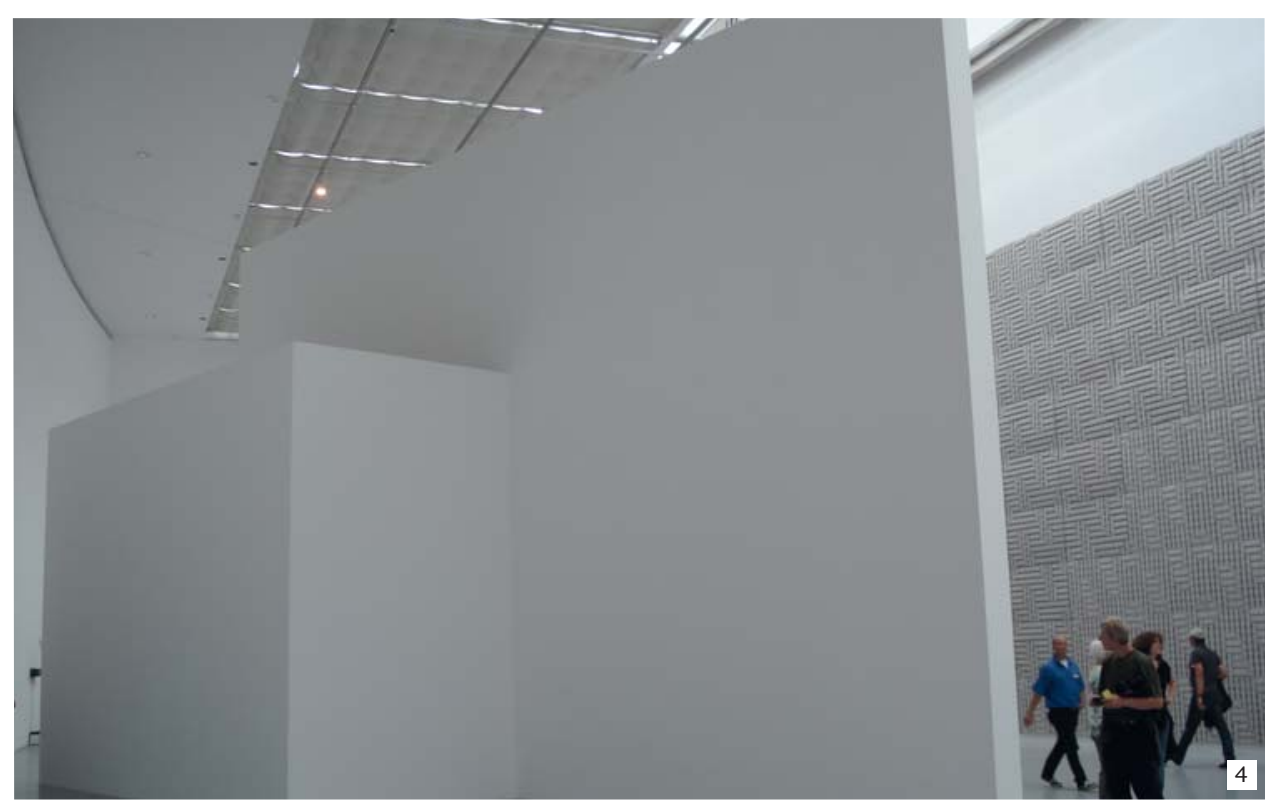

Christov-Bakargiev's professed abstinence from a meta-artistic narrative of her own may further be observed in her insistence on $d(13)$ 's lack of a concept. On closer inspection, however, the concept of a non-concept - which seems quite reasonable against the background of her critiques of logocentrism, cognitive capitalism, and curatorial meta-discursivity - turned out to be an elaborate concept indeed. $d(13)$ 's conceptual foundations were laid out, for example, in Christov-Bakargiev's programmatic essay, "The dance was very frenetic, lively, rattling, clanging, rolling, contorted, and lasted for a long time" (2012a), which appeared in the press portfolio and the Book of Books. An excerpt of the text was also prominently posted on the wall in the otherwise empty entrance hall of the Museum Fridericianum, which - as the traditional starting point of a tour of the documenta - is the ideal site for a curatorial prologue. In other words, dOCUMENTA (13) was by no means characterized by a relinquishment of theory and curatorial discursivity. In fact, the show was accompanied by a considerable amount of text and theory. Examples are the numerous conferences and seminars that took place within the framework of $d(13)$ or the 100 Notes - 100 Thoughts series published as a prelude to the show, as well as their compilation in The Book of Books, which for its part not only makes a weighty impression with its title, but also with its massive dimensions and its extensive "Reading list: Propaedeutics to fundamental research" comprising nearly four hundred entries (18-26). 
The paradox of this ostentatious curatorial modesty, expressed in the concept of 'conceptlessness' as well as in a declared curatorial scepticism that with its emphasis on the propositional, the open, and process-oriented (e.g. Christov-Bakargiev 2012a: 36f; idem in: Jocks 2012: 366) - tends to totalize non-knowledge, was moreover mirrored in the exhibition's visual identity as a non-identity. The corporate design developed by the agency Left-Loft consisted chiefly of a rule for how to write the word DOCUMENTA (13), which was permitted to appear in various typefaces and to be applied to various backgrounds. The design of the notebooks from the 100 Notes - 100 Thoughts series that vary in colour and size, as well as the rule that there are no rules (Christov-Bakargiev 2012c) with regard to the wearing of the green silk scarf serving as a 'non-uniform' for the guards (fig. 3), adhered to a similarly inflectional pattern. As we shall see next, this modulation of supposedly individual possibilities within a prescribed template could also be encountered in the exhibition design.

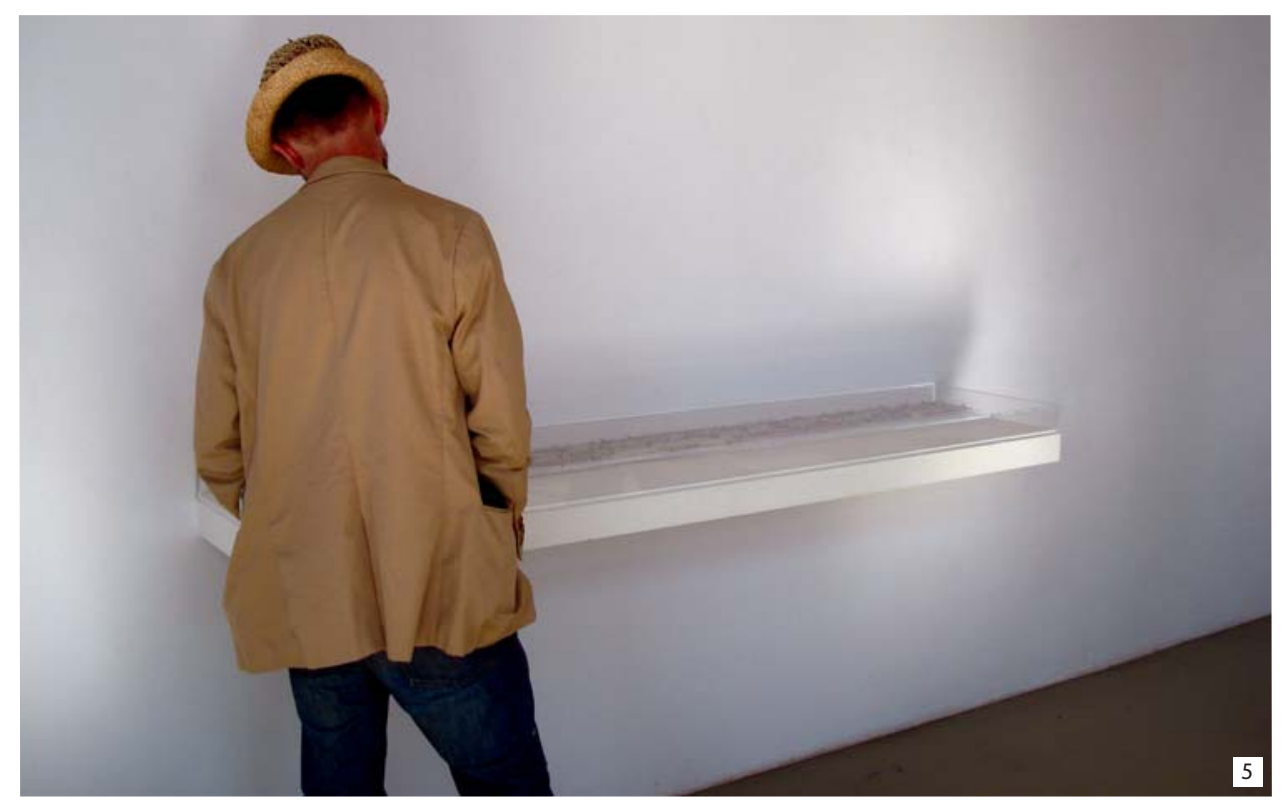

The Invisibilization of Display at dOCUMENTA (13)

On the display level, too, the exhibition rhetoric of DOCUMENTA (13) was characterized by a discrepancy between curatorial disclaimers of authorship, including the respective foregrounding of the artists, and a less obvious concentration of author-ity in the hands of Christov-Bakargiev. The most prominent parts of the show were staged in the modernist style of the white cube. That, as well as the tendency to isolate individual artistic positions from one another and to prioritize biographical information in exhibition texts, turned the artists' subjectivity into one of the main attractions, while the curatorial powers of display were backgrounded for the sake of expository neutrality, an ethics of care, and artistic autonomy. Due to her critical attitude towards the dominance of 'starchitects' (Christov-Bakargiev in: Stock 2012), Christov-Bakargiev commissioned punkt4 to be in charge of the exhibition architecture of $d(13)$ because the firm's architects presented themselves as 'modest' and tried "to restrain themselves as designers" (Stöbe 2012: 8, orig. German). According to their website, "No exhibition architecture has been 'designed', but rather the existing materials have been left to speak for themselves to the greatest extent possible. Solutions for the visible interventions (passages, entrances, ramps, gates) are indebted to a pragmatic aesthetic that is always close to the artist and the function" (punkt4, orig. German). Furthermore, the website mentions that the architects tried to follow the principle of "the most minimal 
interventions possible" and therefore even resorted to "hidden architectonic interventions" (ibid.). ${ }^{8}$

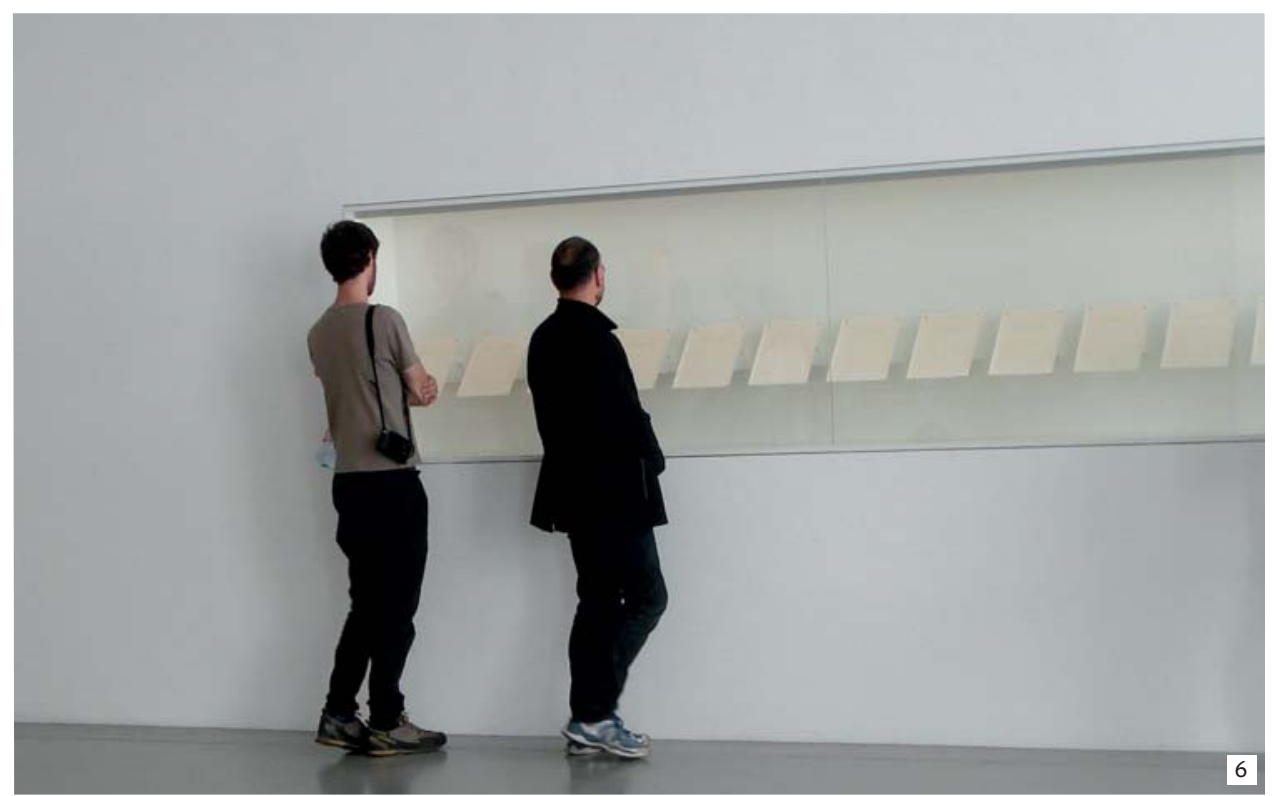

This minimally invasive agenda was also applied to the show's installation design. With very few exceptions, the walls in the main venues - Fridericianum, Neue Galerie, documenta-Halle and Kulturbahnhof - were painted white. Likewise, the display systems were kept so plain and unobtrusive that they tended to blend in with the white walls. In fact, most of them self-effacingly faded into the background in a manner that calls to mind the notion of 'camouflage' (figs. 4-6). Moreover, the lighting in these spaces was generally inconspicuous. Besides the spotlights evenly illuminating the exhibits, the prevailing light-diffusing ceiling lamps neither called attention to themselves nor to their subtle powers to produce atmospheres and direct attention. Furthermore, many of the windows were discreetly covered with shades of different degrees of transparency that softened the sunlight. These window screens were kept so simple that they could easily be overlooked. And finally, even the furniture and technical equipment were blended into the surroundings in an optically neutral manner (fig.7). Loudspeakers or fans, for instance, were veiled under white covers so that the galleries were kept clean of anything that could disrupt the experience of art or remind viewers of the manifold ways in which it is mediated.

As a consequence, the spaces appeared so pure that curatorial dramaturgy remained largely unnoticeable at first glance. In fact, the steering of the viewers' attention and movement was very subtle. Visitor guidance and the architectural positioning of the audience were so inconspicuous that visitors were apparently free to choose their route through the show. Moreover, the means of directing the viewer's gaze were used sparely, formal relationships between the objects were highlighted only rarely, and visual axes played a subordinate role. In many cases, vistas were even blocked by partitions at the transitions from one space to the next. Instead of providing an overarching curatorial narrative, $d(13)$ almost came across as a conglomeration of solo exhibitions. Monographic rooms devoted to individual artistic positions prevailed. In the Auepark, practitioners even had little houses at their disposal, which the architects helped to design according to the respective artists' wishes. The only decision made by the curator was that the little cabins be positioned in isolation from each other to make it impossible to see from one 
house to the next. As a result, the aforementioned constellation of individual articulations in a predetermined serial framework was repeated here as well. Where works shared exhibition spaces, each artistic position usually had at least a corner or wall to itself. This clear spatial separation of the different contributions, as well as the delegation of responsibility for the installation to the artists, apparently followed an ethos of curatorial non-intervention and thus suggested the greatest possible autonomy for the artists.
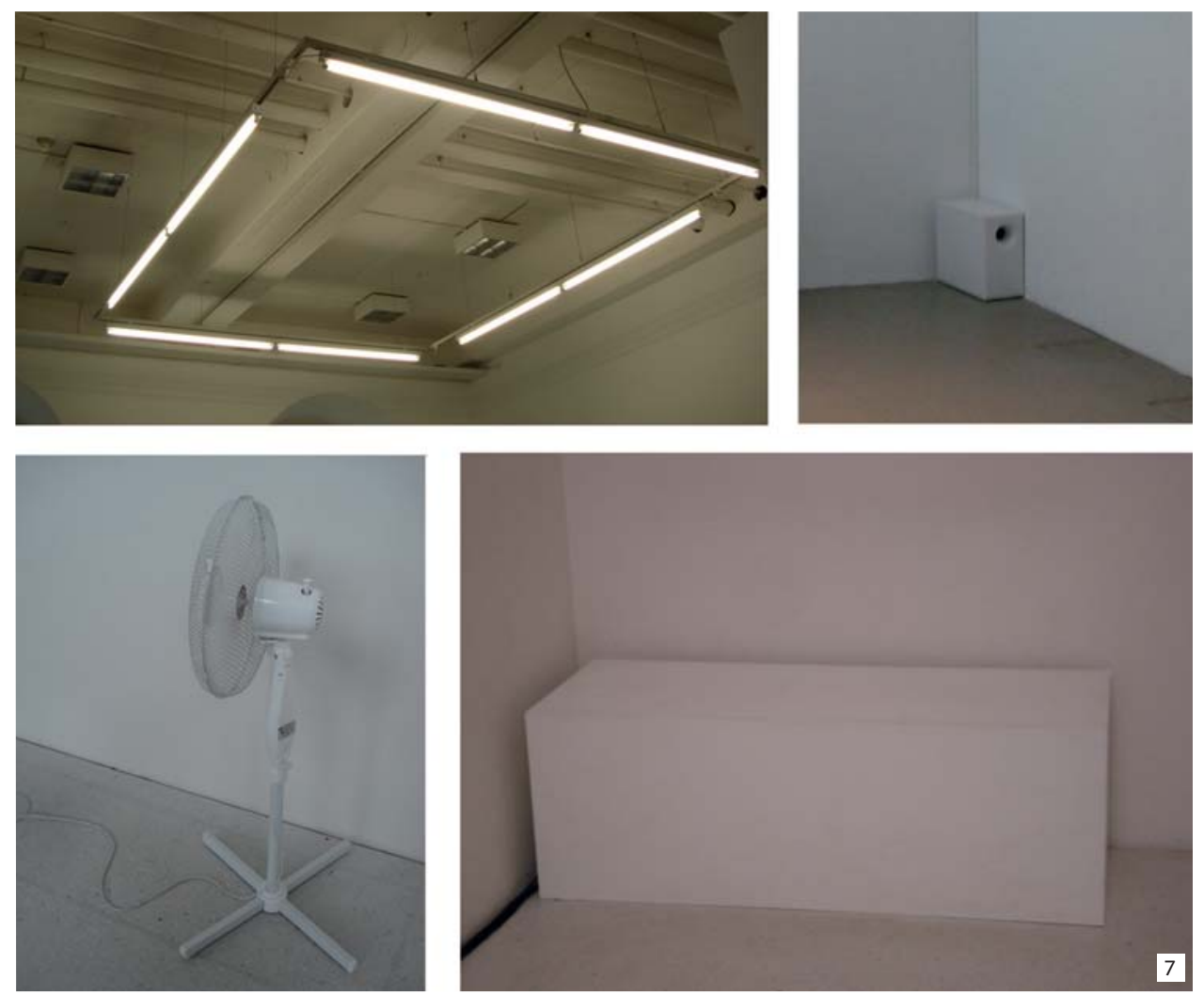

The space called The Brain was perhaps the most notable exception (fig. 8). Situated at the heart of documenta's traditional main venue, the Rotunda of the Museum Fridericianum, it was reminiscent of cabinets of curiosity - containing, as it did, a multiplicity of heterogeneous objects, a Latourian parliament of things, gathered to represent the exhibition's leitmotifs. In fact, many of the artworks staged in mutual isolation in the rest of the show bore a relationship to the themes outlined by the curator in The Brain. According to The Guidebook, "The many threads of DOCUMENTA (13) inside and outside Kassel are held together precariously in this 'Brain,' a miniature puzzle of an exhibition that condenses and centers the thought lines of dOCUMENTA (13) as a whole" (2012: 23). This materialized object-based mind map of $d(13)$ functioned as a miniature curatorial museum, a glimpse into the brain of the show's mastermind. Its associative character was underscored by the seemingly random combination of various styles of display furniture. Yet even if The Brain with its collection of glass cases from differing time periods could easily be interpreted as an act of the musealisation of the museum or as a media-reflexive meta-exhibition of display systems, that particular interpretation was apparently not intended. According to a member of the curatorial team, the glass cases were used for purely pragmatic - more specifically, conservatorial - reasons, so that here curating presumably is to be understood less in the strong sense of an authorial (self-reflexive) steering of perception, but rather in the weak sense of a custodial "care of objects". According to the punkt4 architects' website, 
even the glass wall separating The Brain from the rest of the exhibition had been inserted for the purpose of climate control "in such a way as to make it invisible to the visitor" (punkt4, orig. German). Here, once again, the ubiquitous effacement of curatorial interventions becomes transparent, so that the pane of glass reads like a pars pro toto for $d(13)$ 's negation of the mediality of exhibiting.

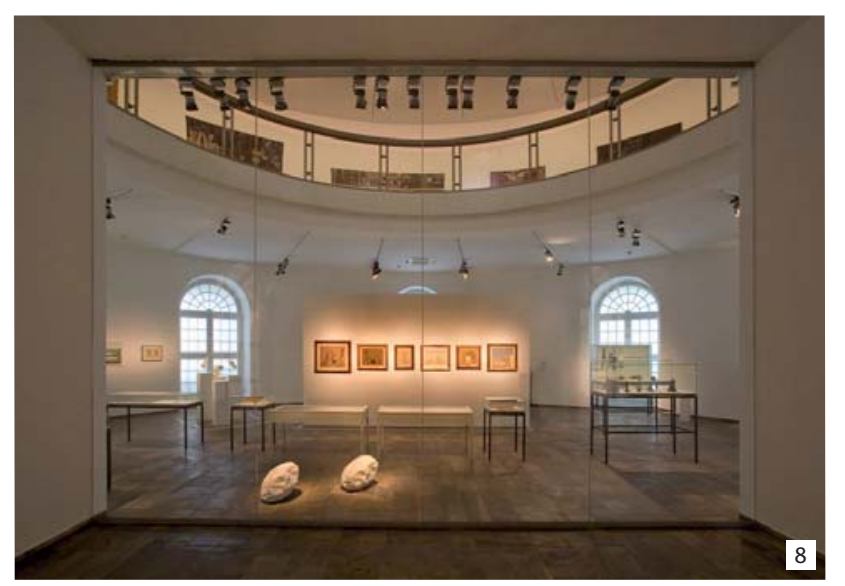

Ambivalent Hospitality. The Hostess as a Liminal Figure

Despite the quite obvious mediatedness of objects separated from the viewer's eyes by display cases and panes of glass, Christov-Bakargiev's self-denying rhetorics of care, her foregrounding of the artists' intentions, and her insistence that the objects speak for themselves (e.g. Christov-Bakargiev in: Vahland 2012; idem 2011: 7) suggested the possibility of direct access to the things as such. Consequently, as I have tried to show in this essay, the author-ity of the display to generate meaning - i.e., to give the objects a voice and to influence aesthetic experiences and readings - was largely obscured, while curatorial control nevertheless prevailed. By turning a blind eye to the discursive, institutional, and material framings, $d(13)$ 's purportedly non-interventionist approach thus not only effaced the curator's author-ity but also neglected the recipients' contributions to meaning-making in favour of the pure presence of the "the real thing" (Buchmann 2015: 127). ${ }^{9}$ The disguise of curatorial authorship had the side effect of weakening traditional patterns of curator-bashing. Since at least the 1970s, curators have been accused of imposing their curatorial concept on the artists, of disregarding the latter's individuality and intentions in favour of curatorial meta-narratives topheavy with discourse, or of heretically entering into competition with artists by claiming an authorial position. Of course, these patterns of critique - which have meanwhile ossified into formulaic clichés that are often applied regardless of the specific exhibition's qualities - can also be found with regard to d(13). Nevertheless, many critics have refrained from them and lauded the curator's authorial restraint (e.g. Sommer 2012: 3).

Thanks to the vacillating interplay between verbal- and display-rhetorical declarations of innocence on the one hand, and the now implicit, now explicit concentration on her person on the other, Christov-Bakargiev came across as an enabling hostess who merely created conditions and set the stage for others to shine. With the aid of this hospitable set-up, she was able to insist on the autonomy and individuality of the artists without relinquishing a demonstration of her own significance. This model of curatorial hospitality, however, is ambivalent in that it can simultaneously contribute to relativize author-ity and to reproduce centralist notions of authorship (Buurman 2016b). Switching back and forth between the role of the protagonist on stage and the function of the stagehand behind the scenes, 
Christov-Bakargiev may be characterized as a kind of reversible figure, a liminal presence betwixt ergon and parergon. As a hostess, she was - on the one hand able to blend into the background like the Angel in the House, while - on the other hand - presenting herself as the main subject of $d(13)$. This oscillation between foreground and background, opacity and hyper-visibility makes it difficult to determine whether this 'coy ploy' was a masquerade or mimicry, an affirmation of clichés or their subversion.

Finally, this equivocal performance of curatorial authorship provokes further considerations about the ambivalent functions of in/visibility in post-disciplinary neoliberal societies of control. As Elena Filipovic has pointed out, the model of neoliberal globalization paradoxically lives on in the white cube, often against the curators' intentions (2010: 328ff). Therefore, one may ask to what extent the white cube, defended by Christov-Bakargiev as a "space of emancipation" (idem in:

Schlüter 2012b: 98), can also be understood as a neoliberal smooth space, in which invisible curatorial hands create the impression of an egalitarian libertarianism that glosses over existing hierarchies, exclusions, and restrictions. In 1990, Gilles Deleuze diagnosed a turn from Foucauldian disciplinary societies to societies of control, where direct disciplinary measures are replaced by barely noticeable means of soft power. With this in mind, it is perhaps no coincidence that the metaphor of the "curator-as-prison ward" - coined by Robert Smithson when he accused Harald Szeemann and documenta 5 of "Cultural Confinement" (1972) - has been replaced by that of the "curator-as-healer" - Hanno Rauterberg's epithet for Christov-Bakargiev in his article "Die Heilerin" (2012). Against the background of general biopolitical deployments of femininity, I worry that the 're-feminization' of curating - or, more precisely, curatorial performances of "womanliness as masquerade" (Riviere 1929) - not only risks upholding the myth of the white cube's virginity but also - despite best intentions - whitewashing the actually existing inequalities of the current capitalist regime.

This is a revised and expanded version of the article "Angels in the White Cube. Rhetoriken kuratorischer Unschuld bei der dOCUMENTA (13)", originally published in FKW/Zeitschrift für Geschlechterforschung und visuelle Kultur, 58, Special Issue Revisionen des Museums. Praktiken der Sichtbarmachung im Feld des Politischen, eds. Jennifer John and Daniela Döring, April 2015, pp. 63-47.

Translation from German by Judith Rosenthal, expanded by Nanne Buurman.

\section{Captions}

1 Mirrored entrance hall of the Museum Fridericianum during documenta 12 (2007), Photo: Ryszard Kasiewicz, (c) documenta Archive

2. Whitewalled entrance hall of the Museum Fridericianum during dOCUMENTA (13) (2012), Photo: Nanne Buurman

3 Silk scarf as sign of identification for the dOCUMENTA (13) guards, Photos: Nanne Buurman

4 Display (for the work by Thomas Bayrle) in the documenta-Halle, Photo: Nanne Buurman

5 Display (for the work by Kristina Buch) in the documenta-Halle,

Photo: Nanne Buurman

6 Display (for correspondence between Alighiero Boetti and Harald

Szeemann) in the Museum Fridericianum, Photo: Nanne Buurman

7 Furniture, technical equipment and ceiling lights in the Neue Galerie, Photos: Nanne Buurman

8 Installation view of The Brain (with works by Judith Hopf, Giorgio 
Morandi, Giuseppe Penone, Horst Hoheisel, Lawrence Weiner), Copyright: the artists/VG Bildkunst, Bonn 2012, Photo: Roman März Please dont't print this image in large, for reasons of reproduction rights.

All pictures courtesy of documenta and Museum Fridericianum Veranstaltungs $\mathrm{GmbH}$.

\section{Notes}

1 For feminist curating, see, for instance, de Zegher (1996), Baert (2006), Butler/Mark (2007), Hayden/Skrubbe (2010), Dimitrakaki/Perry (2013), Kivimaa (2013), Red Min(e)d et al. (2013). For feminist museology and problematizations of racist and sexist display, see, for example, Hauer et al. (1997), Pollock (2007), John (2010), Krasny (2013).

2 Barbara Paul (2007) and Dorothee Richter (2012), for instance, have addressed the construction of masculinity in curatorial self-stagings.

3 As Lucy Lippard remarked, "It is far easier to be successful as a woman critic, curator, or historian than as a woman artist, since these are secondary, or housekeeping activities, considered far more natural for women than the primary activity of making art" (cited in: Bryan-Wilson 2009: 164).

4 Many more examples could be cited, see for instance Obrist $(2009,2014)$.

5 Nora Sternfeld $(2010,2012)$ has prominently criticized the appropriation of educational aspects into the curatorial field as being primarily beneficial for curators. She problematizes how it does not challenge the gendered division of labour that marks curators as producers (linked to the artists) and educators as reproducers (linked to audiences) and thus maintains an unequal distribution of reputation and (social and economical) capital amongst these groups of actors. For the gendering of power relations between curators and educators, see also Kaitavuori et al. (2013).

6 I am referring to the impact of philosophical currents, such as Speculative Realism, New Materialism, Object-Oriented Ontology, which have emerged as part of a more general theoretical (re)turn to materiality and the agency of nonhuman actors, as, for instance, represented by theorists such as Donna Haraway or Bruno Latour.

7 For a striking example of the strong concentration on Christov-Bakargiev see, for example, The Logbook. In my article "CCB with" I discuss how the curator turns into the prime exhibit of this second part of $d(13)^{\prime}$ 's three-part catalogue (Buurman 2016a).

8 Beyond the main venues discussed in the following, this agenda emphasized the character of the existing architectures adopted by $d(13)$ so strongly that these locations sometimes became "authentic" exhibits themselves, as, for example, the bunker in the vineyard.

9 In many ways, Buchmann's findings, concur with my own analyses. According to her, d(13)'s harmonized notion of collectivity remained uncritical of the "mediatedness of reality," which has "apparently become invisible" (ibid.138, orig. German).

\section{Bibliography}

Baert, Renee (ed.), "Curatorial Strategies," n.paradoxa, international feminist art journal, Vol. 18, July 2006.

Beck, Martin, "Sovereignty and Control," in About the Relative Size of Things in the Universe, Utrecht/London, Four Corners, 2007, pp. 44-59. 
von Bismarck, Beatrice, "Kuratorisches Handeln.>Immaterielle Arbeit< zwischen Kunst und Managementmodellen," in von Bismarck, Beatrice and Alexander Koch (eds.), beyond education. Kunst, Ausbildung, Arbeit und Ökonomie, Frankfurt am Main, Revolver, 2005, pp. 175-190.

von Bismarck, Beatrice, "Display/Displacement. Zur Politik des Präsentierens," in John, Jennifer; Richter, Dorothee and Sigrid Schade (eds.), Re-Visionen des Displays. Ausstellungs-Szenarien, ihre Lektüren und ihr Publikum, Zürich, jrp/ringier, 2008, pp. 69-82.

Bryan-Wilson, Julia, Art Workers. Radical Practice in the Vietnam War Era, Berkeley/Los Angeles/New York: University of California Press, 2009.

Buchman, Sabeth, "(Kunst)Kritik in kollaborativen Zusammenhängen," in Everts, Lotte; Lang, Johannes; Lüthy, Michael; Schieder, Bernhard (eds.), Kunst und Wirklichkeit Heute. Affirmation - Kritik - Transformation, Bielefeld, Transcript, 2015, pp. 125-142.

Butler, Cornelia and Mark, Lisa Gabriele (eds.), Wack! Art and the Feminist Revolution, Museum of Contemporary Art, Los Angeles, MIT Press, 2007. Exhibition Catalogue.

Buurman, Nanne, Ausstellen ausstellen. Ausstellungsautorschaft auf der documenta 12, unpublished master's thesis, Universität Leipzig, 2009.

Buurman, Nanne, "CCB With...: Displaying Curatorial Relationality in dOCUMENTA (13)'s The Logbook," Journal of Curatorial Studies, 5.1 Special Issue on Affect and Relationality, forthcoming 2016[a].

Buurman, Nanne, "Hosting Significant Others. Autobiographies as Exhibitions of Co-Authority," in von Bismarck, Beatrice and Benjamin Meyer-Krahmer. (eds.), Hospitality. Hosting Relations in Exhibitions, Berlin, Sternberg, 2016[b].

Christov-Bakargiev, Carolyn, "On the Destruction of Art - or Conflict and Art, or Trauma and the Art of Healing," in 100 Notes - 100 Thoughts Series, 100 vols. Ostfildern, Hatje Cantz, Notebook no. 040, 2011, pp. 4-9.

Christov-Bakargiev, Carolyn, "The dance was very frenetic, lively, rattling, clanging, rolling, contorted, and lasted for a long time," in The Book of Books (vol. $1 / 3$ of the dOCUMENTA (13) catalogue), Ostfildern, Hatje Cantz, 2012[a], pp. $30-45$.

Christov-Bakargiev, Carolyn, "Introduction: Notes on Perceptual Thinking and Its Possibilities Today," in The Book of Books (vol. 1/3 of the dOCUMENTA (13) catalogue), Ostfildern, Hatje Cantz, 2012[b], p. 650.

Christov-Bakargiev, Carolyn, 2012[c]. "A lesson in the possibilities of a scarf or, how to be an art project attendant." Accessed 15.12.2015. http://d13. documenta.de/de/\#/research/research view/a-lesson-in-the-possibilities-of-ascarf-or-how-to-be-an-art-project-attendant.

Deleuze, Gilles, "Postscript on the Societies of Control," October, Vol. 59, Winter 1992, pp. 3-7.

Dimitrakaki, Angela and Perry, Lara (eds.), Politics in a Glass Case, Liverpool: University Press, 2013.

Filipovic, Elena, "The Global White Cube," in van Hal, Marieke; Ovstebo, Solveig and Filipovic, Elena (eds.), The Biennial Reader, Bergen/ Ostfieldern, Hatje Cantz, pp. 322-345, 2010.

Germer, Stefan, "Documenta als anachronistisches Ritual," Texte zur Kunst, vol. 2, no. 6, 1992, pp. 49-63.

Grammel, Søren, Ausstellungsautorenschaft. Die Konstruktion der auktorialen Position des Kurators bei Harald Szeemann. Eine Mikroanalyse, Frankfurt am Main, Revolver Archiv für aktuelle Kunst, 2005.

Hauer, Gerlinde; Muttenthaler, Roswita; Schober, Anna and Wonisch, Regina (eds.), Das inszenierte Geschlecht Feministische Strategien im Museum, Vienna, Bohlau Verlag, 1997. 
Hayden, Hedlin and Sjöholm Skrubbe, Jessica (eds.), Feminisms is still our Name. 7 Essays on Histiography and Curatorial Practice, Cambridge, Cambridge Scholars Publishing, 2010.

Heinich, Nathalie and Pollak, Michael, "From Museum Curator to Exhibition Auteur," in Greenberg, Reesa; Ferguson, Bruce W; Nairne, Sandy (eds.), Thinking About Exhibitions, New York: Routledge, 1996, pp. 231-250.

Heiss, Alanna, "Placing the Artist," in The Book of Books (vol. 1/3 of the dOCUMENTA (13) catalogue), Ostfildern, Hatje Cantz, 2012, p. 491.

Jocks, Heinz-Norbert, "Das Erzählen als Wille zur Wahrheit, Gespräch mit

Carolyn Christov-Bakargiev," Kunstforum International, vol. 216, 2012, pp. 364-376. John, Jennifer; Richter Dorothee and Sigrid Schade (eds.), Re-Visionen des Displays. Ausstellungs-Szenarien, ihre Lektüren und ihr Publikum, Zürich, jrp/ringier, 2008, pp. 17-27.

John, Jennifer, White Cube Gendered Cube. Einschreibungen von Geschlecht in die diskursiven Kunstpraktiken von Museen. Eine Untersuchung am Beispiel der Hamburger Kunsthalle, Dissertation at the University of Oldenburg, 2010.

Kaitavuori, Kaija; Sternfeld, Nora and Kokkonen, Laura (eds.), It's all Mediating. Outlining and Incorporating the Roles of Curating and Education in the Exhibition Context, Cambridge, Cambridge Scholars Publishing, 2013.

Kivimaa, Katrin (ed.), Working with Feminism: Curating and Exhibitions in Eastern Europe. Tallinn: Tallinn University Press, 2013.

Krasny, Elke (ed.), Women's Museum. Curatorial Politics in Feminism, Education, History, and Art, Vienna, Löcker Verlag, 2013.

O'Neill, Paul and Wilson, Mick (eds.), Curating and the Educational Turn, Amsterdam/London, Open Editions/de Appel, 2010.

Obrist, Hans Ulrich, A Brief History of Curating, Zürich: JRP Ringier $\Theta$ Les Presses du Réel, 2009, pp. 234-39.

Obrist, Hans Ulrich, Ways of Curating, London: Allen Lane/Pengin, 2014.

O'Doherty, Brian, Inside the White Cube, Larkspur, CA, Lapsis Press, 1976.

Paul, Barbara, "Kuratoren und andere(s). documenta und Männlichkeitskonstruktionen," in k60 Kunstuniversität Linz, Linz, 2007, pp. 132-147.

Pollock, Griselda, Encounters in the Virtual Feminist Museum: Time, Space, and the Archive, London, Routledge, 2007.

punkt4: http://www.punkt4.net/punkt4/NEWS.html Accessed 15.12.2015.

Rauterberg, Hanno. 2009. "Kassel ist Australien. Vom Außenrand ins Zentrum der Weltkunst: Das erste große Interview mit der neuen Leiterin der Documenta, Carolyn Christov-Bakargiev," in DIE ZEIT, vol. 28, no. 2. July. Accessed 15.12.2015. http://www.zeit.de/2009/28/Interview-Christov-Bakargiev Rauterberg, Hanno., 2012. "Die Heilerin." Zeit Magazin, vol. 24, June, pp. 16-18.

Red Min(e)ds and Vesić, Elena (eds.), 54 October Salon: The Living Archive. Curating Feminist Knowledge, Belgrade, Cultural Center of Belgrade, 2013.

Richter, Dorothee, "Artists and Curators as Authors: Competitors, Collaborators, or Teamworkers?" in von Bismarck, Beatrice; Schafaff, Jörn; Weski, Thomas (eds.), Cultures of the Curatorial, Berlin, Sternberg, 2012, pp. 229-48.

Riviere, Joan, "Womanliness as a Masquerade," International Journal of Psychoanalysis, 10, 1929, pp. 303-313.

Schlüter, Ralf, "Madame Maybe," Art. Das Kunstmagazin, June 2012[a], pp. 21-24.

Schlüter, Ralf, "Das Herz der documenta schlägt in Kabul, Gespräch mit Carolyn Christov-Bakargiev," Art Spezial. Documenta 13, July 2012[b], pp. 96-98.

Schwarze, Dirk, Die Expansion der documenta-Kritik. Eine Ausstellung im Spiegel der Presse, Nordlingen, Steinmeier, 2006.

Smithson, Robert, "Cultural Confinement," Artforum, October 1972, p. 39. 
Sommer, Tim, "Eine Lehrstunde für Kritiker. Diese documenta ist gut!" Art Spezial. Documenta 13, July 2012, p. 3.

Staniszewski, Mary Ann, The Power of Display. A History of Exhibition Installations at the Museum of Modern Art. Cambridge and London, MIT Press, 1998.

Sternfeld, Nora, "Unglamorous Tasks: What Can Education Learn from its Political Traditions," e-flux journal, no. 14, March 2010.

Sternfeld, Nora, "What Can the Curatorial Learn from the Educational?" in von Bismarck, Beatrice; Schafaff, Jörn; Weski, Thomas (eds.), Cultures of the Curatorial, Berlin, Sternberg, 2012, pp. 333-342.

Sternfeld, Nora and Ziaja, Luisa, "What Comes After the Show. On Post-Representative Curating," OnCurating, no. 14, 2012, pp. 21-24.

Stock, Adolf. 2012. "Documenta 13: Interview mit Carolyn Christov-Bakargiev." Accessed 15.12.2015. https://www.torial.com/adolf.stock/portfolio/13818

Stöbe, Sylvia, "Architektur der documenta (13)," in Deutsches Architektenblatt, no. 11, 2012, pp. 8-9.

The Book of Books (vol. 1/3 of the dOCUMENTA (13) catalogue), Ostfildern, Hatje Cantz, 2012. Exhibition Catalogue.

The Guidebook (vol. 3/3 of the dOCUMENTA (13) catalogue), Ostfildern, Hatje Cantz, 2012. Exhibition Catalogue.

The Logbook (vol. 2/3 of the dOCUMENTA (13) catalogue), Ostfildern, Hatje Cantz, 2012. Exhibition Catalogue.

Vahland, Kia. 2012. "Über die politische Intention der Erdbeere, Gespräch mit Carolyn Christov-Bakargiev," in Süddeutsche Zeitung, 31 May. Accessed 15.12.2015. http://www.sueddeutsche.de/kultur/documenta-leiterin-carolyn-christov-bakargiev-ueber-die-politische-intention-der-erdbeere-1.1370514

Woolf, Virginia, "Professions for Women," in The Death of the Moth and Other Essays, London, Hogarth Press, 1942. Accessed 15.12.2015. http://gutenberg.net. au/ebooks12/1203811h.html\#ch-28.

de Zegher, Catherine (ed.), Inside the Visible. An Elliptical Traverse of Twentieth-Century Art in, of, and from the Feminine (1994-96), Cambridge, MIT Press, 1996. Exhibition catalogue.

Nanne Buurman is a Leipzig based art educator, curator, and scholar currently working on a PhD in art history at Freie Universität Berlin, where she was a member of the DFG (German Research Foundation) funded International Research Training Group InterArt Studies from 2012 to 2015. Her main research areas include curatorial- and exhibition studies with a focus on curatorial authorship and gender. Besides being involved with numerous exhibition-, education-, and publication projects, she has worked as an art mediator for documenta 12 and as an adjunct lecturer in the Cultural Studies Department at Leipzig University. She is co-editor of the forthcoming volume Situating Global Art. Topologies Temporalities - Trajectories. 

Imprint

Issue 29

\section{Publisher}

Dorothee Richter

\section{Editors}

Elke Krasny, Lara Perry, Dorothee Richter

\section{Contributors}

Nanne Buurman, Laura Castagnini, Susanne Clausen, Lina Džuverović, Victoria Horne, Amelia Jones, Elke Krasny, Kirsten Lloyd, Michaela Melián, Gabrielle Moser, Heike Munder, Lara Perry, Helena Reckitt, Maura Reilly, Irene Revell, Jenny Richards, Dorothee Richter, Hilary Robinson, Stella Rollig, Juliane Saupe, Sigrid Schade, Catherine Spencer

Artists inserts by

Michaela Melián

Electric Ladyland, 2016, detail (c) the artist

Michaela Melián is a visual artist and a musician, since 2010 Professor for time based media, the University of Fine Arts, Hamburg, founding member of the Band F.S.K. Recent exhibition Electric Ladyland at Kunstbau,

Lenbachhaus Munich.

\section{Proofreading}

Stephanie Carwin

Web Design and Graphic Design Concept

Ronald Kolb, Biotop 3000

Graphic Design Issue 29

Ronald Kolb, Biotop 3000

\section{Supported by}

Postgraduate Programme in Curating, ZHdK

(www.curating.org)

Institute for Cultural Studies in the Arts (ICS),

Department of Cultural Analysis,

Zurich University of the Arts (ZHdK)

fCU, feminist Curators United

(www.feministcurators.org)

Department of Art, University of Reading,

Research Platform for Curatorial and Cultural Studies, Practice-Based Doctoral Programme

College of Arts and Humanities,

University of Brighton 

Imprint

Issue 29

\section{Publisher}

Dorothee Richter

\section{Editors}

Elke Krasny, Lara Perry, Dorothee Richter

\section{Contributors}

Nanne Buurman, Laura Castagnini, Susanne Clausen, Lina Džuverović, Victoria Horne, Amelia Jones, Elke Krasny, Kirsten Lloyd, Michaela Melián, Gabrielle Moser, Heike Munder, Lara Perry, Helena Reckitt, Maura Reilly, Irene Revell, Jenny Richards, Dorothee Richter, Hilary Robinson, Stella Rollig, Juliane Saupe, Sigrid Schade, Catherine Spencer

Artists inserts by

Michaela Melián

Electric Ladyland, 2016, detail (c) the artist

Michaela Melián is a visual artist and a musician, since 2010 Professor for time based media, the University of Fine Arts, Hamburg, founding member of the Band F.S.K. Recent exhibition Electric Ladyland at Kunstbau, Lenbachhaus Munich.

\section{Proofreading}

Stephanie Carwin

Web Design and Graphic Design Concept

Ronald Kolb, Biotop 3000

Graphic Design Issue 29

Ronald Kolb, Biotop 3000

\section{Supported by}

Postgraduate Programme in Curating, ZHdK

(www.curating.org)

Institute for Cultural Studies in the Arts (ICS),

Department of Cultural Analysis,

Zurich University of the Arts (ZHdK)

fCU, feminist Curators United

(www.feministcurators.org)

Department of Art, University of Reading,

Research Platform for Curatorial and Cultural Studies, Practice-Based Doctoral Programme

College of Arts and Humanities,

University of Brighton 